NIST NCSTAR 1-8

Federal Building and Fire Safety Investigation of the World Trade Center Disaster

\title{
The Emergency Response Operations
}

\section{(Appendices A-I)}

J. Randall Lawson

Robert L. Vettori

NSTational Institute of Standards and Technology - Technology Administration • U.S. Department of Commerce 
Appendix A

INCIDENT COMMAND SYSTEM 

DCN: 1.05 .13

Appendix A

Incident Command System

Reproduced with permission of The Fire Department of the City of New York 



\section{INCIDENT COMMAND SYSTEM MANUAL}

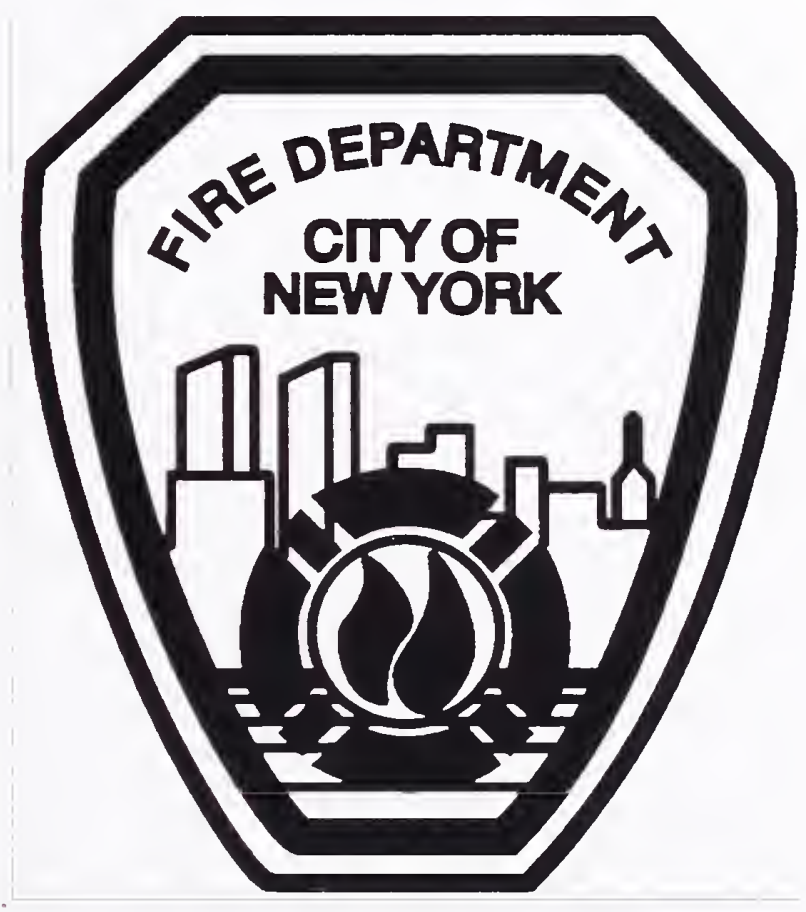





\section{Appendix A \\ Incident Command System \\ Reproduced with permission of The Fire Department of the City of New York}


PART 1 FDNY INCIDENT COMMAND SYSTEM

PART 2 ICS TERMINOLOGY AND COMMUNICATIONS PROTOCOL (Not published)

PART 3 ACCOUNTABILITY AND REPORTING

(Not published)

PART 4 ICS POSITION GUIDES

PART 5 EMERGENCY RESPONSE PLANS AND CHECKLISTS

PLAN 1. HAZ-MAT

PART 6 GLOSSARY OF ICS TERMS 
DCN: 4.03 .08

ICS MANUAL

PART 1

May 16, 1997

FDNY INCIDENT COMMAND SYSTEM

Appendix A
Incident Command System
Reproduced with permission of The Fire Department of the City of New York 


\section{POLICY}

1.1 To provide guidelines and concepts to manage an incident in an efficient organized manner, this document describes the components, operating capabilities and functions of the New York City Fire Department Incident Command System (ICS).

1.2 The Incident Command System will improve firefighter safety by providing better accountability of personnel and improved use of resources and tactical effectiveness.

1.3 This part of the document includes a general description of the organizational structure. Descriptions of the duties and responsibilities for each position at various types of incidents appear in other portions of the ICS document.

1.4 The FDNY-ICS breaks down the elements that are required to successfully manage an incident into 5 main functions. The functions are: COMMAND, PLANNING, OPERATIONS, LOGISTICS, and FINANCE.

1.5 It is the responsibility of the initial Incident Commander, whether a Company Officer or a Chief, to implement the necessary functions within this System based on the needs of the incident. As the needs of the incident grow in complexity and the Command function is transferred to succeeding officers, further expansion of the ICS should take place.

1.6 The FDNY INCIDENT COMMAND SYSTEM is the official policy for the management of all incidents and the development of standard operating procedures.

The Department will implement the system at all incidents for which it has management responsibility.

1.7 The charts depicted in this document describe the standard ICS designation, level of responsibility and hierarchy of reporting responsibility within the system.

The following chart indicates the various ICS positions within the system. It depicts management responsibility for reporting and levels of authority for issuing orders. The vertical structure of the system does not show the horizontal communication between the various functions for purposes of coordination and safety. Actions, conditions, or deployment of resources that affect or alter the strategy or tactics of the IC must be reported to the next higher level of command. 
FDNY INCIDENT COMMAND SYSTEM MODEL

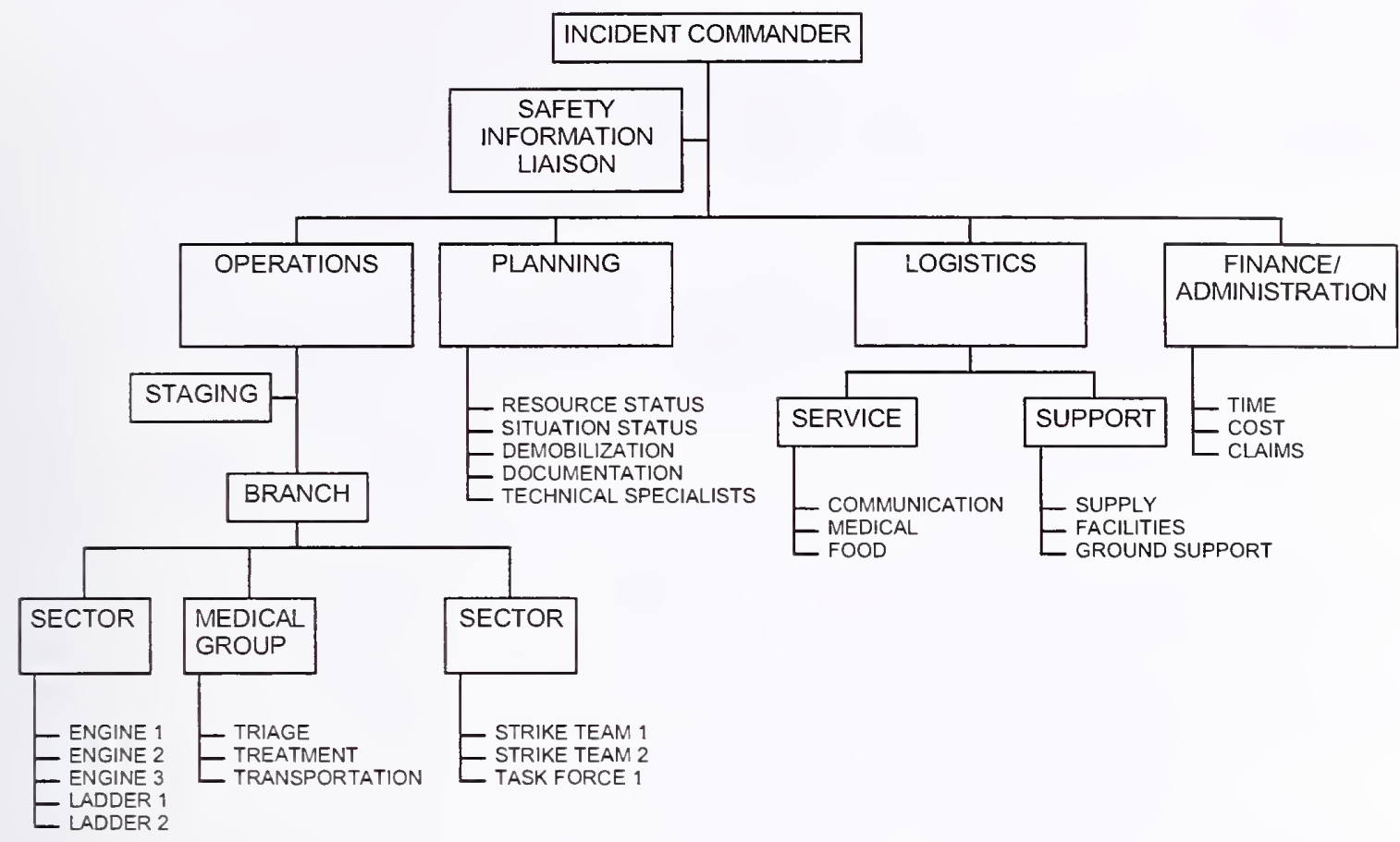

2. CAPABILITIES

2.1 The New York City Fire Department Incident Command System provides for the following kinds of operations:
A. Single jurisdiction and single agency.
B. Single jurisdiction and multi-agency.
C. Multi-jurisdiction and multi-agency involvement.

2.2 This organizational structure is capable of adapting to any type or size incident to which the department responds. The system effectively utilizes existing technology and is adaptable to new technology that may become available. It expands in a logical manner based on the needs of the incident, from the initial response to a major incident.

2.3 The System provides basic elements in organization, standard terminology and procedures that ensure efficient operations by trained personnel. It can be implemented with a minimum of disruption to existing procedures and provides the means for adding or subtracting resources in a cost-efficient and effective manner. As the incident grows the IC can staff positions that will focus on specific functional responsibilities to assist in managing the incident. As the incident de-escalates, the organization structure can be reduced. 


\section{CHARACTERISTICS}

The ICS has several characteristics or components. These components interact to create a system that ensures optimum information management and control under normal or crisis conditions. The characteristics are:

- COMMON TERMINOLOGY

- MANAGEABLE SPAN OF CONTROL

- MODULAR ORGANIZATION

- INTEGRATED COMMUNICATIONS

- UNIFIED COMMAND STRUCTURE

- INCIDENT ACTION PLANNING

- DESIGNATED INCIDENT FACILITIES

- RESOURCE MANAGEMENT

\subsection{COMMON TERMINOLOGY}

3.1.1 The use of common terminology insures that all members are able to communicate effectively. Standard ICS terminology (for functions, resources, facilities) and the utilization of standard procedures for communicating insures effective intra-agency communication and greater understanding and coordination among different agencies or departments that operate under an incident command system.

3.1.2 The common terms used in the FDNY ICS are contained in the Glossary of this document.

\subsection{MANAGEABLE SPAN OF CONTROL}

3.2.1 Safety and sound management practice dictates that a reasonable span of control exist. The organizational options within the FDNY-ICS are designed to provide span of control ratios that meet these requirements.

3.2.2 In general the span of control of any individual with management responsibility should range from three to seven with five being the ideal. Of course, there is allowance to vary this ratio under certain circumstances. For example, when units are in the process of "taking-up" from an incident "under control", there is less need for the close supervision required during the active firefighting period. 
3.2.3 The kind of incident, nature of the tasks, safety factors and communications will affect the span of control consideration. If tasks are simple and routine, take place in a limited or small area, communications are good, no unusual safety hazards are present and the incident is reasonably stable, then one individual may supervise up to seven subordinates. Conversely, if tasks are demanding, take place over a large area, and the incident is escalating, the span of control might be reduced to three or four.

3.2.4 It is important to be proactive, anticipate change and prepare for it. This is especially true when an incident is escalating and good management is difficult because many people are reporting to the Incident Commander.

\subsection{MODULAR ORGANIZATION}

3.3.1 Modular organization means that the ICS organization evolves based on the type and complexity of the incident. A routine incident will have a simple structure. A complex incident will require a larger organizational structure. The structure may be expanded in anticipation of events that are predictable or those that have the potential for complex incident needs. The organization structure is reduced as the incident is brought under control and resources are released.

3.3.2 Incident Commanders are responsible for the performance of the five main functions within the ICS. The functions are COMMAND, PLANNING, OPERATIONS, LOGISTICS and FINANCE.

3.3.3 Following the span of control guidelines, an IC may respond initially with only a few units. If the IC can manage all the major functional areas no expansion of the organization is required. If, however, the incident continues to escalate, the IC may delegate one or more functions to other persons.

3.3.4 Each function or supervisory authority that is delegated performs a specific role in the system and is identified by specific ICS terminology.

\subsubsection{If any function is not delegated, it remains the responsibility of the Incident Commander.}

\subsection{INTEGRATED COMMUNICATIONS}

Communications in the System is managed through the use of a communications plan. Initial communications are on the tactical frequency. At major incidents, primary and secondary Tactical and Command channels are available. The Field Communications Unit or the Communications Coordinator will consult with the IC to satisfy the incident needs. Radios capable of communicating with other city, state and federal agencies are available. 


\subsection{UNIFIED COMMAND}

3.5.1 Unified Command is a means of organizing different agencies who have statutory authority and responsibility at large scale incidents, into one coordinated and controlled effort. It is designed to minimize "turf battles" and promote close working relationships among different departments.

Under a "Unified Command" each department or agency will maintain control over its own personnel. It enables all involved agencies to perform their roles effectively, minimize inefficiency, and avoid duplication of effort.

3.5.2 The goal of this concept is to develop a single collective approach to managing an incident. The departments act as "one organization" and are managed as such. Instead of several command posts operating independently, the operation is directed from only one "Command Post".

3.5.3 Implementing the plan of action will be under the direction of an Operations Chief. The Operations Chief is normally from the agency which has the greatest involvement and responsibility at the incident.

3.5.4 Under a Unified Command, the Senior Officials from the agencies meet and work together at one location, developing a strategy and preparing a single plan of action that ensures an integrated operation that will maximize the use of all assigned resources. Communications flow and the ability to rapidly cope with changing incident conditions is improved.

3.5.5 For example, a plane crash will involve the Fire Department, Police Department, Federal Aviation Administration, National Transportation Safety Board, Port Authority and perhaps other agencies. All of these agencies will have different missions to perform in the same location and at the same time and will require a Unified Command Structure.

\subsection{INCIDENT ACTION PLANNING}

3.6.1 All incidents require a plan to solve problems. For routine incidents the initial IC (the first arriving officer) will do this according to established SOP. The plan of action (SOP) established is based on the known risks and hazards that are expected in the majority of our emergency response activities. Specific conditions requiring variations or adaptation of standard procedures are addressed by the first arriving officer and succeeding commanders.

3.6.2 At complex incidents with a large commitment of resources from multiple agencies, such as Hazardous Materials or mass casualty incidents, the SOP used in the early stage of the incident would be replaced by a written plan of action developed at the scene. 
3.6.3 The plan is developed by a systematic process. The strategy and objectives are established by the IC. The tactical organization is directed by the Operations Chief. The tasks are performed by assigned resources. The planning process answers "What do we need to know?" and "What do we need to do?" at complex incidents.

\subsection{DESIGNATED INCIDENT FACILITIES}

3.7.1 An incident facility is an area that is established to serve a particular purpose. In the FDNY-ICS the facilities are given designated names. There are several types of facilities that can be established at an incident. Some are mandated by SOP.

3.7.2 The Incident Commander determines and designates the type(s) of facilities needed based on the incident.

The following are examples of facilities used in the FDNY-ICS:

A. Command Post - The Command Post (CP) is the area from which the IC performs the function of managing the incident. There should be only one " Command Post".

Initially, the $\mathrm{CP}$ will be staffed by the $\mathrm{IC}$ and his aide. If the incident escalates, individuals assigned to the Command Staff, Operations, Planning or Logistics will be present.

In multi-agency operations, the individuals designated by their respective agency should be located at the command post (Con-Edison, Department of Environmental Protection, U.S. Coast Guard etc.). It is from the CP that the IC delegates management functions to subordinate officers while he provides overall direction.

B. Staging - The area where resources are held awaiting assignment. A staging area may be located away from the incident or on the upper floor of a high rise building or any appropriate location based on need. Staging is under the direction of a staging officer who reports to the IC or Operations Chief when Operations has been staffed.

C. Recuperation and Care - The area where personnel are placed to rest, replenish fluids and be protected from the weather (heat or cold). 


\subsection{RESOURCE MANAGEMENT}

3.8.1 Within the FDNY-ICS resources are organized in several ways, depending on the incident. Some resources are managed either as single units or teams. The ability to form single units into teams maximizes the use of resources, and reduces the communications load. Various options are available to the IC.

3.8.2 Knowledge of the current status of resources at an incident is critical to effective management. Up to date status of resources is accomplished by the resource and situation status unit. This function is initially performed by the aide of the first to arrive Battalion Chief. The status of resources is continually monitored and this keeps the IC informed and up to date.

3.8.3 All resources at the incident are assigned a status. In the FDNY-ICS resources are assigned to one of three status conditions:
A. Available - ready for immediate assignment.
B. Assigned - performing an active assignment.
C. Out of Service/R\&R - not ready for assignment.

3.8.4 Changes in status or location of resources must be promptly reported by the individual who makes the change. This provides an accurate accounting of all tactical resources at the incident.

\section{DESCRIPTION OF THE INCIDENT COMMAND SYSTEM FUNCTIONS}

4.1 COMMAND - is the functional authority the IC exercises over subordinates. It includes the responsibility for effectively using resources to accomplish strategy. It is the function through which all the incident activities (tactical and support) are directed, coordinated and controlled to accomplish the mission. It encompasses the personnel, equipment, communications, facilities and procedures to plan for what has to be done, issue orders and supervise the execution of operations.

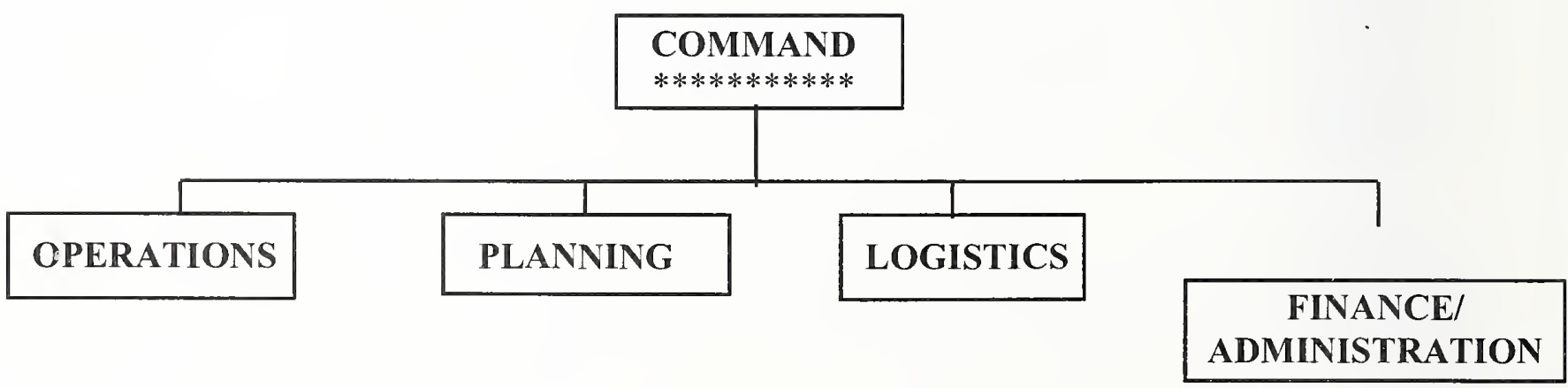


4.1.1 At all incidents, COMMAND conducts a size-up, develops a strategy and is responsible for its outcome. Command staffs the functions necessary to support the incident.

4.1.2 The IC retains responsibility for Command and the performance of any functions or areas in the system that are not delegated.

4.1.3 At most incidents the IC will handle all the major functions within the ICS. As the incident becomes more complex or progresses to greater alarms, the IC must delegate some of the authority for performance of the functions to other individuals. Some ICS functions are automatically addressed in our SOPs.

4.1.4 Delegation is the key to the FDNY-ICS. Each of the major functional sections concentrates on a primary assignment and is not distracted by other responsibilities. This provides functional clarity, greater attention to the details of a specific function and fixes accountability.

4.1.5 The IC has the option of implementing a COMMAND STAFF.

The Command Staff includes the following functions:

A. The Liaison Officer is the point of contact for assisting and cooperating agency representatives.

B. The Information Officer is responsible for gathering pertinent factual information concerning the incident. Upon approval from the IC, he will interface with the media and other agencies.

C. The Safety Officer is responsible for monitoring hazardous or unsafe conditions and initiating action to protect personnel from life-threatening situations.

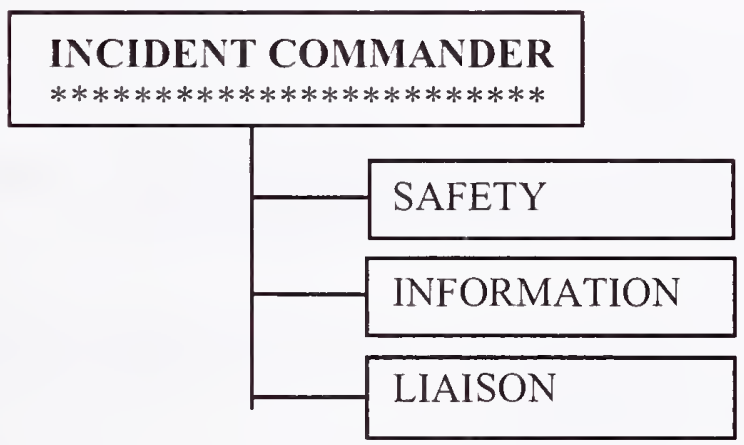


4.2 PLANNING - is the function responsible for gathering, evaluating and disseminating information about the incident and status of resources. It prepares alternate strategies and objectives to control the incident. The Planning Section is comprised of several functions:

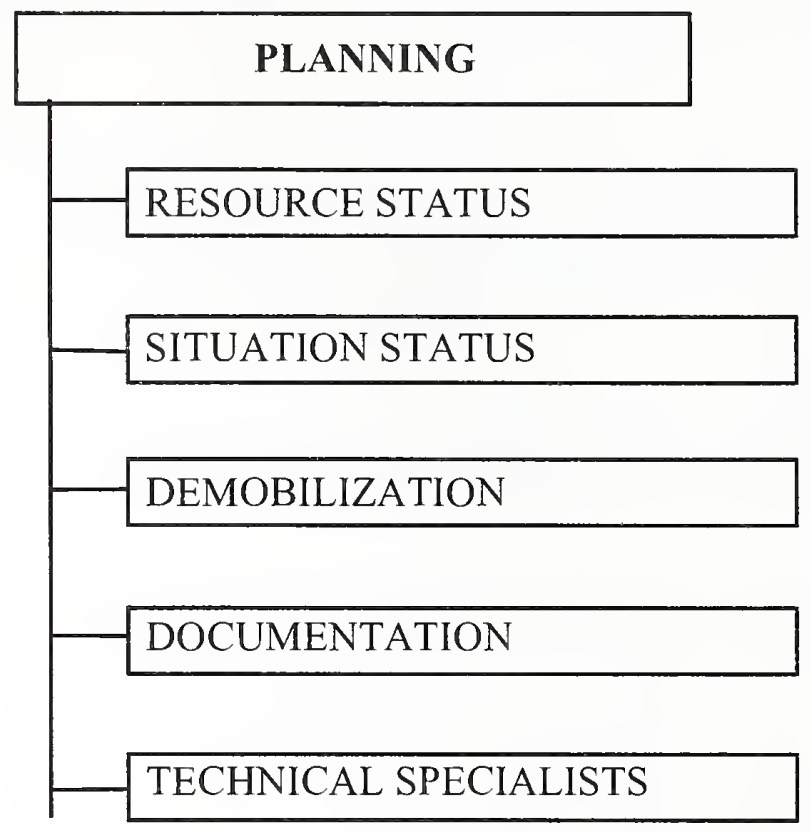

4.2.1 The Resource Status function is responsible for maintaining resource status information of all assigned resources at the incident.

4.2.2 The Situation Status function is responsible for the collection, processing and organization of incident information. Generally this information is graphically displayed on the command board.

4.2.3 The Demobilization function ensures safe, effective, organized release of resources from the incident.

4.2.4 The Documentation function maintains an accurate and complete log of incident records for analytical, historical and legal purposes.

4.2.5 Technical specialists advise the IC on technical matters concerning incident operations such as environmental concerns, building construction, hazardous materials, specialized operations, etc. 
4.3 OPERATIONS - is the function of managing all the tactical operations at the incident to accomplish the primary mission and plan of the Incident Commander.

All units are managed using the fundamental principles of Incident Command. An Officer assigns and supervises various functions (such as pump operator, forcible entry etc.) at each operation. These functions form the basis of our standard operating procedures. The Company organization provides for a manageable span of control over specific functional areas.

As operations escalate beyond the first responder SOP, succeeding commanders have several options available. Unless mandated, the specific command options utilized at an operation (within the ICS parameters) depend on the nature and complexity of the incident and the needs of the Incident Commander. ICS is not rigid. Experience, common sense, and imagination are the guiding principle in using these options.

These options may be activated at any appropriate level of command to solve/reduce span of control problems. They provide control, supervision and coordination in a designated area or for a specific function. They fix personnel accountability.

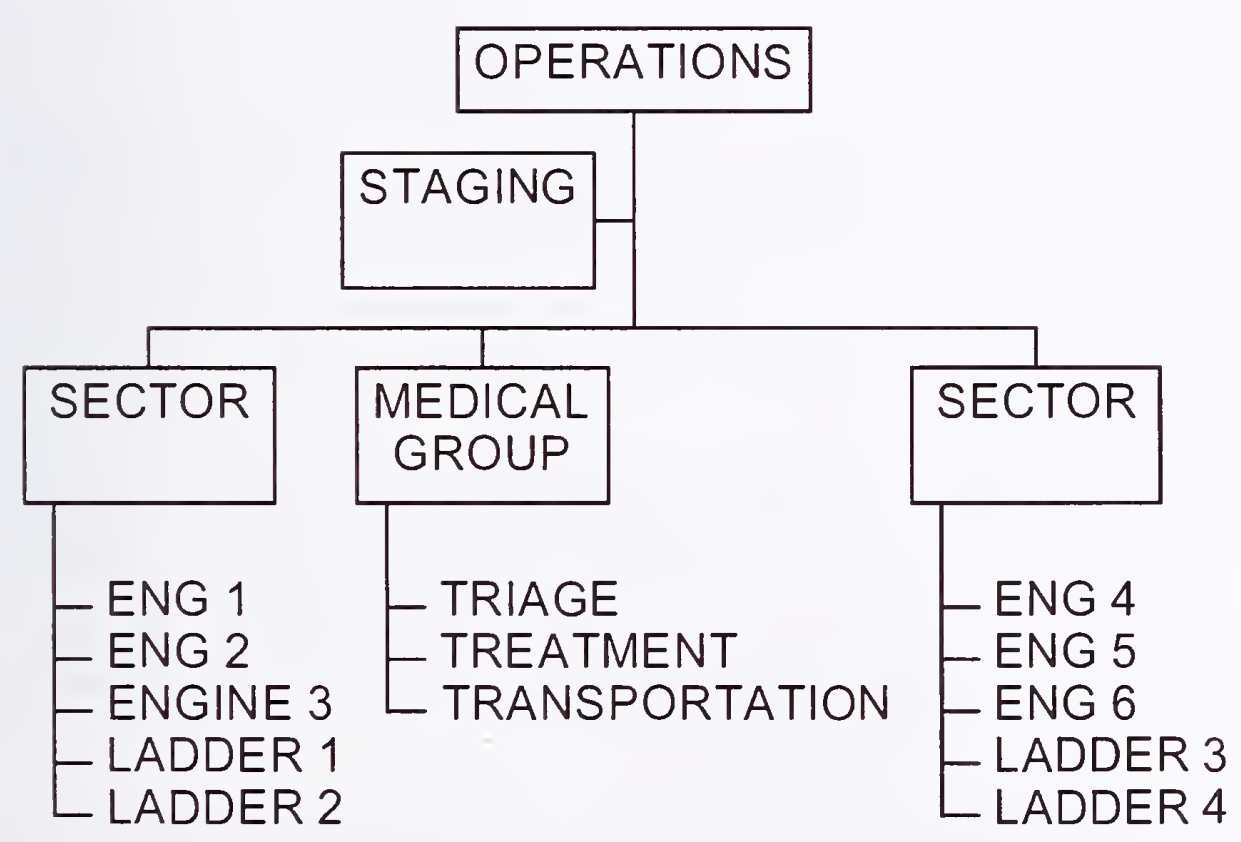


4.3.1 The following describe the options available within the System to utilize resources:

\section{A. SINGLE RESOURCES}

Company - A company is a vehicle providing equipment capability and personnel such as an Engine Company, Ladder Company, Rescue Company.

Team - A specific number of personnel assembled for an assignment such as search, ventilation under the direction of a team leader.

\section{B. COMBINING RESOURCES}

To maintain a manageable span of control, reduce communication, improve control and coordination, single resources may be combined into sectors and groups.

1. Sector - Defines the activities and operations of resources within an assigned geographical area. For example, the IC might form a sector from units operating in an exposure to reduce the span of control and more efficiently manage radio traffic by only dealing with one sector supervisor. A sector is managed by a sector supervisor.

2. Group - Consists of resources formed to address specific functional tasks. For example, the IC forms a group to search specific floors of a high rise building. Each resource within the group performs the search function and reports to a group supervisor. Additionally, at the scene of a multiple casualty incident resources may be assigned to perform the functions of triage treatment and transportation. The IC has achieved closer supervision of the units and a reduced number of radio contacts. This allows more time to deal with other problems that exist. A group is managed by a group supervisor.

a. Functional and geographical assignments may not always require the implementation of a group or sector. An activity that requires one unit to effectively handle the problem would not need the activation of a sector or group. There would not be a coordination problem and the assignment does not cover a large area or the supervision of many units.

b. While sectors are restricted to a specific geographical area such as an exposure, groups may cross sector boundaries to accomplish an assigned functional task e.g., search. When a group is assigned a task or function that overlaps sector boundaries, the sector may be relieved of that responsibility. Groups and sectors coordinate their efforts and report to the next higher level of command. 
c. Sector/group supervisors are responsible for the implementation of their assigned portion of the tactical plan and they coordinate activities within their assignment. They assign specific tasks to units or teams under their control.

d. Sector/group supervisors keep the next higher level of command informed of the status of conditions and resources within their assigned area of responsibility.

e. Sector/group supervisors require certain information from the next higher level of command. They must know their radio designation, assigned objectives, and resources assigned to their command.

\section{SPECIAL APPLICATION}

1. Strike Team - Specific combinations of the same kind and type of resources, with common communications under the supervision of an officer (e.g. five engine companies and a Chief Officer dispatched to other jurisdiction, Suffolk/Nassau County, New Jersey).

2. Task Force - Any combination of resources with communications capability under the supervision of an Officer, put together for a temporary assignment. The number of resources in a task force should be limited to five for control purposes. A task force may be formed when more than one unit must be managed. Task forces may be formed for many functions. They may be pre-established or made up at the incident (members of FDNY-FEMA Urban Search and Rescue Task Force).

\subsubsection{BRANCHES - EXPANDING THE ORGANIZATION}

The next higher form of organizational tool available to the IC is called a BRANCH. A branch is created when the span of control over sectors and groups is excessive or at major incidents when resources from other agencies are committed. A branch is managed by a Branch Commander.

Branch Commander:

1. Manages a specific part of the tactical plan appropriate to that branch.

2. Coordinates the activities of units within the branch.

3. Assigns specific tasks to sectors or groups within the branch.

4. Keeps the next higher level informed of the status in the area of responsibility.

Branches may be established at an incident to serve several purposes. In general, branches may be established for the following reasons:

- Span of control

- Functional

- Multi-agency 
A. SPAN OF CONTROL

Branches should be utilized at incidents where the span of control of sectors or groups becomes unmanageable.

In the following example, if the organization were formed this way the operations chief would be beyond a manageable span of control.

Before Multi-Branch Structure

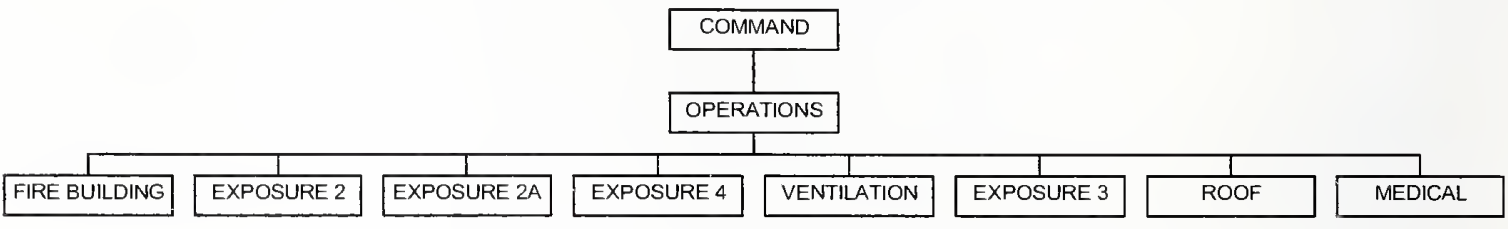

A two-branch organization would be appropriate.

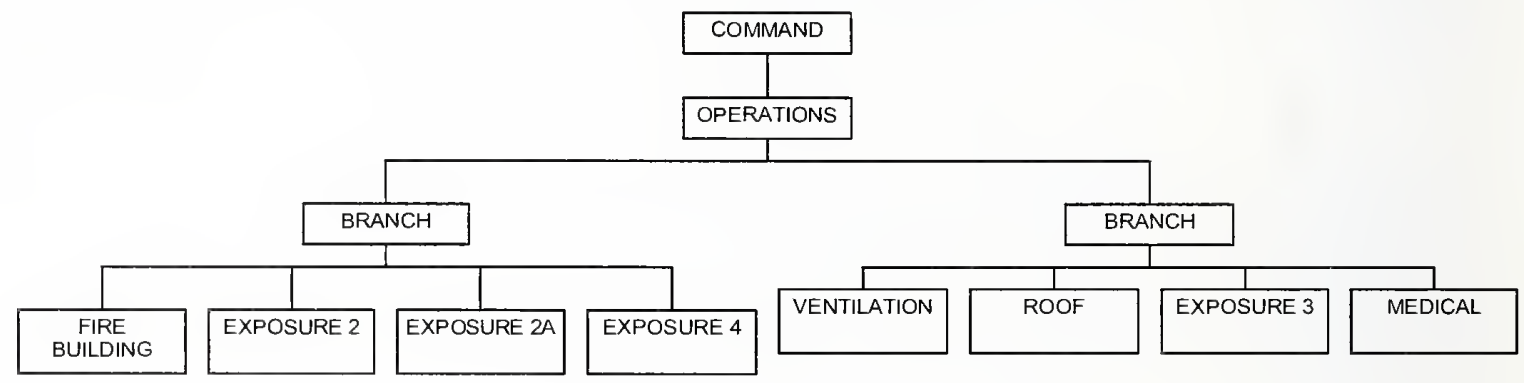

Branches should operate in their area of responsibility. The radio designation should reflect the objective of the branch. When Operations implements a branch, the sector should be notified of their new supervisor. 
B. FUNCTIONAL BRANCHES

When the nature of the incident calls for a functional branch structure, the organization is created with each functional branch under the direction of a single operations chief.

In the following example a medical function was added because the complexity of the operation was beyond the sector or group level's capability.

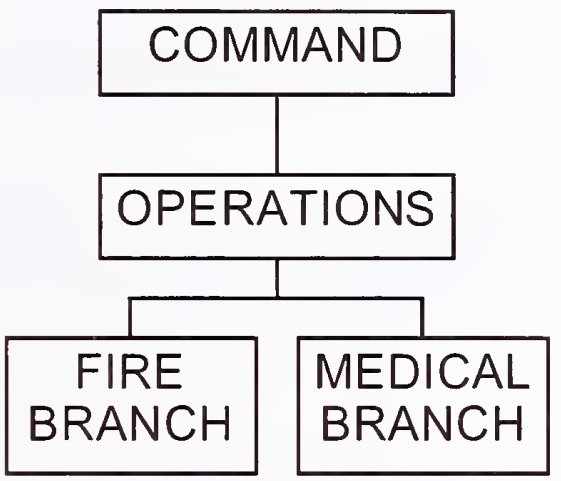

C. LARGE SCALE MULTI-AGENCY INCIDENTS

When the incident requires a large commitment of resources from multiple agencies, resources are best managed by the agency which has normal control over those resources. It is anticipated other agencies would operate as their branch under the direction of a single operations chief.

An example would be a major hazardous materials incident requiring multi-agency commitment.

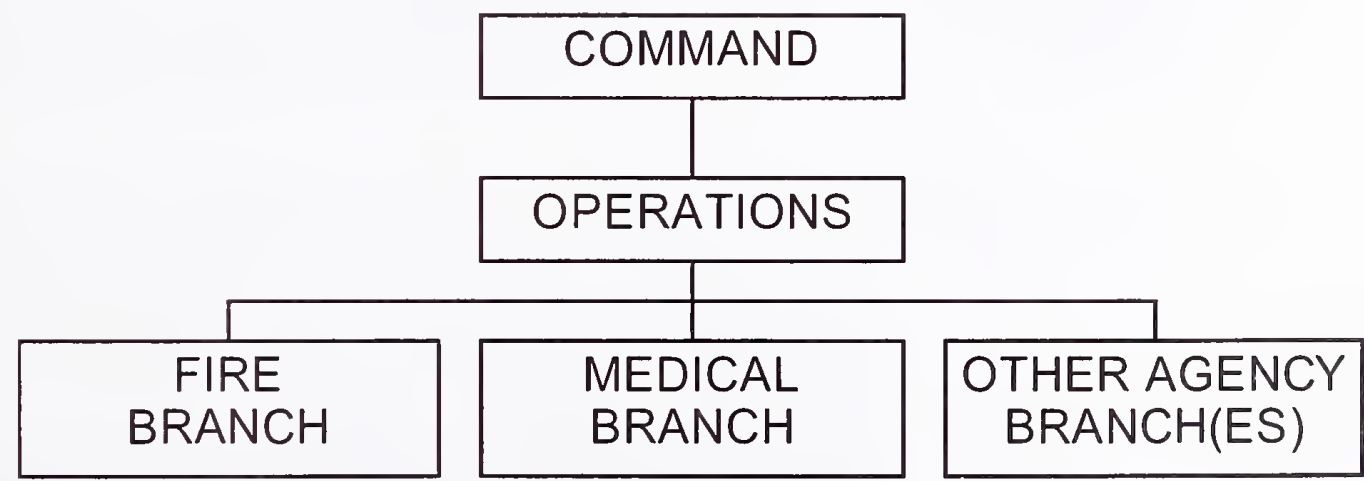


4.3.3 STAGING - A specific area to which resources are assigned before deployment. Staging has several advantages:

1. It gives the IC breathing room to make better decisions about deployment.

2. It is a checkpoint to provide accountability and prevent freelancing.

3. It provides an area of protection from exposure in hazardous environments.

4. It establishes a reserve immediately available for a contingency.

Initially, the staging area can be managed by the IC. If an incident is very complex, the IC can set up a formal staging area and assign an Officer as Staging Area Manager.

If the position of Operations is staffed, Staging reports to Operations since this Chief now is managing the tactical part of the incident action plan. The Operations Section allocates the available resources from a defined staging area.

4.4 LOGISTICS - is the function which provides the supplies, services and facilities needed support the incident. Within the Logistics Section, functions are carried out through various Service and Support functions.

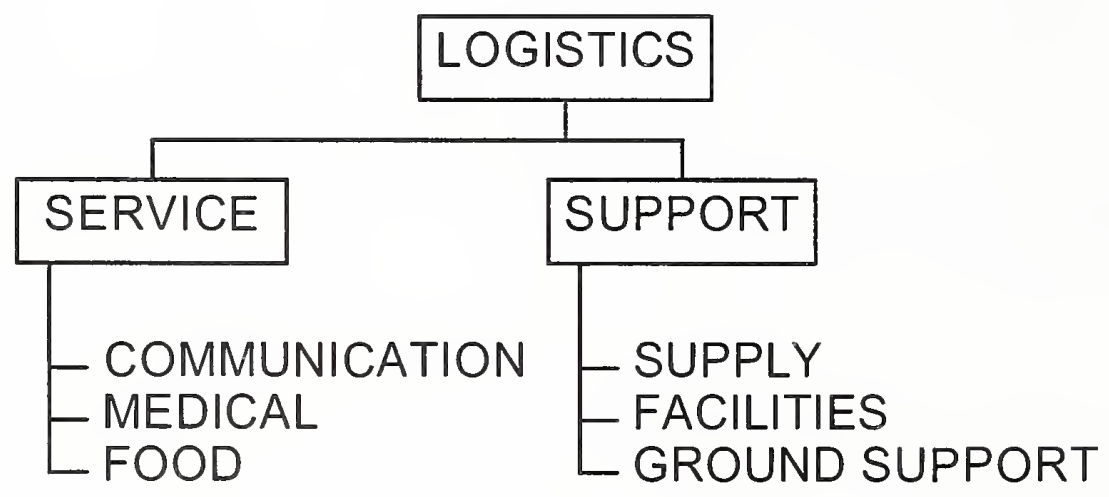

4.4.1 Service branch includes Communication, Medical, and Food Units.

A. Communications establishes and operates the network of resources to manage the radio traffic and information flow within the ICS and between the Command Post and the dispatcher.

B. Medical - responsible for ensuring medical aid and transportation for injured and ill incident responders. This unit does not provide treatment for civilians.

B. Food - responsible for coordinating the feeding of personnel at extended operations, if necessary. 
4.4.2 Support branch includes the Supply, Facilities and Ground Support Units. It's function is to supply and re-supply the hardware and special equipment to carry out and sustain the operation.

A. Supply - responsible for providing, ordering equipment and receiving supplies for the incident.

B. Facilities - responsible for layout and activation of incident facilities e.g., Command Post, and Rehab.

B. Ground Support - is responsible for support of out-of-service resources, fueling, service, and repair of vehicles, as well as transportation.

C. Special units - responsible for providing any equipment and supplies for the incident.

4.5 FINANCE/ADMINISTRATION - is the function responsible for financial cost recording and recovery when possible for the incident operations.

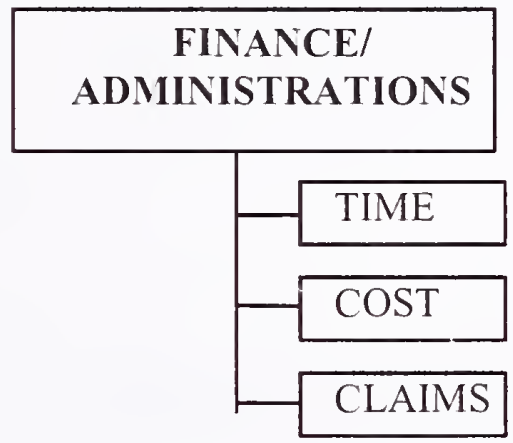

4.5.1 The Finance Section is responsible for recording vendor contracts and collecting expenses and cost data for the incident. It provides cost estimates and cost-saving recommendations.

4.5.2 Under most circumstances, this function is performed as part of the Department's normal administrative function. However, cost recovery and budget justification begin with data collection and tracking. Commanders at every level should be aware of the actual and potential impact of the costs of emergency operations in decision making. 


\section{SUMMARY}

5.1 Think of the FDNY-ICS as a toolbox, available to help the IC manage the incident. Use only the tools that are needed. The use of the tools that are available to you will make the job of managing an incident more tolerable and less stressful. Tools that are not needed should be left in the box.

5.2 Incident Command is not a static concept. The System and this document are meant to be used and constantly improved to meet the changing and challenging environment facing emergency services. Other training materials, checklists, guides and support materials and SOP's are under development to support professional operations in the field.

5.3 Practice and experience using the Incident Command System and its components will determine the level of professionalism, safety and efficiency achieved in emergency operations by this Department.

\section{- END OF PART 1 -}


DCN: 4.03 .08

ICS MANUAL

PART 4

July 17, 1995

ICS POSITION GUIDES

Appendix A

Incident Command System

Reproduced with permission of The Fire Department of the City of New York 


\section{INTRODUCTION}

This part of the ICS manual will deal with the factors which must be considered when the various positions of the ICS are to be established.

\section{LOGISTICS}

\subsection{ESTABLISHMENT OF RECUPERATION AND CARE (RAC) AREA}

Any incident that is large in size, long in duration, and/or labor intensive will rapidly deplete the energy and strength of personnel and therefore merits consideration for rehabilitation. Severe climactic or environmental conditions will also necessitate the establishment of a Rehabilitation area. The following factors must be considered

A. Location:

The Incident Commander shall designate the location of the RAC Area. When a RAC Area is established, it may be necessary for the Incident Commander to designate a RAC Officer. Large scale operations may require the assignment of a Chief Officer to fill this position. (See AUC 230 Section 2.3, 3.1 and 3.2for the duties of the Rac Officer/Chief).

B. Site Characteristics:

1. A location that can accommodate the placement of RAC Units. (See AUC 230, Sections 1 and 2 for the description, response, and duties of RAC units).

2. A location that offers protection from environmental conditions.

3. Free of exhaust fumes, apparatus, and equipment.

4. Large enough to accommodate several units, and allow members to remove their Bunker Gear.

5. Easily accessible to E.M.S.

C. Hydration:

Members in the RAC Area should maintain a high level of hydration. During heat stress, members should consume at least one quart of water per hour.

D. RAC:

Units/members shall be considered for RAC based not only on energy expended at a fire/emergency, but also on the previous activity of the units/members prior to operating at a fire/emergency. Rest periods of two hours can be given by Battalion Chiefs, and three hours can be given by deputy Chiefs.

Note: Members should not be moved from a hot environment directly into an air conditioned area because the body's cooling system can shut down in response to 
the external cooling. an air conditioned environment is acceptable only after a "Cool Down" period at ambient temperature with sufficient air movement. 
EMERGENCY RESPONSE PLAN:

HAZARDOUS MATERIALS

\section{Appendix A}

Incident Command System

Reproduced with permission of The Fire Department of the City of New York 


\section{CONTENTS}

$\frac{\text { SECTIO }}{\mathrm{N}}$

$\underline{\text { TITLE }}$

$\underline{\text { PAGE }}$

1. INTRoduction ANd Statenent Of Command Concepts ........................ 1

$1.1 \quad$ Planning Basis .......................................................................................... 1

$1.2 \quad$ Agency Coordination ................................................................................ 1

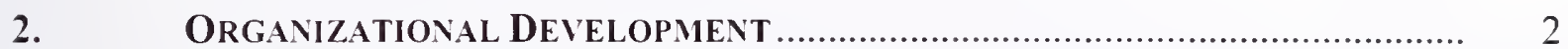

$2.1 \quad$ Response Objectives and Strategy ……..........................................................

$2.2 \quad$ Incident Characterization ........................................................................... 3

2.3 Emergency Alerting and Response ……...................................................... 6

$2.4 \quad$ Response Organization ........................................................................... 7

3. General Incident Procedures And Site Safety ……...................................... 9

3.1 Hazard Assessment ...................................................................... 9

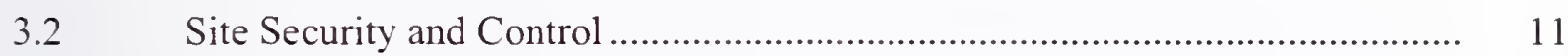

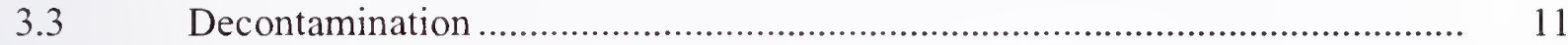

3.4 Emergency Medical Treatment ................................................................... 11

3.5 Personal Protective Equipment ..................................................................... 12

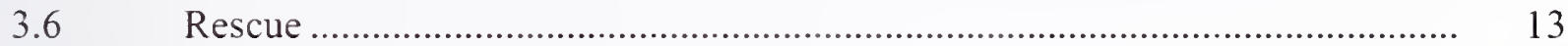

3.7 Evacuation / Sheltering ...................................................................... 13

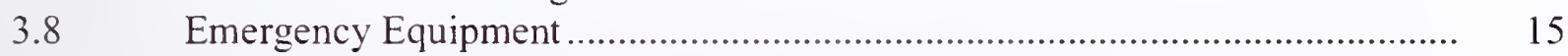

4. RoLES ANd RESPONSIBILITIES OF RESPONDERS ……................................. 16

$4.1 \quad$ Incident Commander ............................................................................ 16

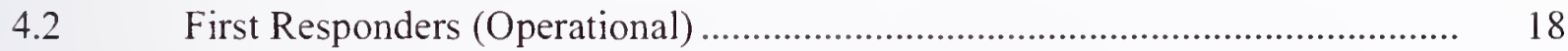

4.3 Hazardous Materials Group ......................................................................... 25

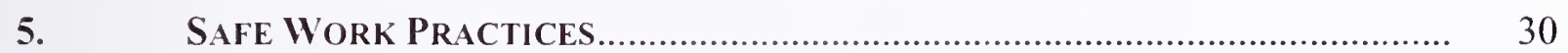

5.1 General Procedures .................................................................................. 30

$5.2 \quad$ Work Zones ...................................................................................... 30

5.3 Decontamination Procedures ........................................................................ 34 
6. ICS FUNCTIONS AND RESPONSIBILITIES ......................................................... 37

6.1 Safety ................................................................................................. 37

6.2 Information............................................................................................. 38

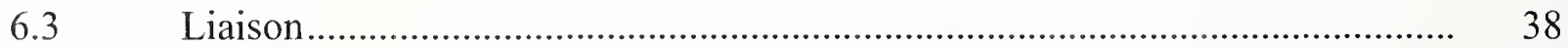

$6.4 \quad$ Operations .............................................................................................. 38

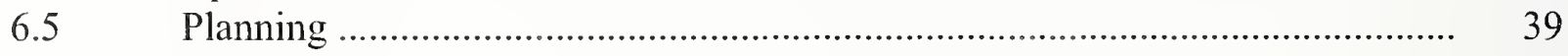

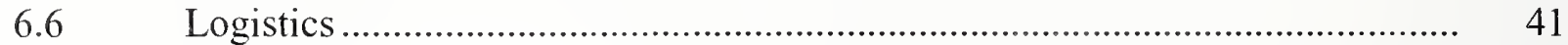

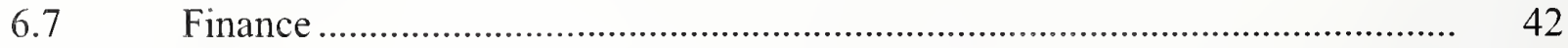

7. Interagency Support System ………....................................................... 43

8. INCIDENT TERMINATION PROCEDURES ......................................................... 44

8.1 Clean Up Operations ..................................................................................... 44

9. POST INCIDENT ProceddreS ...................................................................... 46

9.1 Incident Analysis................................................................................... 46

$9.2 \quad$ Critique Outline.......................................................................................... 47

9.3 Emergency Response Plan Review ……………….......................................... 47

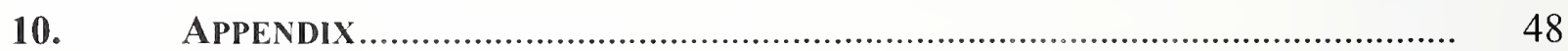

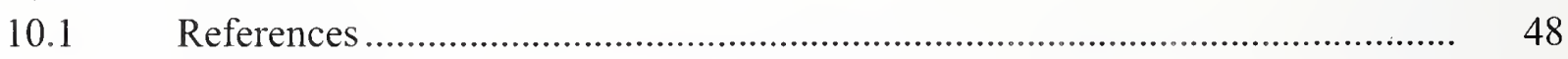

$10.2 \quad$ Abbreviations .......................................................................................... 48 


\section{INTRODUCTION AND STATEMENT OF COMMAND CONCEPTS}

\subsection{PLANNING BASIS}

In order to carry out the responsibilities delineated in the New York City Hazardous Materials Response Plan (Mayoral Directive 82-2 Revised) and to comply with standards established by federal legislation the FDNY Emergency Response Plan for Hazardous Materials is established. This plan will guide and direct the action of all responding Fire Department personnel at hazardous materials operations.

In the event of a significant accident or other incident involving a toxic or hazardous material where, because of fire, explosion, radioactivity, toxic air release or chemical reaction there exists danger to the health or safety of emergency personnel or to the general public, the senior Fire Department representative, referred to as the Incident Commander (IC), at the scene will implement the FDNY Emergency Response Plan (ERP) for Hazardous Materials.

\subsection{AGENCY COORDINATION}

This plan is built on the fundamental organization and strategy of the FDNY Incident Command System (ICS) insuring maximum safety and efficiency of the operating forces while fulfilling our responsibility to the public.

It is assumed that all hazardous materials incidents will be managed under Unified Command principles because in virtually all cases fire, police, and public health agencies will have some statutory functional responsibility for incident mitigation.

Implementing the ERP will facilitate the coordination and control of all tasks and functions with the senior on-site representative of the Police Department who has been designated as the "On Scene Coordinator". Using the ERP and working closely with the On-scene coordinator, the Incident Commander will manage the command and control of all mitigation tasks and functions. When the Interagency Command Center (ICC) is established the IC will represent the Fire Department at the Command Center.

All mitigation operations at the incident will be managed by the Fire Department. Tactical operations will be managed by the Fire Department Operations Chief.

Specific tactical objectives will be carried out by Group/Sector Supervisors. Other needs will be met by staffing ICS positions. 


\section{ORGANIZATIONAL DEVELOPMENT}

\subsection{RESPONSE OBJECTIVES AND STRATEGY}

Any hazardous materials incident represents a potentially dangerous situation. Chemicals that are combustible, explosive, corrosive, toxic, or reactive, along with biological and radioactive materials can affect the general public or the environment as well as the emergency responder. Emergency responders may be subject to additional dangers operating in this abnormal environment. While the response activities needed at each incident are unique, there are similarities. One is that every response requires protecting the health and ensuring the safety of the responders.

This document identifies the functions needed to control and mitigate a hazardous materials incident. It also describes the lines of authority, responsibility, and communication between and among the various responders. It defines the interface of the Fire Department with other agencies. Finally, it specifies the authority of each responder in directing specific operations.

This plan will provide instructions on how to accomplish specific tasks in a safe manner. In concept and principle, standard operating safety procedures are independent of the type of incident. Their applicability at a particular incident must be determined and necessary modifications made to match prevailing conditions. However, in the case of hazardous materials operations, the specific requirements of training, equipment, and competence preclude the generalized statements that might apply to other types of emergency work.

The ERP will provide guidance for Fire Department responders in areas related to response, site control, entry, and mitigation of hazardous materials incidents.

This guide is not meant to be a comprehensive treatment of each of the subjects discussed. Formal training in these areas will complement this document. Specific training will provide more information for the technical, administrative, and management oriented skills needed to fulfill our mission. This document will provide standard operating guides to develop more specific procedures.

The priority of the instructions in this plan is as follows:

A. Life safety and health risks to the public and the emergency responders are the most important concern.

B. The Fire Department must stabilize the incident scene and prevent further escalation of the incident with minimum personal risk.

C. The Fire Department's response efforts should be directed toward protecting property and minimizing or lessening the impact of the event on the environment. 


\subsection{INCIDENT CHARACTERIZATION}

In the same way that units now call for additional assistance at a fire, hazardous materials incidents require that a method be established to determine the degree of severity for various types of releases. This avoids the need for calling out full resources for every incident. Personnel arriving at an incident can, of course, request additional resources and thereby raise the level of response based on the actual circumstances of the event. Response planning, procedures, and notifications to Federal, State, and City agencies will be determined by the following standard designations.

2.2.1 LEVEL 1: An incident which can be controlled by the responding unit or units up to 3 Engines, 2 Ladders and 2 Battalion Chiefs and does not require evacuation of other than the involved structure or the immediate outdoor area. The incident is confined to a small area and does not pose an immediate threat to life or property.

A Level 1 incident includes the units on the scene up to and including the full first alarm assignment. It is not a request for additional units or specialized resources. It signifies the degree of hazard and the ability of the units on the scene to safely manage the incident. Additional resources or greater alarms may be transmitted at the discretion of the Incident Commander. This may indicate a need to upgrade the incident to Level 2.

2.2.2 LEVEL 2: An incident involving a greater hazard or a larger area which poses a potential threat to life or property and which may require a limited evacuation of the surrounding area.

A Level 2 incident requires the response of a Deputy Chief, Hazardous Materials Unit, Safety Operating Battalion, Field Communications Unit(DO 154/93) and SOC and a total first alarm assignment of 3 Engines, 2 Ladders and 2 Battalion Chiefs.

2.2.3 LEVEL 3: An incident involving a severe hazard or a large area which poses an extreme threat to life and property and will probably require a large scale evacuation; or an incident requiring the expertise or resources of City, State, Federal, or private agencies and organizations.

A Level 3 incident requires activation of the full NYC Emergency Response Plan. Additional alarms or other Fire Department resources may be called by the Fire Department Incident Commander. 
2.2.4 The following table is presented for guidance in determining these levels. The highest level for any single condition will determine the incident level. For example, poison gas (such as cyanide or phosgene) could initially require a Level three response due to the nature of the danger to the public. An incident level and the response can always be downgraded when additional information or resources become available. However, it is much more difficult to upgrade and obtain control when situations are going beyond the capabilities of the on scene resources. 


\begin{tabular}{|c|c|c|c|}
\hline CONDITION & LEVEL ONE & LEVEL TWO & LEVEL THREE \\
\hline PRODUCT & $\begin{array}{c}\text { NO DOT } \\
\text { PLACARD } \\
\text { REQUIRED } \\
\text { ORM A,B,C,D }\end{array}$ & $\begin{array}{l}\text { DOT PLACARD } \\
\text { PCBs/NO FIRE } \\
\text { EPA REGULATED } \\
\text { WASTE** } \\
\text { ANY } \\
\text { UNIDENTIFIED } \\
\text { SUBSTANCE }\end{array}$ & $\begin{array}{c}\text { POISON A, } \\
\text { EXPLOSIVE A/B, } \\
\text { ORG. PEROXIDE, } \\
\text { FL. SOLIDS(WR), } \\
\text { CHLORINE, } \\
\text { FLUORINE, } \\
\text { ANHYDROUS } \\
\text { AMMONIA, } \\
\text { RADIOACTIVES, } \\
\text { PCBS On FIRE }\end{array}$ \\
\hline NFPA \#704 & $\begin{array}{c}0 \text { OR } 1 \text { ALL } \\
\text { CATEGORIES }\end{array}$ & $\begin{array}{l}2 \text { FOR ANY } \\
\text { CATEGORY }\end{array}$ & $\begin{array}{c}3 \text { OR } 4 \text { ANY } \\
\text { CATEGORY INCL. } \\
\text { SPECIAL } \\
\text { HAZARDS }\end{array}$ \\
\hline $\begin{array}{c}\text { CONTAINER } \\
\text { SIZE* }^{*}\end{array}$ & SMALL & MEDIUM & LARGE \\
\hline $\begin{array}{l}\text { CONTAINER } \\
\text { INTEGRITY }\end{array}$ & NOT DAMAGED & $\begin{array}{c}\text { DAMAGED BUT } \\
\text { SERVICEABLE FOR } \\
\text { HANDLING OR } \\
\text { TRANSFER OF } \\
\text { PRODUCT }\end{array}$ & $\begin{array}{c}\text { DAMAGED, } \\
\text { CATASTROPHIC } \\
\text { RUPTURE } \\
\text { POSSIBLE }\end{array}$ \\
\hline $\begin{array}{c}\text { LEAK } \\
\text { SEVERITY }\end{array}$ & $\begin{array}{l}\text { NO OR SMALL } \\
\text { RELEASE } \\
\text { CONTAINED OR } \\
\text { CONFINED W/ } \\
\text { AVAILABLE } \\
\text { RESOURCES }\end{array}$ & $\begin{array}{c}\text { NOT } \\
\text { CONTROLLABLE } \\
\text { W/O SPECIAL } \\
\text { RESOURCES or } \\
\text { "REPORTABLE } \\
\text { QUANTITIES" }\end{array}$ & $\begin{array}{c}\text { MAY NOT BE } \\
\text { CONTROLLABLE } \\
\text { EVEN WITH } \\
\text { SPECIAL } \\
\text { RESOURCES }\end{array}$ \\
\hline $\begin{array}{l}\text { FIRE / } \\
\text { EXPLOSION } \\
\text { POTENTIAL }\end{array}$ & LOW & MEDIUM & $\mathrm{HIGH}$ \\
\hline LIFE SAFETY & $\begin{array}{l}\text { NO LIFE } \\
\text { HAZARD }\end{array}$ & $\begin{array}{l}\text { LOCAL AREA, } \\
\text { LIMITED } \\
\text { EVACUATION }\end{array}$ & $\begin{array}{c}\text { LARGE AREA, } \\
\text { MASS } \\
\text { EVACUATION }\end{array}$ \\
\hline $\begin{array}{c}\text { IMPACT ON } \\
\text { ENVIRONMENT }\end{array}$ & MINIMAL & MODERATE & SEVERE \\
\hline
\end{tabular}

${ }^{*}$ small = Pail, drum, cylinder, package, bag.

medium $=$ One ton containers, portable containers, nurse tanks, multiple packages.

large $=$ Tank cars/trucks, stationary tanks, hopper cars/trucks, multiple medium containers

** e.g. asbestos 
2.3 EMERGENCY ALERTING AND RESPONSE

Initial notification of a hazardous materials incident will be through transmission of the radio signal 10-80. Transmission of the signal 10-80 will serve to warn responders to proceed with caution to avoid entering a restricted area.

As soon as possible, the Officer assuming Command will briefly describe the nature of the incident, identify a preliminary hazard perimeter and transmit this information to the dispatcher for the benefit of other responding units and agencies that will be notified. If possible, a preliminary Staging area should be designated. The intent is to limit unnecessary exposure of personnel and equipment. More specific information should be relayed to the dispatcher in progress reports as it becomes available.

The following notifications of a hazardous materials incident will be made by the Dispatcher upon receipt of all 10-80 code 2 signals (Level 2 or 3 incidents) and when the Hazardous Materials Unit responds.
A. Police Dept. Operations Unit
B. Dept. Of Environmental Protection
C. NYC Emergency Medical Services
D. NYC Dept. Of Health - for incidents involving radioactive materials.
E. NYS Dept. Of Environmental Conservation - for fuel oil spills.

2.3.1 On transmission of a 10-80 code 2 signal (Level 2 or 3 incident), the dispatcher will order the response of a Deputy Chief, Hazardous Materials Unit, Safety Operating Battalion, Field Communications Unit(DO 154/93) and Special Operation Command and a total first alarm assignment of 3 Engines, 2 Ladders AND 2 Battalion Chiefs.

The following Fire Department units will also be notified:

1. Fire Command or the City Wide Command Chief during non-operating hours of the Fire Command.

2. Notifications Desk, Bureau of Operations.

3. Public Information Office

4. Medical Officer on Duty

As is the case in other fire and emergency operations, the Incident Commander may call for additional units and activate and staff any part of the ICS appropriate to the apparent circumstances. 


\subsection{RESPONSE ORGANIZATION}

Under the Incident Command System, the incident organization will develop in a modular progression depending on the exact nature and specific conditions prevailing at the scene.

2.4.1 The first response of the Fire Department will be managed by the senior ranking officer on the initial alarm who will be the Incident Commander. This could be the Lieutenant or Captain of the first company to arrive. Responsibility for command will be transferred to succeeding commanders using the established lines of authority within the Incident Command structure.

The Incident Commander on the first alarm will implement the ERP for hazardous materials and assume responsibility for all command and command staff functions necessary to manage the initial response. The $\mathrm{IC}$ will call additional resources as incident needs dictate.

First responders at this level have been trained to implement offensive and defensive control measures for common hazardous materials involving limited quantities of certain materials as specified in standard operating procedures. (See 10.3 - Hazard Action Guides) They will be capable of performing the following basic procedures:

A. Initiate the Emergency Response Plan including isolating the site, establishing an initial Command Post, and establishing a site safety plan.

B. Notify the Dispatcher of the need for additional resources. Communicate essential information about the incident to other responders through the Dispatcher.

C. Initiate evacuation, if appropriate.

D. Initiate basic hazard and risk assessment activities including the use of personal protective equipment; preliminary identification of materials; containment and confinement of the material within the limits of the resource and protective equipment capabilities available on site.

E. Understand and comply with "decon" procedures.

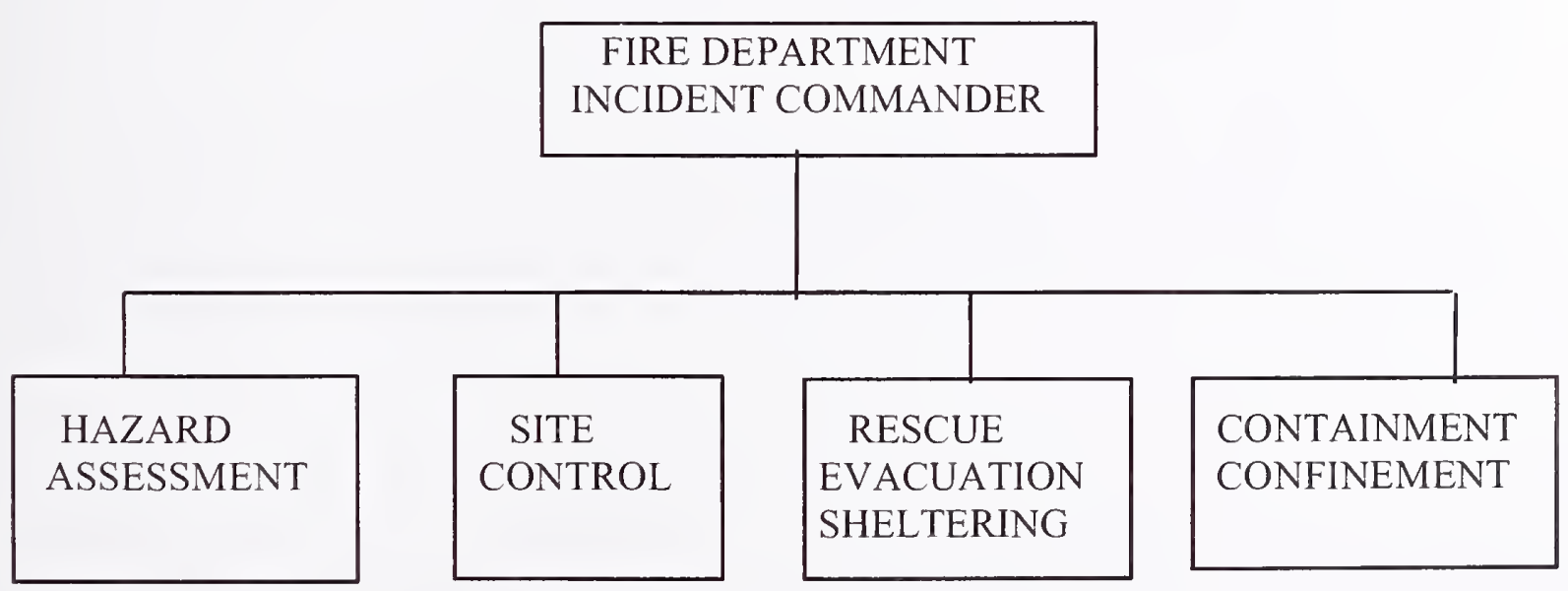


2.4.2 If an incident is beyond the capability of the first responders, the ICS will be expanded to include the Hazardous Materials Group and other responders with a higher level of training and more specialized skills and equipment.

As the incident progresses it may be necessary to modify/expand the organization structure so tasks may be accomplished as efficiently and safely as possible. Changes will be recorded in the Incident Log and the Command/Control Chart with affected positions notified.

Responders at this next level will be operating in a more complex environment that requires the coordination of several different agencies.

2.4.3 A more complex operation requires a unified command structure composed of the senior officials of various agencies. They will determine strategies and objectives that will fulfill their individual responsibilities while coordinating the actions of their respective personnel through the On-scene Coordinator.

Tactical activities for the Fire Department will be managed by the Operations Chief.

The Fire Department Hazardous Materials Group will manage all activities in the contamination zones. Only specially trained and equipped personnel will enter the contaminated zones.

Fire Department personnel in the contaminated zones will be operating in a more aggressive manner than the first responders in that they will actually approach a hazardous material, its container and associated devices in attempting to control, contain, confine, or prevent a release. 
EXAMPLE OF INCIDENT ORGANIZATION: LEVEL 2 or 3 INCIDENTS

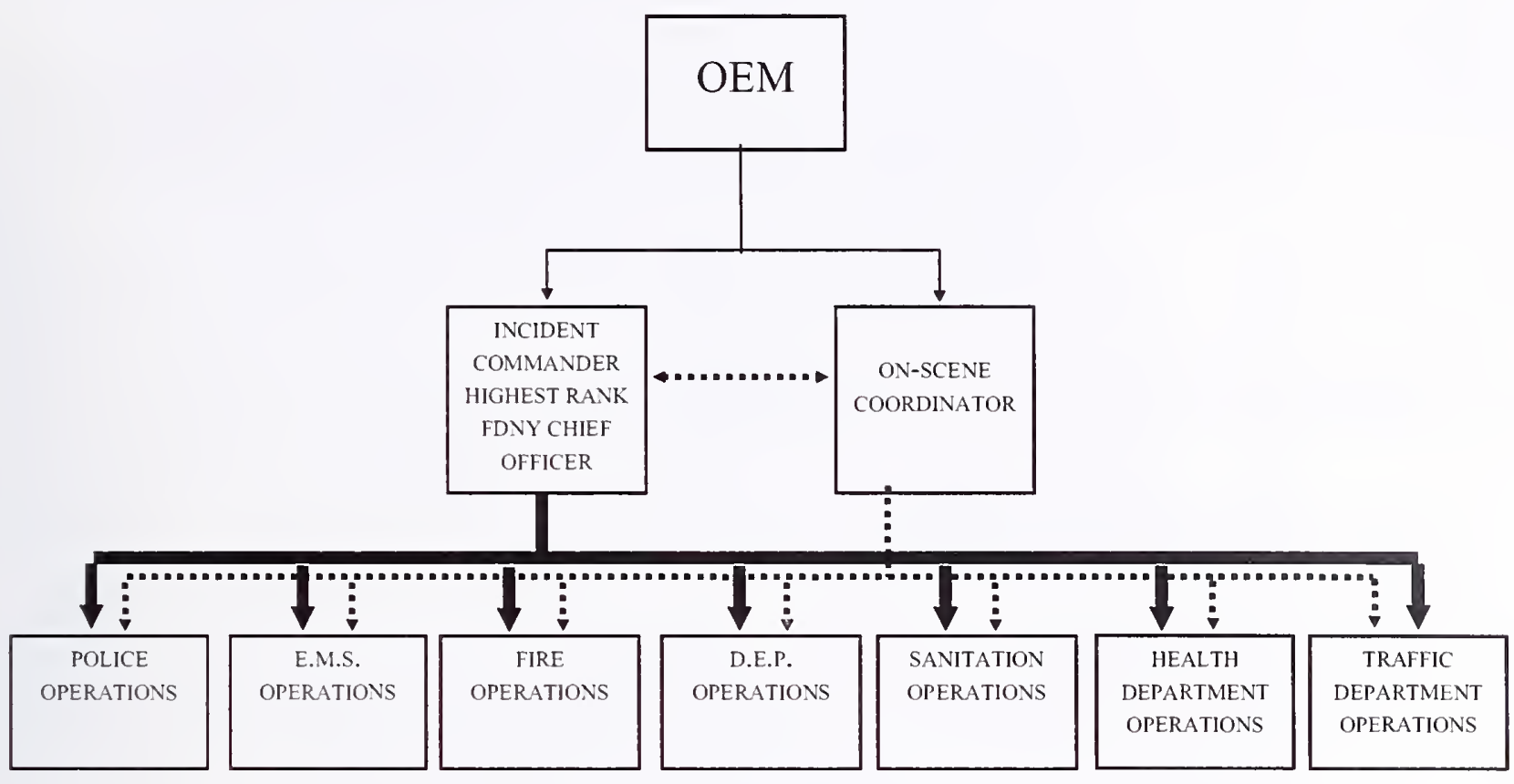

$=$ Activities and Operations directly relating to the mitigation of the problem.

...... = Activities and Operations directly relating to the Coordination and Overall Management of the Incident.

\section{GENERAL INCIDENT PROCEDURES AND SITE SAFETY}

\section{HAZARD ASSESSMENT}

Early recognition of incident hazards and potential risk is essential. The initial responsibility for assessment of incident hazards lies with first responding units.

Responding units will gather and communicate to the Incident Commander pertinent information regarding the presence or release of hazardous materials or chemicals.

Each member should be alert to the signs, evidence, and indications of the presence of hazardous substances during fires and emergencies and report such information to the next higher level of command. 
3.1.1 Persons reporting emergencies will usually describe the kind of incident creating a hazardous condition. They generally are unable to accurately describe a hazardous materials incident.

Since accurate information about the incident or site might not be available when responding, special attention should be focused on the possibility of exposure in the following circumstances:
A. Transportation accidents
B. Industrial accidents
C. Leaks, spills, or suspicious odors
D. Medical emergencies involving chemical inhalation
E. Explosions
F. Structural collapses

3.1.2 Information regarding hazardous occupancies or locations that has been obtained through inspection or preplanning activities should be available from "CIDS Information", described in the Communications Manual. This type of response information prior to arrival will prevent premature entry into dangerous environments and unnecessary exposure to responding personnel. It will also offer a significant measure of protection to responders unfamiliar with the location or occupancy.

3.1.3 On - site information gathering must be limited to that which can be obtained within the limits of each responders level of training and protective equipment. It is not in the best interest of the public or the responders to become part of the emergency problem instead of the solution.

First responders should gather, evaluate, and report information prior to entering into or undertaking activities that would place them in a contaminated environment.

3.1.4 The following are environments that must be evaluated before any commitment of personnel for any reason:

A. Large containers or tanks that must be entered.

B. Confined spaces (manholes, trenches, etc.) that must be entered.

C. Potentially explosive or flammable situations indicated by gas generation or gas release or over pressurization of containers (BLEVE).

D. Presence of extremely hazardous materials such as cyanide, phosgene, or radioactive materials.

E. Visible vapor clouds.

F. Areas where biological indicators such as "Unconscious persons" (refer to Section 3.6), dead animals or vegetation are located. 


\subsection{SITE SECURITY AND CONTROL}

An incident generally involves the escape of normally controlled substances and response activities involve actions to minimize and prevent these discharges. Site Control is preventing or reducing the exposure of any person and the transfer of hazardous substances (contaminants) from the site by civilians, department members and equipment. Site control involves two major activities:

A. Physical arrangements and control of the site work areas.

B. The removal of contaminants from people and equipment.

Control is needed to reduce the possibility of transport from the site of contaminants, which may be present on personnel and equipment. This can be accomplished in a number of ways including:

A. Establishing physical barriers to exclude the public and unnecessary personnel.

B. Establishing checkpoints with limited access to and from the site, or areas within the site.

C. Minimizing personnel and equipment on-site consistent with effective operations.

D. Establishing containment zones.

E. Undertaking decontamination procedures.

F. Conducting operations in a manner to reduce possibility of contamination.

\subsection{DECONTAMINATION}

Decontamination (DECON) is the process of making personnel, equipment and supplies safe by reducing present levels of poisonous or otherwise harmful substances. This process is one of the most important steps in ensuring personal safety at a hazardous materials emergency. The extent of its success depends on the ability of the IC to maintain control of personnel at the site.

The detail of decontamination operations required at an incident depends on the safety and health hazards of the contaminants. An uncontaminated light oil, for example, that presents a minimal hazard can be partially decontaminated by flushing it from protective clothing. In contrast, a poisonous material will require a careful and detailed course of action.

See "SAFE WORK PRACTICES - Decontamination Procedures", Section 5.3 of this document for more detailed information.

\subsection{EMERGENCY MEDICAL TREATMENT}

Teams from the Emergency Medical Service (EMS) are available to assist in medical treatment, and monitor the response personnel and others exposed to hazardous materials. The Fire Department Medical Officer on duty will also be notified of all Level 2 or greater incidents and will respond in accordance with Dept. policy. 


\subsection{PERSONAL PROTECTIVE EQUIPMENT (PPE)}

3.5.1 Structural firefighting gear is designed to protect firefighters from heat and flame.

Hazardous materials can contaminate protective clothing, respiratory equipment, tools, vehicles, and other equipment used at an emergency scene.

First responders should avoid leaks, spills, and obvious sources of hazards, as well as indirect contact with potentially contaminated areas. Full firefighting gear and SCBA will be used at all times as a minimum of protection against exposure. Safe work practices WILL MINIMIZE exposure and contamination.

3.5.2 The use of Chemical protective clothing and equipment requires specific skills acquired through training. It is only available to members of the Hazardous Materials Unit.

This type of special clothing may only protect against one chemical, yet be readily penetrated by other chemicals for which it was not designed. It offers little or no thermal protection in case of fire. No one suit offers protection from all hazardous materials.

3.5.3 The level of special protection required in each zone at an incident will be determined by the Officer in charge of the Hazardous Materials Unit based on information available.

3.5.4 The levels of protection available include:

A. "Level A" highest level of protection to the responder.

B. "Level B" high level of protection to the respiratory tract but a lower level of skin protection than level "A".

Level "A and B" protective equipment is only available for use by members of the Hazardous Materials Unit.

C. "Level C" does not require maximum skin or respiratory protection. This level presupposes that the types of air contaminants have been identified, concentrations measured, and the atmosphere is not oxygen deficient.

D. "Level D" provides minimal protection and is used to guard against nuisance contamination only.

Structural firefighter protective clothing, i.e. turnout or bunker gear, is not classified as chemical protective clothing. The highest level of chemical protection that this level will provide is Level "D". 


\subsection{RESCUE}

In most situations emergency personnel can protect the public by isolating and denying entry to contaminated areas. Initial rescue actions should concentrate on removing ablebodied persons from immediate danger. Involvement in complicated rescue problems or situations should be evaluated before being attempted.

When the probability is high that the victim cannot be saved or is already dead, rescue should not be attempted if it will place the rescuer at unnecessary risk. The danger of exposure to unknown chemicals or a potential explosion may make the risk unacceptable.

The following should be considered in attempting a rescue during a hazardous materials emergency:

A. Has the presence of a victim been confirmed visually or by other credible sources?

B. Is the person conscious or responsive?

C. How long has the victim been trapped or exposed? Is he/she viable?

D. Is the leaking material pooling or vaporizing in the area of the victim?

E. What are the properties of the material involved? What is the concentration of the material around the victim?

F. What special equipment is available to assist in this effort?

Consideration of these questions will help in weighing the likelihood of a successful rescue against the overall risk to the rescuer.

\subsection{EVACUATION / SHELTERING}

There are essentially two ways to protect the public from the effects of hazardous material discharges into the environment.

A. Evacuation: involves moving threatened persons to shelter in another area.

B. Sheltering in place: involves giving instructions to people to remain where they are until the danger passes.

Evacuation is clearly safer with respect to the hazards, but has certain limitations and may pose new problems. Evacuation takes time and may not be possible if large numbers of persons or a large volume of vapor is present. Evacuation through a toxic atmosphere may actually cause more harm than good in some cases.

\subsubsection{Evacuation is best considered when:}

A. There is an immediate danger of fire or explosion.

B. The potential for a discharge is great, it has not taken place, and there is time available to relocate people.

C. The discharge has taken place but people are sufficiently protected to permit time for evacuation.

D. People not yet in the path of a release will be threatened by changing conditions. 
3.7.2 Large scale evacuation will be directed by the On Scene Coordinator and will require the coordinated efforts of several agencies.

3.7.3 The decision to shelter in place is appropriate when the hazardous material will not affect the structure or its occupants or the hazard will pass a structure with little infiltration.

3.7.4 Sheltering in place is the alternative when:

A. Pre-planning has identified options for problem areas such as hospitals, jails, nursing homes, public assemblies, etc.

B. Evacuation cannot be properly managed with the manpower, resources, and facilities presently available.

C. The hazardous material displays the following characteristics:

1. Low to moderate toxicity;

2. Totally released and dissipating;

3. Small quantity solid or liquid leak;

4. A migrating vapor of low toxicity and quantity and people are safer indoors than outside; and

5. Release can be rapidly controlled at the source.

3.7.5 The success of either option will depend on the preplans and effectiveness of communication resources, notification and public information.

\subsection{EMERGENCY EQUIPMENT}

Private corporations, outside agencies, and other city agencies maintain specialized equipment and services that may be placed at the disposal of the Fire Department for use at these incidents. A catalogue of these services and equipment is maintained by the Bureau of Fire Communications. Calls for the use of these services or cooperation of these agencies shall be transmitted to the Dispatcher by the IC. Approval will come from the Commissioner and Chief of Department or their designee.

Liability, costs to the provider, and the availability of certain types of equipment preclude irregular or other informal arrangements.

The IC will designate the exact location to which the special equipment will respond. 


\section{ROLES AND RESPONSIBILITIES OF FIRE DEPARTMENT RESPONDERS}

\subsection{INCIDENT COMMANDER - Responsible for all Fire Department incident} activities, planning and checklist functions, preparation of reports, incident termination, and post incident analysis.

The senior ranking Officer first on the scene will determine the need for the following actions and implement those that are necessary and within the capability of the resources and equipment available at the time.

Succeeding Commanders will further evaluate the needs of the incident and refine, reinforce, or expand the scope and depth of these response activities.

\section{A. COMMAND}

\section{ESTABLISH A SITE SAFETY PLAN}

a. Set up isolation, control, and support zones. Refer to site plans, if available.

b. Limit and control site access.

c. Set up and manage staging areas.

d. Coordinate F.D. personnel, on site personnel and other support agency activities.

e. Call for resources/support units.

2. ESTABLISH LINES OF COMMUNICATION

a. Announce location of Command Post, Staging areas.

b. Report incident and site information to Dispatcher.

c. Communicate plan of action to on scene personnel.

d. Establish contact/communications with other agencies responding.

e. Consult on site personnel/specialists.

3. ESTABLISH A COMMAND POST

a. Establish F.D. Command Post.

b. Set up/maintain Command \& Control Chart.

c. Establish and maintain incident $\log$.

4. STAFF ICS FUNCTIONAL POSITIONS (as needed)

a. Safety, Liaison/Information.

b. Staging.

c. Operations, Planning, Logistics, Finance.

d. Establish appropriate Sectors/Groups. 
B. OPERATIONS

1. CONDUCT A SITE SURVEY/SIZE - UP

a. Determine the nature, source, extent of problem.

b. Estimate incident level.

c. Determine need for evacuation.

2. FORMULATE/IMPLEMENT PLAN OF ACTION

a. Implement initial plan of action as described in the Emergency Response Guidebook and Hazard Action Guides.

b. Communicate plan of action to on scene personnel.

c. If necessary, implement alternate plans as information, personnel, resources and equipment are secured.

\section{TERMINATE INCIDENT ACTIVITIES}

a. Evaluate decontamination needs and support activities.

b. Establish disengagement / demobilization plan including post incident information and transfer of responsibilities.

c. Document remedial efforts during clean up operations.

d. Evaluate compliance with Fire Department regulations and directives and take appropriate enforcement action.

\section{POST INCIDENT ANALYSIS}

a. Conduct a post incident analysis and review.

b. Evaluate response re: Response plan.

c. Make recommendations.

\section{PLANNING}

\section{EVALUATE HAZARDS AND ASSESS NEEDS}

a. Determine strategic goals and tactical objectives.

b. Assess current status and intervention options.

c. Formulate, review, revise goals, objectives, action plan.

\section{LOGISTICS}

Assess logistical support requirements for incident activities.

\section{E. FINANCE}

Record all information re: costs involved in mitigating the incident incurred by the Fire Department. 
4.2 FIRST RESPONDERS (OPERATIONAL LEVEL) - respond to the site for the purpose of protecting persons, property, or the environment from the effects of a hazardous materials release or potential release. They are not trained or equipped to use specialized chemical protective clothing or special control equipment. Their actions are limited to those which may be accomplished using SCBA and structural firefighter protective clothing as described in Department SOP and the Hazard Action Guides (HAG).

In the event that the public or any emergency responder has been exposed prior to recognition of a hazardous substance, those persons exposed should be isolated to avoid spreading any contamination and so that proper medical treatment and monitoring can be arranged. Those not exposed must be kept out of the contaminated area.

\subsubsection{INITIAL ACTIONS}

A. Given the limited capability of units arriving first at the scene of a hazardous materials release or potential release, premature commitment of companies and personnel to unknown, potentially hazardous situations/locations must be avoided.

B. Cautious, methodical, and deliberate size-up combined with immediate site security limits needless exposure of responding personnel and reduces the vulnerability of the public and the environment.

C. As soon as the presence of a hazardous substance is detected or suspected First Responders should take the following actions:

1. Use full structural firefighting clothing and SCBA as a minimum to protect themselves from unnecessary exposure to contaminants.

2. Isolate the hazard.

3. Control access to the hazard area.

4. Communicate available information to the IC or Dispatcher.

5. Alert other responders and call for assistance, if needed.

6. Establish an initial staging area for other responders.

7. Take steps to identify the hazard and evaluate the risk without endangering on scene personnel.

8. Consult Emergency Response Guidebook and Hazard Action Guides (HAG). 
D. Whenever possible, first arriving units must alert other responding units of the hazardous nature of the incident by transmitting signal $10-80$ with a brief description of known hazard information. This will prevent units from unknowingly responding into the hazard area.

E Develop a plan of action consistent with the Department's Emergency Response Plan and Hazard Action Guides for hazardous materials (HAG).

F. Implement the plan within the capability of the available personnel, protective clothing and equipment.

Note: The following assignments (Sections 4.2.2 through 4.2.6) are prescribed as standard procedure for units responding to a known or suspected hazardous materials incident. When the presence of a hazardous material is discovered during fire or other emergency operations, the Incident Commander must isolate units, redeploy or withdraw units and adjust the strategic and tactical objectives to address the hazard affecting the public and the operating emergency personnel.

Individual units must be assigned or reassigned to Hazard assessment, site control for public and personnel protection, and limited containment/confinement or isolation strategies as are possible. Given the limited capabilities of responders trained and equipped to the operational level this could include:

A. Withdrawing from or isolate selected areas.

B. Adjusting tactical objectives. Redeploy or reassign units and personnel.

C. Continuing current strategy, with additional resources called for specific assignments, e.g. the hazardous material problem.

The priorities should continue to be focused on limiting the exposure of personnel and the public; stabilizing the incident until additional resources are available to gain control; limiting the impact of the event by protecting property and the environment from additional harm. 


\subsubsection{FIRST ARRIVING LADDER COMPANY - HAZARD ASSESSMENT}

The first arriving Ladder Co. is responsible for Hazard Assessment.

Some members of this company will be divided into teams, each team equipped with at least one radio. The Officer of this unit will designate team members and a radio contact person.

The purpose of the team concept is to provide for the safety and accountability of all the members. No person involved in the operational activities of these teams is to work alone.

A. OFFICER: Supervise hazard assessment activity of assigned members.

1. Obtains briefing from IC.

2. Assigns and instructs teams regarding hazard assessment activities and limitations.

3. Coordinates apparatus placement with other responding units.

4. Reports information to IC.

5. Monitors Handie-talkie/Radio.

B. LADDER CHAUFFEUR: Apparatus placement.

1. Positions apparatus out of the hazard area and as a barrier for site access control as ordered.

2. Coordinates apparatus placement with other responding units.

3. Remains with apparatus until further ordered.

4. Establishes physical barriers to area access using apparatus, barrier tape, traffic cones, traffic signs, etc., as ordered.

5. Monitors Handie-talkie/Radio.

\section{TEAM 1: Hazard Identification.}

1. Identify occupancy and location hazards, if possible.

2. Identify Container shape and approximate size, if possible.

3. Identify any visible markings, colors, placards/labels, etc.

4. Report information available and stand-by.

5. Monitor Handie-talkie.

D. TEAM 2: Information resources.

1. Access HAG \& DOT GUIDEBOOK locating appropriate Guide, isolation and evacuation recommendations.

2. Confirm Guide Number, isolation distance, and evacuation information with Second Arriving Ladder Co..

3. Report information to Officer.

4. Monitor Handie-talkie. 


\subsubsection{SECOND ARRIVING LADDER COMPANY - SITE ACCESS CONTROL}

The second arriving Ladder Co. is responsible for Controlling Access to the site and for establishing the initial exclusion area. Some members of this company will be divided into teams, each team equipped with at least one radio. The Officer of this unit will designate team members and a radio contact person.

The purpose of the team concept is to provide for the safety and accountability of all the members. No person involved in the operational activities of these teams is to work alone.

\section{A. OFFICER: Coordinate / limit site access.}

1. Obtains briefing from IC.

2. Assigns and instructs teams regarding hazard assessment activities and Limitations.

3. Advises IC re: need for Police assistance in area security and control.

4. Reports information to IC.

5. Monitors Handie-talkie/Radio.

B. LADDER CHAUFFEUR: Apparatus placement.

1. Positions apparatus out of the hazard area and as a barrier for site access control as ordered.

2. Coordinates apparatus placement with other responding units.

3. Remains with apparatus until further ordered.

4. Establishes physical barriers to area access using apparatus, barrier tape, traffic cones, traffic signs, etc., as ordered.

5. Monitors Handie-talkie / Radio.

\section{TEAM 1: Information resources.}

1. Using information from the first arriving ladder company or the IC, access HAG \& DOT GUIDEBOOK locating appropriate Guide, isolation and evacuation recommendations.

2. Confirm Guide Number, isolation distance, and evacuation information with First Arriving Ladder Co.

3. Report information to Officer.

4. Monitor Handie-talkie.

\section{TEAM 2: Initial Isolation Zone}

1. On orders of the Officer establish physical barriers as an initial isolation/exclusion zone using barrier tape, utility rope, traffic cones, etc., as ordered.

2. Remain outside isolation zone to deny access until relieved or as ordered.

3. Monitor Handie-talkie. 
4.2.4 FIRST ARRIVING ENGINE COMPANY - WATER SUPPLY

The first arriving Engine will Establish The Initial Water Supply.

Based on the existing conditions, a line should be stretched but not placed into operation until ordered by the IC. pending the outcome of the initial hazard assessment. The premature, unnecessary, or incompatible use of water can compound the hazard. The unit will stand-by out of the hazard area.

Members of this unit will remain together as a unit unless otherwise ordered by the Incident Commander to perform duties appropriate to specific tactical objectives. This might include such things as assisting in site control or evacuation.

If and when necessary, some members of this company may be divided into teams, each team equipped with at least one radio. The Officer of this unit will designate team members and radio contact person.

The purpose of the team concept is to provide for the safety and accountability of all the members. No person involved in the operational activities of these teams is to work alone.

A. OFFICER: Supervise hazard assessment activity of assigned members.

1. Obtains briefing from IC.

2. Assigns and instructs teams regarding hazard assessment activities and limitations.

3. Supervises water supply and line placement activities.

4. Coordinates apparatus placement with other responding units.

5. Reports information to IC.

6. Monitors Handie-talkie/radio.

B. ENGINE CHAUFFEUR: Apparatus placement.

1. Positions apparatus out of the hazard area.

2. Establishes a water supply.

3. Coordinates apparatus placement with other responding units.

4. Remains with apparatus until further ordered.

5. Establishes physical barriers to area access using apparatus, barrier tape, traffic cones, traffic signs, etc., as ordered.

6. Monitors Handie-talkie/radio. 


\subsubsection{SECOND ARRIVING ENGINE COMPANY - SITE ACCESS CONTROL}

The second arriving Engine Co. is responsible for assisting and coordinating with the second ladder company to Control Access to the site.

Members of this unit will remain together as a unit unless otherwise ordered by the Incident Commander to perform duties appropriate to specific tactical objectives. This might include such things as assisting the first arriving Engine in water supply or line placement, site control or evacuation.

If and when necessary, some members of this company may be divided into teams, each team equipped with at least one radio. The Officer of this unit will designate team members and a radio contact person.

The purpose of the team concept is to provide for the safety and accountability of all the members. No person involved in the operational activities of these teams is to work alone.

\section{A. OFFICER: Assist Second Ladder Co. in SITE CONTROL.}

1. Obtains briefing from IC.

2. Assigns and instructs teams regarding hazard assessment activities and limitations.

3. Coordinates site activities with other units engaged in site control.

4. Reports information to I.C.

5. Monitors Handie-talkie/Radio.

\section{B. ENGINE CHAUFFEUR: Apparatus placement.}

1. Positions apparatus out of the hazard area and as a barrier for site access control as ordered.

2. Coordinates apparatus placement with other responding units.

3. Remains with apparatus until further ordered.

4. Establishes physical barriers to area access using apparatus, barrier tape, traffic cones, traffic signs, etc., as ordered.

5. Monitors Handie-talkie/radio.

\subsubsection{OTHER UNITS ON INITIAL ALARM}

Members of these units will remain together as a unit unless otherwise ordered by their Officer as directed by the Incident Commander to perform duties appropriate to specific tactical objectives. This might include assisting other units in site control or evacuation.

If and when necessary, members of these companies may be divided into teams, each team equipped with at least one radio. The Officer of this unit will designate team members and a radio contact person.

The purpose of the team concept is to provide for the safety and accountability of all the members. No person involved in the operational activities of these teams is to work alone. 
A. THIRD ARRIVING ENGINE CO.

1. Reports to Incident Commander.

a. Obtain briefing from IC.

b. Assigns and instructs teams regarding hazard assessment activities and limitations.

c. Coordinates apparatus placement with other responding units.

d. Reports information to IC.

2. Stands-by to assist other responders as directed by the IC.

3. Monitors Handie-talkie/radio.

B. RESCUE CO., SQUAD, OTHER UNITS, Etc.

1. Report to Incident Commander.

a. Obtain briefing from IC.

b. Assign and instruct teams regarding hazard assessment activities and limitations.

c. Coordinate apparatus placement with other responding units.

d. Report information to IC.

2. Stand-by to assist other responders as directed by the IC.

3. Monitor Handie-talkie/radio.

\section{ADDITIONAL UNITS}

Additional units responding to the scene of a known hazardous materials incident should be given specific information regarding the location of staging areas and tactical objectives assigned to the unit. If, due to the nature of the event, the Officers of the responding units do not receive this information, they should:

1. Request this information from the dispatcher.

2. Keep their units intact and establish contact with the next higher level of supervision.

3. Members of the units will remain together as a unit unless otherwise ordered by their Officer who is directed by the Incident Commander to perform duties appropriate to specific tactical objectives. If and when necessary, members of these companies may be divided into teams, each team equipped with at least one radio. The Officers of these units will designate team members and a radio contact person. 
4.3 HAZARDOUS MATERIALS GROUP - Individuals who respond to releases or potential releases for the purpose of stopping or controlling them. They assume a more aggressive role than a first responder at the operational level in that they will approach the point of the release. Their duties require a more directed or specific knowledge of the various substances they may be called upon to contain. Their training includes knowledge of procedures for the use of specialized chemical protective clothing, survey equipment, and special procedures for containing a chemical hazard and decontamination.

Some members of the Hazardous Materials Unit will be divided into teams, each team equipped with at least one radio. The Officer of this unit will designate team members and the radio contact person.

The purpose of the team concept is to provide for the safety and accountability of all the members. No person involved in the mitigation activities of these teams is to work alone.

The Haz-Mat Group consists of the Hazardous Materials Unit and members of the Special Operations Command. Each has a specific role and objective to accomplish at an incident. They are generally described as follows:

A. Analysis

1. Verify, identify, or classify hazardous materials and determine their concentration.

2. Collect and interpret hazard and response information.

3. Estimate damage to containment systems.

B. Planning

1. Select appropriate PPE for incident activities.

2. Develop decontamination procedures.

3. Develop plan of action consistent with the ERP and within the capability of the personnel, PPE, and equipment available.

C. Operations

1. Carry out planned activities under the direction of the IC as per the ERP.

4.3.1 HAZ-MAT GROUP SUPERVISOR - On duty Officer of Hazardous Materials Unit who will supervise the "hands-on" mitigation operation. He will coordinate the following activities as directed by and report to the IC or a level of supervision assigned by the IC as per FDNY-ICS.
A. Obtains briefing from the Incident Commander.
B. Confirms the development of Control Zones and Access Control Points and the placement of appropriate control lines.
C. Ensures that a Site Safety Plan is developed and implemented.
D. Participates in the development of the Incident Action Plan; Develops the Hazardous Materials portion of the Incident Action Plan.


E. Evaluates and recommends evacuation, sheltering, and decontamination options to the Incident Commander.

F. Conducts safety meetings with the Hazardous Materials Unit members. The Hazardous Materials Group Supervisor is responsible for site safety and operations inside the area bounded by the Contamination Control Line including the Exclusion Area or "Hot Zone".

G. Ensures that the proper Personal Protective Equipment is selected and used.

H. Ensures that current weather data and future weather predictions are obtained.

I. Supervises the activities of and maintains communications with:

1. Haz-Mat Unit Team members.

2. Incident Commander or next higher level of supervision, if a position has been staffed.

J. Establishes environmental monitoring of the hazard site for contaminants.

K. Ensures that appropriate agencies are notified through the Incident Commander.

L. Terminates operations.

4.3.2 ENTRY TEAM - The Entry Team consists of a minimum of two members assigned to the Haz-Mat Unit. One member will be designated the Team Leader. The Team Leader will, on orders from the Haz-Mat Group Supervisor, perform the following functions:

A. Obtain briefing from the Hazardous Materials Group Supervisor.

B. Supervise entry operations.

C. Recommend actions to mitigate the situation within the Exclusion Zone.

D. Carry out actions, as directed by the Hazardous Materials Group Supervisor, to mitigate the hazardous materials release or threatened release.

E. Maintain communications and coordinate operations with:

1. Hazardous Materials Group Supervisor.

2. Decontamination Team Leader.

3. Resource Technician / Hazardous Materials Reference.

4. Back-up Team.

F. Maintain control of the movement of people and equipment within the Exclusion Zone, including contaminated victims.

G. Direct rescue operations, as needed, in the Exclusion Zone.

H. Terminate operations. 
4.3.3 BACKUP TEAM - The Backup Team consists of a minimum of two members assigned to the Haz-Mat Unit. One member will be designated the Team Leader. The Team Leader will, on orders from the Haz-Mat Group Supervisor, perform the following functions:

A. Obtain briefing from the Hazardous Materials Group Supervisor.

B. Assist Entry Team in site survey and product identification.

C. Carry out actions as directed by the Hazardous Materials Group Supervisor.

D. Ensure all equipment is prepared for use according to action plan.

E. Maintain sight contact with Entry Team whenever possible.

F. In proper PPE, act as a backup Entry Team from safe area. Be prepared to rescue the Entry Team.

G. Complete operations in Exclusion Zone should Entry Team fail to complete assignment.

H. Maintain communications and coordinate operations with:

1. Entry Team Leader.

2. Hazardous Materials Group Supervisor.

3. Resource Technician / Hazardous Materials Reference.

4. Decon Team Leader.

I. Furnish additional equipment or supplies to the Entry Team as needed. Replace equipment used.

J. Terminate operations.

4.3.4 DECONTAMINATION (DECON) TEAM - The Decon Team consists of a minimum of two members assigned to the Haz-Mat Unit. One member will be designated the Team Leader. The Team Leader will, on orders from the Haz-Mat Group Supervisor, perform the following functions:
A. Obtain briefing from the Hazardous Materials Group Supervisor.
B. Manage the Control Zones and Access Control Points and the placement of appropriate control lines.
C. Ensure appropriate action is taken to prevent spread of contaminants.
D. Set up Decon area. Implement decontamination process of Haz-Mat Team.
E. Decon, as possible, all equipment used.
F. Maintain communications and coordinate operations with:
1. Entry Team Leader.
2. Hazardous Materials Group Supervisor.
3. Resource Technician / Hazardous Materials Reference.
4. Back-up Team.
G. Overpack exposed equipment for further decontamination or disposal.
H. Ensure that all equipment is placed back in service.
I. Terminate operations. 
4.3.5 RESOURCE TECHNICIAN - A member of the Haz-Mat Unit designated to provide technical information and assistance to the Hazardous Materials Group using various reference sources such as computer data bases, technical library, CHEMTREC, and phone contact with facility representatives.

The Resource Technician may provide product identification using tests kits and/or any other means of identifying unknown materials.

The Resource Technician will, on orders from the Haz-Mat Group Supervisor, perform the following functions:

A. Obtains briefing from the Hazardous Materials Group Supervisor.

B. Provides support to the Hazardous Material Group Supervisor.

1. Monitors SCBA use time for suit operations.

2. Determines personal protective equipment compatibility to hazardous material.

C. Maintains communications and coordinate operations with:

1. Entry Team Leader.

2. Hazardous Materials Group Supervisor.

3. Back Up Team Leader.

4. Decon Team Leader.

D. Provide technical information management with public and private agencies. Interpret environmental monitoring information.

E. Provide analysis of hazardous material samples.

F. Document operations and notifications. E.g. Document serial numbers of chemical protective suits worn by members.

G. Provide technical information of the incident for documentation.

H. Determine proper decon requirements.

I. Complete all necessary reports and forms and terminate operations. 
4.3.6 SPECIAL OPERATIONS DECON OFFICER - member of Special Operations Command assigned to the Hazardous Materials Group designated responsible for on-site and off site decontamination. The SOC Decon Officer will respond upon the request of the Incident Commander. The SOC Decon Officer reports directly to the Incident commander. The SOC Decon Officer supervises the SOC Decon Team.

The SOC Decon Officer, as directed, will:

A. Obtain briefing from IC, advise IC of decon needs, and formulate plan of action. The Decon procedure to be followed will be determined by DEP, and the SOC Decon Officer.

B. Identify items of equipment and clothing to be decontaminated.

C. Establish a Decon area.

D. Supervise the set-up and operation of all tools and equipment required for the decon procedure.

E. Arrange for collection, transportation, storage, cleaning, and temporary replacement of exposed or contaminated equipment.

F. Insure proper disposition of all processed items.

Procedures and documentation for this phase of operations will be as per policy developed by the Special Operations Command. See Section 5.3, for information on the Decon process.

The SOC Decon Officer will respond with the Decontamination Support Vehicle and the SOC Decontamination Team. Decontamination will, if possible, be accomplished at the scene to place apparatus, clothing and equipment back in service. If this is not possible, decontamination will be conducted at a time and site designated by the SOC Decon Officer.

4.3.7 SPECIAL OPERATIONS COMMAND DECON TEAM - consists of members assigned to Special Operations Command. They report directly to the SOC Decon Officer.

The SOC Decon Team is trained and designated by the Fire Department to perform decontamination of apparatus, tools, and equipment. They are qualified to execute specific procedures and operate decontamination equipment wearing the protective clothing and respiratory protection appropriate to the hazardous substance being processed. 


\section{SAFE WORK PRACTICES}

\subsection{GENERAL PROCEDURES}

The following work practices must be enforced to ensure a safe work-site for all personnel.

A. Always consider the possibility that hazardous materials may possess multiple hazards.

B. Use full structural firefighting clothing and SCBA as minimum protection from unnecessary exposure to contaminants.

C. Each member should be alert to the signs, evidence and indications of the presence of hazardous substances during fires and emergencies and report such information to the next higher level of command.

D. If and when necessary, members may be divided into teams, each team should be equipped with at least one radio. The Officer of the unit will designate team members and radio contact person.

E. Mark all work zones and access points with barricade tape, flagging, or traffic cones.

F. Access to the site should remain free of unnecessary equipment and apparatus to facilitate other types of emergency access to and egress from the site.

G. Persons entering or leaving a work zone must check in/out at the access control point.

H. Access and means of egress must be secured and protected for the safety of persons in work zones. Doors, stairways and ladders should be secured. Ramps, ditches and excavations should be made as secure as possible in the event that rapid escape is required from the site.

I. No eating, drinking, or smoking is allowed in any contaminated area.

J. Implement decontamination based on an analysis of the hazards and risks involved.

(See Decontamination Section 5.3)

\subsection{WORK ZONES}

The method of reducing the potential for transfer of contamination is to delineate work areas within the incident site based upon expected or known levels of contamination. Within the areas assigned, personnel will utilize appropriate personal protective equipment. Movement between areas is controlled at checkpoints. Three contiguous areas will be established.
A. Exclusion area (contaminated) - "HOT ZONE"
B. Contamination reduction area - "WARM ZONE"
C. Support area (non-contaminated) - "COLD ZONE" 


\subsubsection{EXCLUSION AREA - HOT ZONE}

The Exclusion Area is the inner most area and is considered contaminated or "hot". Within the Exclusion Area, prescribed levels of protection must be worn by all entering personnel. A check point must be established at the periphery of the Exclusion Area to control the flow of personnel and equipment between contiguous areas and to insure that the procedures established to enter and exit the areas are followed.

The Exclusion Area boundary would be established initially based on the type of released/spilled materials, initial instrument readings, and a safe distance from any potential exposure.

Subsequently, the boundary may be readjusted based on additional observation and/or measurements. The area should be physically secured by barrier tape into well-defined boundaries.

In the event that the public or any emergency responder has been exposed prior to recognition of a hazardous substance, those persons exposed should be isolated to avoid spreading any contamination and so that proper medical treatment and monitoring can be arranged.

Those not exposed must be kept out of the contaminated area.

Unless otherwise demonstrated, everything leaving the Exclusion Area should be considered contaminated and appropriate methods established for decontamination should be implemented.

\subsubsection{CONTAMINATION REDUCTION AREA - WARM ZONE}

Between the Exclusion Area and the Support Area is the Contamination Reduction area. The purpose of this zone is to provide an area to prevent or reduce the transfer of contaminants which may have been picked up by personnel or equipment returning from the Exclusion Area. All decontamination activities occur in this area.

The boundary between the Support Area and the Contamination Reduction Area is the "Contamination Control Line". This boundary separates the possibly contaminated area from the clean zone. Entry into the Contamination Reduction Area from the clean area will be through an access control point. Personnel entering at this location will be wearing the prescribed level of protection for working in the Contamination Reduction Area. Exiting the Contamination Reduction Area to the clean area requires the removal of any suspected or known contaminated protective clothing and/or equipment and that appropriate decontamination procedures be followed.

At the boundary between the Contamination Reduction Area and the Exclusion Area is the "Hot Line" and access control station. Entrance into the Exclusion Area requires the wearing of the prescribed chemical protective clothing which may be different than the equipment requirements for working in the Contamination Reduction Area. 
At a point close to the "Hot Line", a personnel and/or equipment decontamination station is established for those exiting the Exclusion Area. Unless otherwise demonstrated, everything leaving the Exclusion Area should be considered contaminated and appropriate methods established for decontamination should be implemented.

\subsubsection{SUPPORT AREA - COLD ZONE}

The Support Area is the outermost area of the site and is considered a noncontaminated or "clean" area. It is designated as a controlled area for authorized support personnel and the location for support equipment (Command Post, Equipment, etc.). Since normal firefighting clothing are appropriate within this zone, potentially contaminated personnel clothing, equipment, etc., are not permitted.

\subsubsection{AREA DIMENSIONS}

Considerable judgment is needed to assure safe working distances for each area balanced against practical work considerations. During long term operations zones may be adjusted.

The following criteria are to be considered in determining the area dimensions:
A. Physical and topographical barriers;
B. Weather conditions;
C. Monitoring measurements;
D. Explosion/exposure potential;
E. Physical, chemical, toxicological, etc., characteristics of the contaminant(s); and
F. Clean-up activities.

\subsubsection{OTHER CONSIDERATIONS}

The use of a three-zone system of area designation, access control points and exacting decontamination procedures provides a reasonable assurance against the translocation of contaminating substance. This control system is based on a "worst case" situation. Less stringent site control and decontamination procedures than described may be utilized based upon more accurate information concerning the types of contaminants involved and the contaminating hazards they present. This information can be obtained through air monitoring, instrument survey, etc., and technical data concerning the characteristics and behavior of material present. Site control requirements can be modified within the limits of safety for specific situations once more reliable data has been analyzed. 


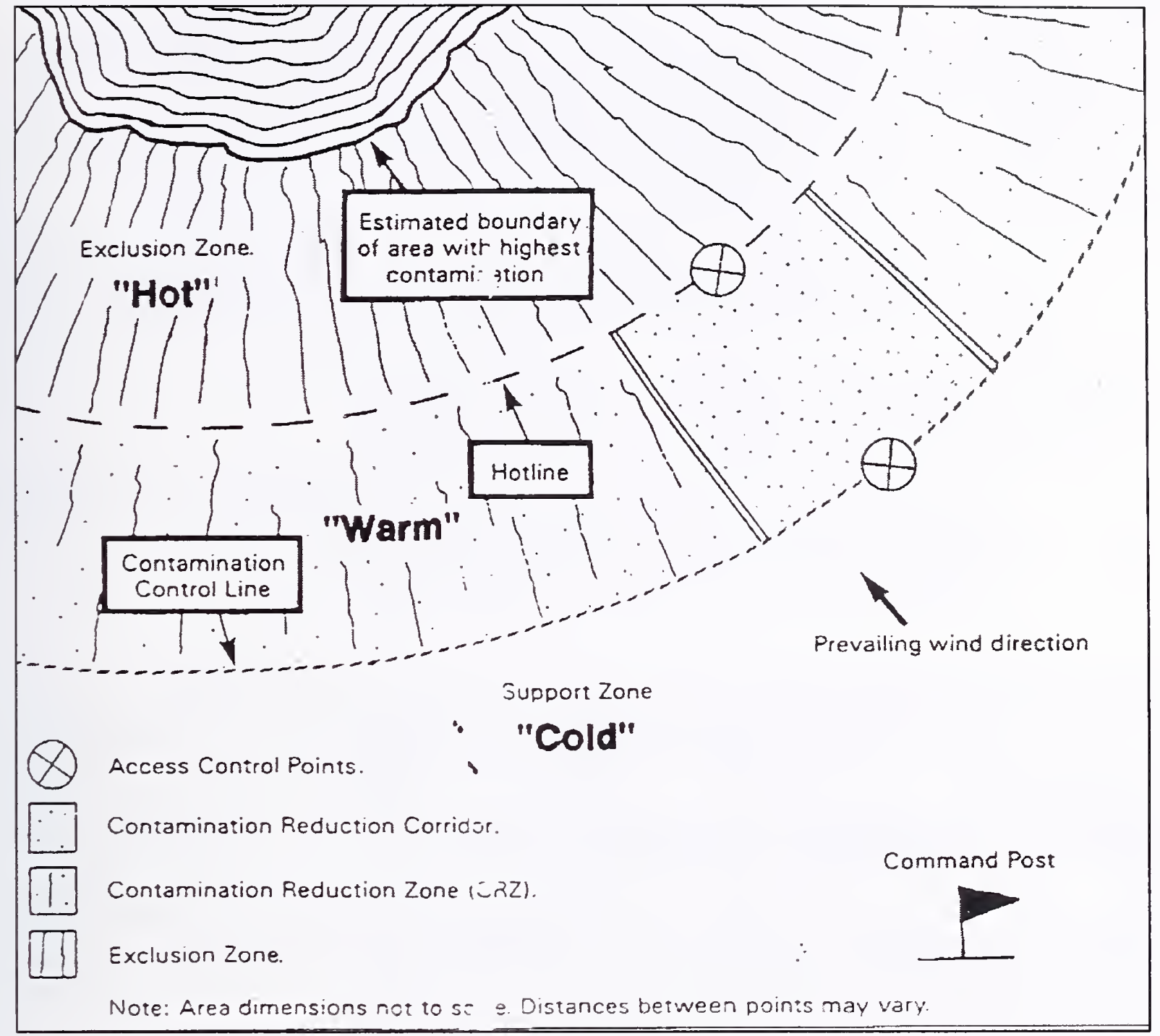




\subsection{DECONTAMINATION PROCEDURES}

As part of the system to prevent or reduce the physical transfer of contaminants by people and/or equipment from the site, procedures will be instituted for decontaminating anything leaving the Exclusion Area and Contamination Reduction Area. These procedures include the decontamination of personnel, protective equipment, monitoring equipment, clean-up equipment, etc.

In the event that the public or any emergency responder has been exposed prior to recognition of a hazardous substance, those persons exposed should be isolated to avoid spreading the contamination and so that proper medical treatment and monitoring can be arranged.

Those not exposed must be kept out of the contaminated area.

5.3.1 The FDNY maintains a Hazardous Materials Decontamination Unit. The Unit consists of the Decon trailer and a support unit. The Police Department has a similar unit that can be utilized as a backup. (See Diagram below)

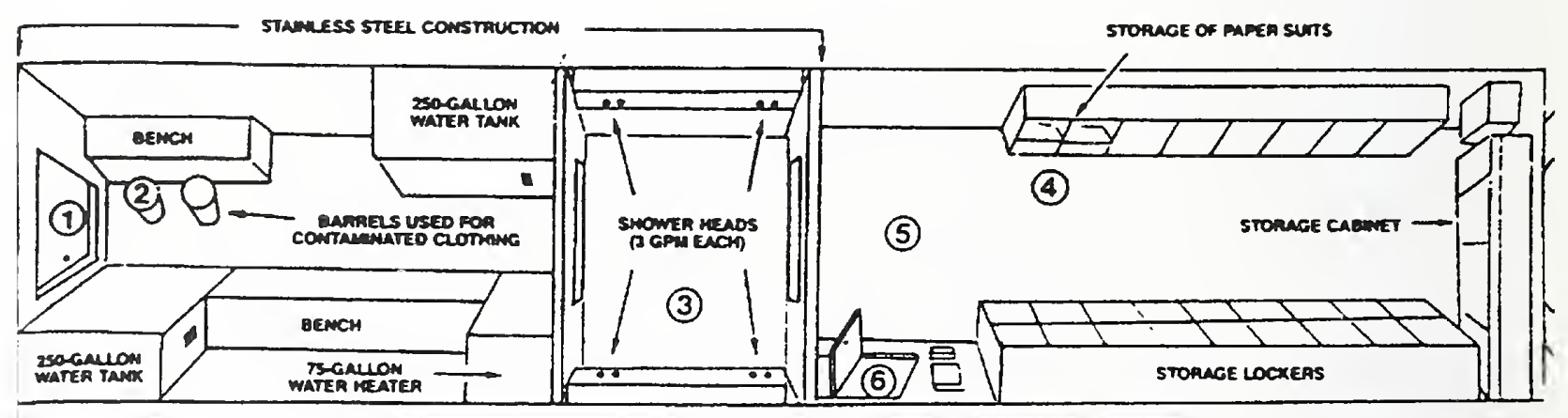

(1) FIREFIGHTER ENTERS

(2) DROPS CLOTHING

(3) SHOWERS

(4) PUTS ON PAPER SUIT

(5) UNDERGOES MEDICAL EXAM

(6) EXITS 
5.3.2 The following steps have been designed to deal with personnel decontamination in worst case incidents. In some situations it will not be necessary to go through the entire procedure. The decision to implement all or part of the decontamination process should be based on a field analysis of the hazards and risks of the hazardous materials involved. The FDNY Hazardous Materials Unit and the N.Y. City Departments of Health and Environmental Protection supply the toxicological and reactivity information that determines which techniques apply.

Step 1: An "entry point" will be established and marked in order to guide contaminated personnel into the DECON area.

Step 2: $\quad$ Protective clothing will be removed and isolated.

Contaminated coats, helmets, etc., should be placed in plastic bags to isolate contaminants. Bagged clothing should be sealed and placed in recovery drums outside the trailer for further analysis and for transportation to another location for laundering or disposal.

Step 3: Members enter the rear of the Decon Unit. EMS personnel will supervise the decon procedures. All personal effects and work clothing are removed and placed in bags and drums.

Step 4: In almost all cases, members will shower for a period determined by the type of substance involved. The exceptions occur when the substance involved is one made more active by water.

Step 5: After showering, members are issued towels and clothing to enable them to proceed to areas designated by EMS personnel. Members exit Decon Unit.

Step 6: EMS personnel examine members taking a medical history, checking vital signs, and follow up on any physical complaints. This will usually take place in the EMS MERVAN on the clean side or Support Zone.

Step 7: Any members that require further evaluation or treatment will be transported by EMS.

Step 8: The Decon Unit will disconnect and store the unit's equipment and apparatus.

Step 9: Waste water from the showers will be analyzed by DEP. 


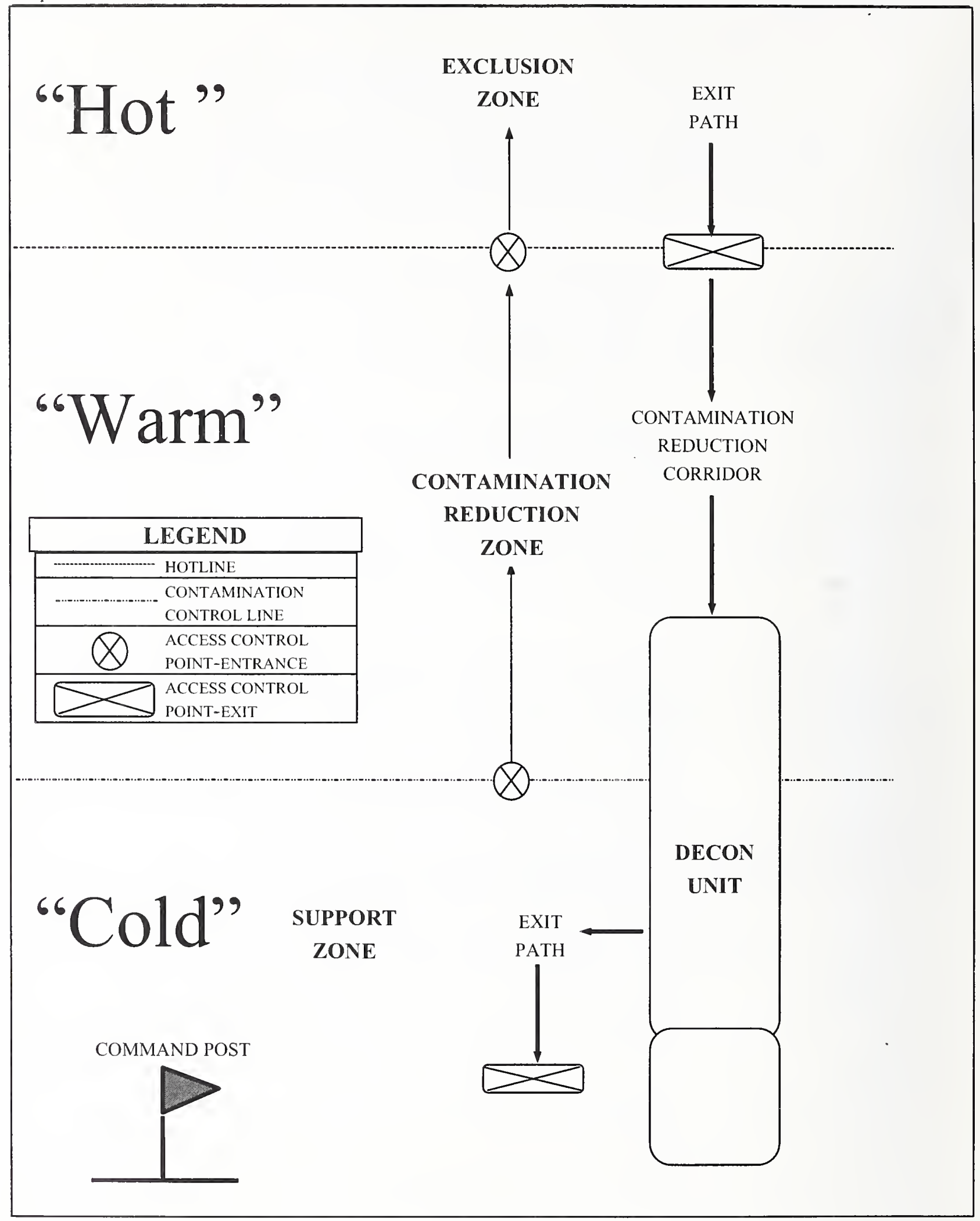


5.3.3 A member of the Special Operations Command will Identify apparatus, equipment and clothing to be decontaminated.

All clothing, personal items, apparatus, tools and equipment will remain at the site pending this determination.

The Special Operations Command (SOC) will arrange for the collection, removal, transportation, storage, cleaning, and temporary replacement of exposed or contaminated clothing and equipment.

On receipt of members' original clothing, Company Commanders will contact SOC to arrange return of replacement clothing.

\section{INCIDENT COMMAND SYSTEM FUNCTIONS AND RESPONSIBILITIES}

Note: These activities are specific to hazardous materials incidents and are in addition to the usual requirements of each position. This does not restrict the IC from staffing other ICS positions or from specifying additional duties that might be required by the incident.

\section{ANY FUNCTIONS NOT DELEGATED REMAIN THE RESPONSIBILITY OF THE INCIDENT COMMANDER.}

\subsection{SAFETY - reports directly to the Incident Commander.}

The Safety Operating Battalion will respond to all 10-80 code 2 signals (Level 2 or 3 incidents) and as requested by the Incident Commander. At a hazardous materials incident, they will monitor conditions and activities in the Support Zone (Cold Zone).

The Safety Operating Battalion Chief at the scene is also designated to confirm that all exposed members participate in the decontamination procedure conducted by the Decon Team and the Special Operations Decon Officer. If for any reason the Safety Operating Battalion does not respond to the scene, the Special Operations Decon Officer will perform this function.

The Safety Chief is responsible for recording the name, rank, Social Security number and unit identification of all members decontaminated with a description of the decontamination procedures employed.

The Safety Chief designated will, as soon as practicable after the incident, forward a report to the Bureau of Health Services and the Bureau of Operations. See "Reports" Section 10.2.

6.1.1 The Hazardous Materials Group Supervisor is responsible for site safety and operations inside the area bounded by the Contamination Control Line including the Exclusion Area or "Hot Zone". 


\subsection{INFORMATION - reports directly to the Incident Commander.}

The Fire Department Public Information Office will be notified upon transmission of signal $10-80$ code 2 (Level 2 or 3 incident).

Firefighters should not make any statements to anyone outside the F.D. chain of command about the character or nature of a hazardous materials incident. Inquiries should be directed to the Incident Commander or Information Officer, if the position has been staffed.

Information to the public will be released in conjunction with the Office of the Mayor as per the NYC Response Plan.

\subsection{LIAISON - reports directly to the Incident Commander.}

This is a senior Fire Department Officer who is the contact point for representatives of assisting and cooperating agencies. The Liaison has the authority given by the IC to commit Fire Department resources to specific incident activities and support functions.

The Liaison assists the IC in assigning Technical Specialists to appropriate functions within ICS.

\subsection{OPERATIONS CHIEF - reports directly to the Incident Commander.}

The Operations Chief directs, coordinates and controls all tactical activities and functions necessary to carry out the objectives of Command. Reports directly to the Fire Department IC.

\section{A. Responsibilities of the Operations Chief.}

1. Directs the management of all Fire Department on-scene tactical efforts needed to gain control of the incident.

2. Works directly with the Fire Department IC and the On-Scene Coordinator developing both primary and alternative strategies.

3. Determines operational necessities and request additional support when required.

4. Establishes Sectors and Groups as determined by operational needs.

5. Assigns objectives to Sector and Group Supervisors.

6. Reports changing conditions to the IC.

7. Supervises the Staging Area Manager. 


\subsubsection{TECHNICAL SPECIALISTS (Assigned to Operations)}

May be assigned by Command or Liaison Officer to advise or assist in the tactical activities under the direction of the Operations Chief.

\subsection{PLANNING CHIEF - reports directly to the Incident Commander.}

A. Gathers, evaluates, disseminates information for the development of alternative strategies.

B. Maintains records of incident activities for analysis and review, tracks current resource and situation status.

C. Establishes and maintains communications network.

\subsubsection{RESOURCE AND SITUATION STATUS}

This function will include preparation and maintenance of a Command and Control Chart as part of the overall site safety plan.

A. The Chart should identify the topographic features of the site, prevailing wind direction, drainage, location of buildings, physical barriers, tanks, etc. This information is helpful in:

1. Planning activities.

2. Assigning personnel.

3. Identifying access routes, evacuation routes, and any problem areas.

4. Identifying areas at the site that require the use of personal protective equipment.

5. As a visual aid during briefing of on site emergency personnel.

B. The Chart should be updated throughout the course of the operation and should reflect:

1. Changes in site activities;

2. Hazards not previously identified;

3. Weather conditions; and

4. Activities of other agencies on site. 


\subsubsection{TECHNICAL SPECIALISTS (Assigned to Planning)}

A. May be assigned by Command or Liaison Officer in an advisory capacity from various parties and agencies with interest or jurisdiction. These might include representatives of the material owner/shipper, chemists, field monitoring personnel from other agencies, code and regulation enforcement officials, members of City agencies with expertise or resource capability of a unique nature.

They will supply technical information, data interpretation, sample analysis, forecasts, etc.

B. Persons assigned at this level generally do not have decision making authority for their particular agency unless specifically authorized. They act in an advisory capacity for incident planning.

C. Information gathered will be used by Command and Operations Chief for the development and execution of various incident activities.

\subsubsection{DOCUMENTATION}

A. The IC will designate a member to keep a Log. Log sheets have been supplied to all Divisions, Battalions, and the Haz/Mat Unit. The Log should be retained by the Fire Department IC.

Records of these incidents are always important but especially when the incident results in personal injury, property damage or damage to the environment.

B. Certain events require more complex documentation. These incidents include but are not limited to:

1. Prolonged multi-agency operation.

2. Multiple changes at the Command level.

3. Major events involving several jurisdictions, private corporations, public utilities, etc.

4. Events involving high risk operations.

5. Multiple injuries or mass exposure.

6. Extensive isolation or evacuation of the public or public areas.

7. Isolation or contamination of environmentally sensitive areas or facilities.

C. Transcripts of this information can be taken from video tapes, photographs, and sound recordings made during the event or from notes kept in a bound log book (not loose-leaf). Log books are carried in each Command Chief's car and in the Field Communications Unit. 
D. All information should be recorded objectively. Each person making an entry should date and sign the document. The number of persons recording the information should be kept to a minimum.

E. Entries should be made in a timely way to insure accuracy and thoroughness. Neatness and legibility are essential.

F. The following information should be recorded:

1. Chronological history of the event.

2. Facts about the incident and when they became available including names, descriptions, source, quantity, and cause of release, if known.

3. Names and assignments of key personnel and resources.

4. Actions, decisions, orders and directions given: by whom, to whom, and when.

5. Actions taken: who did what, when, where, and how.

6. Possible exposure of personnel.

7. Records of all injuries and illnesses during, or as a result of, the emergency.

\subsection{LOGISTICS CHIEF - reports directly to the Incident Commander.}

A. Logistics is the procurement, distribution, maintenance of facilities, services, materials and personnel to support the incident.

B. The Service and Support functions would include the following responsibilities:

1. Service

a. $\quad$ Fire Department Medical Officer:

1. Determine a site for medical facilities.

2. Assist in setting up and recording the transportation of the injured.

3. Provide medical treatment for Fire Department personnel.

b. Facilities

1. Assist in the operation of the Command Post, recuperation and care areas and secondary staging for apparatus. Procuring shelter facilities for personnel. 
2. Support

a. Mask Service

Supply air cylinders or air lines.

NOTE: POTENTIALLY CONTAMINATED CYLINDERS MUST NOT BE EXCHANGED.

b. Special Units (Supplies)

1. Order and supply specialized extinguishing agents (CO2, Foam, Dry Powder etc.).

2. Order and supply diking, absorbent, or neutralizing materials.

3. Facilitate specialized tools or heavy duty equipment (shoring, cranes, etc.), pumps, etc.

c. Fleet Maintenance

1. Repair and refueling of vehicles at extended operations.

2. Supply vehicles for transportation.

C. Liability, costs to the provider, and the availability of certain types of equipment preclude irregular or informal arrangements for the procurement of equipment and supplies. (See Emergency Equipment, Section 3.8)

\subsubsection{TECHNICAL SPECIALISTS (Assigned to Logistics)}

Members from the Special Operations Command (SOC) will respond to the scene of each event that requires Decontamination to supervise and facilitate the procedure for collecting, documenting, and tracking clothing and equipment that is to be confiscated and replaced.

Procedures and documentation for this phase of operations will be as per Department publications.

(See Hazardous Materials Group, Section 4.3.6, 4.3.7, 4.3.8)

\subsection{FINANCE}

Cost recovery/Restitution from the party responsible for the incident or recovery from governmental funding, involves documenting all information pertinent to the costs involved in mitigating the incident incurred by the Department or the City. All costs must be documented and supported with written materials such as damage reports, time records, receipts and invoices. 
7. INTERAGENCY SUPPORT SYSTEM - As part of the response system various agencies will be notified and will respond based on the specific nature of the incident. It is essential that each responder be familiar with New York City's broader plan for response to a hazardous materials emergency since each agency has a specific role in the total response.

The following agency resources are available and will respond as needed and according to the NYC Hazardous Materials Response Plan. Their duties include but are not necessarily limited to the following:

\section{A. OFFICE OF EMERGENCY MANAGEMENT (OEM), Police Dept.}

Coordinate all City agency activities.

Coordinate evacuation, if necessary.

Consult with Dept. of Environmental Protection Response Team and Poison Control Center to evaluate the extent of the hazard.

Staff and support Interagency Command Center (ICC).

Contact and maintain liaison with NY State Office of Emergency Management.

\section{B. ON SCENE COORDINATOR (OSC), Police Dept.}

Establish Interagency Command Center (ICC).

Establish Communications capability between the site and the ICC.

Establish and maintain overall site security.

Coordinate all on site personnel.

Direct activities of Police Dept. Operations Unit.

Coordinate and select Emergency Response Routes.

Coordinate "off loading", if necessary.

\section{POLICE DEPARTMENT, (PD)}

Control traffic and emergency vehicle access in site vicinity.

Crowd control and evacuation, if appropriate.

Provide central information and notification center for all City agencies.

D. DEPT. OF ENVIRONMENTAL PROTECTION (DEP)

Dispatch response Team to provide technical personnel and equipment.

Sample and analyze substances and the environment.

Gather information, provide technical guidance to OEM.

Obtain financial approval for and arrange private sector containment, control, clean up, and disposal of hazardous materials, where necessary.

\section{E. SANITATION DEPARTMENT}

Maintain/supply materials for containment and confinement operations.

Clean up and disposal of materials (except liquids) rendered harmless as determined by DEP and Health Dept.

Investigate/enforce environmental/dumping regulations. 
F. DEPARTMENT OF HEALTH

Provide technical information on materials hazards.

Assess effects to public health.

Provide informational/precautionary press statements concerning public health.

Ensure proper mitigation and disposal of radioactive and etiological agents.

G EMERGENCY MEDICAL SERVICES (EMS)

On site medical services.

Assist in Fire Department decontamination.

H. DEPARTMENT OF TRAFFIC

Facilitate and control traffic flow in area.

\section{MAYOR'S PRESS OFFICE}

Exclusive authority for public information and warnings.

\section{INCIDENT TERMINATION PROCEDURES}

\subsection{CLEAN UP OPERATIONS}

Incident scene activities include removing the hazardous material, all contaminated debris (including dirt, water, containers, vehicles, tools and equipment) and returning the scene to as near normal as it existed prior to the incident.

Clean up operations are not a Fire Department function. However, assuring that this clean up takes place is a responsibility of the Fire Department.

The Fire Department will cooperate with the Department of Environmental Protection (DEP) in arranging clean up activities. The Senior representative of DEP will arrange for authorization to obtain financial approval for and arrange private sector containment, control, clean up, and disposal of hazardous materials, where necessary.

In some cases, the Hazardous Materials Unit will take samples of materials for testing. These samples will be picked up by DEP to be tested and analyzed. Under no circumstances is any Fire Department unit, including the Hazardous Materials Unit, to transport these samples or any hazardous material, even if properly contained, to any Fire Department location or facility or other location or agency.

If operations are concluded and DEP has not arrived at the scene, these samples will remain at the scene for pick up by DEP. The Police Department representative at the scene will safeguard these samples. If the Police Department is not represented at the scene the Police Dept. Operations Unit should be contacted through the dispatcher. The Fire Department IC should request priority response and be prepared to give all particulars regarding the need for Police assistance. 
The Hazardous Materials Unit shall not be detained at the scene for purposes of safeguarding materials after control and containment of the substance has been completed.

Arrangements for the collection, transportation, cleaning, and temporary replacement of exposed or contaminated Fire Department equipment shall be the responsibility of the Special Operations Decon Officer at the scene. (See 4.3.6)

8.2 Prior to leaving the scene, the IC shall review the particulars of the incident to make a preliminary determination regarding compliance with fire prevention regulations and directives. Non-compliance should be addressed through violation orders, summonses, vacate orders etc. If necessary, consult the Bureau of Fire Prevention for assistance.

Additionally, within ten (10) days from the completion of the post incident review, the IC shall notify the Chief of the Bureau of Fire Prevention of any violation or suspected violation of statutes or regulations that he or she became aware of during the course of the response to the hazardous material incident or during the post incident review process.

8.3 Specific incident termination instructions will be listed in the incident checklist.

\section{POST INCIDENT PROCEDURES}

\subsection{INCIDENT ANALYSIS}

A. The Incident Commander's responsibility following each hazardous materials operations includes a review of actions taken. Corrective actions should be taken at the lowest possible level. Recommendations regarding procedures or the elements of the response plan should be forwarded through the chain of command with endorsements to the Chief of Department.

B. Prior to leaving the scene, the IC shall review the particulars of the incident to make a preliminary determination regarding compliance with fire prevention regulations and directives. Non-compliance should be addressed through violation orders, summonses, vacate orders etc.. If necessary, consult the Bureau of Fire Prevention for assistance.

Additionally, within ten (10) days from the completion of the post incident review, the IC shall notify the Chief of the Bureau of Fire Prevention of any violation or suspected violation of statutes or regulations that he or she became aware of during the course of the response to the hazardous material incident or during the post incident review process. 
C. As a standard part of this Emergency Response Plan the Fire Department will review all hazardous materials incidents in order to:

1. Identify and correct any deficiencies in the response plan.

2. Identify trends, patterns, and deficiencies in procedures that need to be addressed in revised operations, safety, or training programs.

3. Develop a database to establish profiles for decisions re: tools \& equipment, training, budgeting, operations, hazard prevention legislation etc.

4. Identify incidents where the Fire Department may seek cost recovery or that may qualify for reimbursement under EPA regulations.

5. Document efforts of proactive intervention to reduce losses.

D. The process begins with a preliminary review of the following incidents:

1. City wide 10-80 response record.

2. Exposure reports CD-73; CD-72 Medical reports indicating Hazmat exposure.

3. Any incident involving "Decon".

4. Level 2 and 3 incidents.

E. Consolidated reports and descriptions of these incidents will be reviewed on a monthly basis by:

1. Bureau of Operations

2. Division of Safety

3. Division of Training

4. OSHA Coordinator

F. Findings and recommendations, if any, from any individual review will be forwarded through the chain of command to the Chief of Department for consideration.

G. A formal critique may be ordered by the Chief of Department. The formal critique report is included in the appendix of this document. 


\subsection{CRITIQUE OUTLINE}

When a formal critique is ordered, the IC for the particular incident shall prepare a narrative report addressed to the Chief of Department, containing at least the following information. Include copies of the incident log to reduce preparation time.

1. Identifying information including the date, box number, location.

2. Description of conditions found and actions taken by the first responding units.

3. Description of conditions found and actions taken by the first Chief Officer to arrive.

4. Describe hazard identification and site control measures taken and results.

5. Describe the personal protective equipment and special chemical protective equipment used by each group of responders at the incident. Describe decision made re: changes in these levels of protection.

7. A timeline describing the notification, change of command and arrival of special units, outside agencies etc..

8. Describe the ICS organizational structure developed. (Include positions staffed, Command post, sectors / groups, control zones, etc.).

8. A description of the key phases of the incident including sufficient detail to explain changes in incident activities or other significant events during the life of the incident. Include description of alternative plans considered, if any.

9. Description of decon procedures.

10. Description of problems encountered and lessons learned.

\subsection{EMERGENCY RESPONSE PLAN REVIEW}

A formal cyclical review process and a method of keeping this document current with existing laws and standards will be developed and implemented at the time this document is finalized and published.

The review process will be developed with the intent described in the Incident Analysis portion of this document. 


\section{APPENDIX}

\subsection{REFERENCES}

The following list of materials will provide greater insight on the individual subject areas discussed in this document:
A. OCCUPATIONAL SAFETY AND HEALTH ADMINISTRATION
29 CFR 1910.120 - Hazardous Waste Operations and Emergency Response;
B. ENVIRONMENTAL PROTECTION AGENCY - 40 CFR 300
C. SUPERFUND AMENDMENT AND REAUTHORIZATION ACT
D. N.Y.C. OFFICE OF THE MAYOR Mayoral Directive 82-2 (revised 1986)
E. OFFICE OF EMERGENCY MANAGEMENT Memorandum of Understanding - Asbestos (12/5/89)

\subsection{ABBREVIATIONS}

\begin{tabular}{|c|c|c|}
\hline CFR & - & Code of Federal Regulations \\
\hline $\mathrm{CP}$ & - & Command Post \\
\hline DEP & - & Department of Environmental Protection \\
\hline DOT & - & Department of Transportation \\
\hline ERG & - & Emergency Response Guidebook (DOT) \\
\hline ERP & - & Emergency Response Plan \\
\hline EMS & - & Emergency Medical Services \\
\hline EPA & - & Environmental Protection Agency (Federal) \\
\hline HAG & - & Hazard Action Guide \\
\hline IC & - & Incident Commander \\
\hline ICS & - & Incident Command System \\
\hline NFPA & - & National Fire Protection Association \\
\hline OEM & - & Office of Emergency Management (NYC) \\
\hline ORM & - & Other Regulated Materials \\
\hline OSHA & & Occupational Safety and Health Administration \\
\hline PPE & - & Personal Protective Equipment \\
\hline SCBA & & Self Contained Breathing Apparatus \\
\hline $\mathrm{SOC}$ & - & Special Operations Command \\
\hline SOP & - & Standard Operating Procedure \\
\hline
\end{tabular}

\section{- END OF PART 5 -}


DCN: 4.03 .08

\begin{abstract}
Appendix A
Incident Command System

Reproduced with permission of The Fire Department of the City of New York
\end{abstract}




\section{AGENCY REPRESENTATIVE}

Individual assigned to an incident from another agency who has been delegated full authority to make decisions on all matters affecting that agency's participation at the incident. Agency representatives report to the Incident Liaison Officer. (See also: LIAISON)

"ASSIGNED" RESOURCES

Manpower and/or equipment assigned and performing tasks at an incident.

\section{ASSISTING AGENCY}

An agency (Law enforcement, EMS, etc.) directly contributing suppression, rescue, support service resources and/or personnel to another agency. (See also: COOPERATING AGENCY; LIAISON )

\section{"AVAILABLE" RESOURCES}

Resources assigned to an incident and not committed to a work assignment, but ready for immediate deployment.

\section{BRANCH}

The organization level instituted by the IC or Operations Chief to maintain appropriate span of control over an excessive number of sectors/groups; when operations may be in several locations; diverse functions are being managed. A branch may be geographical or functional in nature.

Example: An Exposure 3 Branch, EMS Branch.

\section{BRANCH COMMANDER}

An ICS title for individuals responsible for command of a BRANCH. Radio designation is as assigned by the IC or Operations Chief. (In the previous example, "EXPOSURE 3" or "EMS COMMAND")

\section{CHIEF}

ICS title for individuals responsible for command of the functional Sections: Operations, Planning, Logistics and Finance. (See individual listings)

\section{COMMAND}


The function of directing, ordering and/or controlling resources by virtue of explicit legal, agency, or delegated authority; Radio designation for the Incident Commander.

\section{COMMAND POST}

An area from which the Incident Commander exercises command and control over the incident.

\section{COMMAND POST COMPANY}

Engine companies that assist in the operation of the lobby command post at a high-rise fire or emergency.

\section{COMMAND STAFF}

The command staff consists of Information, Safety, and Liaison Officers, who report directly to the Incident Commander. (See individual listings)

\section{COMMUNICATIONS}

A sub-function of the Planning Section. Provides a network for the interchange of information within the ICS and between the command post and the dispatcher.

\section{COMMUNICATIONS COORDINATOR (COMCORD)}

Battalion Chief who serves as a communications manager. Controls all communications and supervises or maintains its associated functions (Field Comm., Command Control Chart, Etc.)

\section{COOPERATING AGENCY}

An agency supplying assistance other than direct suppression, rescue, support, or service functions to the incident control effort (Red Cross, Utility company, etc.). (See also: ASSISTING AGENCY; LIAISON)

\section{COORDINATION}

The process of systematically analyzing a situation, developing relevant information, and informing appropriate command authority (for its decision) of viable alternatives for selection of the most effective combination of available resources to meet specific objectives.

The coordination process (which can be either intra-or interagency) does not, in and of itself, involve command dispatch actions. However, personnel responsible for coordination may perform command or dispatch functions within limits as established by specific agency delegations, procedures, legal authority, etc. (See also: UNIFIED COMMAND)

\section{$\operatorname{COST}$}

A sub-function within the Finance section responsible for tracking cost, analyzing cost data, making cost estimates and recording cost-savings measures. (See FINANCE) 
DEMOBILIZATION

A sub-function within the Planning Section. Responsible for assuring orderly, safe, efficient demobilization of resources committed to the incident.

\section{DOCUMENTATION}

A sub-function with the Planning Section responsible for recording/protecting all documents relevant to incident.

\section{FACILITIES}

A sub-function within the Logistics Section providing for facilities required at the incident. The facilities may include rehabilitation areas, feeding areas, security and lighting for the command post etc..

\section{FIELD COMMUNICATION UNIT}

A mobile facility carrying various types of communications equipment. This tactical command unit may serve as a field command post. It comprises the major portion of the incident communications center. It provides Resource and Situation Status at major incidents. (See also: COMMUNICATIONS; RESOURCE \& SITUATION STATUS)

\section{FINANCE SECTION}

Responsible for tracking all costs and evaluating the financial considerations of the incident. When staffed reports directly to the IC. (See COST; PROCUREMENT; TIME)

\section{FLEET MAINTENANCE}

A sub-function within the Logistics Section responsible for fueling/maintaining/repairing vehicles/equipment and the transportation of supplies. (See also: SUPPORT )

\section{FOOD}

A sub-function within the Logistics Section responsible for providing food/refreshments for personnel involved with incident. This is currently provided by the Third Alarm Association. (See also: SERVICES )

\section{GENERAL STAFF}

The group of incident command personnel comprised of the Incident Commander, Operations Chief, Planning Chief, Logistics Chief and Finance Chief. (See also: INCIDENT COMMAND SYSTEM) 
GROUP

An organizational level responsible for a specified functional assignment commanded by a group supervisor. Examples include: Ventilation group; Search group; Decon group. (See also: SECTOR)

\section{GROUP SUPERVISOR}

Individual responsible for managing a functional group. Radio designation is derived from assigned function. For example, "SEARCH GROUP 1".

\section{H-I}

\section{INCIDENT}

An occurrence or event, caused by human or natural phenomena. It requires action by emergency service personnel to prevent or minimize loss of life or damage to property and/or natural resources.

\section{INCIDENT ACTION PLAN}

The strategic goals, tactical objectives and support requirements for the incident. It is an ordered sequence of events, occurring within a designated period of time, that results in the accomplishment of specific objectives.

\section{INCIDENT COMMANDER (IC)}

The individual responsible for the management of all incident operations. The radio designation for the IC is "COMMAND".

\section{INCIDENT COMMAND SYSTEM (ICS)}

An emergency operations management structure which provides for unity of command and the efficient use of resources for the effective accomplishment of stated objectives pertaining to an incident. It includes the combination of facilities equipment, personnel and communications operating within a common organizational structure.

\section{INFORMATION AREA}

A functional area from which factual and timely reports are disseminated to the news media or other agencies.

\section{INFORMATION OFFICER}

The individual assigned responsibility for gathering and disseminating factual and timely reports to the media and other agencies. The release of information must be approved by the IC. The Information Officer is a member of the Command Staff. Radio designation is "INFORMATION". (See: COMMAND STAFF) 


\section{LIAISON OFFICER}

The point of contact for assisting and cooperating agencies (local, State, Federal, or private sector) as needed or as directed by the Incident Commander. The Liaison Officer is a member of the Command Staff and has authority to commit resources to incident activities. Reports directly to IC. Radio designation is "LIAISON". (See: COMMAND STAFF)

\section{LOGISTICS SECTION}

Responsible for the procurement, distribution, maintenance and replacement of services, materials and personnel to support the incident. Managed by the Logistics Section Chief. Radio designation is "LOGISTICS". (See also: SERVICES; SUPPORT )

\section{MEDICAL OFFICER}

The Fire Department Medical Officer directed by the Incident Commander to respond to the incident and provide medical care for fire personnel. Radio designation is "MEDICAL OFFICER".

\section{MUTUAL AID}

Documents between the City of New York and surrounding communities in which the parties agree to assist one another upon request by furnishing personnel and equipment in an emergency situation.

\section{$\mathrm{N}-\mathrm{O}$}

\section{OFFICER}

ICS title for the Command Staff positions of Safety, Liaison, and Information. Also used when a individual supervises a sub-function within Planning, Logistics, or Finance.

\section{ON-SCENE COORDINATOR (HAZ-MAT)}

The highest ranking Police Dept. official at the incident. Responsible for coordinating responding agencies.

\section{OPERATIONS SECTION}

Staffed by the IC to carry out all the tactical decisions of the Incident Commander. May include as many as 5 Branches, 25 Sectors or Groups, and 125 Single Resources, or teams. Managed by the OPERATIONS CHIEF. 


\section{OPERATIONS SECTION CHIEF}

Responsible for all tactical operations at the incident. Radio designation is "OPERATIONS".

\section{"OUT-OF-SERVICE" RESOURCES}

Resources assigned to an incident but unable to respond for mechanical, rest, or personnel reasons.

\section{PLANNING SECTION}

Collects, evaluates, and disseminates information regarding the incident. Supervises the development of the incident action plan. Sub-functions include resource and situation status, documentation, demobilization, technical specialists and communications. Managed by the Planning Section Chief. Radio designation is "PLANNING".

\section{PLANNING MEETING}

A meeting, held as needed throughout the duration of an incident, to select specific strategies and tactics for incident control operation and for service and support planning.

\section{POLICE OPERATIONS COMMANDER}

Responsible to the Incident Commander for the management of police related functions.

\section{POST INCIDENT ANALYSIS}

A review and discussion of actual operations and support performed in a recent incident, for the purpose of (1) identifying areas of strength and weakness and (2) developing corrective measures. It is conducted by key persons involved in the incident.

\section{PROCUREMENT}

A sub-function within the Finance Section responsible for financial matters involving vendors.

\section{Q-R}

\section{RESOURCES}

All personnel and major items of equipment available, or potentially available, for assignment to incident tasks on which status is maintained. 
A sub-function within the Planning Section. Responsible for recording the status of resources committed to incident and evaluation of: resources currently committed to incident; the impact that additional responding resources will have on incident; anticipated resource needs and analysis of the situation as it progresses.

\section{RECUPERATION AND CARE AREA}

Area designated for personnel to rest or for protection from the elements.

\section{S}

\section{SAFETY OFFICER}

Responsible for monitoring and assessing safety hazards or unsafe situations and developing measures for ensuring personnel safety. Member of the Command Staff. Radio designation is "SAFETY".

\section{SECTION}

That organization level having functional responsibility for primary segments of incident operations, such as: Operations, Planning, Logistics, and Finance. The Section level is established by the IC and supervises or manages various sub-functions. (See individual titles)

\section{SECTOR}

Organizational level having responsibility for Incident Operations in a specified geographical area, commanded by a sector supervisor.

\section{SECTOR SUPERVISOR}

The individual responsible for operations within a defined sector (geographical area). Radio designation is derived from assigned area. For example, "EXPOSURE 2".

\section{SERVICES (LOGISTICS)}

The supplying of medical, food or facility needs to operating fire personnel. (See also: FOOD; MEDICAL; FACILITIES )

\section{SINGLE RESOURCE}

An individual, company, or specialized unit. Radio designation is by unit name unless assigned to an specific ICS function or designation by the IC. (See also: UNIT)

\section{SPAN OF CONTROL}

The supervisory ratio, usually limited to three to seven subordinates, delineating the management limits of a supervisor. 
STAGING AREA

Location where incident personnel and equipment are assembled prior to assignment at an incident. It should provide good access to the scene. It is supervised by a Staging Area Manager.

\section{STAGING AREA MANAGER}

The individual, designated by the Incident Commander, responsible for the assembling of personnel and equipment in the staging area. Reports to the IC until Operations Section is staffed. Radio designation is "STAGING".

\section{STRATEGIC GOALS}

The overall plan that will be used to control the incident. Strategic goals are broad in nature and are achieved by the completion of tactical objectives.

\section{SUPPORT (LOGISTICS)}

A sub-function within the Logistics Section providing the personnel, equipment, and supplies to support incident operations. This includes Mask Service, Fleet Maintenance, and any other specialized supply/support units. (See also individual titles)

\section{T}

\section{TACTICAL OBJECTIVES}

The operations that must be performed in order to satisfy the strategic goals. This is how the job should be done and they must be both specific and measurable.

\section{TEAM}

Any combination of single resources (units) or individuals put together for a temporary assignment under the direction of an officer. The number of individuals or single resources should not exceed five. Radio designation is as per related function or activity. For example "ROOF"(team) or "EXPOSURE 2"(team).

\section{TECHNICAL SPECIALISTS}

Personnel with special skills who are activated only when needed for a particular incident. These may include environmental or hazardous material experts, building engineers, Special Operations officers etc.. May work with the Planning Section or anywhere within the ICS Organization as directed.

\section{TIME}

A sub-function within the Finance Section. Responsible for record keeping of time for personnel working at incident. (See also: FINANCE) 
UNIT

An organization element having responsibility for a specific function as designated by the Department (an Engine Co.; Field communications etc.) or Incident specific activity or function as designated by the IC (Documentation; Food, etc.).

\section{UNIFIED COMMAND}

Shared responsibility for overall scene management as a result of a multi-agency or multi-jurisdiction incident. Goals, tactical objectives, tactical operations and use of resources are decided jointly. Implementation of the joint action plan is the responsibility the OPERATIONS CHIEF who usually is the representative of the agency having the greatest jurisdictional involvement. 


\section{Appendix B \\ POLICE/FIRE PROTOCOL}





\section{POLICE/FIRE PROTOCOL}

\section{Appendix B}

AUC \#276 Police/Fire Protocol

Reproduced with permission of The Fire Department of the City of New York 


\section{INTRODUCTION}

A protocol has been established to put an end to the confusion concerning the roles and responsibilities of the Police and Fire Departments at emergencies.

This protocol was developed in an atmosphere of cooperation and mutual respect between our two departments and with the interest of the public as a top priority.

The Fire Commissioner expects the cooperation of all officers and members to insure the successful implementation of this protocol.

\section{GENERAL OPERATIONAL GUIDELINES}

2.1 NOTIFICATIONS: Under the new protocol, both agencies will be responsible for immediately notifying the 911 communications system of any life-threatening situation which has come to their attention. The 911 system will, in turn, be responsible for notifying the appropriate response agencies. Implementation of the protocol will be monitored and evaluated by the Mayor's Office of Operations.

2.2 At the scene of a fire, the ranking Fire Department officer will assume command. The ranking member of the Police Department will report to the fire officer in charge and offer any assistance that may be required. The police supervisor will request the Fire Department commander to inform Fire Department subordinates that evidence, especially in suspected arson or explosive cases, MUST be preserved and safeguarded.

2.3 The ranking Police Department officer will assume command at the scene of a non-fire emergency. The ranking Fire Department official will report to the police commander and offer any assistance that may be required. The police and fire officers in command will make a joint examination to determine if the potential for a fire exists. In any case, the police commander will consider the recommendations of the fire officer in charge concerning actions to be taken to prevent a fire. 
2.4 At the scene of any emergency, the police and fire officials in charge of their department resources will determine the special equipment carried by police and fire department units on the scene. The most effective and efficient tools required to effect a rescue will be used regardless of whether the tool belongs to the Police Department or the Fire Department. Furthermore, when conducting a joint operation, the special talents and abilities of members of both departments will be considered when making assignments and the first responding unit will commence rescue operations without delay.

2.5 During a joint operation, specific directions to members of both departments will be issued through their department's chain of command. Ranking police and fire commanders will confer frequently concerning orders and directions to be issued. The ranking officers of the Police and Fire Departments MUST be aware of the need for mutual cooperation. All police personnel and fire personnel MUST understand that they will be held strictly accountable for their conduct during joint operations.

\section{SPECIFIC OPERATIONAL GUIDELINES}

3.1 WATER RESCUES: The Fire Department and the Police Department will dispatch qualified divers to the scene of water rescues and upon arrival, will immediately commence rescue operations under the direction of the ranking police officer. The Police and Fire Department Scuba Units will undertake joint training exercises at least twice annually so that their rescue activities are well coordinated.

3.2 BOMB THREATS: Upon locating the explosive device, the NYPD Emergency Services Unit will request the bomb squad to respond to the scene. A Fire Department unit will respond to a nearby mobilization point designated by the ESU officer and await further instructions. The ranking police officer at the scene will remain the coordinator of on site operations.

3.3 HAZARDOUS MATERIALS: Both the Fire and Police Departments will respond to the scene of all hazardous materials incidents. The containment and mitigation of such materials will be done under the direction of the ranking fire officer.

3.4 STRUCTURAL COLLAPSES: Both the Police and Fire Departments will continue to respond to structural collapses. Rescue operations utilizing fire and police personnel will be under the ranking fire officer at the scene. All other on site activities will be coordinated by the ranking police officer. The departments will conduct joint structural collapse training exercises at least twice a year.

3.5 VEHICLE ACCIDENT EXTRICATION: The first extrication equipped unit to arrive on the scene, Police or Fire, will initiate rescue operations, and continue until they have finished, or until they request and receive relief. When both Police and Fire Units are on the scene, command of the overall operation will be under the ranking Police supervisor at the scene. 
3.6 UTILITY EMERGENCIES: The Fire Department will assume primary responsibility for mitigating gas leaks, water leaks, fallen electrical or telephone lines, flooding conditions, fallen trees which are blocking roadways or unstable building facades. Police officers will respond to the scene only if requested by the Fire Department.

\section{CONCLUSION}

Both agencies are committed to insure the most effective response to life or death emergencies. This protocol is an important step towards achieving our objective. 


\section{Appendix C \\ AGREEMENTS BETWEEN \\ THE PORT AUtHoRITY OF NEW YORK AND NEW JERSEY AND THE FIRE DEPARTMENT OF THE CITY OF NEW YORK}

Reproduced with permission of The Port Authority of New York and New Jersey. 
. 
Lawrence S. Hofrichter. Chic: Finance Division

(212) 135.6220

(201) $961-6600 \times 6220$

Chartes G. Sturcken, Deputy General Counsel

The New York City

Department of Buildings - Executive Offices

60 Hudson Street

I 4 th Floor

New York. New York

THE PORT AUTHORITY OF N.Y. \& N.J TENANT CONSTRUCTION REVIEW UNIT RECEIVED

HOV 0 ? 1993

Dear Mr. Sturcken:

Enclosed please find a fully executed original of the Memorandum of Understanding between the Port Authority and the New York City Department of Buildings.

For your information, the gubernatorial review period for the enclosed agreement will end at midnight Wednesday. November 17. 1993. It has been a pleasure working with you on this matter.

Very truly yours.

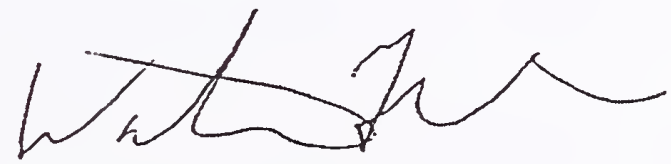

Walter M. Frank

Deputy Chief, Finance Division

Law Department

Enclosures

cc William H. Goldstein. Deputy Executive Director. Capital Proarams

bcc: J.S. Green. P.S. Cooper (5IN). A.A. DiNome (68S), E.J. Fasullo (72S), L.S. Hofrichter, F.J. Lombardi (72S), C.J. Maikish (35E), A.J. Raiola. S.T. Van de Walle 
This Memorandum shall govern the relationship between the New York City Department of Buildings (the "Department") and the Port Authority of New York and New Jersey (the "Port Authority"), both parties entering iato this agreement with the intention to establish procedures to be followed by the Port Authority for any building construction project ("Project"), to be undertaken by the Port Authority or any of its tenants at buildings owned or operated by the Port Authority and located in the City of New York (the "City), to assure conformance of Projects at such buildings with the standards set forth in the New York City Building Code (the "Code").

While the facilities of the Port Authority, an agency of the States of New York and New Jersey, are not technically subject to the requirements of local building codes, the long-standing policy of the Port Authority has been to assure that its facilities meet and, where appropriate, exceed Code requirements.

The purpose of this Memorandum is not only to restate that longstanding policy as part of an understanding with the City but to provide specific commitments to the Department, as the agency of the City responsible for assuring compliance with the Code, regarding procedures to be undertaken by the Port Authority for any Project at its facilities in the City to assure that the buildings owned or operated by the Port Authority within the City are in conformance with the Building Standards contained in the Code.

as follows:

Accordingly, the Department and the Port Authority hereby agree

1. Port Authority Review. To assure conformance with the building standards set forth in the Code at the time of the design and construction of any Project, the Port Authority shall, in the case of each Project, thoroughly review and examine all plans in connection with such Project for conformance with the building standards set forth in the Code. Plans prepared for Projects to be undertaken by Port Authority tenants shall be prepared and sealed by a New York State licensed professional engineer or architect retained or employed by tenant; plans prepared for Projects to be undertaken by the Port Authority shall be prepared by a New York State licensed professional engineer or architect employed or retained by the Port Authority. The Port Authority's examination of plans shall be conducted by New York State licensed architects and engineers retained or employed by the Port Authority. The Port Authority engineer or architect approving the plans for any Project from the standpoint of Code conformance shall be a New York State licensed architect or engineer who shall not have assisted in the actual preparation of such plans.

2. Project File. The Port Authority shall maintain a file (the "Project File") for each Project which file shall at all times contain the most recently 
prepared drawings, plans and any other documents required in connection with the review of the Project from the standpoint of Code conformance. In the case of any Project being effectuated by a tenant of the Port Authority (a "Tenant Project") such file shall also include the Tenant Alteration Application prepared by the Tenant. In the case of any project administered by a line department of the Port Authority. such file shall include any construction application prepared in connection with such Project. The Line Depadments of the Port Authority are currently its World Trade, Aviation. Interstate Transportation, Port, and Regional Development Departments.

3. Project Certification. For each Tenant Project. the Port Authority shall require the Tenant to obtain the certification of a New York State licensed architect or engineer that such Project was constructed in accordance with the approved plans and specifications for such Project. For any Project effectuated by the Port Authority, the Chief Engineer or his successor in duties shall certify that the Project was constructed in accordance with the approved plans and specifications for the Project. Certifications for each Project shall be maintained in the Project File.

4. Copies of Project File. The Department. may at any time request the Port Authority to provide it with a copy of any Project File and the Port Authority shall promptly provide a copy of the Project File to it.

5. Variances. The Port Authority shall promptly advise the Department of any Project approved by the Chief Engineer of the Port Authority which involves, in the judgment of the Chief Engineer of the Port Authority or his successor in duties, a variance from the clear requirements of the Code. In the event that the Department disagrees with the manner in which questions of Code conformance have been or are proposed to be dealt with in connection with such Project, it may so advise the Authority. The Port Authority shall seek expeditiously to resolve the matter. Any matter of Code conformance in connection with such Project which the Department believes involves an unacceptable variance from the requirements of the Code shall be subject to the further review of the Port Authority Board of Commissioners. The Commissioners shall be advised of the Department's views on the matter.

6. Inspections and Surveys. The Port Authority shall continue to conduct or cause to be conducted all building inspections, during both construction and post-construction periods, required under the Code. In addition, the Port Authority will continue to perform structural integrity inspections on a cyclical basis for all of its structures located in the City.

7. Port Authority Responsibility. As indicated above, the purpose of this Agreement is to set forth certain basic understandings between the Department and the Port Authority. It is understood, however, that the Port Authority with its tenants shall continue to bear the responsibility for life safety in buildings at its facilities and nothing in this Agreement is intended to impose any obligations of inspection or review on the Department. The Department shall refer back to the Chief Engineer of the Port Authority any requests for 
information or interpretation which it may receive from tenants of the Port Authority with respect to any Project.

8. No Personal Liability. No Commissioner, officer, agent or employee of the Port Authority or the Department shall be held personally liable under any provision of this Agreement or because of its execution or attempted execution or because of any breach or alleged breach thereof.

IN WITNESS WHEREOF, the parties hereto have caused this instrument to be signed, sealed and attested.

\section{ATTEST:}

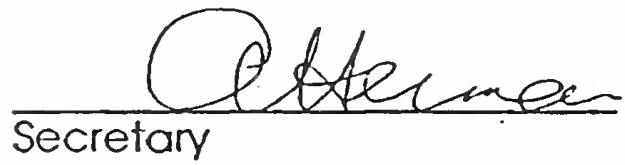

DATE: $\quad 11 / 3 / 93$

\section{ATTEST:}

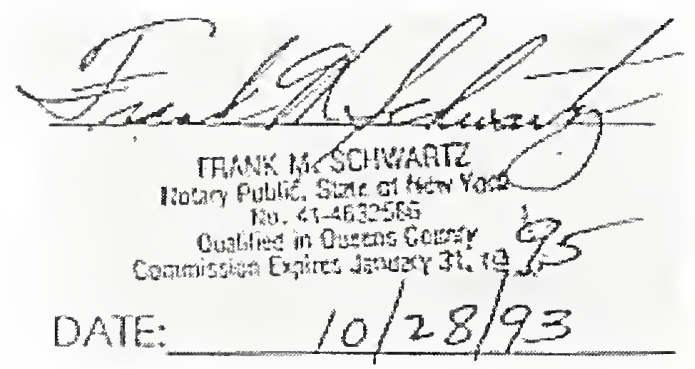

THE PORT AUTHORITY OF NEW YORK AND NEW JERSEY

By:

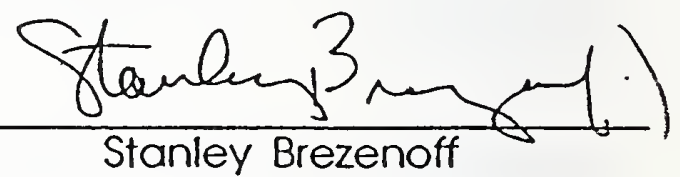

Executive Director
THE NEW YORK CITY DEPARTMENT BUILDINGS
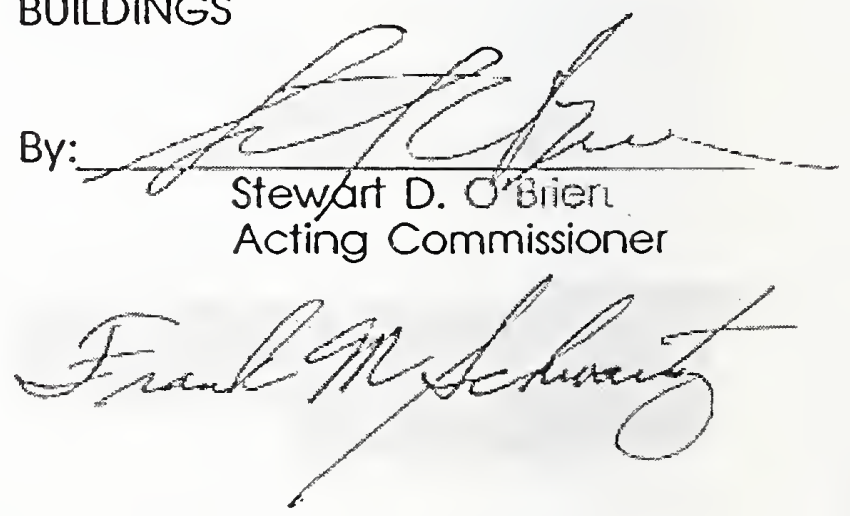
F:- THEPORT AUTHORITY OF NEW YORK AND NEW JERSEY

Commercial Litigation Division (68E)

$0=\pi 18$ All: 02

TO:

Lysa Meduri, Acting Secretary

FROM: Walter M. Frank

DATE: October 16,1995

SUBJECT: Transmittal of Letter Agreement - NYC Department of Bâirdings

Copy to: J. Green, N. Chanfrau, P. Cooper, W. Goldstein, H. Henschel, F. Lombardi

Transmitted for the official records of the Port Authority is a Letter Agreement between the Port Authority and the New York City Department of Buildings providing for a change to the recent Supplement to the Basic Memorandum of Understanding between the Department and the Port Authority in connection with the Port Authority's Tenant SelfCertification Program at the World Trade Center.

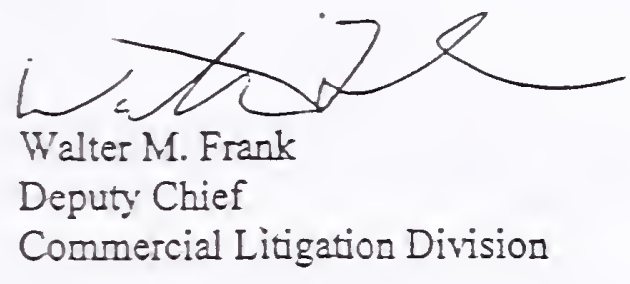

WMF:gk

Encl 
Honorable Joel A. Mlele, Sr., Commissioner

Department of Bulldings

Clty of New York

60 Hudson Streot

New York, New York 10013

Dear Commlsstoner Miele:

As you know, the Port Authorlty of New York and New Jersey (the "Port Authority") and the New York Clty Department of Bulldings (the "Department") recently executed a supplement (the "Supplement") to the Memorandum of Understanding between the Department and the Port Authortty to provide that the Port Authority's tenont at the World Trade Center could. in lleu of any revlew by the Port Authortty. use New York State llcensed archltects or englneers meeting qualifications to be established by the Port Authortty to: (A) prepare and review such tenant's plans for the construction of any project and certify that such ptans conform with the bulding standards set forth in the New York Clty Bullding Code and (B) certify that such profect has been constructed In accordance with the approved ptans and specifications for such project.

As you also know, the supplement provides that the person or firm performing the review and certification described in (A) above shall not be the same person or firm provlding the certification described in (B) above. A copy of the Supplement is attached.

This letter will-confirm the agreement of the Port Authority and the Department that, notwlthstanding the last sentence of paragraph 1 of the Supplement. a single licensed consultant may make both certffications described in (A) and (B) of such paragraph, except where the alteration would change the character of the occuponcy group under paragraph 27-237 of the New York City Building Code which would have been applicable to such space had such space boen located in a privately owned bullding.

If the foregoing meets with your approval, please be good enough to sign this letter on behalf of the Department where indicated below and return one of the originals to me. In light of the fact that three orlginals of the supplement were fumished to the Department, we have, for your record purposes, executed In total four originals of this letter.

Very truly yours.

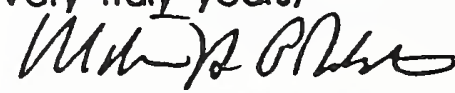

Williom H. Goldstein

Deputy Executtve Director

Copital Progroms

THE NEW YORK CITY DEPARTMENT OF BUILDINGS

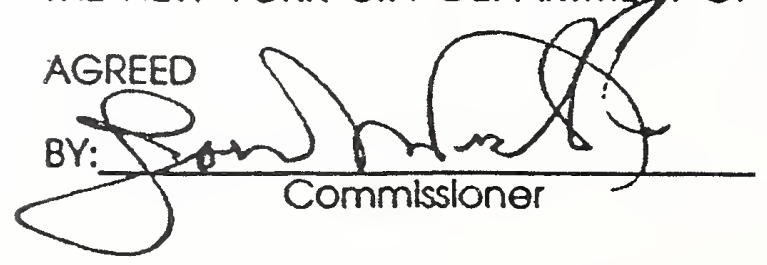


SUPPLEMENT TO MEMORANDUM OF UNDERSTANDING

BETWEEN THE NEW YORK CITY DEPARTMENT OF

BUILDINGS AND THE PORT AUTHORITY OF NEW

YORK AND NEW JERSEY

In November, 1993 the New York City Department of Buildings. (the 'Department') and the Port Authorlty of New York and Now Jersey (the "Port Authorlty") entered into the attached Memorandum of Understandling (the 'Memorandum") establishing certain procedures for the purpose of helping to assure conformance of construction projects to be undertaken at bulldings owned or operoted by the Port Authority in New York Clty with the standards set forth in the New York 'City Buitding Code.

Recently, the Department implemented its own optional plan revlew system provlding for professiond certifications of applicatlons and plans and subsequent constructlon work falling under its jurisdiction.

The purpose of this Supplement to the Memorandum is to provide under the Memorandum for the adoption by the Port Authority of a procedure under which any Port Authority tenants of the World Trade Center mov utllize New York State llcensed architects or engineers to certify. In lleu of any review by the Port Authority. that (i) the tenant's construction plans are in conformance with the standards set forth in the New York City Bullding Code. and (II) construction has been performed in accordance with such plans, It beling understood that the persons making the certificotions described in (i) and (II) shall not be the same.

Accordingly, the Department and the Port Authortty hereby agree that the Memorandum is amended as follows:

1. Professlonal Certtication. Notwlthstanding anything to the contrary in the Memorandum, the Port Authority may, in heu of any revlews or certificotlons by the Port Authortty provided for in the Memorandum, provide procedures pursuant to which its tenants at the World Trade Center may utilize Now York Stote llcensed architects or engineers meeting qualifications to be established by the Port Authority to (A) prepare and revlew such tenant's plans for the construction of ary prolect and certify that such plans conform with the bullding standards set forth in the New York City Building Code and (B) certify that such project has been constructed in accordance with the approved plans and specifications for such project. The person or firm performing the review and certification described in (A) above shall not be the same person or firm providing the certificotion described in $(B)$ above.

2. Other Provisions. Except as provlded herein, all the terms and conditions of the Memorandum shall remain in full force and effect.

3. No Personal Uability. No Commissioner, officer, agent or employee of the Poit Authority or the Department shall be held personally 
llable under any provision of this Supplement or becouse of its execution or attempted execution or because of any breach or alleged breach thereof.

IN WITESS WHEREOF, the parties hereto have caused this instrument to be signed, sealed and ottested.

ATTEST:

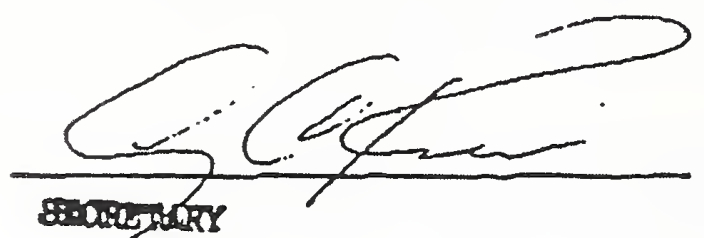

DATE:

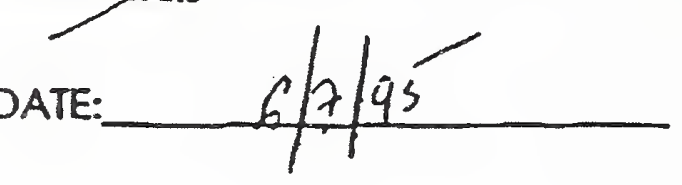

THE PORT AUTHORIT OF NEW YORK AND NEW JERSEY

By:

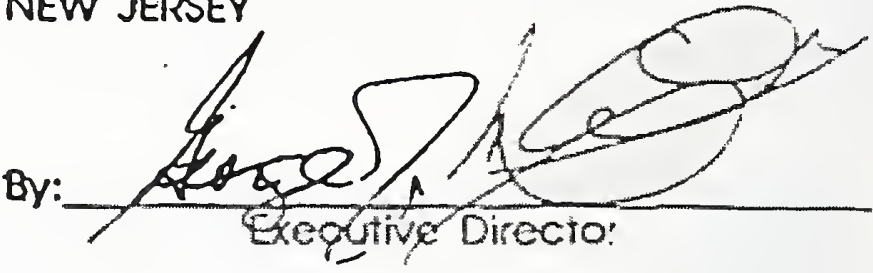

WITNESS:

$$
\begin{gathered}
\text { FRANK M. SCHWARTZ } \\
\text { Notery Public. Stele ol How York } \\
\text { No. } 11-4632586
\end{gathered}
$$

Qualitied in Queens Couaty Commlesion Explros Jan. 32.10 97

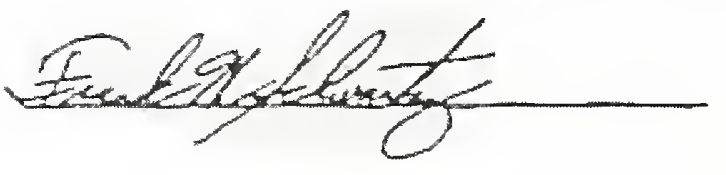

DATE: $6 / 1 / 95$
THE NEW YORK CIT DEPARTMENT OF BULLDINGS

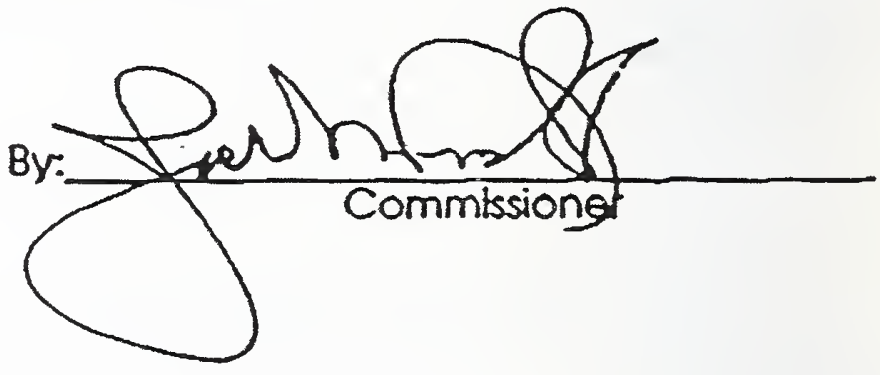


Charles G. Sturcken, Deputy General Counsel

The New York City

Lawrence S. Holrichter. Chici Finance Division

(212) $435-6220$

(201) $961.6600 \times 6220$

Department of Buildings - Executive Offices

60 Hudson Street

THE PORT AUTHORITYOOF N.Y.\& N.J TENANT CONSTRUCTION REVIEW UNIT

RECEIVED

14th Floor

New York, New York

NOV Og 1993

Dear Mr. Sturcken:

Enclosed please find a fully executed original of the Memorandum of Understanding between "the Port Authority and the New York City Department of Buildings.

For your information, the gubernatorial review period for the enclosed agreement will end at-midnight Wednesday, November 17, 1993. It has been a pleasure working with you on this matter.

Very truly yours.

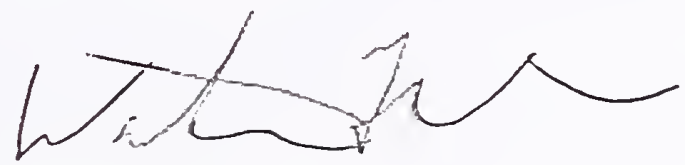

Walter M. Frank

Deputy Chief, Finance Division

Law Department

Enclosures

cc: William H. Goldstein. Deputy Executive Director. Capital Proarams

bcc: J.S. Green, P.S. Cooper (51N), A.A. DiNome (68S), E.J. Fasullo (72S), L.S. Hofrichter, F.J. Lombardi (72S), C.J. Maikish (35E), A.J. Raiola, S.T. Van de Walle 
This Memorandum shall govern the relationship between the New York City Department of Buildings (the "Department") and the Port Authority of New York and New Jersey (the "Port Authority"), both parties entering iato this agreement with the intention to establish procedures to be followed by the Port Authority for any building construction project ("Project"), to be undertaken by the Port Authority or any of its tenants at buildings owned or operated by the Port Authority and located in the City of New York (the "City), to assure conformance of Projects at such buildings with the standards set forth in the New York City Building Code (the "Code").

While the facilities of the Port Authority, an agency of the States of New York and New Jersey, are not technically subject to the requirements of local building codes, the long-standing policy of the Port Authority has been to assure that its facilities meet and, where appropriate, exceed Code requirements.

The purpose of this Memorandum is not only to restate that longstanding policy as part of an understanding with the City but to provide specific commitments to the Department, as the agency of the City responsible for assuring compliance with the Code, regarding procedures to be undertaken by the Port Authority for any Project at its facilities in the City to assure that the buildings owned or operated by the Port Authority within the City are in conformance with the Building Standards contained in the Code.

as follows:

Accordingly, the Department and the Port Authority hereby agree

1. Port Authority Review. To assure conformance with the building standards set forth in the Code at the time of the design and construction of any Project, the Port Authority shall, in the case of each Project, thoroughly review and examine all plans in connection with such Project for conformance with the building standards set forth in the Code. Plans prepared for Projects to be undertaken by Port Authority tenants shall be prepared and sealed by a New York State licensed professional engineer or architect retained or employed by tenant; plans prepared for Projects to be undertaken by the Port Authority shall be prepared by a New York State licensed professional engineer or architect employed or retained by the Port Authority. The Port. Authority's examination of plans shall be conducted by New York State licensed architects and engineers retained or employed by the Port Authority. The Port Authority engineer or architect approving the plans for any Project from the standpoint of Code conformance shall be a New York State licensed architect or engineer who shall not have assisted in the actual preparation of such plans.

2. Project File. The Port Authority shall maintain a file (the "Project File") for each Project which file shall at all times contain the most recently 
prepared drawings, plans and any other documents required in connection with the review of the Project from the standpoint of Code conformance. In the case of any Project being effectuated by a tenant of the Port Authority (a "Tenant Project") such file shall also include the Tenant Alteration Application prepared by the Tenant. In the case of any project administered by a line department of the Port Authority, such file shall include any construction application prepared in connection with such Project. The Line Depatments of the Port Authority are currently its World Trade. Aviation. Interstate Transportation, Port, and Regional Development Departments.

3. Project Certification. For each Tenant Project, the Port Authority shall require the Tenant to obtain the certification of a New York State licensed architect or engineer that such Project was constructed in accordance with the approved plans and specifications for such Project. For any Project effectuated by the Port Authority, the Chief Engineer or his successor in duties shall certify that the Project was constructed in accordance with the approved plans and specifications for the Project. Certifications for each Project shall be maintained in the Project File.

4. Copies of Project File. The Department may at any time request the Port Authority to provide it with a copy of any Project File and the Port Authority shall promptly provide a copy of the Project File to it.

5. Variances. The Port Authority shall promptly advise the Department of any Project approved by the Chief Engineer of the Port Authority which involves, in the judgment of the Chief Engineer of the Port Authority or his successor in duties, a variance from the clear requirements of the Code. In the event that the Department disagrees with the manner in which questions of Code conformance have been or are proposed to be dealt with in connection with such Project, it may so advise the Authority. The Port Authority shall seek expeditiously to resolve the matter. Any matter of Code conformance in connection with such Project which the Department believes involves an unacceptable variance from the requirements of the Code shall be subject to the further review of the Port Authority Board of Commissioners. The Commissioners shall be advised of the Department's views on the matter.

6. Inspections and Surveys. The Port Authority shall continue to conduct or cause to be conducted all building inspections, during both construction and post-construction periods, required under the Code. In addition, the Port Authority will continue to perform structural integrity inspections on a cyclical basis for all of its structures located in the City.

7. Port Authority Responsibility. As indicated above, the purpose of this Agreement is to set forth certain basic understandings between the Department and the Port Authority. It is understood, however, that the Port Authority with its tenants shall continue to bear the responsibility for life safety in buildings at its facilities and nothing in this Agreement is intended to impose any obligations of inspection or review on the Department. The Department shall refer back to the Chief Engineer of the Port Authority any requests for 
information or interpretation which it may receive from tenants of the Port Authority with respect to any Project.

8. No Personal Liability. No Commissioner, officer, agent or employee of the Port Authority or the Department shall be held personally liable under any provision of this Agreement or because of its execution or attempted execution or because of any breach or alleged breach thereof.

IN WITNESS WHEREOF, the parties hereto have caused this instrument to be signed, sealed and attested.

ATEST:

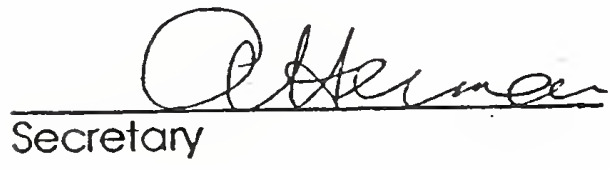

DATE: $\quad 11 / 3 / 93$

\section{ATTEST:}

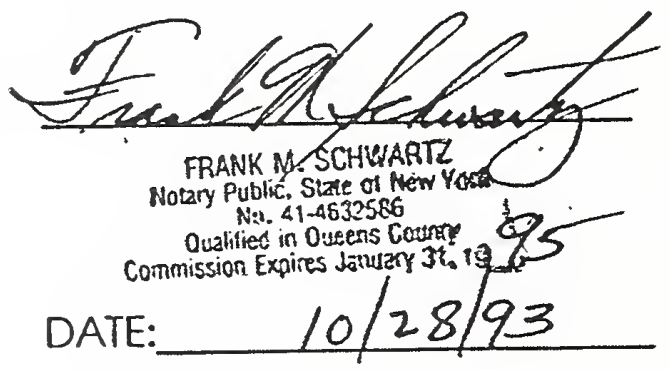

THE PORT AUTHORITY OF NEW YORK AND NEW JERSEY

By:

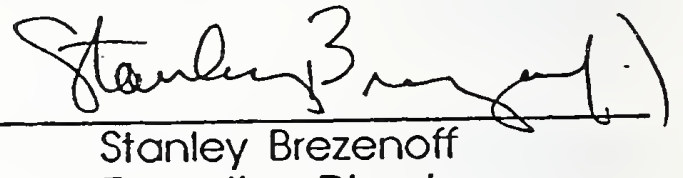

THE NEW YORK CITY DEPARTMENT BUILDINGS

By:
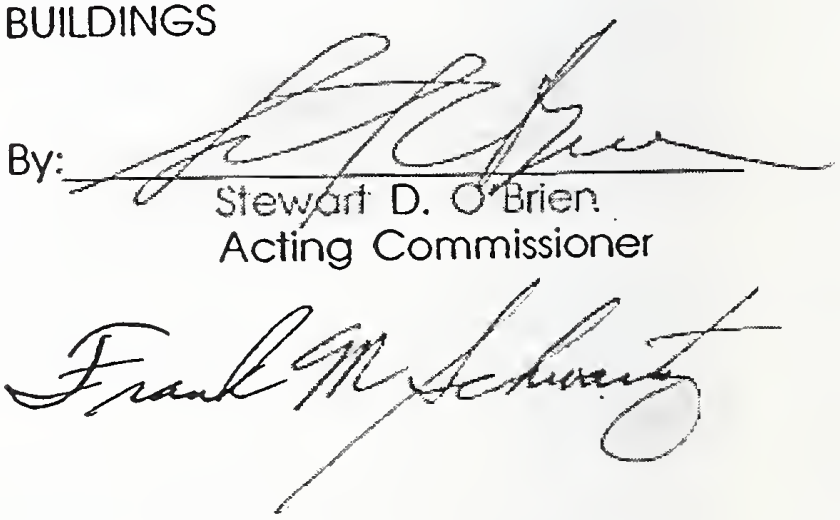


\section{MEHORANDUM OF UNDERSTANDING BETYREN THB FIRB DBPARTHENT (IF TAB CITY OF NEV YORK AND TER PORT AUTBORITY OF NEW YORR AND NEU JERSEI EXECUTIED AS OF DECEKBER 30, 1993}

On April 15, 1993, the Port Authority, in order to maintain and enhance the safety of Port Authority facilities, adopted a policy providing for the implementation of fire safety recommendations made by local government fire departments after a fire safety inspection of a Port Authority facility and for the prior review by local fire safety agencies of fire safety systems to be The purpose of this Memorandum of Understanding is to reiterate the Port Authority's commitment to this policy and to set forth certain procedures to facilitate the implementation of this policy for buildings at Port Authority Eacilities located in New York City.

Specifically, the Fire Department of the City of New York ("FDNY") and the Port Authority hereby agree as follows:

1. FDNY, acting through its Bureau of Pire Prevention ("BFF"), shall have the right to conduct fire safery inspections at any Port Authority facility located in the city of New York. These inspections will generally be coordinated with the Port Authority's General Manager of Risk Management operations, but the BFP, at its option, may conduct inspections without prior notice to the Port Authority.

2. BFP will issue a letterhead report of its fire safety findings and recommendations for corrective action with respect to any deflciencies forming a part of such findings addressed to the Port Authority's General Manager of Risk Management operations. The Port Authority will promptly undertake the implementation of such findings (including undertaking corrective action with respect to any deficiencies) and shall notify BFP of the actions taken to implement such findings. BFP may at any time conduct follow-up inspections with respect to any matters recommended to the Port Authority for corrective action.

Prior to the introduction of a new fire safety system or the introduction of modifications to an existing fire safety system at any building located at a Port Authority facility in the City of New York, the Port Authority shall provide BFP with copies of the drawings and specifications or other appropriate description of such system or modification for review and approval. The Port Authority policy is and wili continue to be to assure that such new or modified fire safecy systems are in compliance with local codes and regulations. When circumstances or conditions are unusual, the Port Authority shall have the right to petition the Bureau of Fire Prevention for a variance in specific cases. 
4. The Port Authority and BPP will seek to expeditiously resolve any issues arising out of matters covered by this Memorandum of Understanding.

5. Nothing in this Memorandum of Understanding is intended to limit or modify in any vay any arrangements which the Port Authority currently has with local fire companies in New York City regarding either facility inspections or joint training exercises or any other matters.

6. The Port Authority shall continue to be exempt from all inspection and permit fees for FDNY inspections at its facilities.

7. No Comaissioner, officer, agent or employee of the Port Authority or PDNY shall be held personally liable under any provision of this Memorandum or because of its execution or attempted execution or because of any breach or alleged breach thereof.

IN UITNRSS THERBOP, the parties hereto have caused this instrument to be signed and sealed by duly authorized officers thereof.

THE PORT AUTEORITY OF NET YORK AND NEW JERSEI

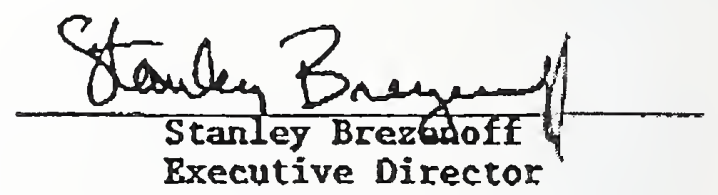

FIRE DEPARTMENT - CITY OF NBW YORR

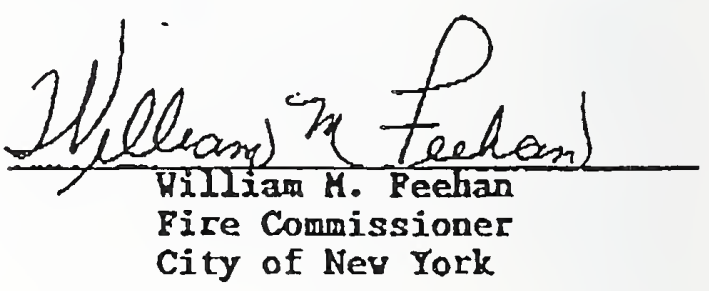




\section{MEHORANDUN OF UNDERSTANDTNG BBTURBN TEIB FIRB DBPARTHENT (IF TER CITY OP NED YORK AND TER PORT AUTHORITY OF NBY YORR AND NER JERSET BXECCITED AS OF DECEKDBER 30, 1993}

On April 15, 1993, the Port Authority, in order to maintain arid enhance the safety of Port Authority facilitles, adopted a policy providing for the implementation of fire safety recommendations made by local government fire departments after a fire safety inspection of a Port Authority facility and for the prior reviev by local fire safety agencies of fire safety systems to be introduced or added to a facility.

The purpose of this Memorandum of Understanding is to reiterate the Port Authority's comitment to this policy and to set forth certain procedures to facilitate the implementation of this pollcy for buildings at port Authority facilities located in Nev York City.

Specifically, the Fire Department of the City of New York ("FDNY") and the Port Authority hereby agree as follows:

1. FDNY, acting through its Bureau of Pire Prevention ("BFP"), shall have the right to conduct fire safery inspections at any Port Authority facility located in the City of New York. These inspections will generally be coordinated with the Port Authority's General Manager of Risk Management operations, but the BEP, at its option, may conduct inspections without prior notice to the Port Authority.

2. BFP vill issue a letterhead report of its fire safety findings and recomendations for corrective action with respect to any deficiencies forming a part of such findings addressed to the Port Authority's General Manager of Risk Management operations. The Port Authority vill promptly undertake the implementation of such findings (including undertaking corrective action with respect to any deficiencies) and shall not fy BFP of the actions taken to implement such findings. BFP may at any time conduct follov-up inspections with respect to any matters recoumended to the Port Authority for corrective action.

3. Prior to the introduction of a nev fire safety system or the introduction of modifications to an existing fire safety system at any building located at a Port Authority facility in the City of New York, the Port Authority shall provide BFP with copies of the drawings and specifications or other appropriate description of such system or modification for reviev and approval. The Port Authority policy is and vill continue to be to assure that such new or modified fire safety systems are in compliance with local codes and regulations. When circumstances or conditions are unusual, the Port Authority shall have the right to petition the Bureau of Fire Prevention for a variance in specific cases. 
4. The Port Authority and BFP will seek to expeditiously resolve any issues arising out of matters covered by this Memorandum of Understanding.

5. Nothing in this Memorandum of Understanding is Intended to limit or modify in any way any arrangements which the Port Authority currently has with local fire companies in New Jork City regarding either facility inspections or joint training exercises or any other matters.

6. The Port Authority shall continue to be exerpt from all inspection and permit fees for PDNY inspections at its faclilties.

7. No Cormissioner, officer, agent or employee of the Port Authority or PDNY shall be held personally liable under any provision of this Memorandum or because of its execution or attempted execution or because of any breach or alleged breach thereof.

IN OITNESS GHERBOP, the parties hereto have caused this instrument to be signed and sealed by duly authorized officers thereof.

THE PORT AUTHORTIT OF NBT YORK AND NET JERSEI

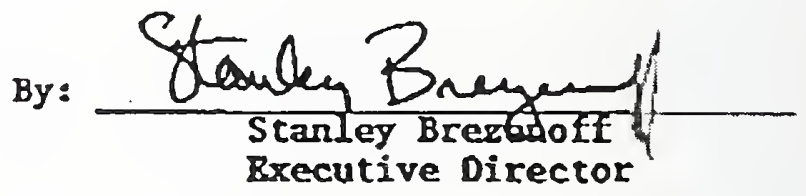

PIRE DEPARTYRINT - CITI OF NBW IORR

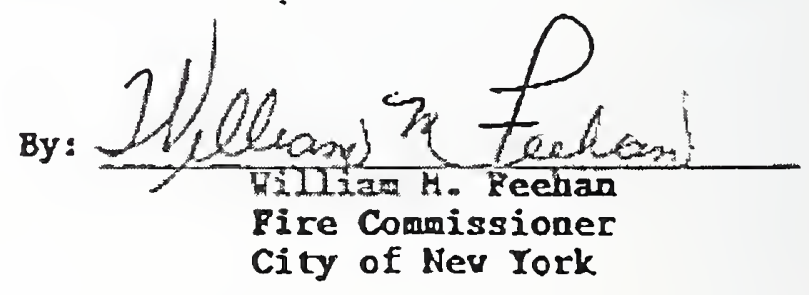




\section{MEMORANDUM OF UNDERSTANDING BETWEEN THE NEW YORK CITY DEPARTMENT} OF BUILDINGS AND THE PORT AUTHORITY OF NEW YORK AND NEW JERSEY

This Memorandum shall govern the relationship between the New York City Department of Buildings (the "Department") and the Port Authority of New York and New Jersey (the "Port Authority"), both parties entering into this agreement with the intention to establish procedures to be followed by the Port Authority for any building construction project ("Project"), to be undertaken by the Port Authority or any of its tenants at buildings owned or operated by the Port Authority and located in the City of New York (the "City), to assure conformance of Projects at such buildings with the standards set forth in the New York City Building Code (the "Code").

. While the facilities of the Port Authority, an agency of the States of New York and New Jersey, are not technically subject to the requirements of local building codes, the long-standing policy of the Port Authority has been to assure that its facilities meet and, where appropriate, exceed Code requirements.

The purpose of this Memorandum is not only to restate that longstanding policy as part of an understanding with the City but to provide specific commitments to the Department, as the agency of the City responsible for assuring compliance with the Code, regarding procedures to be undertaken by the Port Authority for any Project at its facilities in the City to assure that the buildings owned or operated by the Port Authority within the City are in conformance with the Building Standards contained in the Code.

as follows:

Accordingly, the Department and the Port Authority hereby agree

1. Port Authority Review. To assure conformance with the building standards set forth in the Code at the time of the design and construction of any Project, the Port Authority shall, in the case of each Project, thoroughly review and examine all plans in connection with such Project for conformance with the building standards set forth in the Code. Plans prepared for Projects to be undertaken by Port Authority tenants shall be prepared and sealed by a New York State licensed professional engineer or architect retained or employed by tenant; plans prepared for Projects to be undertaken by the Port Authority shall be prepared by a New York State licensed professional engineer or architect employed or retained by the Port Authority. The Port. Authority's examination of plans shall be conducted by New York State licensed architects and engineers retained or employed by the Port Authority. The Port Authority engineer or architect approving the plans for any Project from the standpoint of Code conformance shall be a New York State licensed architect or engineer who shall not have assisted in the actual preparation of such plans.

2. Project File. The Port Authority shall maintain a file (the Project File*) for each Project which file shall at all times contain the most recently 
prepared drawings, plans and any other documents required in connection with the review of the Project from the standpoint of Code conformance: In the case of any Project being effectuated by a tenant of the Port Authority (a 'Tenant Project') such file shall also include the Tenant Alteration Application prepared by the Tenant. In the case of any project administered by a line department of the Port Authority. such file shall include any construction application prepared in connection with such Project. The Line Depadments of the Port Authority are currently its World Trade. Aviation. Interstate Transportation, Port, and Regional Development Departments.

3. Project Certification. For each Tenant Project, the Port Authority shall require the Tenant to obtain the certification of a New York State licensed architect or engineer that such Project was constructed in accordance with the approved plans and specifications for such Project. For any Project effectuated by the Port Authority. the Chief Engineer or his successor in duties shall certify that the Project was constructed in accordance with the approved plans and specifications for the Project. Certifications for each Project shall be maintained in the Project File.

4. Copies of Project File. The Department may at any time request the Port Authority to provide it with a copy of any Project File and the Port Authority shall promptly provide a copy of the Project Fle to it.

5. Variances. The Port Authority shall promptly advise the Department of any Project approved by the Chief Engineer of the Port Authority which involves, in the judgment of the Chief Engineer of the Port Authority or his successor in duties, a variance from the clear requirements of the Code. In the event that the Department disagrees with the manner in which questions of Code conformance have been or are proposed to be dealt with in connection with such Project, it may so advise the Authority. The Port Authority shall seek expeditiously to resolve the matter. Any matter of Code conformance in connection with such Project which the Department believes involves. an unacceptable variance from the requirements of the Code shall be subject to the further review of the Port Authority Board of Commissioners. The Commissioners shall be advised of the Department's views on the matter.

6. Inspections and Surveys. The Port Authority shall continue to conduct or cause to be conducted all building inspections, during both construction and post-construction periods, required under the Code. in addition, the Port Authority will continue to perform structural integrity inspections on a cyclical basis for all of its structures located in the City.

7. Port Authority Responsibility. As indicated above, the purpose of this Agreement is to set forth certain basic understandings between the Department and the Port Authority. It is understood, however, that the Port Authority with its tenants shall continue to bear the responsibility for life safety in buildings at its facilities and nothing in this Agreement is intended to impose any obligations of inspection or review on the Department. The Department shall refer back to the Chief Engineer of the Port Authority any requests for 
information or interpretation which it may receive from tenants of the Port Authority with respect to any Project.

8. No Personal Liability. No Commissioner, officer, agent or employee of the Port Authority. or the Department shall be held personally liable under any provision of this Agreement or because of its execution or attempted execution or because of any breach or alleged breach thereof.

IN WINESS WHEREOF, the parties hereto have caused this instrument to be signed, sealed and attested.

ATIEST:

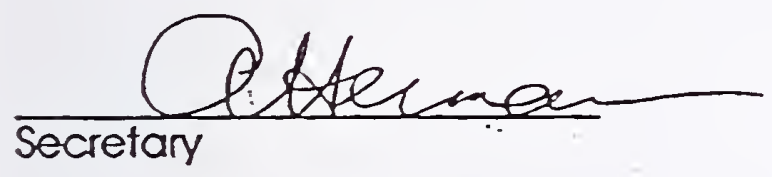

DATE: $\quad 11 / 3 / 13$

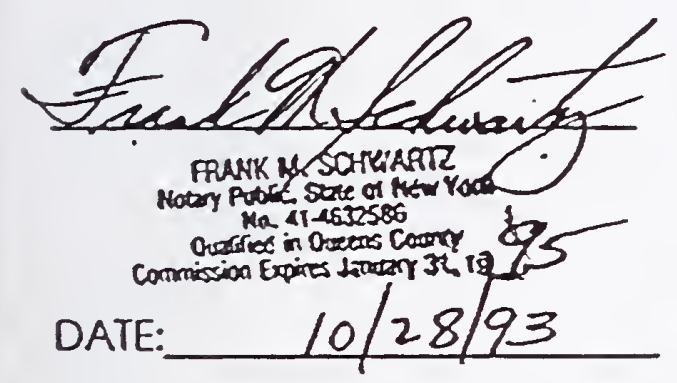

THE PORT AUTHORTY OF NEW YORK AND NEW JERSEY

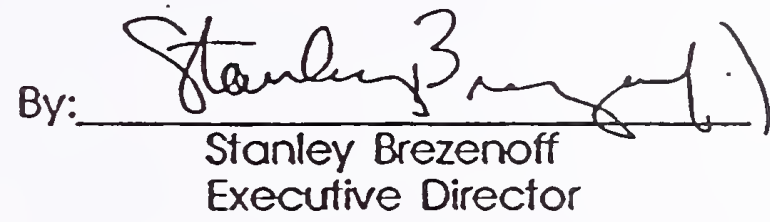

THE NEW YORK CITY DEPARTMENT BUILDINGS

By:
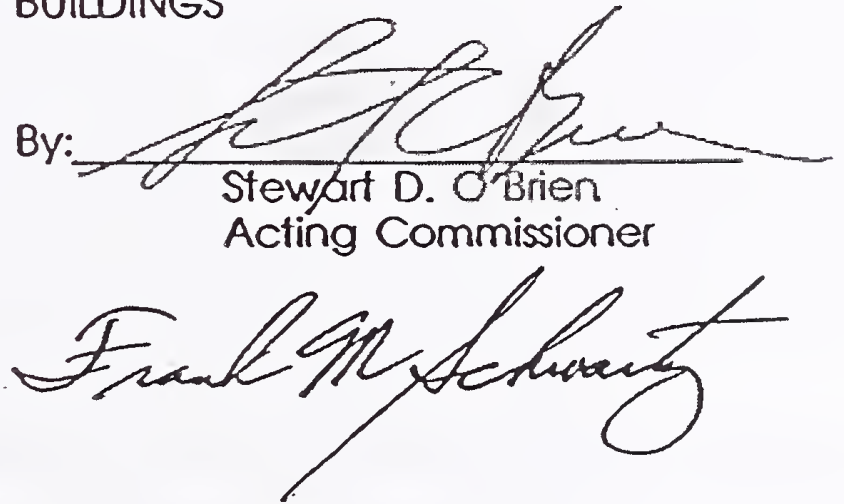
SUPPLEMENT TO MEMORANOUM OF UNDERSTANDING BETWEEN THE NEW YORK CITY DEPARTMENT OF BUILDINGS ANO THE PORT AUTHORIY OF NEW YORK AND NEW JERSEY

In November, 1993 the New York Clty Department of Buildings. (the -Department") and the Port Authorty of New York and New Jersey (the "Port Authortty") entered into the attached Memorandum of Understanding (the "Memorandum") establishing certain procedures for the purpose of helping to assure conformance of construction projects to be undertaken at bulldings owned or operated by the Port Authority in New York Clly with the standards set forth in the New York 'City Building Code.

Recently, the Department implemented its own optional plan review system providing for professionol certifications of applicatlons and plans and subsequent construction work falting under its jurisdiction.

The purpose of this Supplement to the Memorandum is to provide under the Memorandum for the adoption by the Port Authority of a procedure' under which any Port Authority tenants at the Wortd Trade Center moy utllize New York State licensed architects or enginoors to certify, In lleu of any review by the Port Authortty, that (i) the tenant's construction plans are in conformance with the standards set forth in the New York City Bullding Code. and (ii) construction has been performed in accordance with such plans, it beling understood that the persons making the certifications described in (i) and IID shall not be the same.

Accordingly, the Department and the Port Authortty hereby agree that the Memorandum is amended as follows:

1. Professlonal Certification. Notwuthstanding anything to the contrany In the Memorandum. the Port Authority may, in keu of any revilews or certifications by the Port Authority provided for in the Memorandum, provide procedures pursuant to which its tenants of the World Trade Center may uttilze New York State llcensed archltects or engineers meething qualifications to be established by the Port Authority to (A) prepare and review such tenant's plans for the construction of any project and certify that such ptans conform with the bullding standards set forth in the New York City Building Code and (B) certlfy that such project has been constructed in accordance with the approved ptans and speciflcations for such project. The person or firm performing the revlew and certification described in (A) above shall not be the same person or firm providing the certification described in (B) above.

2:- Other Provisions. Except as provided herein, all the terms and conditions of the Memorandum shall remain in full force and effect.

3. No Personal Uability. No Commissioner, officer. agent or employee of the Poirt Authortty or the Department shall be held personally 
ll able under any provision of this supplement or because of its execution or attempted execution or because of any breach or alleged breach thereof.

IN WIINESS WHEREOF. the parties hereto hove caused instrument to be signed, sealed and attested.

ATTEST:
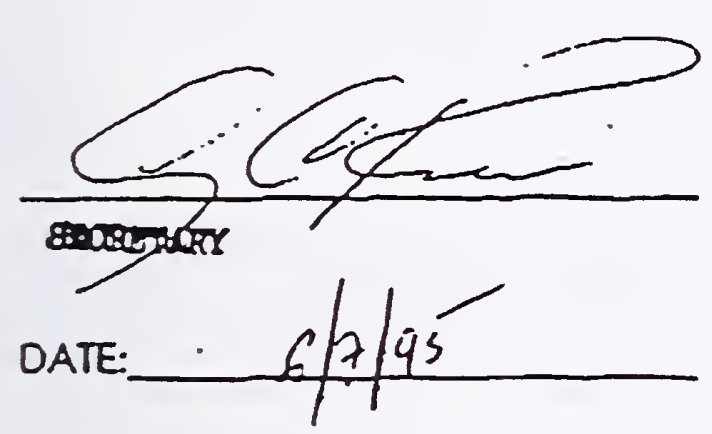

THE PORT AUTHORITY OF NEW. YORK AND

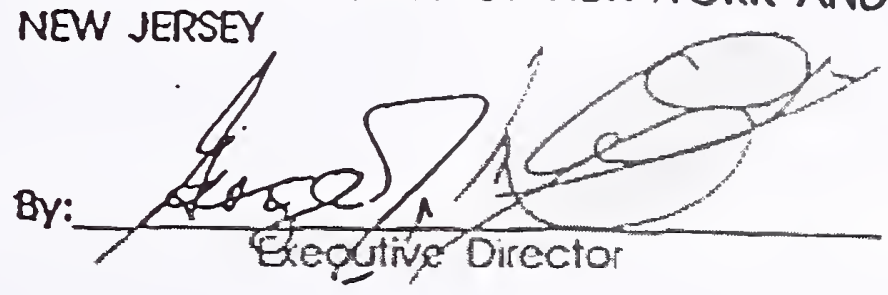

WINES:

FRANK M. SCHWARTZ

Hocery Pubic. SIDle of Her York No_ 11.4632356 Qualliled in Ques na Courtly o Commlessoa Exploits ten. 32.1097

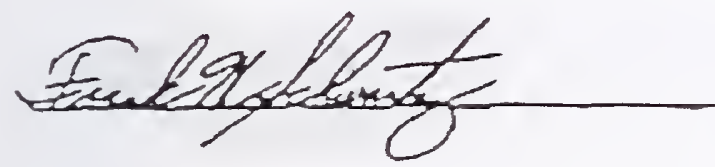

DATE: $6 / 1 / 95$
THE NEW YORK CM Y DEPARTMENT BULLING

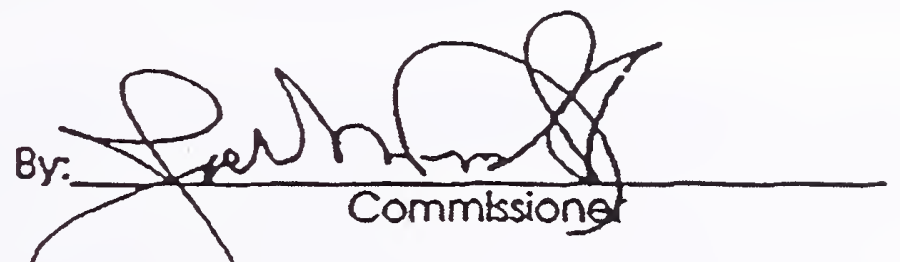


Honorable Joed A. Milele, Sr., Commisstoner

Department of Bulldings

Clty of Now York

60 Hudson Street

Now York, Now York 10013

Door Commisstoner Miele:

As you know, the Port Authortty of New York and Now Jersey (the "Port Authorlty") and the New York Clty Department of Bulldings (the "Department") recently executed a supptoment (the "Supplement") to the Memorandum of Understanding between the Department and the Port Autthortty to provide that the Port Authortty's tenant of the World Trade Conter could, In lleu of any revlew by the Port Authortty. use Now York State llcensed architects or enginoers moeting quallications to be established by the Port Authortty to: (A) prepare and revlew such tenant's olans for the construction of any project and certtfy that such plans conform with the building standards set forth in the Now York Clty Bullding Code and (B) cortify that such profoct has boen constructed in accordance with the approved plans and spectifications for such profoct.

As you also know. the Supplement provides that the person or firm performing the reviow and certification described in (A) above shall not be the same person or firm providing the certification described in (B) above. A copy of the Supplement is attachod.

This letter will-conflim the agreement of the Port Authortly and the Department that, notwilthstanding the last sentence of paragraph 1 of the Supplement. a single licensed consultant moy make both certifications described $h(A)$ and (B) of such paragraph. except where the alteration would change the character of the occupancy group under paragraph 27-237 of the New York City Bullding Code which would have been applicable to such space had such space been located in a ptrately ownod bullding.

If the foregoling meets with your approval, ploase be good enough to stan thits letter on behalf of the Department where indicated bolow and return one of the origlnats to me. In light of the fact that three originats of the supplement were furnished to the Department, we have, for your record purposes, executed in total four orlginats of this letter.

Very truty yours.

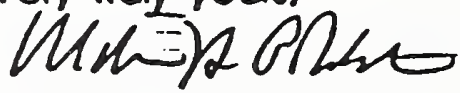

Willam H. Goldstein

Deputy Executive Director

Capltal Programs

THE NEW YORK CTY DEPARTMENT OF BUILDINGS

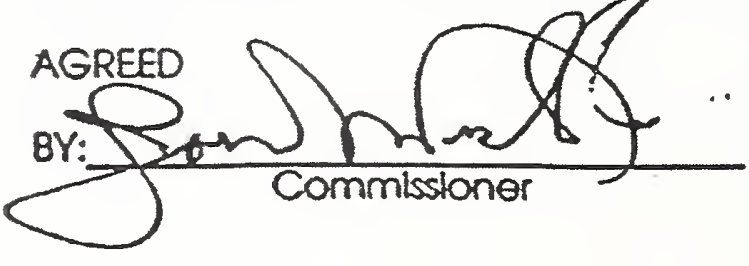




\section{FIRST AMENDHENT TO MEAORANDUM OF UNDERSTANDING BETHEEN THE FIRE DEPARTMENT OF THE CITY OF NEW YORT AND THE PORT AUTHORITY OF NEW YORX AND NEW JERSEY EXECUTED AS OF DECEMBER 30, 1993}

On December 30, 1993, the Port Authority of New York and New Jersey (the "Port Authority") and the Fire Department of the City of Ner York ("FDNY") entered into a Memorandum of Understanding ("MOU") with respect to certain matters relating to the implementation of the policy adopted by the Port Authority on April 15, 1993 regarding the maintenance and enhancement of fire safety at Port Authority facilities.

Under paragraph 3 of the MOU, the FDNY, acting through its Bureau of Fire Prevention ("BFP") was to receive copies of the drawings and specifications of proposed new or modifled fire safety systems for BFP's review and approval. FDNY has requested, and the Port Authority is agreeable, to the following changes to paragraph 3 of the MOU. Accordingly, effective January 1, 1995, FDNY and the Port Authority agree that paragraph 3 of the MOU shail be amended to read as follows:

3. The Port Authority shall notify the BFP in writing prior to the introduction of a new fire safety system or the introduction of modificationst to an existing fire safety system at any building located at a Port Authority facility in the City of New York.

a. Port:Authority Review: To assure conformance with the standards set forth in local codes and regulations at the time of the design and construction of any new or modified fire safety system, the Port Authority shall, in the case of each system, thoroughly review and examine all plans in connection with such system for conformance with the standards set forth in all applicable local codes and regulations. Plans prepared for new or modified systems to be undertaken by Port Authority tenants shall be prepared and sealed by a New York State licensed professional engineer or architect retained or employed by tenant; plans prepared for new or modified systems to be undertaken by the Port Authority shall be prepared by a New York-State licensed professional engineer or architect employed or retained by the Port Authority. The Port Authority's examination of plans shall be conducted by New York State licensed architects and engineers retained or employed by the Port Authority. The Port Authority engineer or architect approving the plans for any new or modifled system from the standpoint of Code conformance shall be a New York State licensed architect or engineer who shall not have assisted in the actual preparation of such plans.

b. New and/or Modified Fire Safety System File: The Port Authority shall maintain a file for each new or modified system which file shall at all times contain the most recently prepared drawings, plans and any other documents required in connection with the review of the systems from the standpoint of Code conformance. In the case of any new or modified system being effectuated by a tenant of the Port Authority, such file shall also include the Tenant Alteration Application prepared by the tenant. In the case of any new or modified system administered by a line department of the Port Authority, such file shall include any application prepared in connection with such new or modified system. The Line Departments of the Port Authority are currently its Horld Trade, Aviation, Interstate Transportation, Port and Regional Development Departments. 
c. Fire Safety System Certification: For each Tenant System, the Port Authority shall. require the Tenant to obtain the certification of a New York State licensed architect or engineer that such system was constructed in accordance with the approved plans and specifications. For any system effectuated by the Port Authority, Risk Management shall certify that the system was constructed in accordance with the approved plans and specifications. Certifications for each System shall be maintalned in the New and/or Modifled Fire Safety System File.

d. Copies of New and/or Modified Fire Safety System File: The BFP may at any time request the Port Authority to provide it with a copy of any Fire Safety System FIle and the Port Authority shall promptly provide a copy of the File as requested. The BFP reserves the right to audit any new or modifled fire safety system to assure conformance with the standards set forth in local codes and regulations.

e. Variance: The Port Authority policy is and w1ll continue to be to assure that such new or modified fire safety systems are in conformance with the local codes and regulations. When circumstances or conditions are unusual, the Port Authority shall have the: right to petition the BFP for a variance in specific cases.

IN HITNESS HHEREOF, the Port Authority and FDNY have caused this First Amendment to the MOU to be signed by duly authorized officers thereof. i.: THE PORT AUTHORITY OE NEW YORK AND' NEW JERSEY

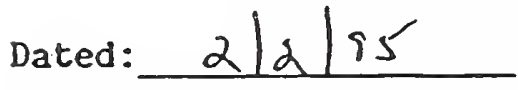
$\checkmark$

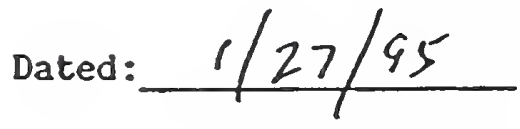

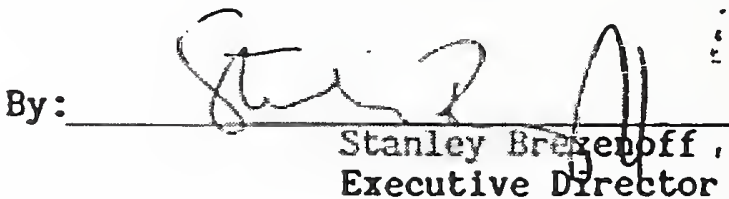

FIRE DEPARTMENT - CITY OF NEW YORK

By:

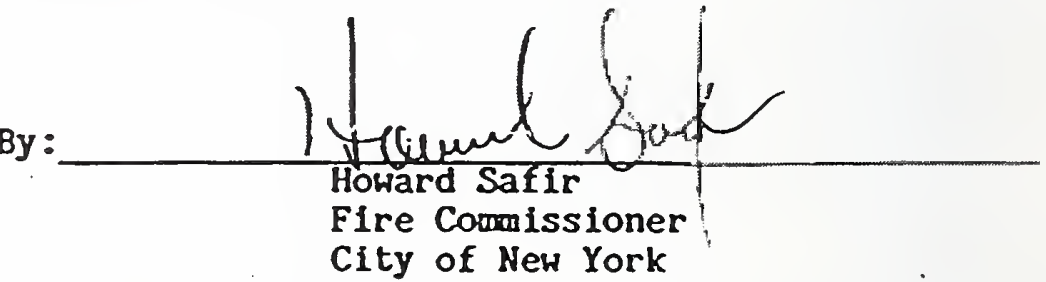


Appendix D

\section{ELEVATOR OPERATIONS}





\section{ELEVATOR OPERATIONS}

Appendix D

Training Bulletin Emergencies 1 Elevator Operations

Reproduced with permission of The Fire Department of the City of New York 


\section{Table of Contents}

\section{Introduction}

2. Fire Department Policy at Elevator Operations

3. Elevator Incidents and Emergencies - Procedures

3.1 Stuck Elevator Cars

3.2 Size Up

3.3 Primary Removal Procedures

3.4 Summon Elevator Mechanic

3.5 Precautions - During Secondary and Emergency Removal Operations

3.6 Secondary Removal Operations

3.7 Emergency Removal Operations

4. Elevator Pit Operations

4.1 Elevator Pit Description

4.2 Operating Procedure

5. Firemen Service

5.1 Firemen Service Regulations

5.2 Description of Firemen Service Components

5.3 Operation of Firemen Service 
6. Elevator Operations During Fire Operations

6.1 General Procedures

6.2 Affects of Fire on Elevator Components

6.3 Firefighter Trapped in Stalled Elevator Cars During Fire Operations

6.4 Firemen Service During Fire Operations

6.5 Operational Considerations

7. Building Code Regulations Effecting Fire Department Operations

7.1 Accidents

7.2 Mechanical Features

7.3 Emergency Removal

8. Elevator Terms and Definitions

\section{ADDENDUM}

1. Staley Swing Door Key

2. GAL Swing Door Key

3. Gal Elevator Pick Tool

4. Otis Swing Door Key

5. "Z" Tool

6. GAL Drop Key

7. GAL Vandal Resistant Key 


\section{INTRODUCTION}

1.1 This bulletin will outline the following:

1.1.1 Operational procedures used at EMERGENCIES and INCIDENTS in which people are trapped in stuck elevators.

1.1.2 Guidelines for the utilization of elevators by this department during a fire situation.

1.1.3 Familiarization of members with elevator components and terminology which are essential in effective and safe operations.

1.2 The instructions and information presented here cannot be expected to cover all conditions that confront the department at elevator operations.

1.3 Members are advised that the training video "Elevator Emergencies" contains additional details.

\section{ELEVATOR INCIDENTS AND EMERGENCIES - DEPARTMENT POLICY}

2.1 The function of the Fire Department at elevator operations is limited to the safe removal of persons trapped in the elevator car or hoistway. Repairs to and reactivation of elevators are not carried out by members of this department.

2.2 Contact shall be made with responsible building management personnel for any information and assistance that will aid the operation. However the first units at the scene should start operations at once without awaiting arrival of the management personnel.

2.3 In the event there is evidence of injuries to trapped persons, the officer in command shall request the response of medical assistance.

2.4 Fire Department elevator operations are divided into two categories; INCIDENTS and EMERGENCIES.

\subsubsection{INCIDENT:}

A stuck elevator with trapped passengers not in immediate danger and no evidence of injury.

Note: Conditions must be constantly monitored, an INCIDENT may escalate to an EMERGENCY. 


\subsubsection{EMERGENCY:}

A situation where one or more of the following exist:

A. Fire endangering passengers in a stuck elevator.

B. Passenger of stuck elevator injured.

C. Passenger of stuck elevator in panic.

\section{ELEVATOR INCIDENT AND EMERGENCY - PROCEDURES}

3.1 Stuck Elevator Cars.

Problems arise from defective or non-functioning electrical or mechanical devices and equipment.

3.1.1 Electrical problems are the most frequent cause of elevator malfunction.

A. Common causes of electrical problems:

1. Car or hoistway door contacts open.

2. Blown fuses.

3. Shorting of electrical cables.

B. When an electrical problem occurs the following can be expected:

1. Elevator cars will be suspended on the hoistway cables.

2. Elevator brake will be applied in the hold position.

3.1.2 Mechanical problems though not as common, may also be encountered.

\subsection{Size Up}

3.2.1 Locate the car using the following.

A. Lobby control panel - check floor indicator.

B. If available use intercom or telephone system of the stuck car. Passengers may be able to give their approximate location.

C. Open the hoistway door at first floor with elevator key and look up shaft. Key devices are usually required at the lower levels and may be present at all levels. 
1. If the hoistway door has a glass panel check the shaft before opening the door. Using a flash light, look for the governor ropes and the counterweight. Movement of either one of these is an indication that the car is in motion, do not open the hoistway door. The governor rope is generally located on either side near one of the far corners of the shaft.

D. The location of the counterweight can be used to approximate the position of the car. For example, in a 6 story building where the elevator serves the basement, if the counterweight is on the 1st floor, the stalled car would be at the 5th. The counterweight can be located by viewing through the wire glass door panel or by opening a hoistway door.

E. Enter a car in the same bank and open top hatch if no damage will be done to the elevator car.

F. Use the floor selector in the machinery room, it indicates the exact location of elevator car.

3.2.2 Methods of communicating with passengers:

A. Elevator car telephone.

B. Elevator car intercom.

C. Call or yell up hoistway, or speak through car and hoistway doors.

Note: If emergency bell is ringing instruct the car passengers to deactivate the alarm and emergency stop button. A ringing bell can cause anxiety, confusion and hamper communications.

3.2.3 Methods of passenger removal:

A. Primary Removal Procedures, section 3.3.

B. Secondary Removal Procedures, section 3.6.

C. Emergency Removal Procedures, section 3.7.

3.3 Primary Removal Procedures

Primary removal procedures are simple approaches performed without turning off the elevator power.

There are two types of primary removal procedures. The order in which they are tried is not important. Try all if necessary. 


\subsubsection{Checking Electrical Contacts.}

The first type of primary removal procedures checks whether simple electrical contacts might have been broken. However if the passengers have activated the Emergency Stop Button, these methods will not work. The passengers must be instructed to deactivate the Emergency Stop Button.

A. Have a passenger press Door Open Button. If the car is level with the landing this may open both the car and hoistway door.

B. Press lobby call button.

C. Instruct passengers to insure the car door is fully closed. Have a person push the door towards the closed position.

D. Have members physically close all hoistway doors on the shaft. Air movement in shaft may have opened an interlock cutting power to the car. Check the hoistway doors in the vicinity of the stuck car first.

\subsubsection{Firemen Service.}

The second type of primary removal procedure is activating Firemen Service if available. Firemen Service will over ride the Emergency Stop Button.

A. Activate Firemen Service - Phase 1. The stuck elevator may return to the main lobby or sky lobby and open its doors.

B. Firemen Service should be deactivated when the car responds by returning to the lobby or if it's clear that the car isn't responding.

3.4 Summon an elevator mechanic if Primary Removal Procedures fail.

3.4.1 Telephone number of the mechanic is required to be posted in the machinery room near the elevator power switch.

3.4.2 Consider the possibility of an elevator mechanic on duty in a nearby building.

3.4.3 Secondary Removal Procedures may be initiated prior to the arrival of the mechanic.

3.5 Precautions During Secondary and Emergency Removal Procedures.

\subsubsection{Power Removal}

Whenever Secondary or Emergency Removal Procedures are used, power removal is essential. Dispatch two members to the elevator machinery room to shut off the power to the stalled car. The machinery room may be located at the top of the shaft, at the bottom of the shaft or two levels above the highest floor serviced by the elevator. 
A. Members should be equipped with a handie-talkie and forcible entry tools. Communication between members in machinery room and on landing is necessary.

B. Building maintenance personnel may be able to provide members with keys to the elevator machinery room.

C. Members assigned to the elevator machinery room will:

1. Determine which shaft the stalled car is in.

2. Shut off power to the stalled car when directed. Each elevator is controlled by its own power switch. Elevator power switch boxes and motors are required to be labeled in a manner which relates motor to switch. (Ex. Switch \#1, Motor \#1)

a. If any doubt exist open as many elevator power switches as required to insure a safe operation. Allow passengers to exit a serviceable car before removing power.

3. Remain at the power switch throughout the operation to insure the power is not restored.

4. Upon completion of the operation DO NOT restore power to the stalled car.

Note: When operating in elevator machinery rooms, located above the shaft, members should avoid stepping on the cover or grating over the elevator shaft ventilation opening. The grating may be improperly seated or removed and replaced with cardboard or other flimsy material. A member stepping on an unsafe grating or covering could fall the entire height of the shaft. The ventilation opening is also known as the smoke hole.

\subsubsection{Other Precautions.}

Once you move beyond the Primary Removal procedures there are several precautions you should be aware of.

A. Members are not to enter the shaft or remove passengers from the car until assured power has been removed.

B. When passengers are removed from a car between floors they should be taken up and out of the car if practical. This eliminates the possibility of a passenger falling down the shaft after exiting the elevator. If they are removed to the lower landing, the shaft opening must be protected.

C. Members operating in the shaft are to be secured by a life saving rope. 
D. Members shall not normally be permitted to enter the shaft below the elevator car. During a rescue necessitating members entering the shaft below the car, the power switch must be turned off.

E. The elevator shall never be jacked up or moved in an upward direction. This action may free the car safeties causing the car to move either upward or downward depending on the live load in the car.

F. No adjustment to or prying of the elevator machinery brake shall be attempted. The brake will be in a safe position and should not be tampered with.

G. In older elevator installations if the condition of the elevator brake is doubtful additional protection can be provided by placing a heavy timber, iron bar or tool between the spokes of the hoisting drum after power is removed. In most newer installations this procedure can be dangerous and impractical. Electrical components are usually in a close proximity to the drum and most drums are constructed in a manner which prevents getting an effective purchase.

H. If conditions indicate that the elevator is unstable additional precautions must be taken to prevent the movement of the car in either direction. Consider securing the car to structural members of the building using utility ropes, chains or shoring.

3.6 Secondary Removal Procedures

3.6.1 All efforts must be made to remove passengers via elevator car and hoistway door using an elevator tool or key or the procedures following in sections 3.6 .3 \& 3.6.4.

A. See addenda to this bulletin for a description of elevator keys and tools and instruction for their use.

3.6.2 Passengers of the stuck car can assist in their removal. Direct the passenger of the car to attempt to open the car door by physically exerting pressure toward the open position. If they succeed in opening the car door instruct them to lift the locking arm on sliding hoistway type doors, or to depress or lift the roller on hinge type hoistway doors.

3.6.3 If the elevator has a two speed system, commonly found in buildings over 10 stories, the following procedure may work:

A. If Emergency Stop Button has been activated have passengers deactivate it.

B. Have members in elevator machinery room shut power to the stuck car and turn it on again. 
Note: This is the only circumstance in which the elevator power may be restored by members of this department. If this procedure fails, power must be shut off and members are not to restore power after completion of operations.

C. If the car is to restart it will do so within 10 seconds.

D. Communications must be maintained when attempting this procedure. Passengers and members must be prepared for the sudden movement of the car or car door.

3.6.4 If stuck car is in a multi car hoistway "POLING" can be used to remove the passengers:

A. Have member work from an adjacent car which is nearest the leading edge side of hoistway door of the stuck car.

B. Adjacent car should be positioned to give access to upper portion of the hoistway door to be opened.

C. Have one member remain on the landing at the hoistway door of the stuck car.

D. Member in the adjacent car inserts pole or hook between the striking post and the hoistway door and trips the lock by either depressing the roller or pushing on the locking arm.

1. Hinge type door - Depress the roller.

2. Sliding type door - push up on locking arm.

E. Member on the landing near hoistway door of the stuck car opens hoistway door when the lock is disengaged.

F. Elevator car door is then opened.

3.7 Emergency Removal Procedures

This section outlines procedures which may only be used during an EMERGENCY as defined in section 2.4.2, or when directly advised by an elevator mechanic. Primary and secondary procedures are usually quicker and more efficient than the methods outlined in this section. The decision of what method to use will be based on the size-up of the officer in command.

3.7.1 Power to the stuck elevator must be off when you use Emergency Removal Procedures. This should have been done before trying Secondary Removal Procedures.

3.7.2 An elevator car will have a top hatch or a side exit - sometimes both. One of these may provide a route by which you can remove trapped passengers. 
A. Top Hatch Removal.

Although the law prohibits welding or bolting top hatches shut on elevators, it does happen and it can make this procedure very time consuming.

1. Open a hoistway door or access panel (required in single car blind hoistways) on floor above the stuck car.

2. Provide adequate lighting.

3. Lower a portable ladder to the elevator roof. Use straight ladder if possible. If an extension ladder is used tie the halyard around the rungs of both sections of the ladder. This will prevent the lower section from dropping on to the car roof.

4. Climb down to the car roof. Maximum of two firefighters are to be permitted on the roof of the car at one time.

5. All members working in the shaft are to be secured with a life saving rope.

6. Open the top hatch.

a. This may require the use of a wrench or screw driver.

b. Forcible entry tools may be required.

7. A small portable ladder is lowered into the elevator.

8. One member equipped with a handie talkie enters car. Member in the car must determine the order of removal. Secure each person with a life saving rope.

9. Members are to remain in physical contact with trapped persons while they are being removed.

B. Side Exit Removal.

Useful under conditions of partial power loss in multi car hoistways. It may not be useful where a structural beam blocks a side exit or the rescue car can't be brought level with the stuck car.

1. Members must work from a car that is in the same bank and is adjacent to the stuck car. This will become the rescue car.

2. Bring rescue car even with stuck elevator.

a. If mechanic is present, use his operating key to bring the car level with stuck car. 
3. Remove power to rescue car. Power to the stuck car was previously removed.

4. Open side exit in rescue car.

a. A key or forcible entry is required to open panel from inside the car.

5. Open side exit of stuck car. It is openable by hand from the shaft side.

6. Planks of sufficient lengths ( 6 ' or longer) should be used as a bridge between cars.

7. Member equipped with a handie talkie and secured with life saving rope crosses planks to the stuck car.

8. Member determines the order of removal. Secure each passenger with a life saving rope and assist them to the rescue car.

9. After passengers are removed restore power to the rescue car.

\subsubsection{Forcible Entry}

Forcible entry of hoistway and elevator car doors should only be attempted under the direct advisement of an elevator mechanic or as a last resort during EMERGENCY REMOVAL PROCEDURES. The deformation of the doors and locks may add to the problem and delay the rescue. Upon completion of forcible entry operations have maintenance personnel secure the hoistway door or have police or security warn people of the danger.

Choose one of the following procedures based on the type of hoistway door.

A. Hinged door.

1. Knock out glass panel if present. If not, breach hoistway shaft above hoistway door

2. Push down roller, located near side opposite hinges, on shaft wall.

3. Open hoistway door.

4. Push open elevator car door.

B. Slide type door.

1. Maxi Force Air Bag System.

This is the preferred forcible entry method. It is less likely than the others to push the door off its hangers or out of its track.

a. Take a small purchase with a forcible entry tool. 

ELEVATOR OPERATIONS

b. Place bag between the leading edge of the door and jamb as high as possible to apply a more direct force on the linkage and the locking mechanism.

c. Position the bag to permit the center of the air bag to be as close as possible to the door edge, this increases the spreading capability of the air bag. It may be necessary to have a passenger in the car push open the car door to permit the air bag to obtain a good purchase.

d. Inflate air bag until hoistway door opens.

e. If necessary push open elevator car door.

\section{Rabbit Tool}

a. Use forcible entry tool to gain a purchase for the jaws of the rabbit tool.

b. Insert the jaws of the Rabbit Tool between the jamb and the leading edge of the hoistway door, as high as possible.

c. Ensure that the tool is flush with the hoistway door.

d. Operate tool to open door taking care not to cause the door to come off its track.

e. If necessary push open elevator car door.

3. Forcible entry tools

a. Go to landing directly above door to be opened.

b. Use a forcible entry tool to lift hoistway door out of its guide.

c. Tilt bottom of the hoistway door slightly into the shaft, just enough to allow the passing of a hook into the shaft.

Note: Care must be taken not to tilt the door too much. It may dislodge from hanger and drop into the shaft.

d. Use a hook to reach down to the lock arm mechanism and pull it up.

e. If necessary push open elevator car door.

C. Blind hoistway.

1. Determine the side of hoistway the car door faces.

2. Breach hoistway wall on that side.

3. Push open elevator door. 


\section{ELEVATOR PIT OPERATIONS}

4.1 Elevator Pit Description.

The Elevator Pit is the lowest portion of the elevator shaft.

4.1.1 Types of Elevator Pits.

A. Jump Pits.

1. Usually 4 ' to 6 from lowest landing level to base of pit.

2. Elevator descends to within a couple of feet of the bottom of the shaft.

3. Pit is entered by opening the lowest hoistway door and using a portable ladder.

B. Walk In Pit.

1. Usually 6 ' to $10^{\prime}$ from lowest landing to base of pit.

2. Car descend to the floor level above bottom of shaft.

a. A high buffer and lower limit switch prevent the car from entering the pit.

3. Access to the pit is via a door located at the bottom of the shaft.

a. Door is not required to have an interlock switch.

b. Door is opened by a regular key. Emergency elevator keys are not usable.

4.2 Operations in Elevator Pits

\subsubsection{Jump Pit.}

A. Shut off elevator power switch.

B. Open the lowest hoistway door on shaft.

C. Use portable ladder to enter shaft.

D. For additional safety, trip lower limit switch and secure it in an open position. 


\subsubsection{Walk In Pit.}

A. Shut off elevator power switch.

B. Enter via pit door.

C. If there is a fire in the pit, be cautious of the buffers (A device designed to stop a descending elevator beyond the normal limits of travel), they may be filled with combustible or inflammable liquid.

D. In an EXTREME EMERGENCY (immediate action necessary to save life) entry to a Walk in Pit before the elevator power switch is off may be made using the following precautions:

1. Open a hoistway door on shaft to be entered. The interlock will prevent car from moving

2. Use caution around mechanical and electrical components.

3. Turn off power as soon as possible.

\section{FIREMEN SERVICE}

All Fire Department personnel should be familiar with the operating procedure and limitations of Firemen Service. This section describes Firemen Service components and operational procedures. Section 6.4 outlines use of Firemen Service during fire operations.

5.1 Firemen Service Regulations.

5.1.1 Firemen Service is required in all elevators that serve three or more landings or travel 25 feet or more if plans for the elevator were filed after January 1, 1980.

5.1.2 Firemen Service elevators are required in all buildings classified in occupancy group E whose plans were filed subject to Local Law \#5.

5.1.3 Firemen Service elevators are required in buildings classified in occupancy group E and deemed as an "existing building" under Local Law \#5 if the building is 100 feet or more in height. 
5.1.4 In all buildings classified in occupancy group E, 100' or more in height, the number of elevators that must be equipped for Fire Service is as follows:

A. Where a floor is serviced by three or less elevator cars, every car shall be equipped for Firemen Service.

B. Where a floor is serviced by more than three elevator cars, at least three elevator cars with a total rated capacity of not less than 6,000 pounds shall be equipped for Firemen Service. Such cars shall include not more than two cars which serve all floors, and at least one other car in another bank servicing that floor.

C. If the total load capacity of all cars servicing the floor is less than 6,000 pounds, all such cars shall be Firemen Service. 


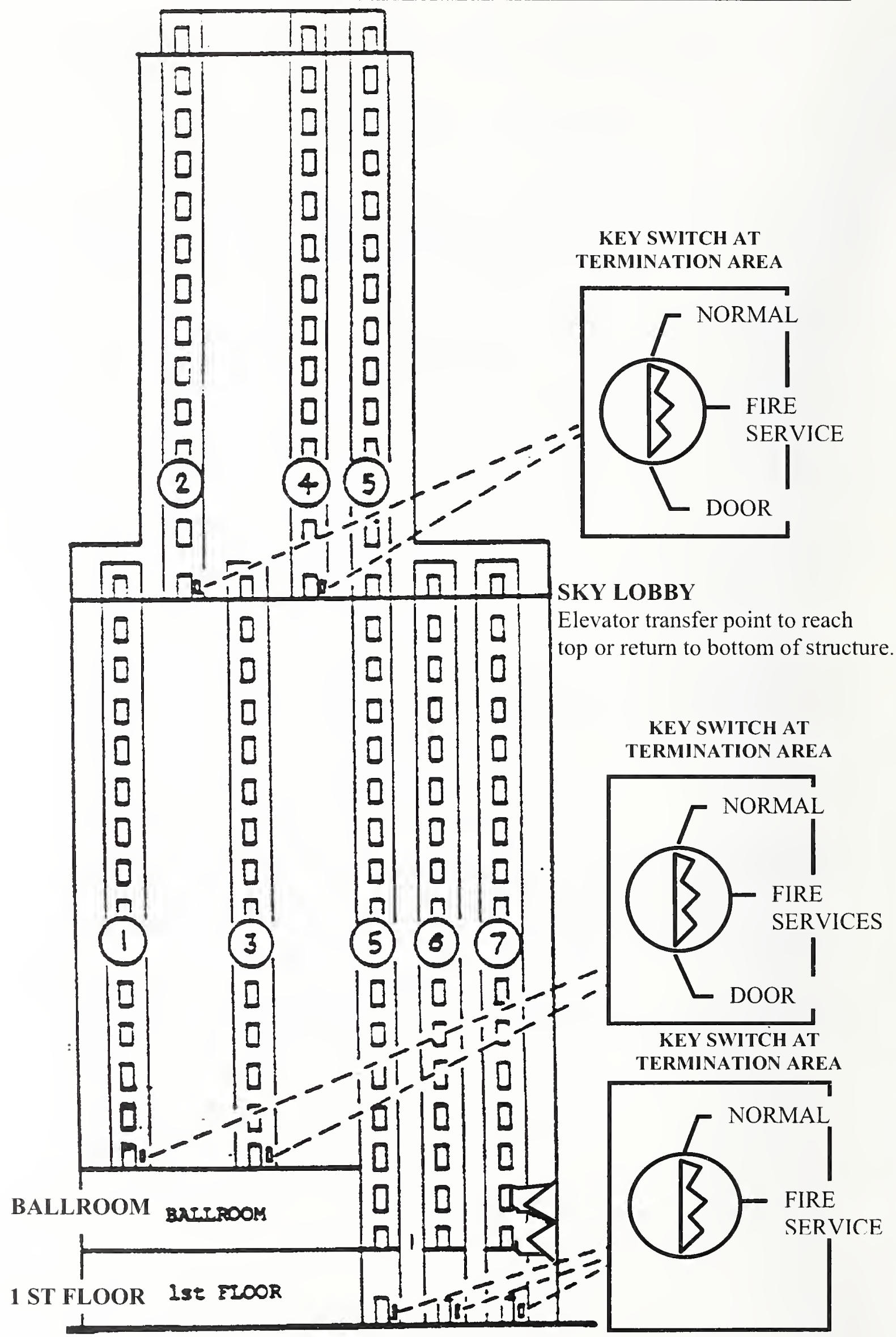

Fig. 1 Elevator Configuration 
Fireman Service Lobby Switch Plates
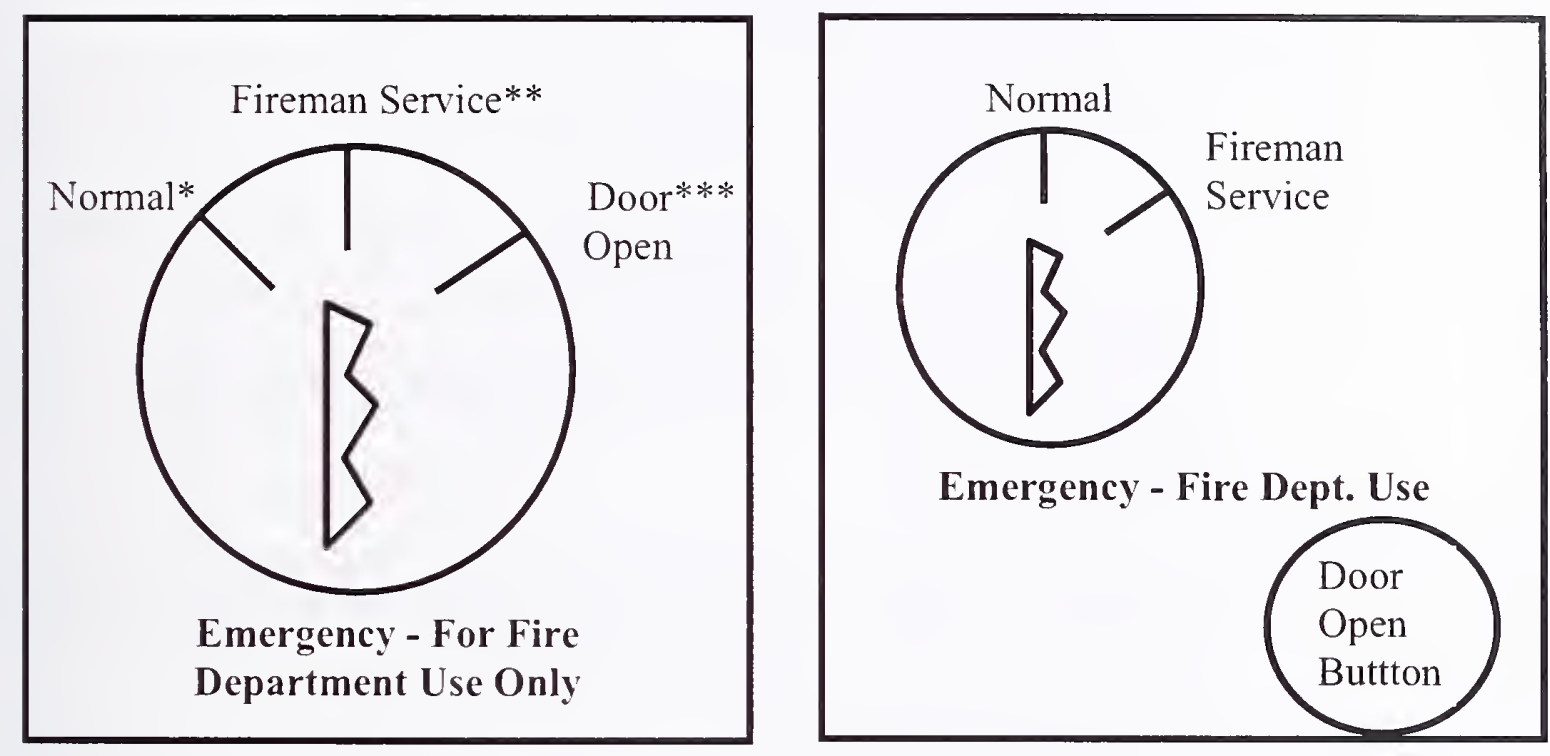
Often Abbreviated as
Off *
On $* *$
DO ***

Fig. 2A

Fig. 2B 


\subsection{Firemen Service Controls.}

\subsubsection{Lobby Keyed Switch.}

A. A switch at the street floor or terminal floor for each bank of elevators. Terminal floor is the lowest landing above the street floor of any elevator that does not serve the street lobby floor, also known as a Sky Lobby. (Fig. 1)

B. The key switch is required to be within 4 feet of the lobby call button.

C. The key switch is operated by use of the Fire Department key, or by city wide standard elevator key.

Note: Worn keys may not work.

D. Switch Configurations.

1. Three position key - Normal, Firemen Service and door open. (Fig. 2A)

2. Two position key - Normal and Firemen Service with a door open button. Door open button is required to be located in the same faceplate as the key switch. Button is only operable when key switch is in the Firemen Service position. (Fig. 2B)

Note: In both situations the cylinder face is approximately $11 / 2$ " in diameter and colored red. Switch faceplate is required to be inscribed "for fire department use only" or similar terminology.

E. The Normal and Firemen Service position in the keyed switch permit the removal of the key. The key is not removable in the door open position.

5.2.2 Elevator Car Keyed Switch.

A. Firemen Service keyed switch is provided inside each Firemen Service elevator car.

B. This switch is identified by red lettering "FOR FIRE DEPARTMENT USE ONLY" and has two positions. Normal and Firemen Service.

Note: Elevators approved for installation after March 1991 are required to be equipped with a three position switch:

\section{NORMAL HOLD GIREMAN SERVICE}

The Hold Position has the following features:

1. Permits the firefighter to remove the key from the switch.

2. Allows the firefighter to leave the car without the danger of an individual, without a key, moving the car to another location. 
3. A firefighter with a key can move the car by changing the switch position from HOLD to FIREMAN SERVICE.

THIS ACTION SHALL NOT BE TAKEN WITHOUT FIRST INFORMING THE FIREFIGHTERS OPERATING ON THAT FLOOR.

4. Elevator cars equipped with a two position switch are not required to be retro-fitted with a three position switch.

C. To operate the car, the switch must be placed in the Firemen Service position while the car is at the landing where the lobby keyed switch is located.

D. The lobby keyed switch must be in the Firemen Service position prior to placing the car keyed switch to Firemen Service.

E. Once the car switch is in the Firemen Service position it can not be overridden by the lobby keyed switch.

F. The key is not removable from the elevator car keyed switch when it is in the Firemen Service position.

\subsection{Operation of Firemen Service.}

\subsubsection{Phase I - Recall Phase.}

The recall of ALL elevators in the bank to the street or terminal floor either automatically or manually.

A. Manual Recall.

By the use of the key at the keyed switches located in the elevator lobby at the street floor or terminal floor.

Note: For elevators whose terminals are above the street floor (sky lobby), a two position keyed switch will be at the fire command station. The switch will allow the elevators to be brought down non-stop to their lowest floor landing. A three position keyed switch will also be at their terminal floor landing.

B. Automatic Recall.

1. Activation of elevator landing smoke detector.

2. Water flow from a sprinkler system. 
Note: If the Firemen Service Phase I was initiated automatically by the activation of a lobby smoke detector or sprinkler water flow, the elevator cannot be returned to normal operation until the smoke detector or water flow alarm has been cleared.

C. Initiating Phase I Recall.

1. If Phase I (recall phase) has not been initiated upon arrival, Phase I shall be initiated and all cars accounted for and examined as they arrive at the street lobby floor.

2. If Phase I has been initiated before arrival and all elevator doors are closed, the following procedure are to be followed.

a. Determine if Phase I was initiated manually or automatically.

b. If Phase I was initiated manually the Firemen Service lobby keyed switch will be found in the Firemen Service position. Place the Firemen Service lobby keyed switch momentarily in the "Normal" (OFF) position. Then returned it to the Firemen Service position. This will cause all elevator car doors in this bank to open.

c. If Phase I was initiated automatically (by lobby smoke detectors or sprinkler water flow), place the lobby keyed switch in the "Door Open" position. The doors of the Firemen Service cars will then open. In some older installations the doors of the non- Firemen Service cars will not open and must be opened by use of the emergency hoistway door key.

D. Results of Initiating Phase I Recall.

1. By placing the keyed switch in the Firemen Service position, all elevators in that bank will be returned to the street lobby or terminal floor.

2. An elevator traveling away from the street floor or from its lowest landing floor will reverse direction at the next landing without opening its doors, and return non-stop to the street lobby or terminal floor.

3. Doors opened at any floor will immediately close and the elevator shall return non-stop to the street or terminal floor.

4. Door reopening devices for power operated doors, which may be affected by smoke, heat or flame so as to prevent door closure, shall be rendered inoperative except for those mechanically activated by a safety edge.

5. "Emergency Stop" buttons will be rendered inoperative. 
6. When the elevator car reaches its terminal floor, one of the following will occur:

a. All car and hoistway doors open. The doors remain open for at least 8 seconds and no more than one minute and then close.

b. All car and hoistway doors open. The Firemen Service elevator car and hoistway doors remain open with the car lights remaining on. Non Firemen Service elevator car and hoistway doors close between 8 seconds and one minute after opening.

c. All elevator car and hoistway doors open and remain open. The car lights in the Firemen Service elevator cars remain on and the lights in the Non Firemen Service cars go off.

Note: Option "c" is required for all installations for which plans were filed after 1980.

Caution: Do not return the switch to the "normal" position at this time.

5.3.2 Phase II - Operational Phase.

The actual operation of the elevator car by use of the controls located within the car.

A. Operations:

1. Place the key in the car Firemen Service switch and turn to the Firemen Service position.

2. Press the car "Door Close" button and select a floor. It is not important which floor button is pressed first.

a. In some elevator cars there may be two floor selection panels. The one to use for Firemen Service is the one nearest to or the one with the Firemen Service keyed switch.

3. As soon as the car begins to move, press the "Call Cancel" button to verify the operation of the "Call Cancel" button.

a. If the car stops at the next available landing in response to the "Call Cancel" button, select the desired floor on the "Floor Selection" panel.

b. If the car does not stop at the next available floor in response to the "Call Cancel" button:

1) Immediately select the next available safe floor. If the car stops at the next available floor, press the "Door Open" button and leave the car. Notify the officer in command that the car is out of service. 
2) If the car does not stop at the next available floor, attempt to stop the car by forcing the car doors open, thus interrupting the interlock relay switch. Notify the officer in command and initiate emergency evacuation procedures.

4. If more than one floor selection is made, the elevator car will stop at the nearest floor selection in the direction of travel.

5. If the car is operating normally when you reach the selected floor, press the "Door Open" button. You must keep your finger on this constant pressure button until the door is fully open, otherwise the door will close on its own. This is a built in safety feature.

6. If the doors open on heat and smoke, the simple removal of the finger from the "Door Open" button should enable the doors to close.

a. If they fail to close automatically, press the "Door Close" button and manually assist the closing.

b. If the car doors still fail to close, don Mask facepiece, evacuate the elevator and proceed to the nearest safe stairway.

7. When the elevator doors have fully opened, the elevator car will remain at the selected floor, with the doors open.

8. The elevator car shall not be returned to the lobby street floor until the officer has determined that the unit has arrived at the proper location.

a. Due to internal building security, it is often necessary to force your way out of an elevator landing area on upper floors. Units may have to force their way from the elevator lobby to a fire stair or fire tower, either for reasons of safety or in order to operate. Someone should stay with the elevator, to see that it is not moved from the floor, until safe access to the fire stair or fire tower is assured.

9. To move from any floor, the "Door Close" button must be pushed, and another floor selected.

10. An elevator can be placed on Firemen Service or taken off of Firemen Service only when the car is at the landing where the lobby keyed switch is located.

11. Once a Firemen Service car has been placed in Phase II operation, it will continue in Phase II operation, regardless of the Position of the lobby keyed switch. This feature may be utilized to restore other cars in the elevator bank to normal operation, while the Fire Department continues to use the Firemen Service car or cars.

12. When an elevator car has been placed on Firemen Service, it shall be operated by a member equipped with a handie talkie and forcible entry tools. 


\subsubsection{Controls for Phase II.}

A. Door Close Button.

1. It is a momentary touch type button.

2. Once fully opened the elevator car doors close only in response to the Door Close Button.

B. Floor Selection Button.

1. When the car is in Firemen Service, the car responds only to the floor selected by the Floor Selection Button in the car.

2. All elevator landing call buttons are rendered inoperable on landings served by this elevator.

C. Call Cancel (reset) Button.

1. The Call Cancel Button allows the operator to change floor selection or direction of travel prior to reaching the original selected floor.

2. When the Call Cancel Button is operated, the elevator car stops at the next available floor landing (i.e., the first floor, in the direction of travel, that the elevator is electrically and mechanically capable of serving). The doors remain closed. A new floor selection must then be made.

3. It is recommended that the Call Cancel Button be pressed whenever a member enters a car on Firemen Service to clear the floor selection panel of any previous floor selection that may have been made.

D. Door Open Button.

1. The elevator door opens only when the Door Open Button is pressed.

2. The Door Open Button must be held until the doors are fully opened.

3. If the Door Open Button is released before the doors are fully opened, the doors return to the closed position. This feature is provided so that the release of the Door Open Button will automatically close the doors in the event the car inadvertently stops at the fire floor.

4. Members leaving the elevator car must verify that the doors are fully opened. If the member leaves the car before the doors are fully opened, the door will close behind him, isolating the car and placing it out of service. 
E. Emergency Stop Button.

1. The Emergency Stop Button is rendered inoperative during the Phase I operation.

2. The Emergency Stop Button should be operational during Phase II operation.

3. Activation of the Emergency Stop Button in Phase II will quickly stop the elevator car.

\section{ELEVATOR OPERATIONS DURING FIRE OPERATIONS}

\subsection{General Procedures.}

6.1.1 Account for all elevators serving the fire floor, checking them for victims.

6.1.2 When it is confirmed that the fire is on the 7th floor or below units should avoid the use of elevators. It is safer to utilize the stairway to reach the fire floor.

6.1.3 Do not use an elevator in a bank which services the fire floor if a lower bank of elevators reaches within five floors of the fire floor.

6.1.4 When it is necessary to use an elevator in a bank which serves the fire floor:

A. If Firemen Service is available, use a car with the Firemen Service feature.

B. Select a floor at least two floors below the fire floor or two floors below the lower level of an access stair in the fire area, whichever is lowest.

6.1.5 A service elevator shall not be used until it is declared safe for use by the officer in command of the fire. Be aware that in many high rise office buildings the service elevators have been converted for Firemen Service. Use of such an elevator must be avoided until declared safe by the officer in command.

6.1.6 Before entering the elevator car, all members shall have donned their mask. The facepiece shall be maintained in the standby position.

6.1.7 There must be a member equipped with a handie-talkie in each car whenever the elevator is in use.

6.1.8 Not more than six members are to be permitted in any elevator car. This precaution is required to prevent overloading.

6.1.9 Forcible entry tools must be carried aboard each elevator car.

A. In the event the car does not stop at the selected floor, a tool may be used to pry the elevator car door open disengaging the car door interlock.

B. In the event the car should become disabled a tool may be needed to extricate the members.

C. Tools may be required if elevator gives access into a secured area. 
6.1.10 Elevator should be stopped every five floors (precautionary stops) to confirm that the elevator will respond to the selected floor. At each stop a new selection must be made.

6.1.11 Before leaving the lobby and at each precautionary stop direct a flashlight up between the elevator car and the hoistway shaft to determine if there is any accumulation of smoke in the elevator shaft.

6.1.12 The relationship of the elevator to the stairway should be noted. This can be accomplished by inspecting the "YOU ARE HERE" sign which is required to be posted at each floor near the call button. This should be done at the first and last precautionary stop. Floor configurations may change.

6.1.13 Determine as soon as possible if the location of the fire could affect the elevator operation.

6.1.14 Members must be careful during any emergency stop. They should prepare themselves for the jolt of a fast moving elevator car stopping abruptly.

6.1.15 If you are in a smoke filled hallway, remember, elevator doors will swing toward you and apartment doors will swing away from you. If the electric interlock malfunctions it might be possible to open the elevator door and not have the car on that floor.

Some elevator doors are of the sliding type. If forced by mistake due to smoke conditions, they may pop inward and be mistaken for an apartment door.

6.2 Affects of Fire on Elevator Components

6.2.1 Mechanical or electrical systems can become affected by heat or water causing erratic behavior of the elevator car.

A. Elevator car may move leaving a hoistway door in open position.

1. Consequences:

a. Injury to operating personnel.

b. Elevator shaft unprotected, possibly indiscernible in a smoke environment.

c. Delay in firefighting.

2. Precautions:

a. During fire operations do not straddle elevator doors to hold the car. Use Firemen Service if available or folded lengths of hose to hold car.

b. If the elevator moves leaving the door open close the hoistway door manually if possible. 
B. Hoistway door warped by heat.

1. Consequences:

a. Interlocking device inoperative.

b. Elevator stalled in shaft.

c. Possibly trapped passengers in car.

2. Precautions:

a. If possible avoid using elevator cars that service the fire floor.

C. Malfunction of interlock of hoistway door.

1. Consequence:

a. Member might be able to open swing type door with no elevator car at landing.

2. Precautions:

a. Feel for floor before moving through door way.

D. General Precaution:

1. In any situation where the elevator operates erratically, exit the car at the nearest safe floor. Place the car out off service, either via the car controls or by blocking the car door. Notify the Officer in Command immediately.

6.3 Firefighters trapped in stalled elevator cars during fire operations.

6.3.1 Operations of Fire Department members in a stalled car.

A. If elevator car door opens on fire floor (heat, smoke), attempt to close the door.

1. Push Door Close Button.

2. Force door closed.

B. Select lower floor.

C. If car fails to move: 
1. Check Emergency Stop Button, it may have accidentally been activated. Deactivate it by pulling it out, or if switch type, moving switch to off position.

2. Open Top Emergency Exit to relieve smoke in car.

3. Keep low in car.

4. If necessary don Mask facepiece. Remember it is important to conserve air.

5. Communicate situation to officer in command.

6. If necessary use side emergency exit for rope slide to the safety of lower floor. Have power removed to the adjacent car if this is to be attempted.

7. In an EXTREME EMERGENCY, Fire Department hose can be used to slide down to the floor below. If more than one length of hose is used, first tie the lengths together, then couple them.

8. Members can be lowered to the hoistway door interlock and exit at the floor landing below the fire.

9. Hose line on the floor below can be used to spray a fog stream between the car and the hoistway door. A 30 degree fog pattern should be used to cool and protect trapped persons during the rescue operation.

6.4.1 Assure the elevators serving the affected areas have been placed on Firemen Service.

6.4.2 When Firemen Service is available use the elevator cars so equipped.

6.4.3 First arriving units should, if possible, initially avoid a Firemen Service elevator which is capable of stopping at all floors. Many of the converted "Service" freight elevators are so arranged, and therefore are capable of being affected by fire on any floor. Only after the officer in command has determined that the fire is not adjacent to the shaft should these elevators be utilized. (Experience indicates that many fires in high-rise office buildings have been found in the service elevator lobby, in piles of collected rubbish. Heat and flame have affected the doors and control wiring of nearby service elevators).

6.4.4 Members shall never take a Firemen Service elevator which services all floors to go above the fire. When assigned to go above the fire via an elevator, choose an elevator which has a blind shaft on the fire floor. Remember a "Firemen Service" elevator is not necessarily a "safe" elevator. It can still be affected by heat, smoke or water entering the shaft. If there is no blind shaft elevator to go above the fire, stairs shall be used. 
Note: Use a fire tower or a stairway other than the attack stair.

6.4.5 There are situations in which units will encounter "exceptions to the rules". Time must be taken to become familiar with particular elevators before leaving the lobby. Early manning by one or more members who have become familiar with the elevators is indicated. Utilize stairs whenever possible, and try to limit elevator use to those in banks that cannot be affected by the fire. Where elevator problems exist, consider calling in elevator company repairmen on emergency duty. Many high-rise buildings have these men on twenty-four hour call, and phone numbers must be posted in the elevator machinery room, and are often posted in the vicinity of the elevator lobby.

6.4.6 If Firemen Service elevators have not been installed in the building, Fire Department operations shall be conducted using elevators that have been placed in the "Manual Mode" if possible. When using elevators in the "Manual Mode" all the applicable sections of this procedural guide shall apply.

\subsection{Operational Considerations}

\subsubsection{Locked Hoistway Doors.}

A. For security reasons, some occupants lock the hoistway door on their floor when closing.

B. If your elevator arrives at the selected floor, but the car door does not open, make no attempt to force it. In this instance, the locked hoistway door, attached via the vane to the elevator car door, is keeping both doors closed. Any attempt at forcing them open may damage the interlock putting the car out of service.

C. If your car arrives at a floor and the car door opens revealing a locked hoistway door, the following considerations must be made:

1. If the hoistway door security lock can be removed or opened with no damage to the door, do so.

2. If removal of the locking device threatens any bending or warping of the door or door buck, make no attempt at removal. Warping or springing of the door assembly may interfere with the car's electrical circuits, putting the car out of service.

D. A preferable method, in both 1 and 2, is to drop down to a floor where exit is possible. Find the stair and move up to the original floor.

Note: In high rise buildings, on the street floor and above, any locks placed on passenger elevator car or hoistway doors must be openable with a key. 
7. BUILDING CODE REGULATIONS EFFECTING FIRE DEPARTMENT OPERATIONS

7.1 Accidents.

7.1.1 The Building Department is required to investigate elevator accidents. Officers in command at such occurrences are to notify the Building Department via the dispatcher.

7.2 Mechanical Features.

7.2.1 The winding drum or traction sheave machinery are required to have a mechanical brake that is applied automatically when the power is removed from the system. The brake shall only release when the power is restored.

7.2.2 A manual power control switch for each elevator is to be located adjacent to, and visible from, the elevator machinery.

7.2.3 A mechanical safety device is attached to the car frame. It will be brought into play when any of the following conditions exist:
A. Car over speed.
B. Car free fall.
C. Slackening of the hoistway cable. Car safety devices will apply with downward motion of the car and may be released by reverse or upward motion of the car.

7.2.4 In automatic cars a transfer switch that puts the car solely under the control of the car operator must be provided. Elevator mechanics and some building service employees have operating keys.

\subsection{Emergency Removal.}

7.3.1 Emergency hoistway door key hole and keys themselves are to be of such a design that inhibits the use of common tools.

7.3.2 In a single car blind hoistway emergency access openings shall be provided at every third floor, but not more than 36 feet apart.

7.3.3 If emergency side exit door is provided it must have the following features:

A. Hinged to open into the car.

B. Locking device that requires the use of a key inside the door.

C. A means of being opened by hand from the shaft side.

D. Line up with the door of adjacent car.

E. Be within 3 feet of the adjacent car side door. 
F. An electrical door contact that will prevent motion of the car when the door is open.

\subsubsection{Top Emergency Exit.}

A. Cars installed under the 1938 Building Code.

1. Top hatch required in all cars.

2. Opens outward.

3. Designed to unlock by thumbscrew from inside and outside of the car.

Note: To prevent access to the car roof by juveniles and vandals many have been bolted closed in the interest of safety.

4. May have a contact power switch.

B. Cars installed under the 1968 Building Code.

1. Top hatch required in all cars.

2. Opens outward.

3. Not required to be openable from the interior of the car.

4. Openable from exterior, wrench or screwdriver usually required.

5. May have contact power switch.

6. May be concealed by grill work, lights, mirrors or other decorative finish. 


\section{ELEVATOR TERMS AND DEFINITIONS}

Alarm button (switch) - Button (switch) in elevator car which activates the alarm bell.

Car Door - Elevator car door.

Car Door Contact - An electrical device used to prevent the operation of the car unless the car door is in the closed position.

Car Safeties - Stop car in the event of an emergency. Controlled by car governor.

Counterweights - Used to counterbalance the weight of the elevator car.

Elevator Car Selector - Panel inside car containing emergency stop button, alarm button, door open button, floor selection buttons and Firemen Service key switch if required.

Elevator Control Panel - A visual display unit located in the lobby which indicates the status and location of all elevator cars and the necessary controls for the operation of the cars. Common in High-Rise buildings.

Elevator Door Vane - The connection between the elevator car doors and the hoistway doors. It allows the elevator car door to drive the hoistway door.

Elevator Machinery Room - Area where the equipment that raises and lowers the elevator is located. Usually located at the top of the shaft, machinery room may also be found at shaft bottom or two floors above the highest floor serviced by the elevator.

Elevator Motor - Turns winding drum raising and lowering elevator car.

Emergency Stop Button - Elevator car button which when activated cuts power to car and sounds alarm bell. Note: Do not rely on this button, elevator power switch must be used to insure motor power is off.

Emergency Escape Ladder - On the top of some elevator cars used to assist in top hatch removal operations.

Emergency Exit - Side door of a car in multi car hoistways.

Final Lower Limit Switch - A switch located in the elevator pit which prevents the elevator from descending too low in the shaft. When tripped by elevator it cuts the power to elevator motor. Acts as a backup to lower limit switch.

Firemen Service - A feature required in many elevators which enables the department to gain control of the elevators 
Floor Call Button - Located at elevator floor landing, used to call car to the floor when service is desired.

Floor Selector - Located in the machinery room can be used to determine the exact location of the elevator.

Governor - Regulates elevator car speed. Also engages car safeties and shuts off electrical power in the event of free fall or over speed.

Governor Rope - A wire rope or cable which travels with the car. If engaged by the governor it mechanically activates the car safeties.

Hoistway - The shaft the elevator moves in. Types: Single car (local service), multi car (local service), single car blind (express service), multi - car blind (express service).

Hoisting Cable - Cable (cables) used to raise and lower the elevator.

Hoistway Door - door leading from landing to elevator shaft.

Interlock - A switch on hoistway door, and some emergency exits that will prevent the elevator from moving when in open position.

Limit Switch - A mechanical electrical device which is located at the top or bottom of the shaft. Its purpose is to prevent over extension of elevator car in an upward or downward direction.

Lower Limit Switch - A switch which stops the car in pit area, below lowest landing.

Main Electrical Power Switch - Located in machinery room, each switch controls the operation of one elevator.

Terminal Landing - lowest landing for discharge of passengers, may be at ground floor or above in which case it is known as a Sky Lobby.

Traction Sheave - Free turning pulley for elevator cables.

Ventilation Opening - "Smoke hole" - opening providing for the movement of air in the shaft caused by the movement of the elevator.

\section{BY ORDER OF THE FIRE COMMISSIONER AND THE CHIEF OF DEPARTMENT}




\section{Appendix E \\ AIR SUPPORT PLAN - HIGH RISE FIRES}



Air Support Plan High Rise Fires AUC 269

Reproduced with permission of The Fire Department of the City of New York 


\section{INTRODUCTION}

1.1 In recent years, several high-rise fires have occurred throughout the world at which occupants became isolated from fire forces when they fled to the roof. Due to the media attention given to these events and the spectacular nature of helicopter evacuation, it can be anticipated that at future high-rise fires, people will ignore fire department advice and flee to the roof. Roof evacuation by helicopter is both hazardous and time consuming. Therefore, it shall only be undertaken as a last resort, and only upon the direction of the Fire Department Incident Commander (IC). However, large numbers of people on the roof cannot be ignored and the possibility exists that a helicopter approach may be the only access available.

At high-rise fires in which people were evacuated via helicopter, operations took a great deal of time, and presented an unwarranted risk to the rescuers and evacuees. FDNY observers who visited the scene of these fires concluded that evacuation was unnecessary since the people on the roof were never in any immediate danger. On the other hand, many of the fatalities at these fires were people who suffered smoke inhalation in the halls and stairwells while attempting to reach the roof. Had fire personnel been airlifted, ventilation and search of the stairwells and halls could have been effected. In order to address this problem, a plan to provide helicopter capabilities at high-rise fires has been developed in conjunction with the New York City Police Department.

\section{DESCRIPTION OF THE AIR SUPPORT PLAN}

\subsection{Objectives:}

2.1.1 Provide FDNY with the capability to place fire personnel on the roof of high-rise buildings, otherwise inaccessible due to fire conditions for the purpose of ventilation and search.

2.1.2 Control, comfort and direct people who view themselves as trapped and remote from help.

2.1.3 Provide the lobby command post with intelligence on roof conditions.

2.1.4 Evacuate persons in need of immediate medical attention.

2.1.5 Provide the capability to evacuate the roof as a last resort.

2.2 The plan is divided into three phases:

ALERT: Notification is made by the Manhattan Fire Department Dispatcher direct to the Police Aviation Unit upon transmission of a third alarm for a fire in a high-rise building. 
ASSEMBLE: Fire Department units, Police Helicopters and Rappelling Team are assembled at a selected mobilization point.

AIRLIFT: Air Support Teams are airlifted to the vicinity of the roof of the fire building, pending the decision of the IC to actually land members on the roof.

2.3 Criteria For Use:

2.3.1 The decision to "Assemble" rests with the IC at the fire. The conditions under which Assembly may be ordered are generally, but not limited to:
A. Fire located above 10th floor in a high-rise building.
B. Access to the roof limited to exterior of building, via helicopter.
C. Fire in possession of two or more floors.
D. Interior access routes above fire blocked.

2.3.2 The decision to "Airlift" may be made only by an IC who is at the staff officer level.

2.3.3 If the decision is made by the Fire Department IC to utilize the High-Rise Support plan the operation shall be in conformity with guidelines contained in this document. This decision rests with the Fire Department IC until fire operations are completed.

\subsection{Mobilization Points:}

In the event of a major high-rise fire in the midtown area, most 3rd Division units will be engaged and streets in the midtown area are likely to be clogged with traffic. Similarly a high-rise fire in lower Manhattan, will involve most 1st Division units. For this reason, two high-rise helicopter mobilization points have been selected, each with a different High-Rise Roof Chief (HRRC) and different High-Rise Roof Teams (HRRT).

\subsubsection{High-Rise Fire South of 23rd Street:}

$\begin{array}{ll}\text { Mobilization Point } & \text { E. 34 St. Heliport. } \\ \text { HRRC's } & \text { Battalion 8, 9 } \\ \text { HRRT's } & \text { Ladder Co. 2, 7, 21 }\end{array}$


2.4.2 High-Rise Fire North of 23rd Street:

Mobilization Point Wall St. Heliport

HRRC's Battalion 1, 4

HRRT's Ladder Co. 6, 10, 15

2.4.3 For fires in high-rise buildings in other parts of the City, the selection of a mobilization point will be determined by the Manhattan Supervising Dispatcher.

\section{PERSONNEL AND EQUIPMENT INVOLVED}

\subsection{High-Rise Roof Chief (HRRC) Duties}

3.1.1 Upon order to "Assemble", respond to the designated mobilization point and rendezvous with the Police helicopters and Rappelling Team.

3.1.2 Obtain the following information through the Dispatcher while responding to the mobilization point:
A. Command channel
B. Tactical Channel for HRRT
C. Identification of Attack and Evacuation Stairs
D. Identification of the stairs that lead to roof

3.1.3 Notify the IC of the fire through the dispatcher when the High Rise Roof Teams, the Police helicopter/s and the Rappelling Team are assembled at the mobilization point.

3.1.4 Insure that HRRT's are on the proper handie-talkie channel prior to lift off.

3.1.5 Monitor both the Command channel for contacting the Lobby Command Post and the Tactical channel for communications with the HRRT. To accomplish this, it will be necessary to take the Battalion firefighter's handie-talkie.

3.1.6 If hardwired communication is established (warden phone, standpipe phone, telephone) use an HRRT member to assist with communications.

3.1.7 Be equipped with SCBA (Self-Contained Breathing Apparatus) and clipboard.

3.1.8 The HRRC's Battalion firefighter will remain at the mobilization point to provide security for the Battalion car and HRRT apparatus. 
3.1.9 The HRRC's Battalion firefighter must obtain keys to both HRRT apparatus. If additional equipment is needed a helicopter will return to the mobilization point to transport it. The Battalion firefighter will monitor the department radio for instructions.

3.1.10 Upon the order to "Airlift", the helicopter will fly the HRRC and Rappelling Team to the fire building where the HRRC will make observations from the air and advise the IC to the need and advisability of a roof landing. If the IC orders a roof landing, the Police personnel will rappel and gain control of building occupants on the roof, prepare the roof for landing and guide the aircraft to land. The HRRC will advise the IC of the need for fire personnel on the roof. If the IC authorizes the placing of Fire Department personnel on the roof, a second helicopter will land the HRRT and the high-rise roof kit (HRRK). The HRRC will be in command of roof operations. If necessary, an additional HRRT can be airlifted to the roof.

3.1.11 Battalions $1,4,8 \& 9$ have been trained as HRRC's. If they are unavailable, any battalion may be selected.

\subsection{High-Rise Roof Team (HRRT)}

3.2.1 An HRRT consists of a ladder company made of an officer and five firefighters. Upon the order to "Assemble", the Manhattan Dispatcher will notify two HRRT's to respond to the designated mobilization point. The HRRC will designate units as primary and secondary HRRT. The primary HRRT will load the HRRK aboard the second helicopter and board the aircraft.

3.2.2 Upon the order to "Airlift", the primary HRRT will fly to the fire building and remain airborne in the vicinity of the fire building until landing is authorized by the IC via the HRRC or directly from the Command Post. Upon landing, they will operate under the HRRC. The secondary HRRT will remain at the mobilization point and await orders.

\subsection{High-Rise Roof Kit (HRRK) See Fig. 1}

3.3.1 Due to space and weight considerations aboard the helicopter, the only tools and equipment included in the High-Rise Roof Kit are:
A. 6 SCBA with 1 hour cylinder
B. 1 Bolt Cutter
C. 2 Halligan Tools
D. 2 Axes
E. 2 Search Ropes
F. 1 Rabbit Tool

3.3.2 Only these tools are to be brought to helicopter operations.

3.3.3 Tools shall be stowed on helicopter as per directions of Aircraft Commander. 


\subsection{NYPD Aviation Bureau}

3.4.1 Under normal conditions, it can be anticipated that a time span of 30 to 40 minutes can be expected between the order to "Assemble" and pickup of fire personnel at the mobilization point. This time lag should be given consideration in the strategy of Incident Commanders at high-rise operations.

3.4.2 If two helicopters are available, the first will carry the HRRC and the Police Rappelling Team. The second will carry High-Rise Roof team. If only one helicopter is available, it will return to the Mobilization Point to pick up the HRRT after depositing the HRRC and the Rappelling Team on the roof.

3.5 N.Y.P.D. Emergency Service Division

The Police Emergency Service Division provides two important components of the Air Support Plan: A Command Post Communication Liaison and a Rappelling Team

3.6 Command Post Communication Liaison

3.6.1 Upon order to "Assemble", the nearest available emergency service radio car will be dispatched to the fire building. Their portable Special Operations Division (SOD) radio will be used in the Lobby Command Post to provide the Incident Commander (IC) of the fire with direct communication with the helicopter and the Rappelling Team on the roof.

3.6.2 Police Aviation will provide a radio headset in the helicopter for the HRRC to monitor the SOD channel.

3.6.3 One member of the Rappelling Team with a SOD radio will remain with the HRRC on the roof to act as a communicator with the helicopters and as a backup communication link with the Lobby Command Post.

3.7 Rappelling Team

"Rappelling" is defined as the "activity of lowering oneself by means of ropes onto a designated target". The duties of the Police Rappelling Team at a high-rise fire are as follows:

3.7.1 Control, comfort and direct persons who have fled to the roof. Until order is established, the helicopter cannot land for fear that people may rush to the aircraft causing injury to themselves or disability to the craft.

3.7.2 Preparation of the roof for helicopter landing.

3.7.3 First Aid - Tend to the immediate medical needs of people on the roof, freeing fire personnel for ventilation and search. 
3.7.4 Ground Crew for Helicopters - the Team leader acts as landing officer, directing the helicopters to the landing site. Team members will also direct persons on and off the aircraft.

3.7.5 Communications - Provide communications for HRRC as per sec. 3.6.3

\section{HIGH-RISE ROOF KIT}

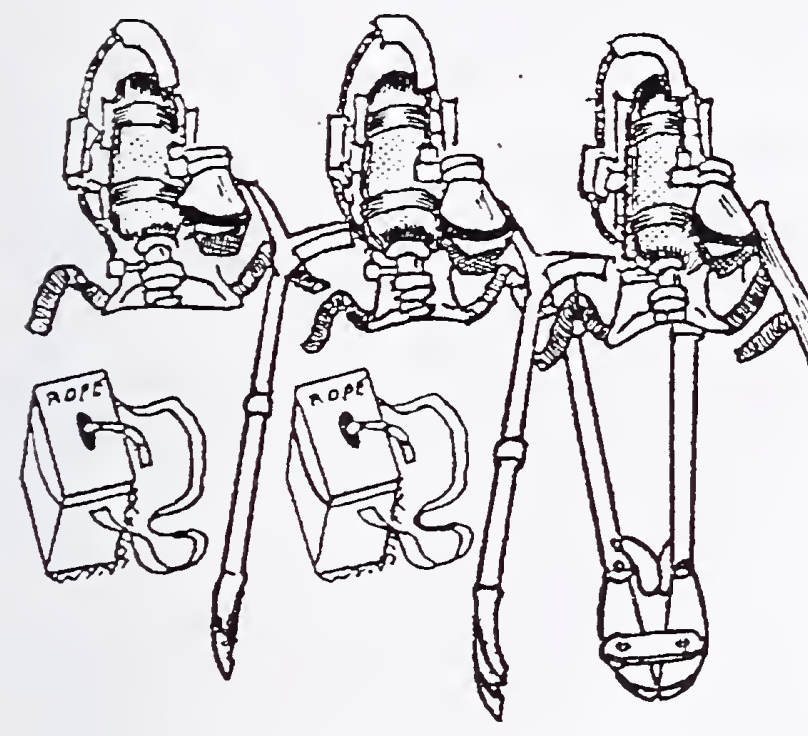

$6 \operatorname{SCBA}$ ( 1 HR. CYL. )

2 AXES

2 HALLIGAN TOOLS

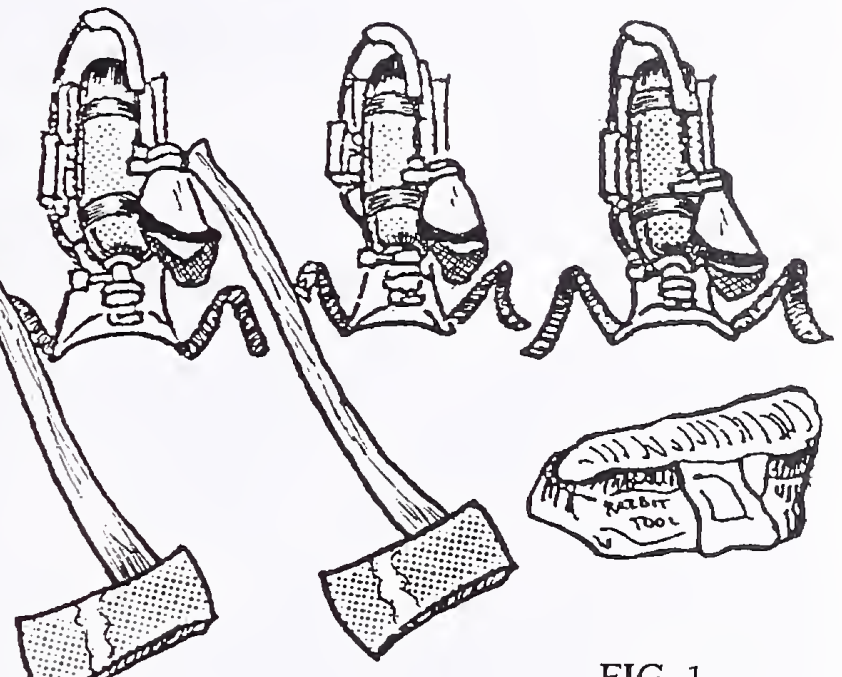

FIG. 1
2 SEARCH ROPES

1 BOLT CUTTER

1 RABBIT TOOL

\section{AIR SUPPORT PLAN OPERATIONS}

4.1 Alert Phase

Upon receipt of a third alarm for a fire in a high-rise building the Manhattan Fire Department Dispatcher will contact the Police Aviation Unit.

The purpose of the "Alert" phase is to allow the Police Aviation Unit time to prepare for Air Support Operations.

There will not be any movement of Fire Department personnel in this phase.

\subsection{Assemble Phase}

4.2.1 The IC at a high-rise fire will give the order to "Assemble" via Manhattan Dispatcher. 
4.2.2 The Manhattan Communications Office will:

A. Notify the Police Dispatcher via Police City-Wide radio of the fire and to "Assemble" the Air Support Teams, at the proper mobilization point. (Sec. 2.4) Follow-up notification will be made by phone.

B Have the designated HRRC and HRRT respond to the mobilization heliport, or provide units if they are unavailable. This information must be transmitted to the Command Post at the fire building.

C. Obtain information required in Section 3.1.2 and relay to the HRRC.

4.2.3 The Police Operations Division will notify the Aviation Bureau and the Emergency Service Rappelling Team to respond to the mobilization point.

4.2.4 An Emergency Service radio car will be dispatched to the Fire Department Command Post at the fire scene for use of the SOD radio.

4.3 Airlift Phase

4.3.1 Upon the order to "Airlift," units at the mobilization point will proceed via helicopter/s to the vicinity of the roof of the fire building, pending the decision of the IC to actually land members on the roof.

4.3.2 Operate in accordance with orders received from the Command Post and with applicable sections of this circular.

\section{SAETY}

5.1 All Department personnel must observe the following safety rules:

5.1.1 Approach and leave the helicopter only within the field of vision of the pilot and only from the front. (See Fig. 2).

5.1.2 Do not approach the tail section under any circumstances.

5.1.3 Approach and leave the aircraft in a semi-crouched position. Do not run.

5.1.4 Raise nothing above the head in the vicinity of the helicopter.

5.1.5 Each member will carry his/her mask and assigned tools to the helicopter. There must be no unnecessary movement in the area of the helicopter.

5.1.6 When loading HRRK, one member will enter the cabin and stow the equipment as it is passed to him/her. 


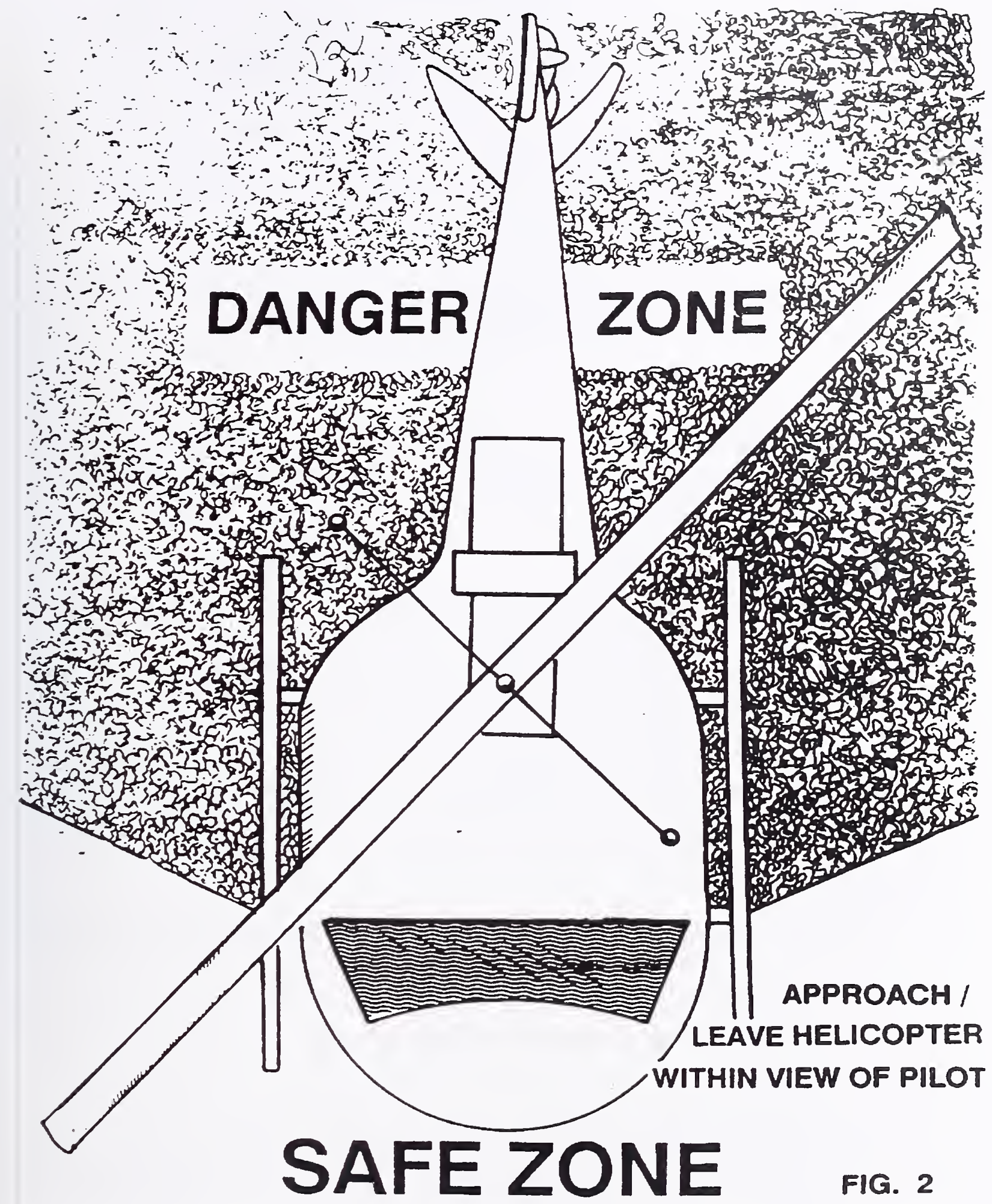


5.1.7 Riding positions on the helicopter are designated by the Aircraft Commander.

5.1.8 Do not step on or place tools on or near the rubber pontoons of the helicopter.

5.1.9 Leave the helicopter only when directed by the pilot or co-pilot.

5.1.10 Be alert for other helicopter landings and takeoffs.

5.1.11 Due to unpredictable effect of ventilation in high-rise buildings, interior stairs or shafts must not be vented unless ordered by the IC of the fire.

5.2 The HRRT Officers' prime function during loading and unloading of the of the helicopter is to maintain direct control over the movement of his/her members.

The HRRT officer will:

5.2.1 Approach the helicopter after receiving the signal from the pilot.

5.2.2 Maintain a position alongside the helicopter at the rear of the compartment door.

5.2.3 Control approach of members.

5.2.4 Supervise loading/unloading.

5.2.5 Be the last one to board and the first to leave helicopter.

5.2.6 Monitor handie-talkie during flight.

5.2.7 Maintain same position by door during unloading.

5.2.8 Control route of members leaving helicopter.

5.2.9 Select an "assembly" area near bulkhead or other roof projection away from landing area, and have members proceed immediately to it.

\section{PRORAPIINTENANE}

6.1 The Manhattan Borough Commander is the PROGRAM OFFICER and is responsible for:

\subsubsection{Liaison with the N.Y.P.D.}

6.1.2 Condition of all equipment required for the program.

6.1.3 Training.

6.1.4 Notifying the Bureau of Operations when major drills are planned.

6.1.5 Forwarding reports when items requiring the attention of the Chief of Operations surface. 


\author{
Appendix $F$ \\ APPROVEd SAFETY BULLETIN 67 \\ APPROVED RIDING POSITIONS ON APPARATUS
}


Approved Safety Bulletin 67 Approved Riding Positions on Apparatus Reproduced with permission of The Fire Department of the City of New York 
1. Prior to the establishment of a riding position policy in November 1971, falls from a moving apparatus were averaging one a month. This number his been reduced; nevertheless five members fell from an apparatus in the year 1981 and four members have fallen in the first nine months of 1982.

2. Vehicular accident records of this Department indicate that the location of members on moving apparatus can be the difference between a safe trip or serious injury and even death. Choice of riding location has been an important factor in cases where the apparatus has hit a bump or depression in the road, made a sharp or unexpected turn, or was involved in an accident.

3. This bulletin classifies and illustrates riding positions in order to provide safer transportation of members. At the start of each tour, officers shall select riding locations commensurate with the number of members working, and assign each member a location. (See Pages 4 and 5, Examples of Riding Positions).

Officers shall enter each member's location on "Riding List" (BF 4). Responsibility for enforcement rests on the officer, and responsibility for compliance rests on the individual member.

4. Bearing in mind that an enclosed, seated, belted position is the safest location while riding an apparatus, officers shall assign these positions first. The officer then assigns positions in a descending order of priority. Ex.: 1. Enclosed, seated, belted position; 2. Seated, belted position; 3. Standing - side positions/ with restraining devices; 4 . without restraining devices.

The rear step of the apparatus is never to be used as a riding position. Its sole function is to load and unload hose.

5. Members assigned to standing locations must maintain a firm grip at all times with both hands. If vertical hand rails are used, members should buttress themselves by using a second hand hold with their other hand. Remember, members must hold on with both hands...they are not to break their grip (to don clothing, reach for a tool, or change locations) while the apparatus is moving. Members must accept their personal responsibility to protect themselves to the greatest degree possible. When gates or guards are provided on side standing locations, they must be in place for proper protection. 
6. Under no circumstances shall members sit on battery box, running board, steps, or turntable. Only designated seats, or other approved locations, shall be used. Where seats are provided, they shall be used.

7. The major part of the responsibility for falls from apparatus and resultant injury rests with the member who fell. Each member must recognize and accept this responsibility. Each individual member must take steps to prevent himself from falling from a moving apparatus.

8. Reasons for such falls have been:

1. Sitting on turntable, or battery box.

2. Not prepared for unexpected turn.

3. Holding on to portable ladder which worked loose.

4. Changing position of hands on straps or other hand holds.

5. Apparatus making a turn or sudden stop.

6. Reaching for a tool, mask, etc., before fire apparatus had stopped.

7. Moving while apparatus is traveling.

8. Donning fire clothing while apparatus is in motion.

9. Not using available seat belts.

10. Loose grip on hand rails.

11. Lack of communication between Officer, chauffeur, and members riding, when apparatus stops and suddenly starts moving, catching members off guard.

Note: A recent court case (New York State Court of Appeals) indicates that failure to use a seat belt is a factor which may be considered in compensating accident victims.

BY ORDER OF THE FIRE COMMISSIONER AND THE CHIEF OF DEPARTMENT 


\section{DEFINITIONS}

OFF

$\mathrm{CHAU}$

TILL

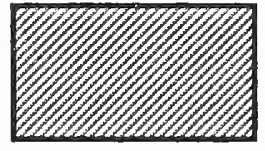

$\mathbf{L}$

$\mathbf{R}$

C

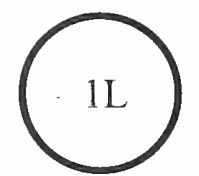

$3 \mathrm{R}$
RIDING LOCATION OF OFFICER

RIDING LOCATION OF ECC AND/OR QC

RIDING LOCATION OF TILLERMAN

INDICATES AREA OVERHEAD IS COVERED

INDICATES LEFT SIDE OF APPARATUS

INDICATES RIGHT SIDE OF APPARATUS

INDICATES CENTER SEAT

NOTE: Numerals in circle, in front of letters " $L$ " or " $R$ ' indicate priority. (Unless otherwise indicated.)

EXAMPLES:

Indicates first priority and left side of apparatus

Indicates third priority and right side of apparatus 
Example Of Pumper Riding Positions

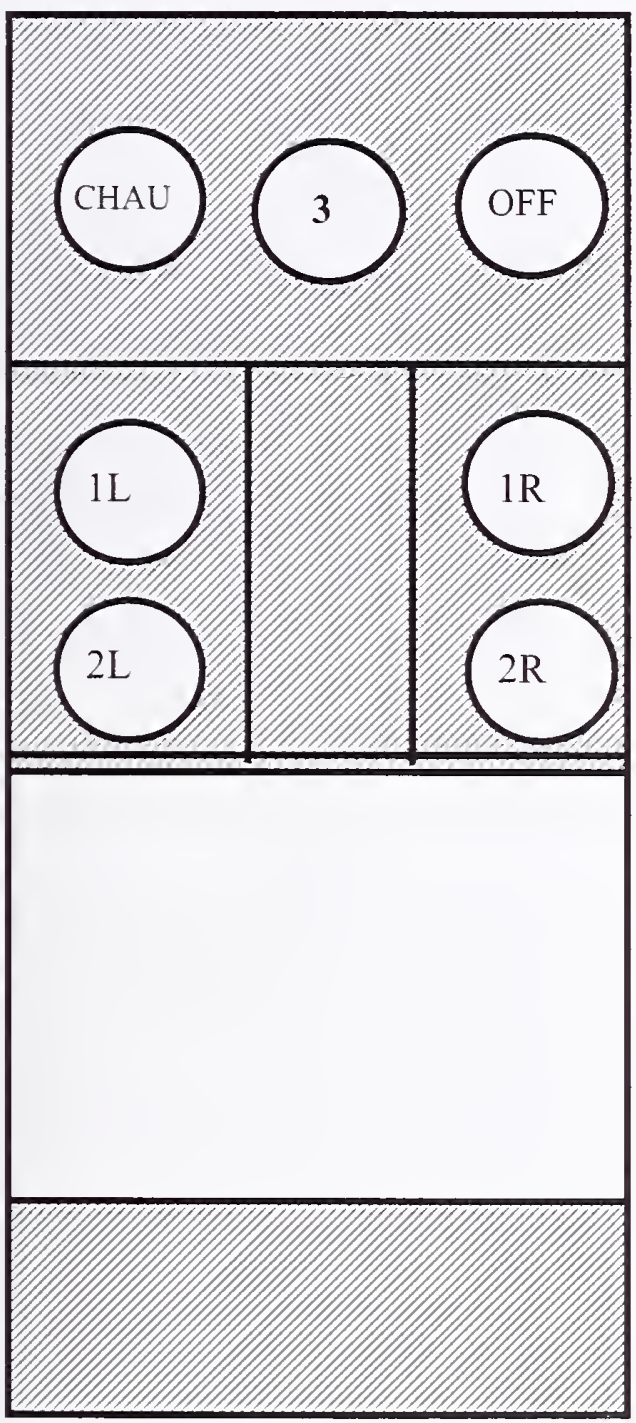

Example of Ladder Riding Positions (Tiller Type)

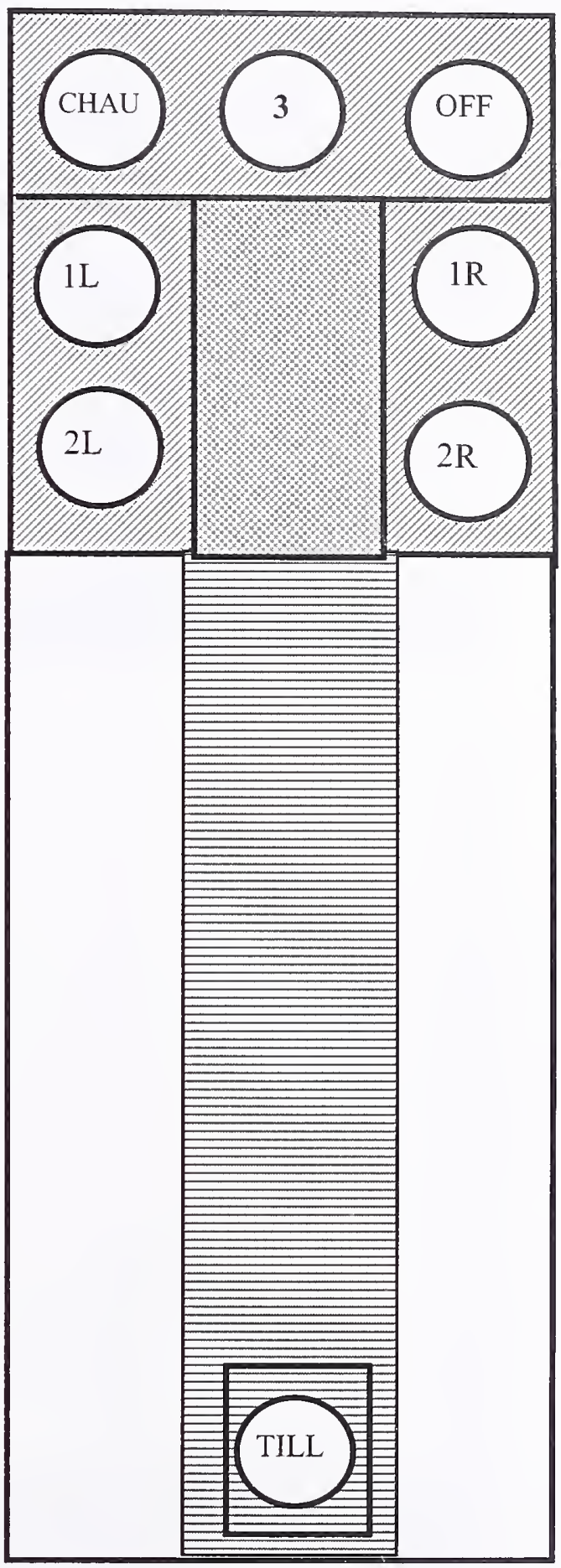


FDNY

December, 1982
DCN: 1.07 .03

APPROVED RIDING POSITIONS ON APPARATUS
Example of Ladder Riding Positions (Rear Mount)

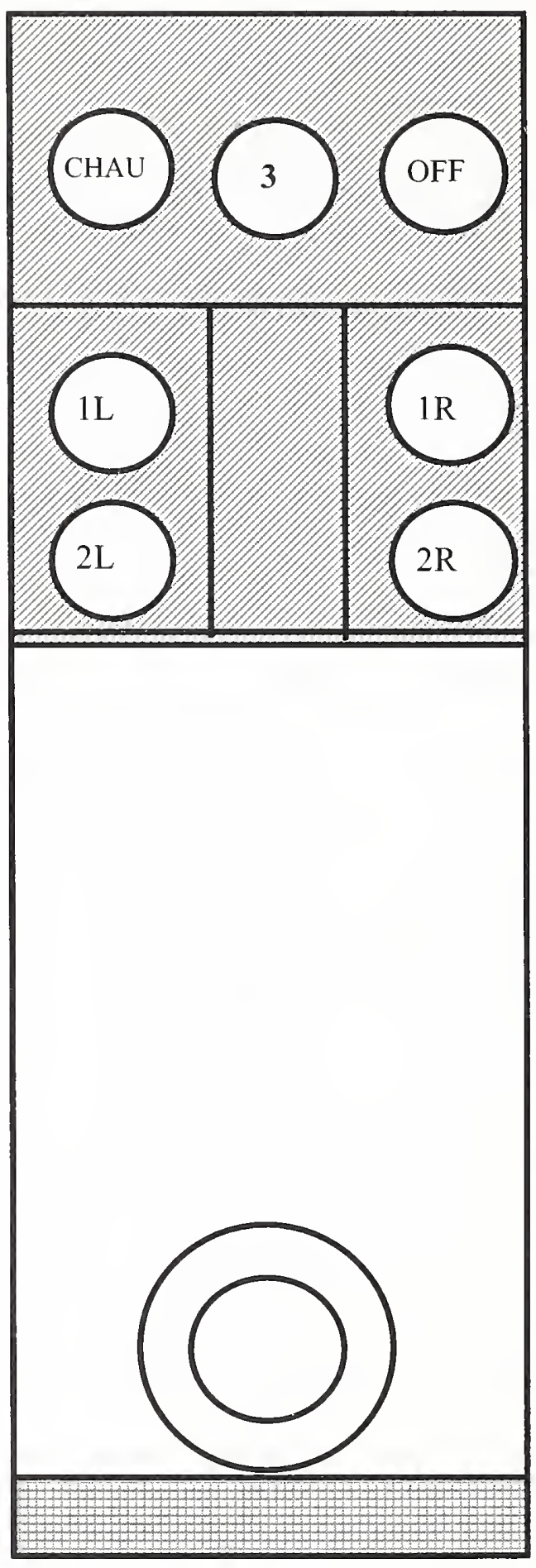

Note: It is absolutely prohibited to ride on rear step.

\section{Example of Ladder Riding Positions}

(Tower Ladder)

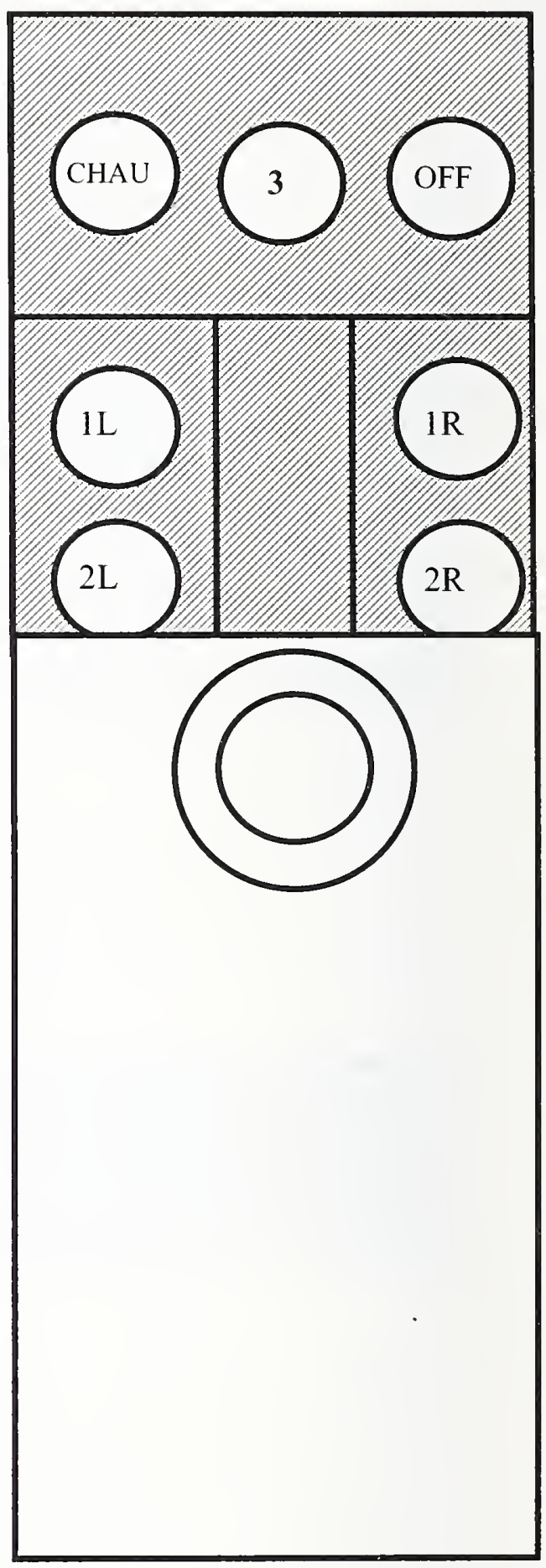


Appendix G

Training Bulletin Tools 22 Portable Command Post 


\section{Appendix G}

Training Bulletin Tools 22 Portable Command Post

Reproduced with permission of The Fire Department of the City of New York 


\section{INTRODUCTION}

The Portable Command Post will assist the Incident Commander in efficiently executing the responsibility of incident management.

The Portable Command Post (PCP) will be carried in the division vehicle. Deputy Chiefs shall utilize the PCP at fires, emergencies and other incidents here its deployment will assist in the operation.

\section{ADVANTAGES}

2.1 Establishes a Fire Department Command presence at the scene.

2.2 Serves as a physical focal point for incoming Fire Department Units as well as other agencies reporting to the operation.

2.3 Provides a convenient means of direct radio communication with the Borough Communications Office.

2.4 Facilitates the recording of the location and status of Fire Department units.

2.5 Facilitate the recording of the ranking official present from other agencies.

2.6 When manned by an aide, the Incident Commander will be freed from the distraction of units and agencies reporting in to the operations.

2.7 Satisfies federal regulations regarding the establishment of a Command Post.

2.8 Provides own light for viewing and recording information.

2.9 Improve safety by promoting accountability of personnel, efficient use of resources and tactical planning.

2.10 As a visual aid the PCP will assist Incident Commander in assigning chief's area of responsibility. 


\subsubsection{Radio}

A. Motorola max trac

B. 25 Watt

C. 6 Channel

1 - Citywide

4 - Manhattan

2 - Queens

D. Antenna

3 - Brooklyn

5 - Bronx/Staten Island

6 - Not in use

- Magnetic base

- Place on a ferrous metal object.

Caution: Antenna must not be placed on Portable Command Post or within 3' of people.

3.1.5 Power supply compartment (Figure 3)

A. 12 volt maintenance free lead acid battery. Operational time averaging between 3 - 4 hours.

B. Charging plug

C. Wiring and terminal blocks

D. Micro switch which stops battery from charging when case is closed.

3.1.6 Rain shield - clear plastic attaches to top and bottom portions of case with velcro strips. Keeps PCP dry preventing icing on surfaces and running of dry markers.

3.1.7 Command Post Flag (Figure 3) - orange flag which fits in hole in top right-hand corner of case.

3.1.8 Light (Figure 3) - turn off when not in use to conserve battery.

3.2 Power pack (Figure 3) - battery charger with special plug which permits its use only with PCP.

3.2.1 Charger fed by 110 volt service and supplies 12 volts of DC current to PCP power plug.

3.2.2 PCP is supplied through charging plug located on left side lower portion of case.

3.2.3 Power pack should always be taken to location of the PCP. Necessary preparation should be made to permit its deployment.

3.2.4 Power pack is to be used during extended operations or if PCP battery is low.

3.2.5 Unit fits on the leg rails of the PCP. There it will be approximately 4" above the ground protected from runoff. Case will provide some protection from rain and stream spray. 


\subsection{Stand - (Figure 3)}

3.3.1 Consists of folding aluminum legs which pivot at the center and nylon straps used to support the PCP case.

\section{LOCATION}

The following guideline are to be used in selecting site for PCP placement.

4.1 Where possible location should afford the Incident Command with a good view of operation.

4.2 Clearly visible to incoming units and other agencies.

4.3 Avoid loud noise areas such as a location adjacent to operating pumper or tower ladder.

4.4 Avoid areas likely to be sprayed with stream.

4.5 Avoid area likely to be disrupted by expanding operations.

4.6 When practical locate PCP near a vehicle or apparatus which would permit mounting of radio antenna.

5. SETTING UP PCP (Figure 3)

5.1 Place stand on firm flat surface.

5.2 Place PCP case on stand, open case and lock hinge arms.

5.3 Place magnetic base antenna on ferrous metal such as vehicle or apparatus.

5.4 Turn on light if necessary.

5.5 Turn on radio, insure it is set to Borough of incident's location.

6. USING PCP

6.1 Draw diagram of incident on horizontal surface.

6.2 Take appropriate unit identifier from vertical surface and place them on diagram according to location and duties assigned.

6.3 Utilize PCP radio for transmitting reports. 


\section{PRECAUTION}

7.1 Antenna is not to be placed on portable Command Post.

7.2 Keep antenna at least 3 ' from people.

7.3 P C P lid must be open while charging its battery to prevent hydrogen build up and possible explosion.

7.4 Do not overcharge battery.

7.5 Portable Command Post could be blown over by high wind. During windy conditions, if unable to find appropriate sheltered area, position PCP to avoid wind from striking post from the operating side.

7.6 P C P will be carried in a secure place in the vehicle. If necessary protect it from damage caused by movement.

8. MAINTENANCE

8.1 Test radio weekly

8.2 Charge battery one hour per week and after each use.

8.3 Arrangements for repairs shall be made through the Bureau of Fire Communications. 
Figure 1

Vertical Magretic Surface

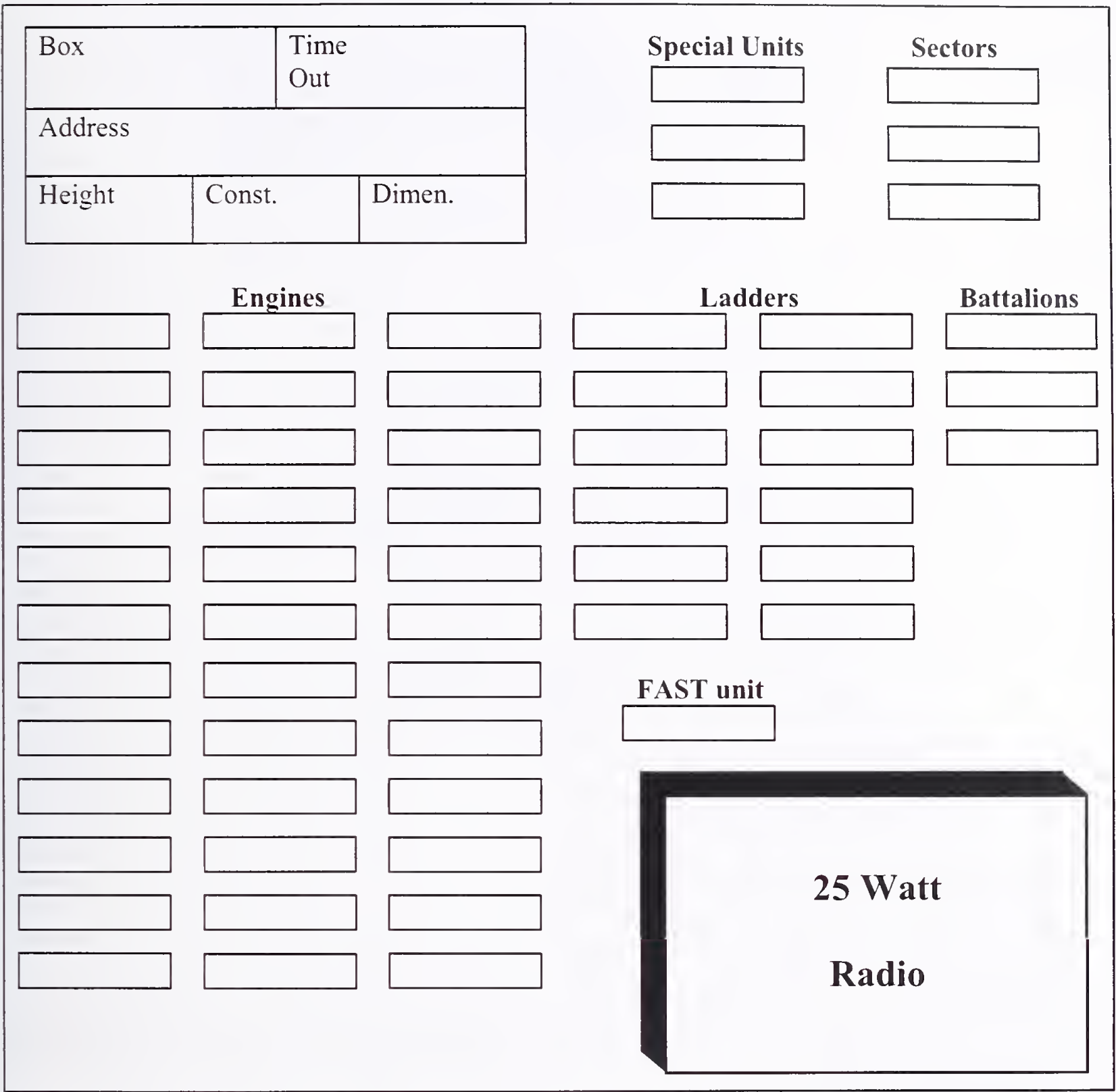


Figure 2

Horizontal Magnetic Surface

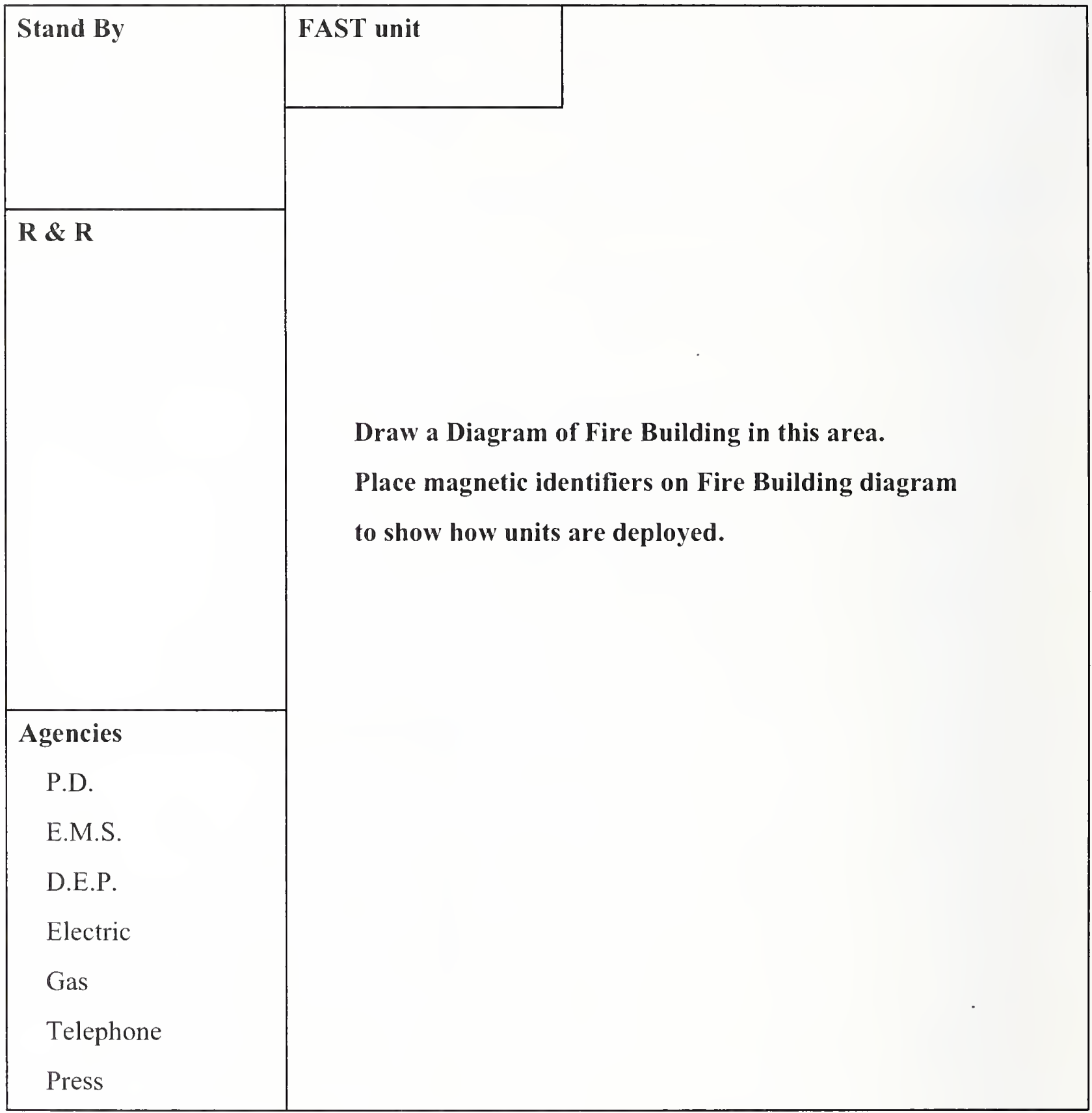


Figure 3

PORTABLE COMMAND POST

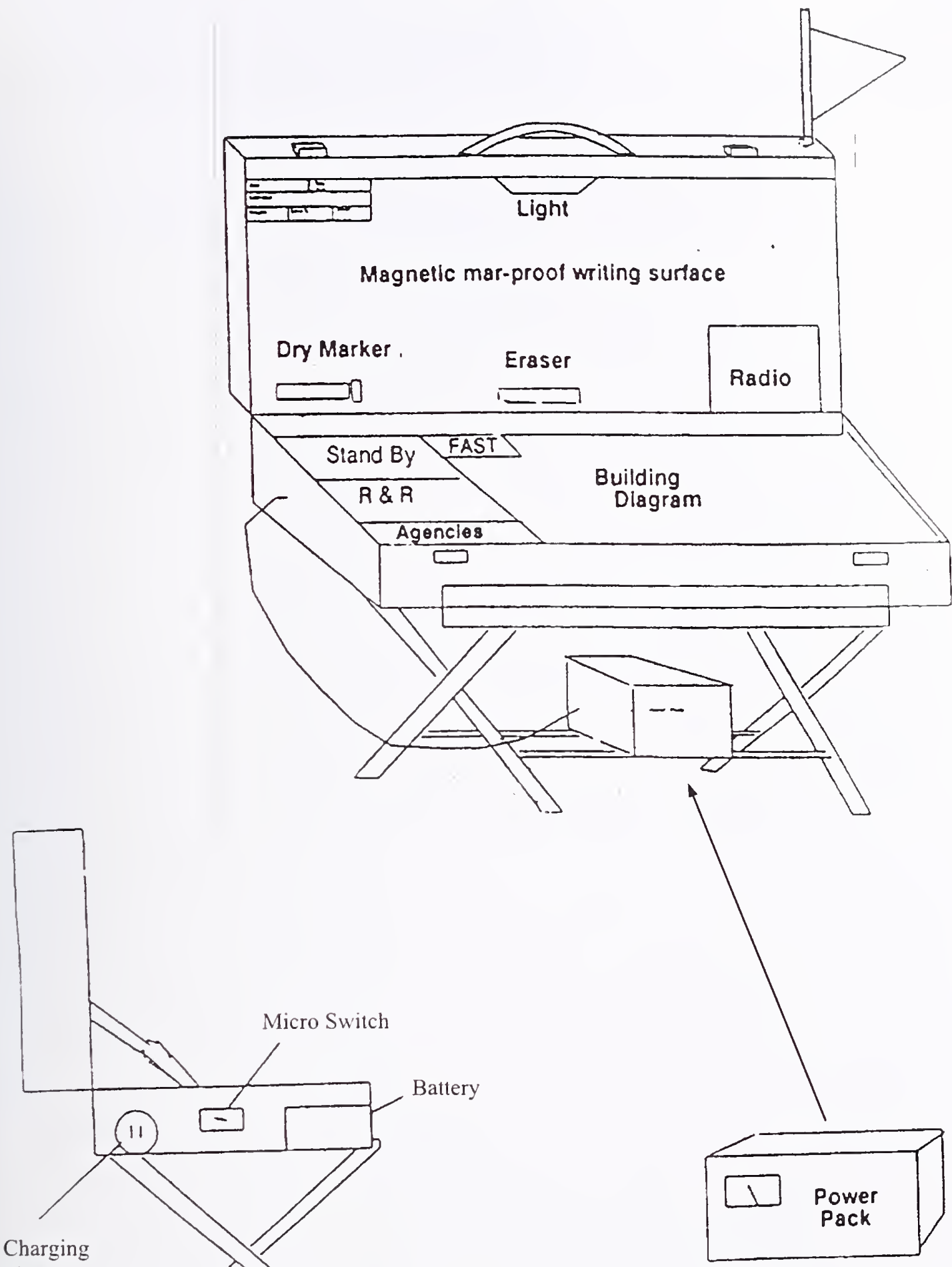

Plug

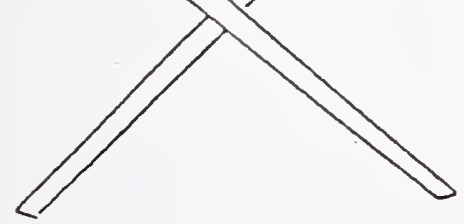

Power pack used to recharge battery and for power during extended operations 

Appendix $\mathrm{H}$

REGULATIONS FOR RECALL 



\section{DCN: 2.06 .00}

\section{REGULATIONS}

CHAPTER 18

January 1, 1997

\section{RECALL}

Appendix $\mathrm{H}$

Regulations Chapter 18 Recall

Reproduced with permission of The Fire Department of the City of New York 


\subsection{RECALL PROCEDURE}

18.1.1 In the event it becomes necessary to augment temporarily the numerical strength of manpower on duty within the Department during actual or potential emergency conditions, the signal 65-2 will be transmitted under jurisdiction and authorization of the Fire Commissioner.

18.1.2 Upon receipt of signal 65-2 transmitted to implement recall, chief and company officers shall follow instructions transmitted. Depending upon the area affected and the degree of necessity, the orders relative to scope of the recall will be announced over the Department radio, voice alarm, and by teleprinter messages.

18.1.3 Recall may be total (city-wide) or partial (confined to one or more boroughs). It may affect all units or selected units, such as engine companies only. The time frame may run from continuous duty to specific tours or hours.

18.1.4 Cancellation of recall will be by the 65-2 signal as above, under authority of the Fire Commissioner.

\subsection{MEMBERS SUBJECT TO RECALL}

18.2.1 During the period recall is in effect, all members, with exceptions noted below, shall be subject to recall duty in accordance with 65-2 instructions and provisions of this chapter.

A. Exemptions:

1. Members assigned to medical leave, limited service or light duty.

2. Members on vacation, military, death, special, or emergency leaves.

B. Conditional: (subject to discretion and as directed by the Fire Commissioner prior or subsequent to recall).

1. Pilots, marine engineers, assistant marine engineer, wipers.

2. Officers, members, firefighters 6th grade assigned to the Bureau of Training (including members who are regularly assigned to units but currently attending such courses as officer training, chauffeur training, etc.).

3. Full duty member - Detailed to other than fire duty. 
18,2.2 During periods of limited recall ordered under directions attendant upon signal $65-2$, members designated, whether by area, group assignment, rank, grade, or classification shall be retained or recalled and perform tours of duty as directed by the Fire Commissioner.

The exemptions and conditional provisions of Section 18.2.1 shall apply unless otherwise specified.

18.2.3 Upon receipt of recall signal, all units out of quarters in affected borough, other than those units operating at a fire or emergency, shall return to quarters immediately. Relocated and interchanged units shall be guided by instructions received from dispatchers.

\subsection{NOTIFICATION OF MEMBERS}

18.3.1 In those instances requiring a citywide recall, it shall be the responsibility of each member to monitor the news media and report for duty as required.

In limited recall situations where media coverage may be limited, officers on duty shall immediately notify affected off duty members as necessary.

18.3.2 Commanding officers shall, in order to insure prompt telephone notification of off duty members, maintain a current and accurate personnel record of emergency telephone numbers in the office record journal, as outlined in section 16.1.1 of the Regulations.

18.3.3 When necessary, notice by telephone shall be direct to affected members. If this is not possible, information shall be conveyed to a person of suitable age and discretion at the members residence or emergency telephone number for prompt relay to the member. In either case, officers on duty shall record in the company journal the time of telephone notification and name of the person notified.

18.3.4 Officers shall endeavor to have members notified of recall information by use of telephones not connected to Bureau of Fire Communications. If this method proves impracticable Department telephones may be used.

18.3.5 Accuracy of emergency telephone information in the personnel record of office record journal shall be the responsibility of individual members. Changes shall be promptly reported to the officer on duty, who shall immediately alter the record.

18.3.6 Members temporarily detailed to other units, affected by the transmission of a recall signal, shall report to such detailed units. 


\subsection{BUREAU OF TRAINING}

18.4.1 Officers, members, (staff or members currently assigned to a training course), and firefighters 6th grade in training shall be subject to recall only under specific orders of the Fire Commissioner. Classes, unless otherwise directed, shall remain in session.

18.4.2 Members regularly assigned to operational units who are currently attending courses conducted by the Bureau of Training, under Departmental orders, when notified either by assigned unit or by an officer of the Bureau of Training that conditional recall exemption has been waived, shall comply with recall provisions presently in effect by reporting without delay, to assigned units.

18.4.3 Sixth grade firefighters enrolled in classes at the Bureau of Training shall, when utilization of their services during recall or other emergency has been directed by the Fire Commissioner, operate under orders and close supervision of officers of the Bureau of Training.

Mobilization, supervision and transportation of sixth grade firefighters to the scene of emergency operations shall be activated in accordance with planned arrangements and schedules devised by the chief of the Bureau of Training.

18.4.4 Officers assigned under recall to supervise sixth grade firefighters responding to emergency conditions, shall report in to Field Headquarters, or to the superior fire officer on duty in the area when Field Headquarters has not been established.

\subsection{SPECIAL OPERATING PROCEDURE}

18.5.1 After transmission of recall notification the following special regulations shall be effective:

A. When two chief officers are on duty in a division or a battalion, only one shall respond to an assigned alarm. The second chief shall operate according to instructions received from the citywide tour commander.

B. Special Units shall respond according to the Communications Manual, unless otherwise specified.

C. Deputy chiefs shall arrange to place spare apparatus in service. They shall cooperate with battalion chiefs in providing details of members to divide units and place the maximum number of companies in service. Dispatchers shall be advised when such companies are placed in service. 


\subsection{RELEASE OF MEMBERS}

18.6.1 Release of members recalled or retained on duty under instructions attendant upon signal 65-2 may be accomplished, at the direction of the Fire Commissioner, by repetition of the signal $65-2$ followed by orders specifying the hour and method for terminating emergency duties.

\subsection{REPORTS}

18.7.1 Commanding officers shall forward reports 24 hours after transmission of a recall signal recording the time each member reported for duty in response to such signal. 
Appendix 1

Fire Fighting Procedures High Rise Office BUILdings 


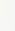




\title{
HIGH-RISE OFFICE BUILDINGS
}

\begin{abstract}
Appendix I
Fire Fighting Procedure High Rise Office Buildings

Reproduced with permission of The Fire Department of the City of New York
\end{abstract}




\section{CONTENTS}

\section{Glossary}

Introduction

Buildings Built Before 1945

Section Revoked

Heating, Ventilation and Air Conditioning Systems

5
Hydraulics

Supply from Fire Department Pumpers

Pumper Pressures

5.2 .2

Chart

Operating Procedures

Building Fire Pump

Other Considerations

\section{8}


Tactical Plan

Tactical Considerations

Operations Post

Command Post Procedures...

Introduction

Communications

Lobby Command Post.

Operations Post

Search and Evacuation Post

Staging Area

Class "E" Communications System.

Introduction

Description

Utilization.

Introduction.

Ladder company response.

First arriving ladder company

Second arriving ladder company 


\section{GLOSSARY}

Access stairs

Air diffusers

Attack stairway

Blind shaft elevators

Building evacuation supervisor

\section{Churning}

Core type building

Compartmentation

Curtain wall

Damper

Diffusers
A stairway, usually open, serving a number of floors of a common tenant. Also known as convenience stairs.

The air supply outlets of the heating, ventilation and air conditioning system (HVAC) into the conditioned space.

A fire stair being used by the Fire Department to gain access to the fire area, where the door between the stairway and the fire area is being maintained in an open position.

Elevators serving the upper areas of a building in a shaft that is not equipped with hoistway doors on the lower floors.

When the fire safety director is not present in a class "E" office building occupied by less than 100 people above or below the street floor or by less than 500 people in the entire building, an employee trained by the fire safety director will man the fire command station and execute the fire safety plan.

A condition in a centrifugal pump in which the impeller is rotating but no water is being discharged.

A building in which the elevators, stairway and building support systems are grouped together in one area of the building. This area could be in the center of the building as in a center core building or on one of the sides of the building as in a side core building.

The subdividing of floor areas by fire resistive separations into smaller spaces or compartments.

A non-bearing wall, built between piers or columns for the enclosure of the structure, but not supported at each story.

A device to seal off or to control air flow in a HVAC system.

See air diffusers. 
ECC

Elevator control
panel

Elevator door vane

Elevator machinery room

Evacuation stairway

Fire dampers

Fire partition

Fire safety director

Fire shutter, (reversible)

Fire tower

Fusible link

Hard wire communications

High-Rise communications kit
Engine Company Chauffeur. A Fire Department member trained and qualified to operate Fire Department pumpers.

A visual display unit located in the lobby to indicate the status and location of all elevator cars and necessary controls for the operation of the cars.

The connection between the elevator car doors and the hoistway doors. It allows the elevator car doors to drive the hoistway doors.

The area where the equipment is located that raises and lowers the elevator car. It can be at the top or bottom of the elevator shaft. In HighRise buildings it is usually found at the top of the shaft.

fire tower or a fire stairs that is remote from the fire area and used for the evacuation of the building occupants. A fire tower is the preferred evacuation stairs.

A damper used to restrict the passage of heat.

A rated vertical unit or assembly of materials that separate one space from another within any story of a building.

A designated employee holding a certificate of fitness from the Fire Department qualifying him to perform the duties as required.

A fire damper that can be controlled from a remote location.

An enclosed stairway connected at each story by an outside balcony or fire proof vestibule vented to the outside.

A device designed to be actuated by an abnormal rise in temperature.

A system of communications in which wiring physically connects both lobby command post and other areas within the building. Viz.: Points of transmission and reception.

Handie-Talkie accessories designed to improve the performance of Fire Department Handie-Talkies when used within High-Rise buildings. (See AUC 179R addendum No. 2) 
Key (1620)

Key (2642)

Locked door fail safe system

Mechanical control center

Mixing dampers

Plenum

"Q" decking

Reversible fire shutters

Safety fire shutters

Safety edge

Set backs

Scissor stairs

Size-up
An official Fire Department alarm box key.

A standard key used by the elevator industry.

A system where the lock mechanism is controlled electrically from a remote location.

A location within a building where equipment is located for the monitoring of the building support systems. It has limited ability to control some of the building support systems. It may or may not be located on the same floor as the mechanical equipment rooms (MER).

Dampers in the HVAC system which control the mixing of the return air and outside air.

An air compartment or chamber to which one or more ducts are connected and which form a part of an air distribution system. In HighRise buildings the space between the suspended ceiling and the under side of the floor above is used as a plenum for the collection of the return air.

A type of composite floor construction in which corrugated steel is used to support the concrete floor. (See Fig. 2-1)

See Fire Shutter (reversible).

\section{See Fire Shutter (reversible).}

The leading edge of an elevator car door which causes the door to reverse its direction when it encounters an obstruction.

The area formed when the floor area of a building is reduced thus requiring the exterior wall of a building to be recessed.

Two stairs constructed side by side in the core of a building in which their doors alternate the point of exit to opposite sides of the core.

An estimate of the conditions and problems of a fire or emergency situation by the officer in command. 
Sky lobby

Smoke ejector

Sound powered phone system

Staging area

Search and evacuation post

Standpipe kit

Thermostatic detector

Variation
An elevator terminal point on an upper floor of a building where passengers can change from one bank of elevators to another.

A fan used by the Fire Department to move smoke or air.

A portable hardwire telephone system powered by voice sound.

An area established on a floor below the operations post to provide logistical support to the operations post.

A position established above the fire operations to control and coordinate all operations in that area.

A collection of tools used by an engine company to effectively operate a hose line from a standpipe system.

A device to detect an increase in temperature.

Permission given by the Department of Buildings and/or Board of Standards and Appeal to construct a building in variation with the existing Building Code. 


\section{INTRODUCTION}

\section{$1.1 \quad$ PURPOSE}

The purposes of this book are:

1.1.1 To describe High-Rise Class "E" office buildings. Over 800 of these structures can be found in New York City.

1.1.2 To point out the problems and features of such buildings with regard to fire.

1.1.3 To establish methods of operating at fires in such buildings, and recommend precautions that should be taken.

\subsection{TYPES OF BUILDINGS}

1.2.1 The types of buildings included in this book are:

A. High-Rise Class "E" office buildings built before 1945 .

B. High-Rise Class "E" office buildings built between 1945 and 1968 .

C. High-Rise Class "E" office buildings built after 1968.

Note: Many of these buildings are 200' x 400' in area with up to six stairways especially on the lower floors and with three or more stairways on the upper floors. However, others have only two stairshafts from lobby to roof with consequent reduction in our mobility and tactical flexibility.

Therefore, to permit an organized approach and deployment of our units this Bulletin is based upon a serious fire on the upper floors of a two-stairway office tower.

1. Because of the variation in construction techniques and the complexity of the High-Rise class "E" office buildings, the procedures outlined in this bulletin must be general in character and must differ substantially from the "Ladders 3" approach used at multiple dwelling fires.

2. In addition, the multitude of fire problems in these structures occupied with the human factor, i.e.; thousands of occupants on upper floors, severely limit the resources available on the first. alarm. As a result, new signals and response patterns will be introduced which demand all units operate in a controlled and coordinated manner.

3. As described in the operational Sections this article's aim is to establish critical priorities and assign chief officers and/or company units, not individual members or teams of members, to solve these problems. 


\section{DESCRIPTION OF HIGH-RISE CLASS "E" OFFICE BUILDINGS}

\subsection{GENERAL DESCRIPTION}

2.1.1 100 feet or more in height.

2.1.2 Vary in area from 2,000 square feet to over 300,000 square feet.

2.1.3 Class 1 non-combustible.

2.1.4 Buildings shall be classified in the Class "E" occupancy group when they are primarily occupied for transacting business; for rendering professional services that may incidentally involve the storage of limited quantities of stocks of goods for office use or purposes. Buildings and spaces used for providing public and civic services shall also be classified in this group.

Examples are:
A. Office spaces
B. Showrooms
C. Banks
D. Telephone exchanges
E. Civic administration
F. Assembly occupancies such as restaurants, cafeterias, etc., also may be found in office buildings.

\subsection{CLASS "E" HIGH-RISE OFFICE BUILDINGS BUILT BEFORE 1945}

2.2.1 The construction techniques used in these buildings resulted in a "heavy-weight" building, usually weighing about 20 to 23 pounds per cubic foot.

2.2.3 Structural steel components were encased in concrete.

2.2.4 Exterior walls were of masonry construction.

2.2.5 Exterior walls were substantially tied to all floors.

2.2.6 Plenum type ceilings are generally not found in these buildings.

2.2.7 Normally steam heated.

2.2.8 Usually not centrally air conditioned.

2.2.9 Exterior windows were openable.

2.2.10 All buildings erected between 1938 and 1968 were required to have a fire tower. Some built prior to 1938 have fire towers.

2.2.11 Floors were constructed of reinforced concrete.

2.2.12 Core construction techniques were not used. 


\subsection{CLASS "E" HIGH-RISE BUILDINGS BUILT BETWEEN 1945 AND 1968.}

2.3.1 The construction techniques used resulted in a "medium-weight" building, usually weighing between 10 and 20 pounds per cubic foot.

2.3.2 Fire towers were required in all of these buildings

2.3.3 The characteristics of these buildings are a mix of the pre- 1945 buildings and the post 1968 buildings. These buildings were required to conform to the 1938 Building Code but because of the numerous variances granted they used many of the construction techniques of the post 1968 buildings.

\subsection{CLASS "E" HIGH-RISE OFFICE BUILDINGS BUILT AFTER 1968}

2.4.1 The construction techniques used in these buildings resulted in a "lightweight" building, usually weighing about 8 to 10 pounds per cubic foot.

2.4.2 They were constructed with a lack of compartmentation.

2.4.3 The protection of the structural steel component is usually done by spraying on a fireproofing material.

2.4.4 Exterior walls are curtain walls constructed of a combination of glass and metal.

2.4.5 The method of securing the exterior curtain walls leaves a space of 6 to 12 inches which requires additional fire stopping.

2.4.6 The ceiling plenums of these buildings are extensive and lack fire stopping. they are used to return the air to the air-conditioning system and for electrical, communications and other building support equipment.

2.4.7 They are usually heated by the heating, ventilating, and air-conditioning system (HVAC).

2.4.8 HVAC systems are usually multi-floor systems.

2.4.9 Exterior windows are usually not openable.

2.4.10 Fire towers are not required.

2.4.11 Floors are light in weight usually consisting of lightweight concrete, "Q decking", etc. [See Fig. 2-1]

2.4.12 Core construction techniques are used extensively.

3. DELETED 


\section{HEATING, VENTILATION, AND AIR CONDITIONING SYSTEM (HVAC)}

\subsection{INTRODUCTION}

4.1.1 The strategic objectives of good HVAC management are to use the HVAC system to limit the spread of fire and to control the movement of smoke within the building. Also, this system provides the greatest assistance to Fire Department members who are being deployed to control the fire, and who are conducting the primary search for any trapped occupants.

4.1.2 To utilize the HVAC system to its full potential during a fire in a High-Rise office building, the officer in command of the fire must know how the system functions and have a strategic plan for its use.

\subsection{DESCRIPTION OF HVAC SYSTEMS}

4.2.1 The HVAC systems found in High-Rise office buildings fall into two general categories:

A. Central air conditioning systems, in which the processing equipment supplies air to more than one floor.

B. Non-central air conditioning systems that serve only the floor on which the processing equipment is located.

Note: Because central air conditioning systems are the most commonly found in High-Rise office buildings and create the most problems during a fire, the main emphasis of this section will be central air conditioning systems.

4.2.2 The HVAC system may be divided into three sub-systems:

A. Processing equipment.

B. Supply of processed air to the floors of the building.

C. Return of the air from the floors to be reprocessed.

4.2.3 The processing of the air is usually done on the floors of the building where the mechanical equipment rooms (MER) are located.

4.2.4 The following equipment necessary for the processing of the air will be found on the MER floor: [see Fig. 4-1]

A. Outside air supply dampers.

B. Equipment for the filtering, heating, cooling and humidity control of the air.

C. Supply air fans.

D. Smoke and heat detectors.

E. Duct work to the supply air shaft.

F. Duct work from the return air shaft.

G. Return air fans.

H. Exhaust dampers.

I. Mixing dampers. 
4.2.5 The supply of processed air to the floors is accomplished by the following: [see Fig. 4-2]
A. Supply air shaft.
B. Fire dampers.
C. Supply air ducts.
D. Air diffusers.

4.2.6 The return of air from the floors to be reprocessed is accomplished by the following. [see Fig. 4-2]
A. Return air inlets.
B. Return air plenums.
C. Fire dampers.
D. Smoke detectors.
E. Return air shaft.

4.2.7 In a typical centrally air conditioned High-Rise building the large volume of air required precludes the use of a single HVAC system. We will usually find a number of HVAC systems each supplying a group of floors. These groups are referred to as HVAC systems supply zones. [see Fig. 4-3]

4.2.8 The normal flow of air through an HVAC system is as follows:

A. Through the processing equipment. [see Fig. 4-1]

1. Air is returned from the building via the return air shaft (RAS) for reprocessing.

2. A return air fan (RAF) is used to assist the movement of air in the return air shaft (RAS).

3. Air from the return air fan then will flow through the mixing dampers.

4. The air is then mixed with a percentage of outside air. The amount is dependent upon outside air temperature and humidity and is determined by the building engineers on duty or by a computer.

5. The mixed air then is processed by flowing through filters, heating/cooling equipment and equipment to control its humidity.

6. The supply air fan is used to assist the movement of air into the supply air shaft.

B. Through the supply system. [see Fig. 4-2]

1. Air is distributed to the floors via the supply air shaft (SAS).

2. Air from the supply air shaft is distributed on each floor by ducts. The ducts are found in the plenum.

3. Fire dampers will be found in these ducts where the ducts meet the supply air shaft and wherever they pass through a rated fire partition.

4. Air from the supply ducts is distributed to the occupied areas by air diffusers mounted in the hanging ceiling. 
C. Through the return system. [see Fig. 4-2]

1. Air from the occupied areas flows through the return collectors into the plenums.

2. The air flows through the plenums to the return air shaft. The return air in the plenums is not ducted.

3. Fire dampers will be found where the air enters the return air shaft from the plenum on each floor and wherever the air flows through a rated fire partition.

4. The air then is returned to the processing equipment via the return air shaft.

\subsection{HVAC STRATEGIC OPERATING PLAN}

4.3.1 Determine the status of all the HVAC systems in the building. Any systems that have not been automatically shut down shall be manually shut down. This shall include both the supply and return fans.

Note: In some systems, the smoke detectors only shut down the supply fans and allow the return air fans to remain operating. The return fans will have to be shut down manually.

4.3.2 Before any further action can be taken with the HVAC system, the fire floor must be accurately determined.

4.3.3 All the HVAC systems shall be placed in the non-circulating mode by:

A. Opening all outside air supply dampers.

B. Closing all mixing dampers.

C. Opening all exhaust dampers. [see Fig. 4-1]

4.3.4 After the fire floor has been adequately determined, all HVAC zones that do not include the fire area shall have their supply fans activated. This will supply fresh outside air to these zones, pressurizing these zones and limiting the spread of smoke. It will also supply fresh outside air to any occupants on the floors in these zones.

\subsubsection{Warning!}

Whenever The HVAC Systems Are Reactivated, All Units Operating In The Building Shall Be Alerted To Report Any Adverse Effects. 
4.4.1 Automatic closure of the fire dampers is usually effected upon operation of an approved fusible link or other approved heat activated device located where they would be readily affected by an abnormal rise in temperature in the duct. Fusible links should have a temperature rating approximately $50 \mathrm{~F}$ above the maximum temperature that would normally be encountered with the system in operation or shut down.

A. Once a fire damper has closed it must be manually opened before air can pass thought the opening it is protecting.

4.4.2 Local Law No. 5 of 1973 requires an approved product of combustion ionization detecting device, or a combination of an approved smoke detecting device and an approved fixed temperature thermostatic device. These devices shall be located at the air return shaft at each floor in order to monitor each inlet to the return air shaft.

A. Activation of any of the detectors installed in an HVAC system shall stop the air supply into and the air return from the affected floor. The air supply and the air return are stopped by the activation of an approved remote controlled reversible fire shutter or by automatically shutting down the air supply fans and the air return fans serving the floor where activated.

B. The fans cannot be reactivated until the smoke detector has been cleared or the smoke detector relay has been electrically bypassed. This can be difficult and time consuming.

4.4.3 Temperature variations that occur in the periphery of the building, due to weather changes and movement of the sun, require supplementary treatment of the air. This is accomplished by the following: [see Fig. 4-4]

A. Air supply may be from the main air supply shaft or from a separate periphery air supply shaft.

B. The air supply is ducted through the plenum on the floor below to the periphery of the building.

C. Flexible connectors are used between the ducts and the periphery air treatment equipment on the floor above.

1. Fire experience has shown that fire entering the plenum can extend from one floor to another when these flexible connectors fail.

D. The air then is passed through the air treatment equipment to meet the demands of the periphery. Piping containing heated or chilled water is used to condition the air. The air then is discharged into the periphery of the building.

E. The air is returned through the normal air return system. 
4.4.4. The chief in charge must contact the building engineer and obtain the following information concerning the HVAC system:
A. Location of the MER floors and the zones they supply.
B. Special HVAC zones in the building (Theaters, Restaurants, Computer Rooms, Stores, etc.).
C. Central control of the HVAC systems and their location.
D. Number of return air shafts and their location.
E. If return air shafts are common to more than one HVAC supply system.
F. If supply and return dampers on each floor are controllable from a central location.
G. If there is a periphery air supply system.

4.4.5 Due to variations found, chief officers must consult building engineers to become familiar with HVAC systems in their district.

\section{HYDRAULICS}

\subsection{SUPPLYING HIGH-RISE STANDPIPE SYSTEM USING FIRE DEPARTMENT PUMPERS}

\subsubsection{CLASSIFICATION OF PUMPERS}

A. Conventional pumpers: Two-stage 1000 gpm or 2000 gpm pumpers.

B. High-Pressure pumper: A pumper with a third stage capability. The third stage can supply $500 \mathrm{gpm}$ at $700 \mathrm{psi}$.

5.1.2 To insure adequate water supply to the standpipe system:

A. Supply the system with at least two pumpers.

B. Supply at least two separate Siamese's.

C. If only one Siamese is available, supply the first floor hose outlet with the second line.

D. When a High-Pressure pumper is going to activate the 3rd stage, only one 3" special high pressure hose supply line may be stretched into a Siamese connection.

E. To insure that water is being supplied to the standpipe system:

1. When the pumper is equipped with flow meters, use a discharge gate to which a flow meter is connected.

2. If the pumper is not equipped with flow meters, it must be monitored to prevent churning and overheating of the water in the pump.

3. Chauffeurs supplying the standpipe system must coordinate their pumping pressure.

F. If the building is equipped with a combination standpipe/sprinkler system (yellow Siamese caps), augmentation is required. 
5.2.1 To simplify computing pump pressure when supplying a standpipe system, a chart has been formulated. These calculations are based on nozzle pressure, friction loss of three lengths of 2-1/2" hose, head loss, system friction loss and friction loss of two lengths of 3-1/2" hose supplying the Siamese.

\subsubsection{Chart.}

\section{RECOMMENDED PUMP PRESSURES}

\begin{tabular}{llcccc} 
FIRE & FLOOR(S) & CONTROLLING & \multicolumn{2}{c}{ FOG NOZZLE } \\
& & \multicolumn{2}{c}{ NOZZL } & & \\
Floors & $1-10$ & 150 & $\mathrm{psi}$ & 200 & $\mathrm{psi}$ \\
Floors & $11-20$ & 200 & $\mathrm{psi}$ & 250 & $\mathrm{psi}$ \\
Floors & $21-30$ & 250 & $\mathrm{psi}$ & 300 & $\mathrm{psi}$ \\
Floors & $31-40$ & 300 & $\mathrm{psi}$ & 350 & $\mathrm{psi}$ \\
Floors & $41-50$ & 350 & $\mathrm{psi}$ & 400 & $\mathrm{psi}$ \\
Floors & $51-60$ & 400 & $\mathrm{psi}$ & 450 & $\mathrm{psi}$ \\
Floors & $61-70$ & 450 & $\mathrm{psi}$ & 500 & $\mathrm{psi}$ \\
Floors & $71-80$ & 500 & $\mathrm{psi}$ & 550 & $\mathrm{psi}$ \\
Floors & $81-90$ & 550 & $\mathrm{psi}$ & 600 & $\mathrm{psi}$ \\
Floors & $91-100$ & 600 & $\mathrm{psi}$ & 650 & $\mathrm{psi}$ \\
Floors & $101-110$ & 650 & $\mathrm{psi}$ & 700 & $\mathrm{psi}$
\end{tabular}

5.2.3 If the height of the fire floor requires pressure in excess of $250 \mathrm{psi}$ the officer in charge can order higher pressures at the pumper if the following precautions are followed:

A. All civilian and Fire Department personnel are removed from a zone 50 feet on each side of the hose line supplying the siamese. 3" special high-pressure hose must be used.

B. Warning tapes, stanchions or utility ropes are utilized to maintain this area clear.

C. A Battalion Chief is designated to control this pumping operation.

D. An audible alert be used to inform civilians and personnel on the scene. (Public address systems on apparatus may be utilized)

E. Supply line to the siamese or standpipe outlet valve must be secured by utility rope to a substantial object.

F. Only special high-pressure fittings may be used. They are painted white and are noticeably heavier than standard fittings.

G. Maintain safety zones of at least $50^{\prime}$ around a working pumper (high-pressure) in all directions. 
H. Supply lines must be connected to the pumper on the side opposite the control panel.

I. Unused gated inlets and outlets must be closed and all caps secured to the pumper.

J. Each pumper being utilized at pressures in excess of 250 psi must be controlled by the E.C.C., assisted by an E.C.C. from a non-operating pumper.(One man to operate pumper and one man to maintain radio communications)

K. Command post to establish radio communications with all units involved in high-pressure pumping operation.

L. During high-pressure pumping, members must not utilize stairways as staging or rest areas. Utilize minimum amount of personnel in stairways served by standpipes.

M. The Chief in Command must designate a unit(s), to control and mark off safety zones.

Note: On the scene, the Safety Operating Battalion may be utilized to control this operation.

5.2.4 When the fire is above the 50th floor, or the building water supply is unsatisfactory, it may be necessary to use the third stage of the high-pressure pumper. Only the Chief in Charge of the fire may order this use. Chauffeurs of high pressure pumpers must ensure that tether security ropes are in place prior to activating the third ( $3 \mathrm{rd}$ ) stage of the pump.

\subsection{OPERATING PROCEDURES}

5.3.1 Pump pressure must be increased slowly and floor outlet valves opened slowly to avoid pressure surges at the nozzle.

5.3.2 Member operating floor outlet valve must open it sufficiently to provide the required nozzle pressure as determined by the officer supervising the line.

\subsection{MANUALLY OPERATED BUILDING FIRE PUMPS}

\subsubsection{Introduction}

A. The purpose of this section is to familiarize members with manually operated fire pumps.

B. The 1968 Building code requires a manual fire pump to supplement the standpipe system in buildings over 300 feet high. The 1938 Building Code requires a manual fire pump in buildings over $250 \mathrm{high}$.

C. Many times there are manual fire pumps in other than High-Rise buildings. The same guidelines should be used in all buildings where building fire pumps exist. 
D. It always has been the responsibility of building engineers to start the building fire pumps and this section in no way releases them from this assignment. We have found, however, that some engineers have been assigned to other duties when a fire starts. There is also the possibility that the building engineer might not be on duty at the time of the fire.

\subsubsection{Pump room location.}

A. Follow signs or directions to the pump room which is normally located on the lowest floor (cellar or sub-cellar-cellar).

B. Locate the pump and note the gauges on (C) inlet and (D) discharge lines. [see Figs. 5-1, 5-2 and 5-3]

C. Locate the bypass valve (B) on the discharge side of the fire pump. The discharge side can be readily identified by examining the gauges. The discharge gauge is calibrated for higher pressures than the inlet gauge.

D. The bypass valve should be in the closed position (stem in). Some engineers keep them open for test purposes, so they must be checked by the ECC assigned to operate the pumps. If they are found to be open, they should be closed by turning in a clockwise direction.

E. Some systems are quite complex and the bypass valve is not readily discernible. If such a situation is present, it is permissible to start pump as ordered without checking bypass valve. Notify the engineer upon his arrival of this and any other actions taken. The efficiency of the pump will be affected if the bypass is open. A loss of $25 \%$ can be expected in an 8 " riser, and a loss of $45 \%$ can be expected in a $6 "$ riser, with the bypass open.

F. Locate the Fire Pump Control cabinet [see Figs. 5-4 and 5-5] in the vicinity of the pump and read the instruction plaque. (7)

\subsubsection{Description of control cabinet.}

A. The control cabinet for a 750 gallon fire pump will be in the shape of a large cube. It varies from $6^{\prime} \times 6^{\prime} \times 6^{\prime}$ to as large as $8^{\prime} \times 8^{\prime} \times 8^{\prime}$ in the older models. The front of the cabinet will be the control panel. [see Figs. 5-4 and 5-5] 
5.4.4 Four step procedure for starting of fire pumps, using the control panel.

\section{OPERATION}

A. Close knife switch (1) to on position. [Fig. 5-4 or 5-5]

B. Close circuit breaker(s) (2) $\&$ power "on" light will glow.

C. Push starting button (3) \& pump "on" light will glow. [Fig. 5-4 or 5-5]

D. Move selector lever (4) to desired position increasing pump speed and thereby increasing pressure.

\section{LOCATION}

1. On front panel (or)

2. Inside panel door

1. On front panel (or)

2. Inside panel door

1. On front panel (or)

2. Inside panel door (or)

3. Adjacent to panel door

1. On front panel (or)

2. Inside panel door (or)

3. On outside cabinet on either side of front panel

5.4.5 The fire pumps should now be operating, if they have failed to start, the emergency power lever located at the panel shall be used. Push or pull to "on" position (5). [see Fig. 5-4 or 5-5]

5.4.6 Additional duties of the member assigned will include:

A. Contact be maintained with fire command station, via

1. Handie-talkies (or)

2. Fire Command station phone located in pump room.

B. Checking of the pressure gauge on the discharge side of the fire pump located near the riser. This is to insure that the pressures called for are being maintained. The following chart will help determine the proper setting of the speed selector lever. The building management is encouraged to provide just such a chart. The chart they supply should be located at the control panel and may vary slightly depending upon efficiency of the pump.

\subsubsection{Recommended Pump Pressure}

FIRE FLOORS

Floors 1 to 10

Floors 10 to 20

Floors 20 to 30

Floors 30 to 40

Floors 40 to 50
CONTROLLING NOZZLE

$150 \mathrm{psi}$

$200 \mathrm{psi}$

$250 \mathrm{psi}$

$300 \mathrm{psi}$

$350 \mathrm{psi}$
FOG NOZZLE

200 psi

$250 \mathrm{psi}$

300 psi

350 psi

400 psi 
5.4.8 Building fire pump data.

A. The engineers should be used if available but they may not have any knowledge of the pressures required to supply hose lines on upper floors. ECC shall be assigned to either assist the engineer, or to start and operate the building fire pumps.

B. Building fire pumps are usually located in the cellar or sub-cellar and fire lines connected to them should be painted red.

C. Pump capacity is usually $750 \mathrm{gpm}$ Most High-Rise buildings have two pumps side by side which are connected in the parallel position.

D. The operation of these pumps is usually standard from building to building even though the physical layout may differ.

E. Some buildings have a combination standpipe/sprinkler system with the siamese connected to both systems. The same starting procedures will apply in these buildings. The usual arrangement for the fire pumps is that one will be automatic and one manual. The automatic fire pumps may be of smaller capacity. (250 gpm or $500 \mathrm{gpm})$.

F. When a building is equipped with two manual fire pumps, as is the case in most High-Rise buildings, each pump will have its own control panel. Both pumps shall be started and used.

G. Since fire pumps are connected in parallel position, it is necessary to have both pumps operating at or near the same pressures. Should one manual pump be operated at a pressure far in excess of the other, it could partially overcome the check valve making the second pump less efficient. A visual check should be made of the discharge gauges of both pumps. When both are operating correctly, the pressures should be equal or nearly so.

$\mathrm{H}$. Where one gauge reading is considerably lower than the other, the pressure can be increased on the less efficient pump by moving the pump position lever to a higher position.

I. When the engineer of a building is present, this should be left to him to adjust since he will be familiar with the system's maintenance history and prior malfunctions.

J. Near each fire pump is a standpipe phone providing direct communication with the lobby command post.

$\mathrm{K}$. When the command to shut down the building fire pumps is received, and the engineer in charge is not available, the pumps are deactivated by reversing the starting procedure.

1. Return pump position lever to lowest speed.

2. Push "off" button.

3. Open circuit breakers.

4. Open knife switch-(off position).

5. Advise the lobby command post that the pumps have been deactivated. 


\subsection{OTHER CONSIDERATIONS}

5.5.1 The building fire pumps shall be capable of delivering their rated capacity at a pressure of $50 \mathrm{psi}$ at the highest floor hose outlet.

5.5.2 A relief valve is required at the fire pump limiting the pressure to $15 \mathrm{psi}$ above that required to deliver its rated capacity at $50 \mathrm{psi}$ to the highest floor outlet.

5.5.3 Because of the above restrictions, the building fire pump may not be capable of supplying adequate nozzle pressure to hose lines at the upper floors. The primary water supply to the standpipe system in many buildings is a gravity tank. In many instances, there will be inadequate head pressures supplied to the uppermost floor-hose outlets supplied by that gravity tank. For these reasons, the primary water supply for Firefighting in most operations shall be the Fire Department pumpers.

5.5.4 When the building fire pumps and Fire Department pumpers are being used to supply the standpipe system, both systems must be monitored to prevent overheating caused by churning.

5.5.5 The high pressures required to supply water to the upper floors of a High-Rise building limit the amount of water that a Fire Department pumper can supply. A good "rule of thumb" is to have a separate pumper supply the standpipe system for each hand line in operation. 


\subsection{STRATEGIC OPERATING PLAN}

6.1.1 The following is a basic strategic operating plan for use at major High-Rise fires. (Listed in order of importance)

A. Determine specific fire floor (if possible) or the floors on which smoke is reported from any information that is available to you in the building lobby.

1. Frequently (especially during off business hours) specific fire floor information will not be available other than a report of smoke on numerous floors (e.g. 20th to 35th floors).

B. Verify fire floor. Sift information received from responsible occupant/building management personnel and/or first arriving ladder company.

1. We must determine the fire floor location as rapidly as possible. All future actions hinge on this vital piece of information.

C. Simultaneously, or as soon as possible, begin the process of controlling evacuation.

1. Occupants of numerous floors may have self-initiated evacuation causing almost a mob scene or near panic in stair shafts or building lobby.

2. Due to large floor areas or maze like corridors, occupants on the fire floor may be unaware of the fire until it is too late to evacuate. Search of large areas will be required.

3. Search and evacuation of the floor above the fire will also be required as soon as possible.

D. Gain control of the building systems.

1. Elevators.

2. HVAC.

3. Communications.

4. Fire pumps.

E. Confine and extinguish the fire.

1. Experience indicates any serious fire will require a large commitment of units and equipment because of extensive logistic problems and a need for frequent relief of members.

F. Battalion Chief assignments and duties at High-Rise fires are pre-determined only for the Lobby and Operations Posts. Battalion Chief operations after these positions are covered shall be designated by the Incident Commander. The Search and Evacuation, Staging area, and Attack positions shall be assigned as conditions dictate. Section 6.5.4 defines fire situations where the services of "Attack Chief" shall be utilized. 


\subsection{PROCEDURES TO IMPLEMENT THE STRATEGIC OPERATING PLAN}

6.2.1 For the first arriving battalion chief to achieve the above outlined strategic operating plan, the prime position is at the lobby command post. From this Post he will have control over all building systems through the fire safety director or his surrogate. He will receive first hand information about other problems that may develop on floors above the fire through the building communications networks. He will have liaison with the Police Department for control of the lobby and the streets in the vicinity of the fire building, Under the direct control of an alert and knowledgeable battalion chief, the lobby position is of prime importance. To provide continuity of operations, it is essential that the first arriving battalion chief remain at the lobby command post to assist the chief in charge of operations. He shall remain at the lobby command post until his services are no longer deemed necessary.

6.2.2 The first arriving battalion chief will be required to make an initial size up to determine the adequacy of the response and the need for additional response.

A. A 10-76 signal shall be transmitted when a report of fire is confirmed. Any fire in a High-Rise office building which requires the stretching and operating of one hose line will necessitate the use of "All Hands."

B. A second alarm is warranted for any visible fire or smoke emanating through the exterior skin of the building or when a serious fire has been verified.

C. Because of the large number of occupants in High-Rise office buildings, even fires of a minor nature may require additional units to prevent unnecessary evacuation and panic.

6.2.3 The first arriving battalion chief shall establish liaison with the fire safety director if present, or his surrogate to determine the following:

A. Has the fire floor definitely been determined?

B. What is the extent of the evacuation that has been implemented?

C. Have there been any reports of severe life hazards?

D. What is the status of the elevators and the HVAC system?

E. Are there any access stairs in the vicinity of the reported fire floor?

F. What communications have been established between the fire floor and the lobby command post?

G. What communications have been established between the lobby command post and the occupants of the building? 
6.2.4 The battalion chief should arrange for the fire safety director or the evacuation supervisor to make an announcement over the PA system or the intercom system. "This is your Fire Safety Director, Dr. John Doe. The New York City Fire Department has just arrived to extinguish a fire on the floor. As they obtain information, we will pass it along to you. If your assistance is required, I will make such an announcement. In the meantime, please remain calm at your place of employment."

6.2.5 The fire safety director MUST be informed to remain in the lobby where his assistance will be available at any time.

6.2.6 Obtain copies of the floor plan of the fire floor from the fire safety director.

6.2.7 As soon as possible, the first arriving battalion chief shall start obtaining the additional information required by the High-Rise check list. [see Fig. 6-11]

\subsection{TACTICAL PLAN}

6.3.1 To achieve the basic strategic plan, the first arriving battalion chief shall use the following tactics:

A. Contact any units that are on the scene before his arrival, to ascertain their location, fire conditions, and the operations they have implemented. This information may be obtained from the Fire Department member who is manning the command post pending the arrival of the battalion chief.

B. Deleted

C. The placement of the 10-76 assignment shall be as follows:

1. The first and second arriving engine companies shall be teamed to stretch and operate the first line.

2. The third and fourth arriving engine companies shall be used to stretch and operate the second line.

3. The first arriving ladder company shall be assigned to search and evacuate the fire floor.

4. The second arriving ladder company shall be assigned to augment the search and evacuation of the fire floor.

5. The third arriving ladder company shall be assigned to search and evacuate the floor above the fire.

6. The fourth arriving ladder company shall be assigned similarly, to operate on the upper floors.

7. The rescue company shall be used to perform special tasks as determined by the officer in command of the fire.

8. The second arriving battalion chief shall be assigned to establish and operate the operations post. (See Section 6.5) 


\subsection{TACTICAL CONSIDERATIONS}

6.4.1 A prime decision that the first arriving battalion chief must make is the placement of the first line. The following conditions must be considered:

A. To select the stairway from which to operate the first line (attack stairway), evaluate information received form operating units as to the location of the fire in relation to the stairways and the standpipe system.

B. The number of stairways serving the fire floor.

C. The stair or stairways being used by the occupants of the building.

1. A line shall not be operated from a stairway until it has been cleared of building occupants.

2. A stairway shall be selected for evacuation of building occupants (evacuation stairway) preferably a fire tower if available.

3. The specific fire floor and the floor above are initially all that are required to be evacuated. However, occupants of many other floors may self-initiate evacuation utilizing any or all stairways until instructed otherwise.

6.4.2 After the placement of the first line has been determined, the first arriving battalion chief then must consider the need for and the placement of the second line. The items to be considered in making this decision are:

A. Information received from operating units.

B. Number of stairways available to the fire area.

C. Type of construction:

1. center-core construction.

2. side-core construction.

3. non-core construction.

D. Location of the stairway with regard to the core.

E. Has the first line been stretched to the most advantageous position for attacking fire?

F. Has search and evacuation of the fire floor been completed.

6.4.3 Considering all the above items the placement of the second line may be used to:

A. Reinforce the position of the first line.

B. Protect the position of the first line.

C. Protect the search and evacuation of the fire floor.

D. Contain and confine fire spread and/or prevent fire from wrapping around the core and endangering operation of the first line. 
6.4.4 Is this fire within the reach of outside streams?

6.4.5 Are there any set-backs in the vicinity of the fire floor, which may be used for:
A. Ventilation?
B. Attack on the fire?
C. Search and evacuation?

6.4.6 Are there any horizontal exits to other buildings near the fire floor, which must be protected or may be used advantageously in the operation?

6.4.7 The time of day must be considered as this will affect:
A. The occupancy load.
B. The status of the buildings systems.
C. The response time of the units.

6.4.8 Ventilation by the removal of windows on the fire floor or other floors is not an initial consideration. It should be delayed until an evaluation can be made of its effect on air movement in the fire area and throughout the building. Before ventilation by the removal of windows is undertaken, safety precautions have to be taken in the area that will be affected by falling glass shards.

\subsection{OPERATIONS POST}

6.5.1 The second arriving battalion chief shall establish and man the operations post.

\subsubsection{Establishment of the operations post.}

A. It shall be established on the first floor below the fire, where conditions permit.

B. The location of the operations post shall insure reliable communications with the operating units and the lobby command post.

C. The operations post shall be equipped with the following:

1. High-Rise communications kit.

2. Resuscitator.

3. Masks for all personnel required for the operations of this post.

4. Copy of the floor plan.

5. Operations post log. [see Fig. 6-2] 
6.5.3 The chief in charge of the operations post shall be responsible for:

A. Control and coordination of the units operating on the fire floor and the floor above.

B. All communications between the operations post and the units operating within his sector.

C. All communications between the operations post and the lobby command post.

D. The implementation of the tactical procedures as received from the lobby command post.

E. Advising the lobby command post of conditions, problems and the need for additional units.

F. Consulting with the lobby command post as to additional tactical procedures required.

G. Communications with the staging area once it has been established.

H. Keeping in reserve an adequate number of units at the operations post for the orderly relief of unit operating on the fire floor and the floor above.

6.5.4 When conditions require, the third and fourth arriving battalion chief will operate under the direction of the chief in charge of the Operations Post. The Attack Chief shall direct unit attacks on the fire floor, and communicate progress reports to the Operations Post. Attack Chief and shall be assigned as conditions dictate. 


\section{COMMAND POST PROCEDURES}

7.1 INTRODUCTION

7.1.1 Fires in High-Rise office buildings place unique demands upon the fire service. The large floor areas, the height of the buildings, the large number of occupants and the complex building support systems, all require that the fire service establish procedures to command, control and coordinate our operations at fires within these buildings.

\subsection{COMMUNICATIONS}

7.2.1 The command, control and coordination of fire department operations at fires in High-Rise office buildings require a well defined and structured communications network, composed of the following elements: [see Fig. 7-1]

A. Equipment:

1. Fire Department Handie-Talkies.

2. High-Rise communications kits.

3. Fire Department radio.

4. Hard wire communication as follows:

a. Class "E" system.

b. Standpipe telephones.

c. In-house telephones.

d. Outside telephones.

e. Sound-powered phone systems.

5. Building Handie-Talkie radio network.

Note: At the present time extensive experimentation is being conducted with a Cross Band Repeater Radio System (WNYF-1st Issue 1981) and Sound Powered Phone Systems which will substantially alter our High-Rise communication procedures.

B. The lobby command post will be the center of all communications, and shall establish the following communications network:

1. Department radio and hard wire with the Fire Department dispatcher.

2. Handie-Talkie communications on the command channel with the operations post, staging areas and search and evacuation post. Hard wire communications also shall be established.

3. The chief in charge of the lobby command post shall operate on the command channel. His aide shall operate on and monitor the primary tactical channel.

4. Further information on Lobby Command Post in contained in Section 7.3. 
C. The chief-in-charge of the operations post shall establish the following communications network:

1. Handie-Talkie communications on the primary tactical channel with the units under his command. When the operations post is established, units under its command shall not communicate with the lobby command post unless urgent.

2. Handie-Talkie communications with the lobby command post on the command channel. Hard wire communications also shall be established.

3. Handie-Talkie communication between the operations post and the staging area shall be conducted on the command channel.

4. The chief-in-charge of the operations post shall operate on the primary tactical channel. His aide shall operate on the command channel.

5. Further information on Operational Post is contained in Section 7.4.

D. The chief in charge of the search and evacuation post (SAE) shall establish the following communications network:

1. Handie-Talkie communication with the units under his command on the secondary tactical channel. When the SAE post is established, units under its command shall switch to secondary tactical channel and shall not communicate with the lobby command post unless urgent.

2. Handie-Talkie communications with the lobby command post on the command channel. Hard wire communication also shall be established.

3. The chief in charge of the search and evacuation post will operate on the secondary tactical channel. His aide will monitor and operate on the command channel.

4. Further information on Search and Evacuation Post is contained in Section 7.5 .

E. The chief in charge of the Staging Area shall establish the following communications network:

1. Handie-Talkie communications with the lobby command post and the operations post on the command channel. Hard wire communications also shall be established with the lobby command post.

2. The chief in charge of the staging area shall operate on the command channel. His aide shall monitor the primary tactical channel.

3. Further information on Staging Area is contained in Section 7.6. 
7.2.2 In all communications directed to the lobby command post, the operations post, the search and evacuation post and the staging area, the post designation shall be used rather then the unit designation. Examples:
A. "Operations post to lobby command post
B. $\quad$ "Ladder 8 to operations post."
C. "SAE post to lobby command post."
D. "Lobby command post to staging area."

7.2.3 High-Rise communications kits shall be utilized at lobby command post (2), operations post (1) and staging area (1). [see Figure 7-1]

\subsection{LOBBY COMMAND POST}

7.3.1 The early establishment of a lobby command post will enable the chief in charge to exert central control over:
A. Evacuation.
B. Building systems.
C. The Fire Department units being deployed to locate, confine and extinguish the fire.

7.3.2 To assist the lobby command post, it may be necessary to establish areas of command as follows:
A. Operations post.
B. Search and evacuation post.
C. Staging area.

7.3.3 Location and description of lobby command post.

A. The lobby command post is established by the arriving units in an area in the building and manned by each succeeding officer in command. From this post operations conducted in the building by Fire Department units are coordinated and controlled. It shall afford the officer in command access to the following:

1. The fire safety director.

2. The fire safety plan.

3. Floor plans.

4. The class "E" communications system.

5. Outside telephone lines.

6. In-house telephone lines if available.

7. Building, elevator and window keys. 
B. The lobby command post shall be established at a location that provides the following:

1. Accessibility to incoming units.

2. Control of the elevators.

3. Control of the building fire command station.

4. Facilities for communications with the following:

a. Dispatchers.

b. The fire pump room.

c. The HVAC control center.

d. The operations post, SAE post and the staging area.

e. The building occupants.

7.3.4 Manning of the lobby command post.

A. The first arriving officer shall establish the lobby command post. In the event that he leaves the lobby command post before the arrival of a chief officer he shall designate a member to man the lobby command post, preferably the chauffeur of the first arriving ladder company. This member shall then note the units leaving the lobby command post and their destination.

B. The first arriving battalion chief shall assume command of the lobby command post. When he is relieved by the deputy chief, he shall remain at the lobby command post to assist in its operation.

7.3.5 Operations of the lobby command post.

A. The initial operations performed by the first arriving battalion chief are outlined in section 6 . To continue the initial operation and to meet the demands of an expanding fire situation the following shall be necessary:

1. Determine the need for additional evacuation and develop a plan for its implementation.

a. If necessary, establish a search and evacuation post (SAE).

2. Complete the command post check list.

3. Determine the need for additional assistance. (See Section 7.3.6)

4. Implement a plan for the use of the HVAC system.

5. Supply additional units as required to the operations post.

6. Provide additional mask cylinders to the operations post.

7. Account for elevators in all banks.

8. Using the floor plan for the fire floor, plot the location of the fire, the stairway or stairways being used for the attack, the stairway or stairways being used for evacuation and the location of the elevators in relation to the fire. 
9. Determine the safety of the service elevator for Fire Department use.

10. Provide fire department personnel to man and operate all elevators being used.

11. Determine the need for and if necessary, establish a staging area.

12. Establish a communications network as outlined in Section 7.2.

Note: The above twelve items will require time, a systematic approach and the assistance of one or more additional chief officers to assure each item is checked and updated as conditions change.

\subsubsection{Deleted.}

7.3.7 The chief in charge of the lobby command post has the responsibility of supplying logistical support to the operations post, SAE post and the staging area. This support shall consist of manpower and equipment. To accomplish this, he shall do the following:

A. Supply sufficient units to the operations post to support the operations on the fire floor and the floor above.

B. Supply sufficient units to the SAE post to support the operations on the floors above the fire. At least one unit for every five floors to be covered shall be supplied (use more units if necessary).

C. Supply sufficient units to the staging area to enable it to meet the needs of the operations post. At least three engines and two ladder companies shall be at the staging area for immediate support of the operations post.

D. Supply sufficient spare Scott cylinders to the staging area to support operations. A supply of at least 20 spare cylinders shall be maintained at the staging area.

E. Engine companies reporting to the staging area shall bring with them the following equipment unless otherwise directed:

1. A mask for each member.

2. A standpipe kit and a nozzle.

3. A length of hose per member.

4. A spare Scott cylinder for each member.

F. Ladder companies reporting to the staging area shall bring with them the following equipment, unless otherwise directed:

1. A mask for each member.

2. Two sets of forcible entry tools and six foot hooks.

3. Search and utility ropes.

4. A spare Scott cylinder for each member. 
G. The High-Rise Unit shall be used by the chief in charge of the lobby command post as a logistical support unit to supply the following:

1. Spare Scott cylinders to the staging area or other areas of the building where required.

2. Special tools and equipment to areas of the building as directed by the chief in charge.

7.3.8 A predesignated unit, that has been trained and equipped to operate as a command post company, shall be utilized to assist the chief in charge of the lobby command post. Its duties shall be as follows:

A. Maintain the command post log. [see Fig. 7-2]

B. Control the operations of all the elevators.

C. Insure the proper manning of all elevators.

D. Any other duties as deemed necessary. by the chief in charge of the lobby command post.

7.3.9 Smoke movement in High-Rise buildings and measures to control or remove it are subjects of continuing research. Based on past fire experience and the behavior of normal air movements in tall buildings, a plan for the removal of smoke from the fire building may be developed. Ventilation of High-Rise office buildings shall be supervised and implemented by the chief in charge of the lobby command post. He shall attempt to control the movement of smoke within the building by the following means:

A. The use of the HVAC systems as outlined in Section 4.

B. The use of the Fire Department smoke ejectors (two 9,500 CFM fans) to supply air to the attack stairway three floors below the fire floor. With the doors closed at the top and bottom of the stairway, this will pressurize the stairway in the vicinity of the fire floor, decreasing the stack effect and limiting the spread of smoke throughout the building This will also decrease the effect of drawing the heat and smoke to the stairway causing the member making the attack to be in a high heat area.

C. The smoke ejectors may also be used with the doors open at the top and bottom of the stairway. This will increase the stack effect and assist in the removal of smoke via the stairway,

D. Vertical ventilation is venting the top and bottom of vertical shafts to the outer air. Vertical ventilation is influenced by the stack effect as follows:

1. Its effect becomes noticeable in buildings over 60 feet, and increases as the building's height increases.

2. Its effect can be either positive or negative.

a. The positive stack effect is the upward movement of air in a vertical shaft.

b. The negative stack effect is the downward movement of air in a vertical shaft. 
3. Positive stack effect increases as the outside air temperature decreases in relation to the temperature inside the building.

4. Negative stack effect may occur when the outside temperature is greater than the temperature inside the building. Its possibility is greatest when the outside air temperature is above $90 \mathrm{~F}$.

5. Its effect is intensified by the speed and direction of the wind.

6. To obtain the greatest benefit from the stack effect, the doors at the top and bottom of the stairway must be opened when a stairway is used for smoke removal. The street floor near this stairway must also be vented to the outer air.

CAUTION: When using a stairway for smoke removal, an adverse condition could occur on the fire floor, causing heat and flames to be drawn toward the stairway being used. The drawing of heat and smoke toward stairways is especially evident whenever fire towers have been utilized. Due to this experience, fire towers are not recommended for use as fire attack stairs.

E. Horizontal ventilation by the removal or opening of windows is begun, safety precautions shall be taken in the area that will be affected by failing glass shards.

1. Horizontal ventilation should be the last consideration as its effects are least likely to be beneficial.

a. The stack effect of vertical shafts could cause the movement of air into the building and not allow the smoke to escape to the exterior.

7.3.10 The chief in charge of the lobby command post shall control street operations as follows:

A. Establish communication with the police department superior officer on the scene to clear pedestrian and vehicular traffic on all sides of the fire building.

B. Establish exterior inspection by Fire Department personnel of all sides of the fire building to report the following:

1. Fire and smoke conditions.

2. Persons in distress.

3. Any unusual conditions.

7.3.11 Other considerations of the chief in charge of the lobby command post shall include:

A. The early response of the mask service unit.

B. The establishment of a suitable area within the building for the treatment of injured civilian and Fire Department personnel.

C. The response of emergency medical service and Fire Department ambulances. 
7.4.1 The operations post is an area in the building established by the second arriving battalion chief. Its purpose is the control and coordination of all operations conducted on the fire floor and initially on the floors above.

7.4.2 The operations post shall be established at a location that provides:
A. Proximity to the units operating on the fire floor usually the floor below the fire.
B. Hard wire communications to the lobby command post (Building internal phone system or NYFD Sound Powered Phone System).
C. Reliable Handie-Talkie communications with the units operating under his command.
D. Adequate space for units being held in reserve.
E. Accessibility to units reporting to the operations post.

7.4.3 The operations post shall be equipped with:
A. At least two Handie-Talkies.
B. The High-Rise communications kit.
C. A resuscitator.
D. Masks for all members assigned to the operations post.
E. A copy of the floor plan.
F. The operations post log. [see Fig. 6-2]

7.4.4 The operations post shall be manned as follows:
A. Prior to the arrival of the second battalion chief, the chief in charge of the lobby command post shall designate an officer of one of the first arriving units to coordinate the operations on the fire floor and the floor above.
B. The second arriving battalion chief shall establish and command the operations post, assisted by his aide.
C. The second arriving battalion chief shall remain in command until relieved by the special called deputy chief responding on the 10-76 signal.
D. The deputy chief in :charge of the operations post may establish sectors commanded by attack chiefs to coordinate and control units operating on the fire floor and the floor above.


7.4.5 The operations performed by the chief in charge of the operations post are outlined in Section 6.5. In addition, he shall:

A. Insure that the attack stairway has been cleared of building occupants for at least five floors above the fire.

B. Insure that the evacuation stairway is maintained safe for any required evacuation and for use by Fire Department personnel.

C. Review the operations of the first arriving units to determine the need for changes in tactics or procedures.

D. Advise the lobby command post as to the need for and the placement of the second line in accordance with procedures as outlined in section $6,4.2$ and 6.4.3.

E. Prior to the establishment of the staging area, advise the lobby command post of the need for:

1. Additional units.

2. An adequate supply of Scott cylinders.

3. Any additional equipment that may be needed.

F. After the establishment of the staging area, obtain the items as listed in "E".

G. Advise the lobby command post of the need for additional evacuation of the floors above the fire.

\subsection{SEARCH AND EVACUATION POST (SAE)}

7.5.1 The SAE post is established within the building by the third or fourth arriving battalion chief. Its purpose is the control and coordination of all operations conducted above the fire operations (fire operations is defined as the fire floor and one floor above).

7.5.2 The criteria for the location of the SAE post shall be dependent on the following:

A. Fire location and severity

B. Handie-Talkie effectiveness

C. If possible the SAE post shall be established on a floor which is not serviced by the same bank of elevators as the fire floor. [see Fig. 7-3]

Example:

1. If the fire were on a floor serviced by the low rise bank of elevators the SAE post would be established on the 17th floor or at least five floors above the fire floor.

2. If the fire were on a floor serviced by the intermediate bank of elevators the SAE post would be established on the 31 st floor or at least five floors above the fire floor.

3. When the fire is on a floor serviced by the High-Rise bank of elevators, the SAE post should be established five floors above the fire. 
7.5.3 The SAE post shall be equipped as follows:

1. At least 2 Handie-Talkies.

2. A resuscitator.

3. Masks for all members assigned to the SAE post.

4. A spare Scott cylinder for each member assigned to the SAE post.

5. Floor diagram, Pad and Pen.

7.5.4 The SAE post shall normally be manned by the third or fourth arriving battalion chief and his aide.

7.5.5 The chief in charge of the SAE post shall be responsible for the following:

A. The control and coordination of all units operating above the fire operations area.

B. Obtaining from the lobby command post sufficient units for the operations on the upper floors. All units assigned above the fire operations area shall bring with them a spare Scott cylinder.

C. Preventing unnecessary evacuation and avoiding panic.

D. Controlling necessary evacuation.

1. By the use of the evacuation stairs.

2. By the use of smoke-free blind shaft elevators manned by Fire Department personnel.

E. Preventing the use of the attack stairs for evacuation.

F. Ensuring that all floors above the fire operations area have been searched.

G. Establishing the required communications as outlined in Section 7.2.1 D.

H. Advising the lobby command post of conditions and problems encountered on the upper floors.

\subsection{STAGING AREA}

7.6.1 The staging area is established within the building by a battalion chief. Its purpose is to provide logistical support to the operations post.

7.6.2 The staging area shall be established at a location:

A. Two floors below the operations post.

B. Where there is adequate space to hold units and equipment in reserve.

C. Where the units have ready access to the operations post.

D. That provides hard wire communications to the lobby command post.

E. That provides reliable Handie-Talkie communications between the staging area and the operations post and the lobby command post.

F. That is accessible to units reporting to it. 
7.6.3 The staging area shall be equipped as follows:
A. At least two Handie-Talkies.
B. The High-Rise communications kit.
C. Resuscitator.
D. Staging area log. [see Fig. 7-4]

7.6.4 The staging area shall be manned by a battalion chief and his aide.

7.6.5 The chief in charge of the staging area shall be responsible for the following:

A. Control of all units being held in reserve and those units on R \& R.

B. Obtaining from the lobby command post sufficient units to adequately meet the demands of the operations post. At least three engine and two ladder companies shall be maintained in reserve at the staging area.

C. Maintaining communications with the operations post on the command channel.

D. Maintaining at least 20 spare Scott cylinders.

E. Providing for the treatment and transportation of all injured members to the lobby command post.

\subsection{FORWARD TRIAGE AREA}

7.7.1 The Forward Triage Area (FTA) is established within the building by the Incident Commander.

7.7.2 Its purpose is to ensure the prompt response to fire victims and members.

7.7.3 The FTA shall be established in an environmentally safe location on a floor below the staging area. If conditions deteriorate on this floor, EMS personnel shall change locations. The IC shall be advised.

7.7.4 The IC shall determine, in consultation with the senior Bureau of EMS (BEMS) officer on scene, proper staffing levels of EMT's, Medics and EMS supervisors for the FTA.

\section{CLASS "E" COMMUNICATION SYSTEMS}

\subsection{INTRODUCTION}

Because of the large number of people working in office buildings, the large floor areas and the number of floors involved, a system to alert and direct the occupants in the event of a fire and to transmit an alarm to the Fire Department is required. To meet this need, Local Law No. 5 of 1973 provides for the installation of a Class "E" communications system in Class "E" office buildings. 


\subsection{DESCRIPTION}

8.2.1 Class "E" communications systems shall consist of:

A. The fire command station located in the lobby of the building near the elevator control panel.

B. Loudspeakers, operated from the fire command station, which are located on all floors, in all elevators and in all stairway enclosures.

C. Floor warden stations on each floor which provide two-way communications with the fire command station.

D. Manual fire alarm sending stations on each floor.

E. Associated systems:

1. Smoke detection systems.

2. Sprinkler water flow alarms.

3. Thermostatic alarms.

4. Locked door fail safe system.

8.2.2 The fire command station shall include:

A. A hinged cover which permits the flashing "FIRE" signal to be seen. The hinged cover shall be provided with a lock and key.

B. An information display unit capable of monitoring the following systems in order of priority:

1. Manual fire alarm.

2. Smoke detectors.

3. Sprinkler water flow alarms.

4. Elevator lobby detectors.

5. Fire alarm activation.

6. Central office notification.

7. Fan system on / Fan system off.

8. Locked door fail safe system.

9. Fire system trouble.

10. Fire signal trouble.

11. Tamper switch alarm.

12. Power source indicator.

13. Test/normal mode switch.

14. Other information displays as desired. 
C. Two-ivay communications between the fire command station and the following:

I. Floor warden stations.

2. Mechanical control center.

3. Elevators.

4. Air handling control rooms.

5. Elevator machinery rooms.

D. A public address system to all floors, elevators and stairways either selectively or collectively.

E. The capability to transmit an alarm from the fire command post to the Fire Department via a central station.

F. While Local Law No. 5 mandates specific controls and items that must be displayed at the command station, it gives wide latitude to each manufacturer regarding the physical design and hardware that may be used. As a result, many different systems are utilized. This makes an intimate knowledge of each system difficult. Utilize building engineers or fire safety directors (if available) to assist in extracting all information possible from the equipment and an accurate input of Fire Department requirements as ordered by the chief in command of the fire.

8.2.3 A floor warden station shall be located on each floor between the required exits. It shall be provided with:

A. A telephone type handset.

B. Capability to activate a visual and audible signal at the fire command station.

C. Two-way voice communications with the fire command station.

D. Provisions for making announcements over the loudspeaker system on the floor where it is located.

E. A handset, housing and door painted red and lettered "Fire Emergency-Open Door to Operate".

8.2.4 At least one manual fire alarm sending station shall be located in each path of escape in each story of a building. Additional stations shall be installed so that no point on any floor shall be more than 200 feet from the nearest station. The activation shall cause:

A. Automatic transmission to the Fire Department via a central station.

B. A visual and audible signal at the fire command station, mechanical control center and the regularly assigned location of the fire safety director.

C. Sounding of the alarm on the fire floor and the floor above. 
8.2.5 An approved combustion ionization detection device or a combination of an approved smoke detecting device and an approved fixed temperature thermostatic device shall be installed:

A. At each elevator landing, the activation of this device shall:

1. Recall the elevators.

2. Sound the fire alarm signal on the fire floor and the floor above.

3. Cause a fire alarm signal to be transmitted to the Fire Department via a central station.

4. Cause a fire alarm signal to be sounded at the fire command station, the mechanical control center and the regularly assigned location of the fire safety director.

5. Stop the air supply into and the return air from the floor where activated.

6. Activate the air exhaust fans and dampers in the smoke shaft or the pressurizing fans in the stair enclosure.

7. Unlock the doors on the locked fail safe system.

B. Within the HVAC system, the activation of this device shall accomplish all of the actions listed in $8.2 .5 \mathrm{~A}$ with the exception of recalling the elevators.

8.2.6 The activation of a sprinkler water flow alarm shall accomplish all of the actions as listed in Section 8.2.5A.

\subsection{UTILIZATION OF THE CLASS "E" SYSTEM}

8.3.1 The chief in charge of the command post will be able to obtain the following information from the fire command station:

A. The location and time of activation of the:

1. Manual pull stations.

2. Smoke detecting devices.

3. Thermostatic detecting devices.

4. Sprinkler water flow alarms.

B. Status of the HVAC system.

C. Status of the elevators.

8.3.2 The communication features of the class "E" system can be used as follows:

A. The public address system:

1. To communicate with the building occupants.

2. To control evacuation.

3. To communicate with Fire Department personnel. 
B. The warden telephone system:

1. To communicate with the floor wardens.

2. To establish hardwire communications with Fire Department personnel at the:

a. Operations Post.

b. SAE Post.

c. Staging area.

d. Other locations.

C. Two-way communications with:

1. Elevators.

2. Fire Pump room.

3. Mechanical control center.

4. Air handling control center. 


\section{LADDER COMPANY OPERATIONS}

\subsection{INTRODUCTION}

9.1.1 Fires in High-Rise office buildings present unusual complex problems to the first arriving units. It is essential that the first alarm ladder companies define the fire problem and convey this information to the officer in charge and provide for the rescue and evacuation of occupants in affected areas. The information gathered by the first alarm ladder companies and relayed to the lobby command post will determine to a large extent the success of the overall fire operations.

\subsection{LADDER COMPANY RESPONSIBILITIES}

9.2.1 General goals of first alarm ladder companies.
A. Gain control of elevators.
B. Locate fire floor and determine the best access thereto.
C. Ascertain the general area and extent of the fire on the floor.
D. Provide the necessary search and evacuation of occupants on the fire floor.
E. Conduct a preliminary search and examination of the floor above the fire.
F. Initiate search and examination of the upper most floors of the building.
G. Reconnaissance of the exterior of the building.

\subsection{FIRST ARRIVING LADDER COMPANY}

9.3.1 The first arriving ladder company shall:

A. Obtain as much information as possible from the fire safety director or his surrogate as to:

1. Location of the fire.

2. Evacuation procedures that have been implemented.

3. Status of elevators.

4. Access stairs serving the fire floor.

B. Prior to leaving the lobby:

1. Determine the elevator bank that provides the safest access to the fire area and place the elevator cars to be used on "Firemen Service".

2. Obtain floor plan of the fire area. If only one copy is available do not remove it from the fire command station.

3. Obtain keys necessary to gain access to the fire floor.

4. Insure that the lobby command post is manned by a fire department member. 
5. Due to HVAC and the stack effect, smoke can permeate the entire zone (up to 25 floors) and cause confusion as to the specific fire floor. Numerous reports of fire or smoke may be received and even the original alarm may be from the incorrect floor. Always be prepared for the unexpected, especially when elevators are being utilized.

C. Conduct a preliminary inspection of the exterior of the building by the chauffeur for:

1. Persons in distress.

2. Smoke or fire showing through the skin of the building.

3. The need for any exterior operations.

D. Proceed to a floor at least two floor below the fire floor using a "Firemen Service" elevator as outlined in section 3. A fireman equipped with a Handie-Talkie shall be assigned to remain with the elevator and to operate the elevator until relieved.

E. Upon arrival at the floor below the fire. conduct the following operations and relay all information obtained to the lobby command post:

1. Determine if the reported fire floor is the correct location and return the elevator to the lobby to transport the engine companies.

2. Determine the heat and smoke condition on the fire floor.

3. Determine the life hazard on the fire floor and initiate evacuation procedures where required.

4. Determine the location of the fire on the floor and select a stairway with a standpipe that will provide the best attack on the fire.

5. Conduct a primary search of the fire floor.

6. Provide support to the advancing Engine Company by:

a. Removing obstructions.

b. Forcing entry.

c. Opening the ceiling to expose the plenum.

\subsection{SECOND ARRIVING LADDER COMPANY}

9.4.1 Due to the utilization of manpower from the 1st arriving Ladder Company for:

A. Examination of building exterior.

B. Elevator car operator.

C. Temporary Lobby Command Post supervisor, plus the large area that MUST be searched mandates that the second arriving Ladder Company assists in the search and evacuation of the fire floor. 
9.4.2 The second arriving ladder company shall:

A. Report to the lobby command post.

1. Determine if the fire floor has been verified by the first arriving ladder company.

2. Obtain an elevator car that provides the safest access to the fire area and place the car on "Firemen Service". If possible, the same elevator car used by the 1st arriving, ladder (manned by a H.T. radio equipped member of the 1st ladder company) should be utilized. If a different car must be utilized, a H.T. radio equipped member of the 2 nd ladder shall be assigned to remain with the elevator and operate car until relieved.

3. Upon arriving at the floor below the fire (or on the fire floor) obtain as much information as possible from the 1st arriving ladder company - areas searched, fire area location, occupants reported missing, etc.

4. Coordinate the search operation of fire floor with first arriving ladder company.

\subsection{THIRD ARRIVING LADDER COMPANY}

9.5.1 The third arriving ladder company shall:

A. Report to the lobby command post.

1. Determine if the fire floor has been verified by either the 1 st or 2 nd arriving ladder company.

2. Obtain an elevator that provides the safest access to the fire area and place the car on "Firemen Service".

3. Proceed to a floor at least two floors below the fire floor, using a "Firemen Service" elevator as outlined in section 3.

Note: The 1st arriving and possibly the 2 nd arriving ladder company will already have a H.T. radio equipped member operating one of the "Firemen Service" elevators. Use these cars if available rather than losing a member to operate another car. In ALL cases each elevator car used to transport Fire Dept. members a H.T. equipped member shall be assigned to operate the car. These cars shall then be returned promptly to the lobby to transport additional men or equipment. 
B. Upon arriving at the floor below the fire, obtain as much information as possible from the 1 st or 2 nd arriving ladder company OR by a rapid survey or reconnaissance of this floor and stairway serving it. Signs posted in elevator lobbies ("YOU ARE HERE" signs) can also be used for such familiarization. The Officer and member shall then:

1. Determine the number of stairways serving the fire floor and the floor above.

2. Proceed to the floor above the fire via a stairway other than the attack stairway.

3. Determine which stairway is the best stairway to be used by the occupants for evacuation and advise the lobby command post.

4. Examine the floor above the fire and report to the lobby command post the following:

a. The heat and smoke conditions.

b. The status of the evacuation.

c. Any extension of the fire.

d. Presence of Access Stairs - Down to Fire Floor or Upward to Floor Above.

5. Examine all stairways for occupants and smoke condition.

6. Remove all occupants from the attack stairway for a reasonable distance above the fire floor and prevent its use by the occupants.

7. If difficulty is encountered in clearing the attack stairway of occupants, the officer shall advise the first arriving ladder company or the operations post to withhold the attack until the occupants have been safely removed.

8. Conduct a primary search of the floor above the fire.

C. When his operations are completed on the floor above the fire, report to the operations post either physically or via H. T Radio.

D. Notification to Chief in Charge of Command Post or Operational Post of Missions NOT accomplished can be more important than assignments accomplished. 


\subsection{FOURTH ARRIVING LADDER COMPANY}

9.6.1 The Fourth arriving ladder company shall:

A. Report to the lobby command post.

1. Each member shall be equipped with an extra Scott cylinder.

2. Obtain an elevator that provides the safest access to the roof.

a. If the fire is on a floor that is not serviced by the High-Rise bank of elevators, the High-Rise bank will be used if it is in a blind shaft.

b. If the fire is on a floor that is serviced by the High-Rise bank of elevators, they shall proceed to a location below the fire floor and then use a stairway other than the attack stairway to proceed to the roof.

c. If the High-Rise bank of elevators is used, assign a member equipped with a Handie-Talkie to operate the "Firemen Service" elevator until relieved.

B. Upon arrival at the roof area the officer shall:

1. Report the following conditions to the lobby command Post.

a. Smoke and heat conditions in the area and in the stairways.

b. The presence of any building occupants.

c. All means available for roof ventilation, especially over stair ways and elevator shafts.

d. Any unusual conditions.

e. Fire or occupants at windows visible from roof.

C. Not undertake roof ventilation unless ordered by the Chief in Charge of the lobby command post.

D. Determine the identification of all stairways and elevator shafts so that when ordered, the correct ventilation can be carried out.

E. Conduct a primary search of the top five floors.

F. Remove any occupants to a safe area or assure the occupants what they are safe to remain where they are.

G. Remain in the roof area to monitor and report any changing condition until other wise ordered by the lobby command post.

H. A logical assignment after roof operations would be the terminal floor of elevator bank serving the fire floor.

I. Operate under the control of the lobby command post until the SAE post is established. They shall then operate under the command of the SAE post.

\subsection{CARBON MONOXIDE METERS}

9.7.1 All ladder companies equipped with Carbon Monoxide Meters, when responding to hi-rise fires after the Second Alarm assignment, shall report to the Lobby Command Post with their Meters. 


\section{ENGINE COMPANY OPERATIONS}

\subsection{INTRODUCTION}

10.1.1 The many variables and complexities built into High-Rise office buildings may be compounded by both the fire location and the fire load within the tenant space on the floor.

10.1.2 Many fires will be within easy reach of hose streams operated from the immediate area of the stairway enclosure, but other fires may require both the combining of rolled up lengths and manpower of the first and second due units to advance the first hose line.

\subsection{ENGINE COMPANY RESPONSIBILITIES}

10.2.1 The general goals of the first alarm engine companies are:

A. To stretch sufficient hose to reach the fire and be able to operate effectively during the initial stages of operation.

B. Provide relief of the member operating the first hose lines.

C. Supply the standpipe and sprinkler systems as per sec. 5 .

\subsection{FIRST ARRIVING ENGINE COMPANY}

10.3.1 The first arriving engine company shall:

A. If first to arrive, obtain as much information as possible from the fire safety director or his surrogate with regard to:

1. Location of the fire.

2. Evacuation procedure that have been implemented.

3. Status of the elevators.

4. Access stairs serving the fire floor.

B. Remain at the lobby command post until the first ladder company has verified the fire location.

C. Proceed to the upper floor via the elevator manned by the member of the first ladder company.

D. With the assistance of the second arriving engine company, stretch a hose line from the standpipe outlet on the floor below the fire in the designated stairway.

E. Operate the first hose line until relieved by the second arriving engine company. 


\subsection{SECOND ARRIVING ENGINE COMPANY}

10.4.1 The second arriving engine company shall:

A. Report to the officer in command of the lobby command post.

B. Proceed to the location of the first engine company via a manned "Firemen Service" elevator.

C. Assist the first arriving engine company in stretching sufficient hose to reach the fire.

D. Provide Handie-Talkie communications between the standpipe outlet and the nozzle by having the officer of the second arriving engine company remain at the outlet until the hose line is operating at the correct nozzle pressure.

E. Leave the fire area when the hose line has been stretched and is operating so as not to deplete their air supply.

F. Coordinate with the officer in command of the first hose line so that the relief of members operating the line can be accomplished before their masks are expended.

\subsection{THIRD AND FOURTH ARRIVING ENGINE COMPANIES}

10.5.1 The third and fourth arriving engine companies shall:

A. Report to the chief in charge of the lobby command post.

B. Operate in a manner similar to the first and second engine companies to stretch the second hose line.

C. Stretch and operate the second hose line as directed by the chief in charge of the operations post or the lobby command post. This hose line may be used to:

1. Reinforce the position of the first line.

2. Protect the position of the first line.

3. Protect the search and evacuation of the fire floor.

4. Contain and confine fire spread and/or prevent fire wrapping around the core and endangering operation of the first line. 


\subsection{GREATER ALARM ENGINE COMPANIES}

10.6.1 Greater alarm engine companies shall report to the lobby command post for assignment to the operations post, SAE post or the staging area. Some of the duties they may be assigned to are:
A. Relieve any of the first alarm units.
B. Stretch additional hose line on the fire floor or the floors above.
C. Assist in the search and evacuation of upper floors.
D. Transport special tools and equipment to the staging area.

10.6.2 Units, without specific orders to the contrary shall bring masks, rolled up lengths and spare Scott cylinders to lobby area. If not required for their specific use, such equipment will be added to staging area supply for future use by units engaged in actual fire fighting operations.

BY ORDER OF THE FIRE COMMISSIONER AND THE CHIEF OF DEPARTMENT 


\section{DCN: 3.02.02 FIREFIGHTING PROCEDURES HIGH RISE OFFICE BUILDINGS}

APPENDIX 1 - REFERENCE FIGURES

January 1, 1997

Appendix I

Fire Fighting Procedure High Rise Office Buildings

Reproduced with permission of The Fire Department of the City of New York 


\section{Figure 2-1}

\section{COMPOSITE FLOOR}

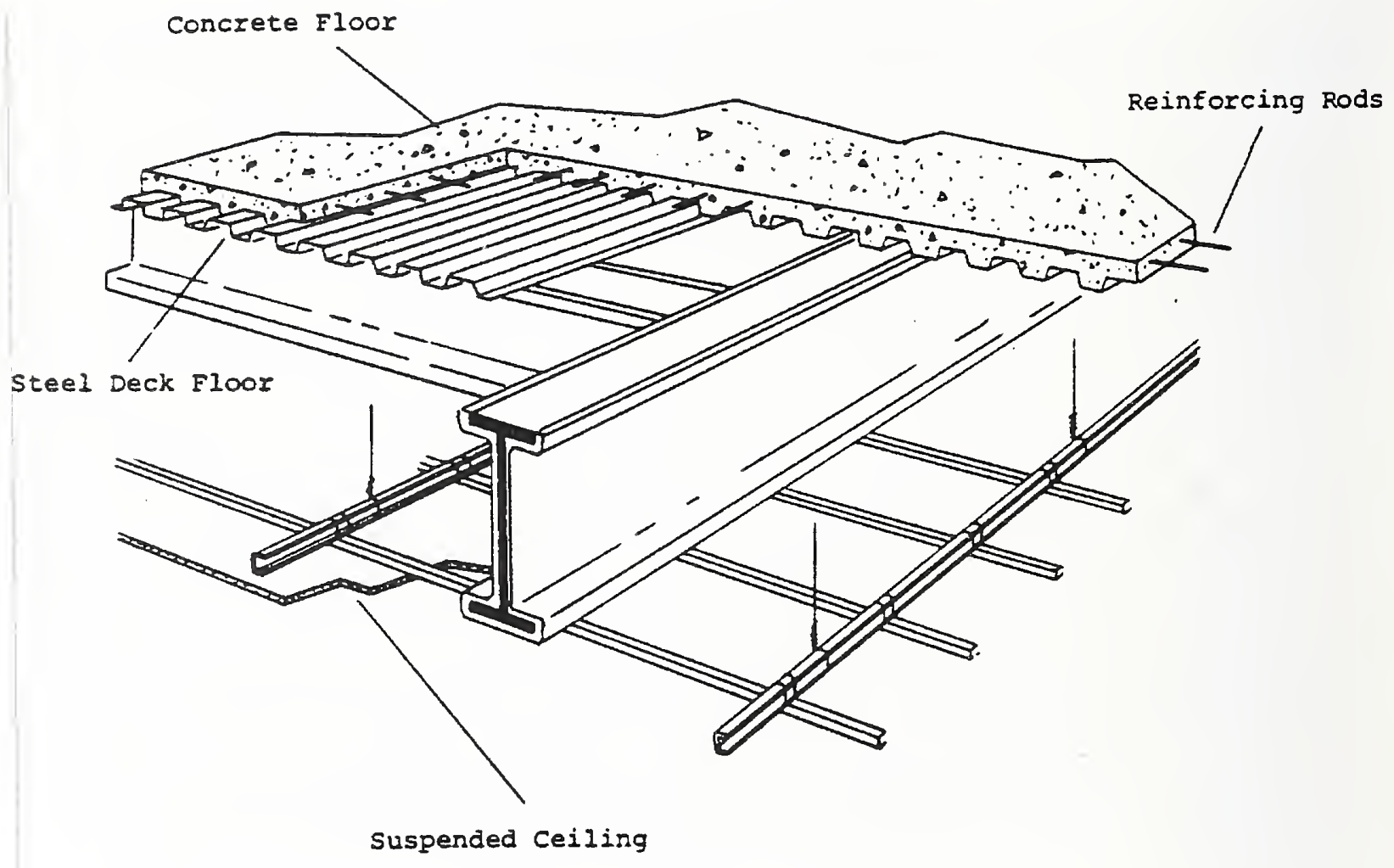


Figure 4-1

MER EQUIPMENT

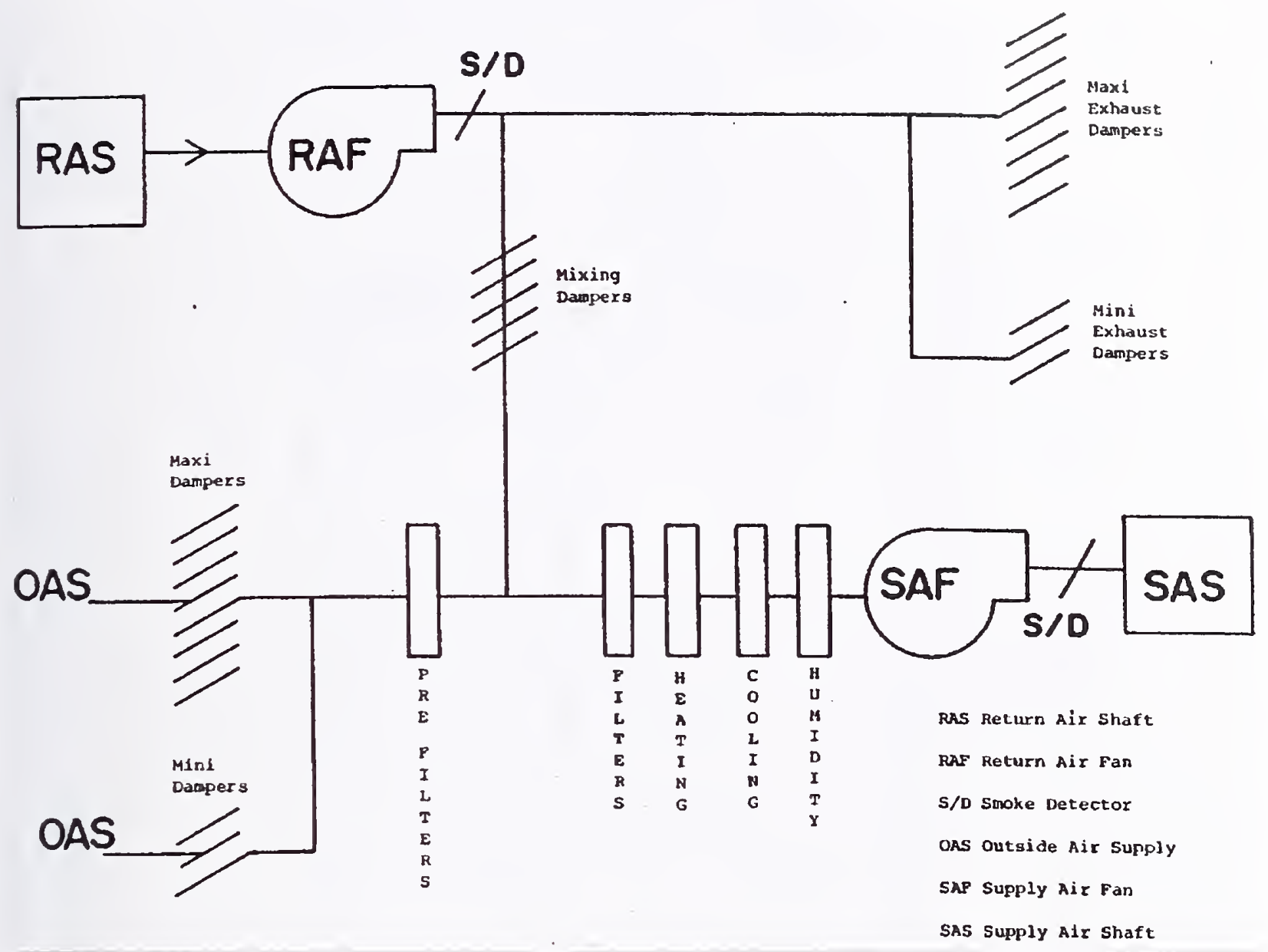


Figure 4-2

\section{HVAC DISTRIBUTION SYSTEM}

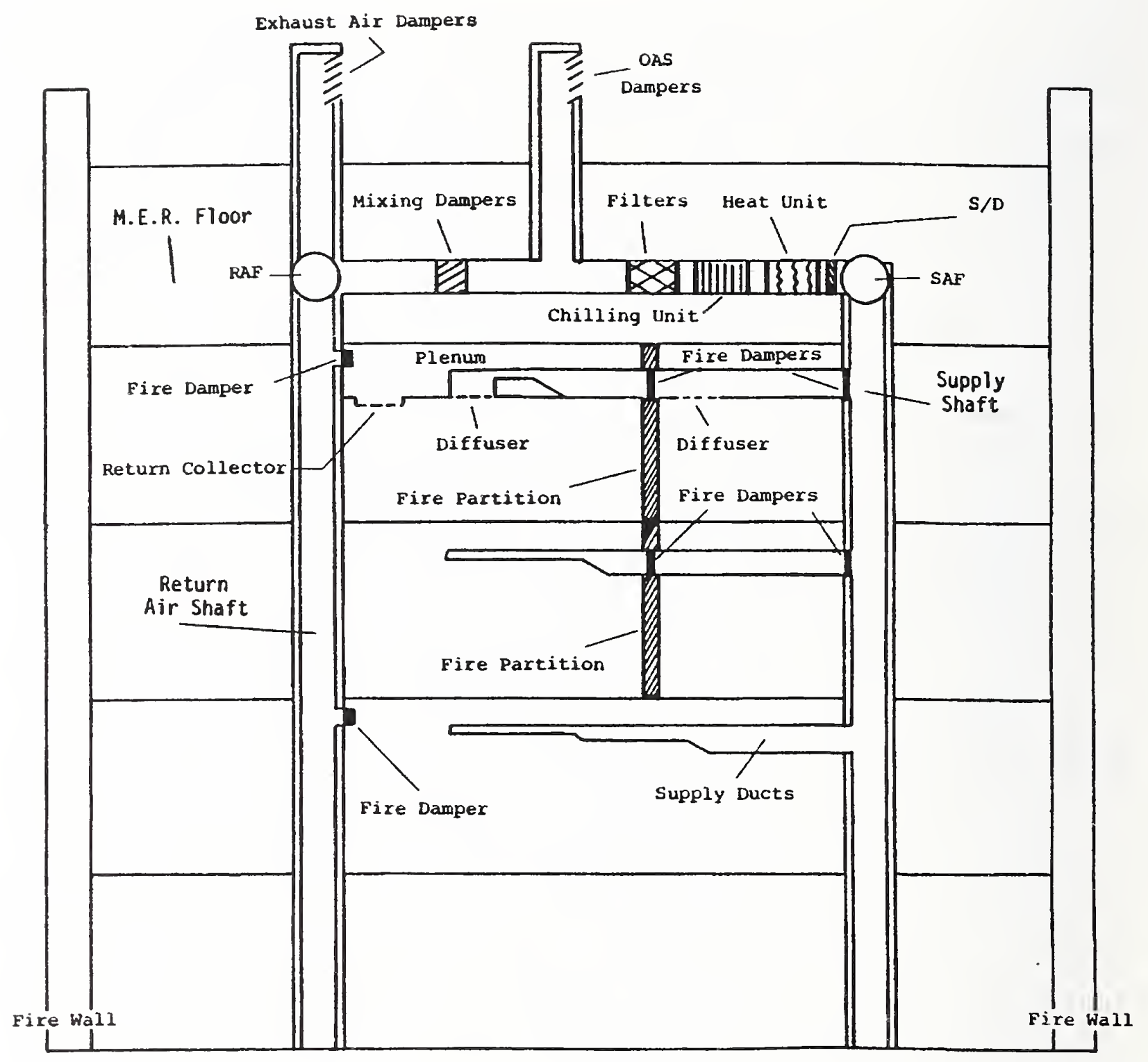


Figure 4-3

HVAC ZONES

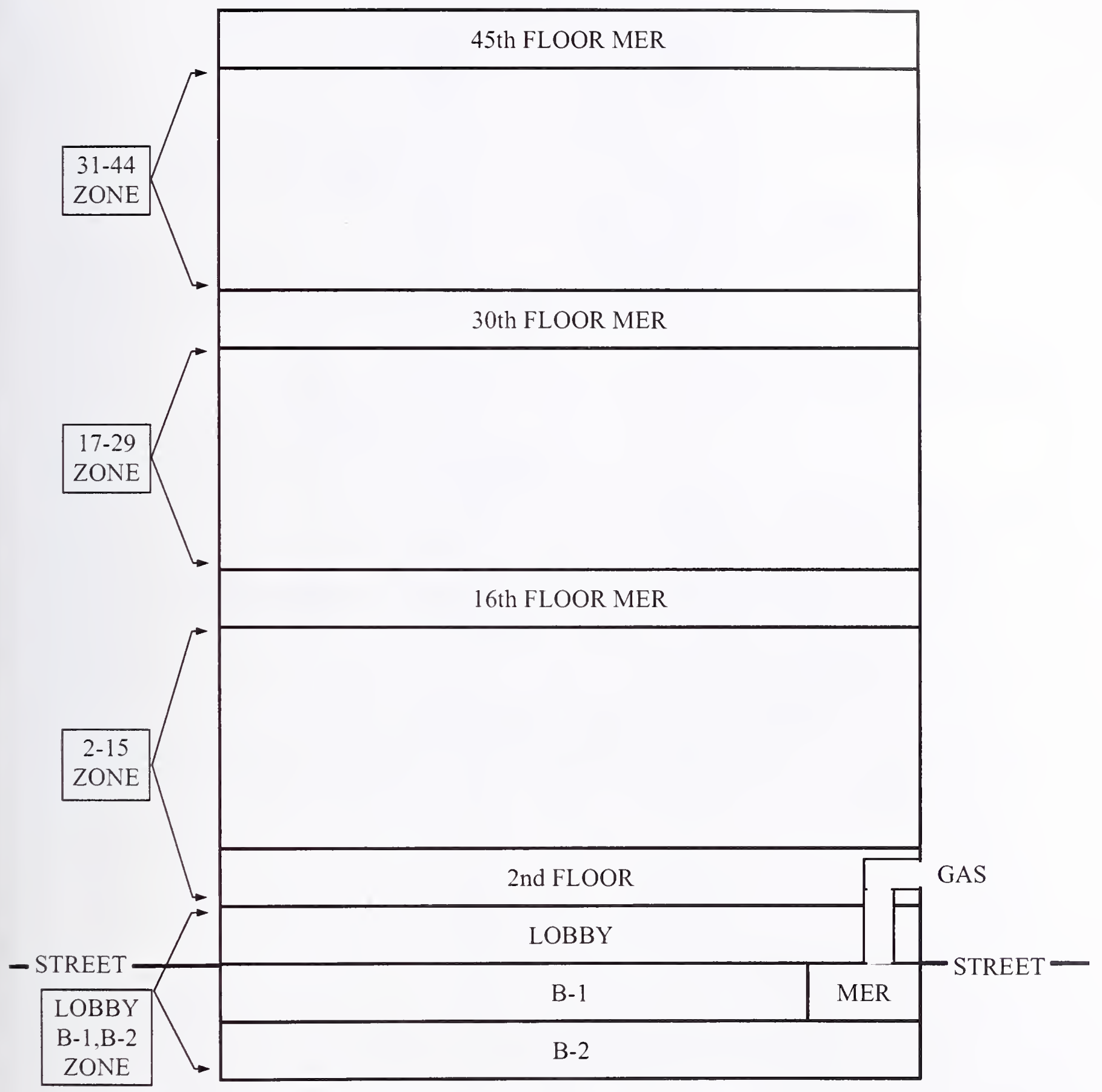


Figure 2-1

HVAC (6 ZONES)

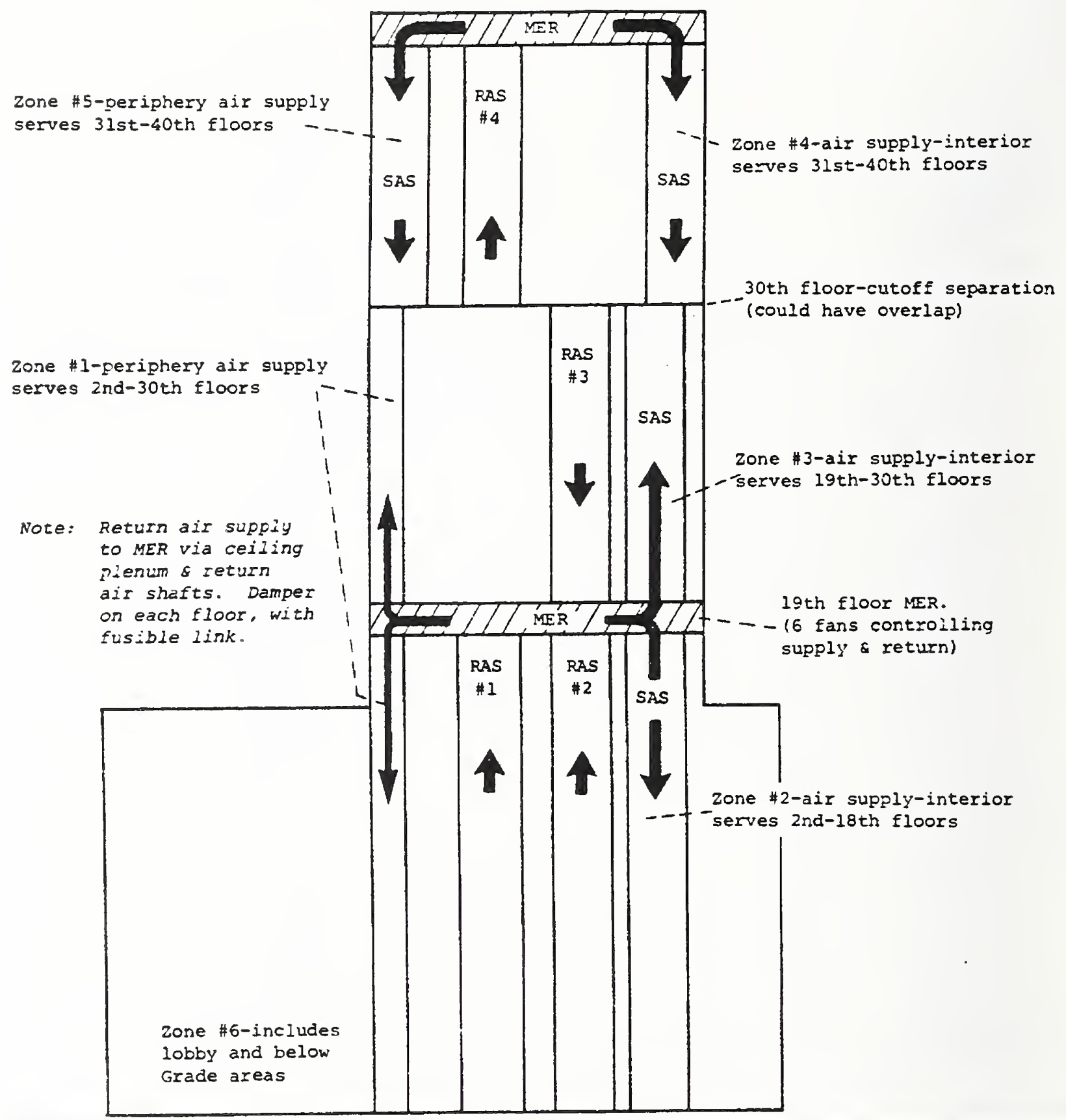

NOTE: Drawing simplified, each supply zone could be interchanged due to fan arrangement 
Figure 5-1

MODEL FIRE PUMP

SHOWING POSSIBLE BYPASS \& BYPASS VALVE LOCATION

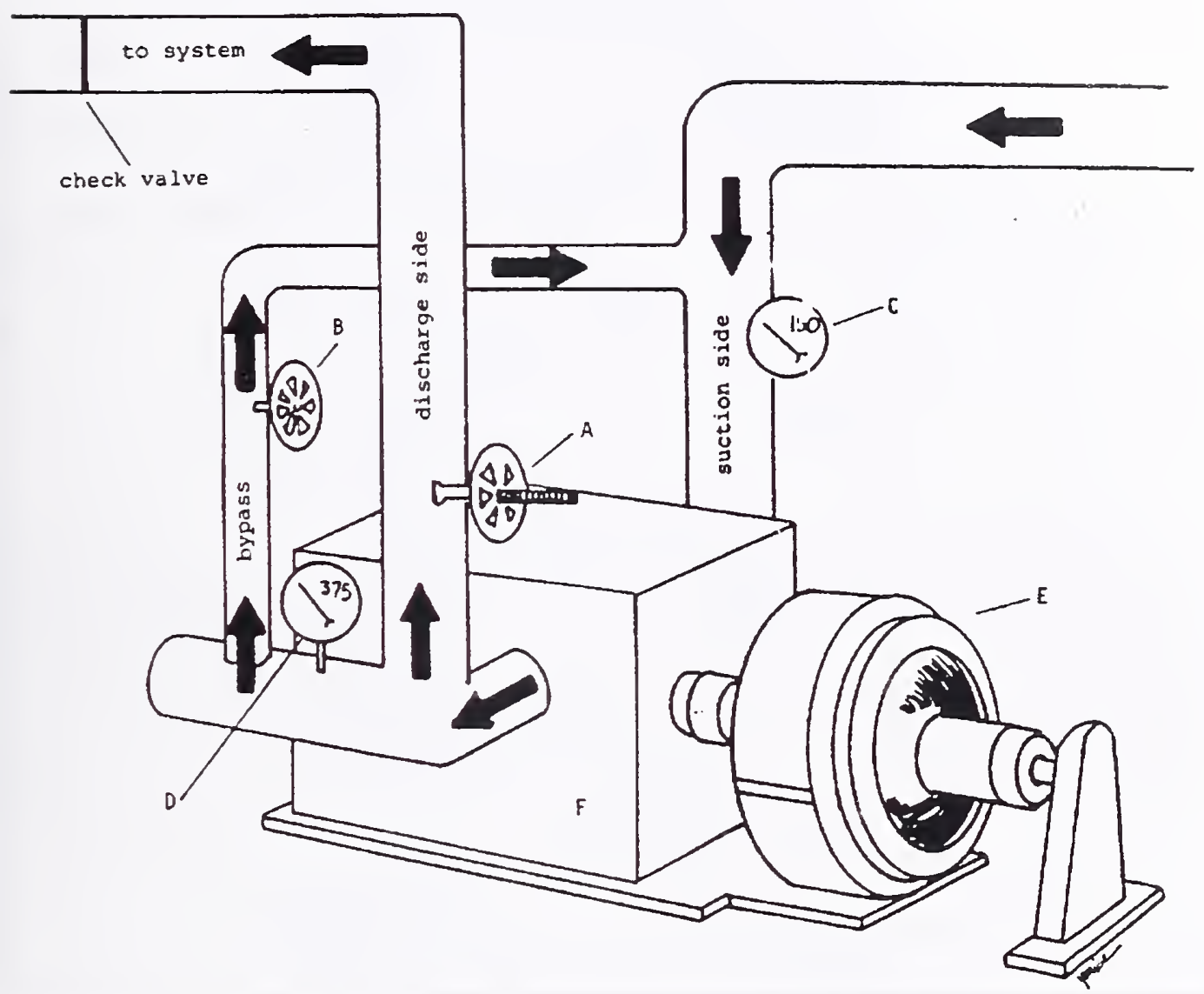


Figure 5-2

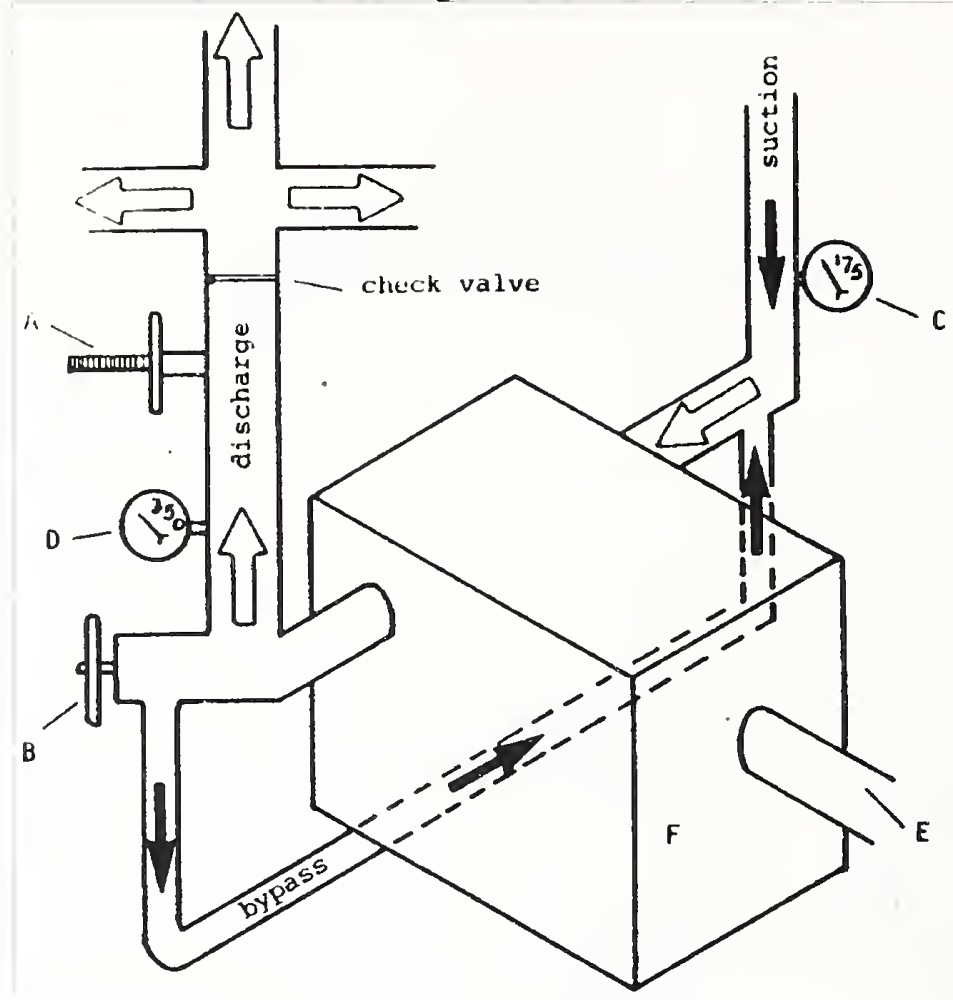

MODEL FIRE PUMP

SHOWING POSSIBLE BYPASS \& BYPASS VALVE LOCATION
A. OPEN O.S.\&Y. VALVE
B. CLOSED
C. INLET GAUGE
D. DISCHARGE GAUGE
E. TO DRIVE MOTOR
F. CENTRIFUGAL
$\rightarrow$ DESIGNATES DIRECTION OF WATER FLOW

Figure 5-3

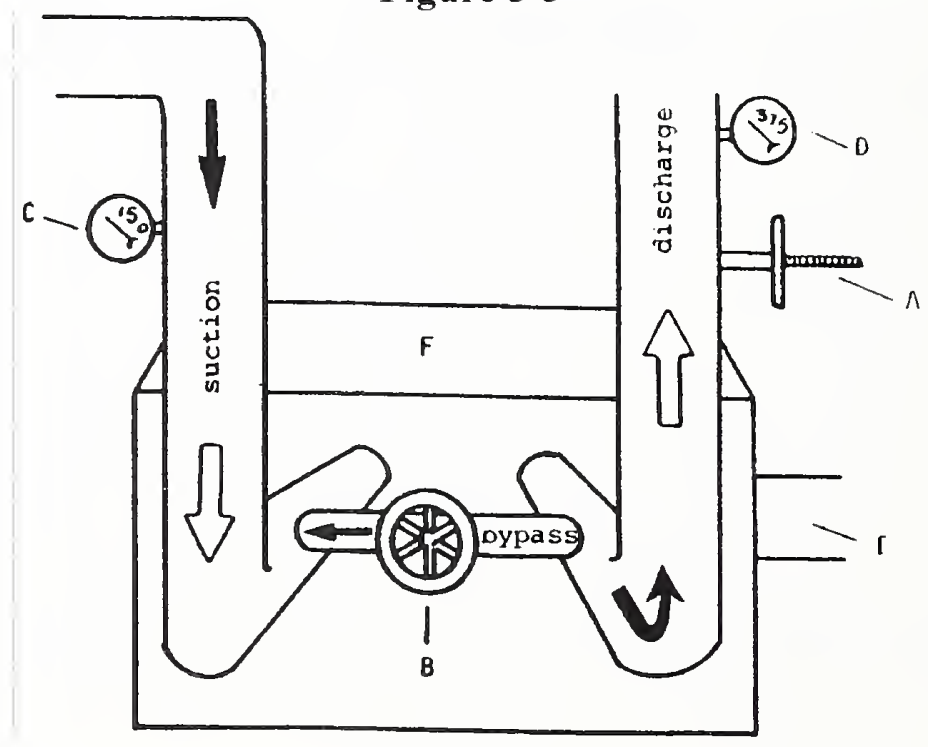


Figure 5.4

FIRE PUMP CONTROL

(FIRETROL)

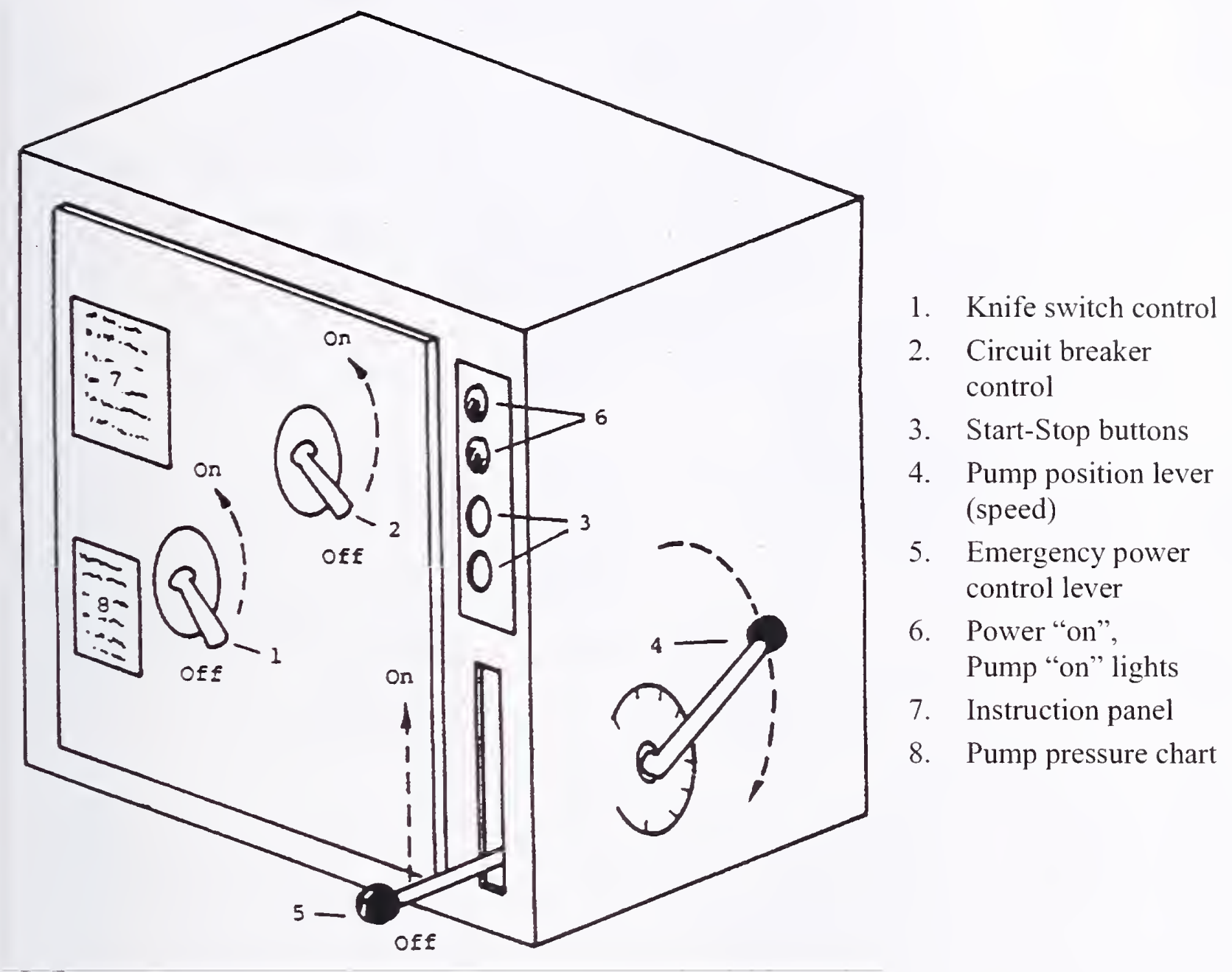

Control Panels may vary in appearance, but operational sequence remains the same.

On newer models such as the illustrated controls above, the controls are located on the outside of a locked door which covers the fuses and high voltage lines. This simplifies the operation because the operator sees only the starting mechanism that is needed for operation. 
Figure 5-5

FIRE PUMP CONTROL PANEL

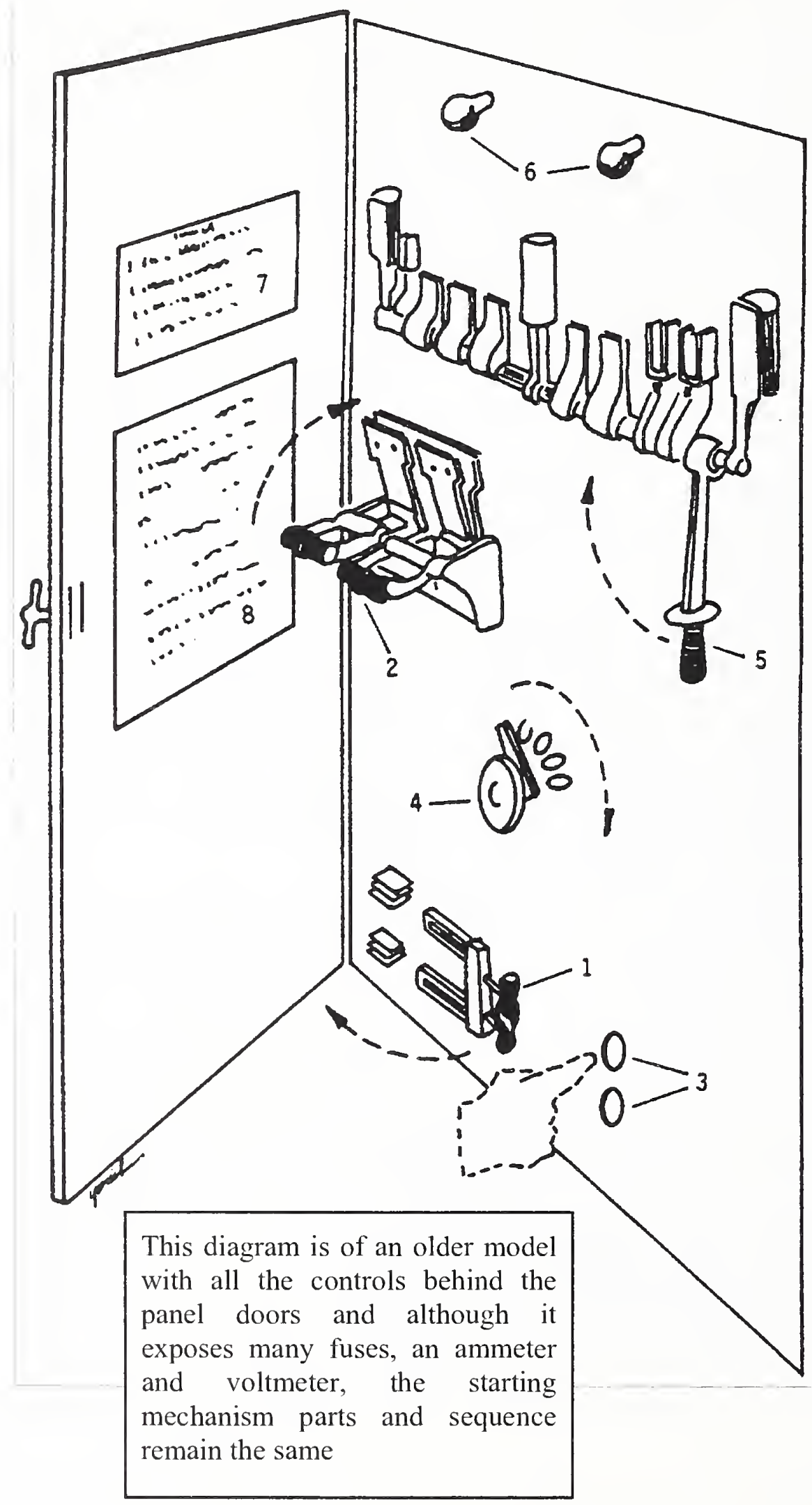

1. Knife switch

2. Circuit breakers

3. "ON" - "OFF" buttons

4. Pump speed lever

5. Emergency power lever

6. Power "on", pump "on" lights

7. Instruction panel

8. Pump pressure chart

When the proper sequence is followed as outlined, the power "on" light will glow with the closing of the circuit breakers and the pump "on" light will glow with the pushing of the starting button.

\section{NOTE}

A variation of this panel may have the knife switch inside panel door as shown with all other controls on the outside of door, through holes in door. On this type it will be necessary to open door to close knife switch before reclosing door and completing operation. 
Figure 6-1

Fire Location \& Conditions

HIGH RISE CHECK LIST

Fire Location

$\begin{array}{ll}\text { Fire Conditions } & \text { Heavy } \square \text { Med } \square \text { Lt } \square \\ \text { Smoke Conditions Heavy } \square \text { Med } \square \text { Lt } \square \\ \text { Heat Conditions } & \text { Heavy } \square \text { Med } \square \text { Lt } \square\end{array}$

\section{Elevators}

Elevators Down

Fireman Service

No. of Cars for F.D. Use

Low

Med

Floors Served

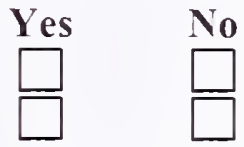

High

\section{Building Information}

Sprinklered

Floor Plans

Stair Re-entry Keys

Window Keys

Occupancy Keys

Open Stairs-Fire Occ.

Building Setbacks

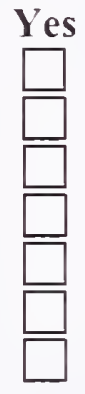

\begin{tabular}{l} 
No \\
$\square$ \\
\hline$\square$ \\
\hline$\square$ \\
\hline$\square$ \\
\hline$\square$ \\
\hline$\square$
\end{tabular}

\section{Communications}

Class "E"

Public Address

S.P. Phone

To Fan Rooms

To Engineer

Public Telephone

Alarm System Turned Off

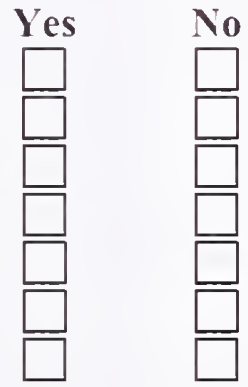

Life Hazard

Trapped

Fire Floor Evac.

Floor Above Evac.

Primary Search Compl.

Secondary Search Compl.

Elevators Searched

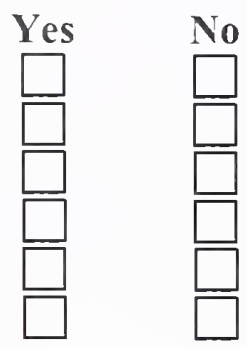

HVAC (Heating, Ventilation, Air Conditioning)

Shut Down

*Mer

Mer

Mer

Number of Zones

Floor Serves

Yes $\square$

$\mathrm{No} \square$

*Mer Mechanical Equipment Room

Stairs Identification

Letter Floors Served S.P. Evac.

$\overline{\text { Scissor }} \overline{\text { Type Stairs }} \overline{\text { Yes } \square} \quad \overline{\mathrm{No} \square}$

Water Supply To

To

To 1st Eng. Floor

2nd Eng. Floor

3rd Eng. Floor

4th Eng. Floor

2nd Batt. Ch. Floor

3rd Batt. Ch.
Standpipe Fed

Sprinkler Fed

Bldg. Fire Pumps On

Unit(s) Feeding Stp.

Pressures Required

$1-10(150 \#) \quad 10-20(200 \#) \quad 20-30(250 \#)$

$30-40(300 \#) \quad 40-50(350 \#) \quad 50-60(400 \#)$

UNIT LOCATIONS

1st Ladder Floor

2nd Ladder Floor

3rd Ladder Floor

Stair

Stair

Stair

Stair

Stair

Rescue

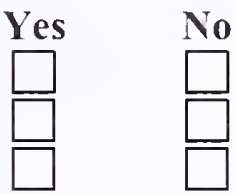
Stair Stair

Assignment 
Figure 6-3

SAMPLE BUILDING FLOOR PLAN AND PROFILE

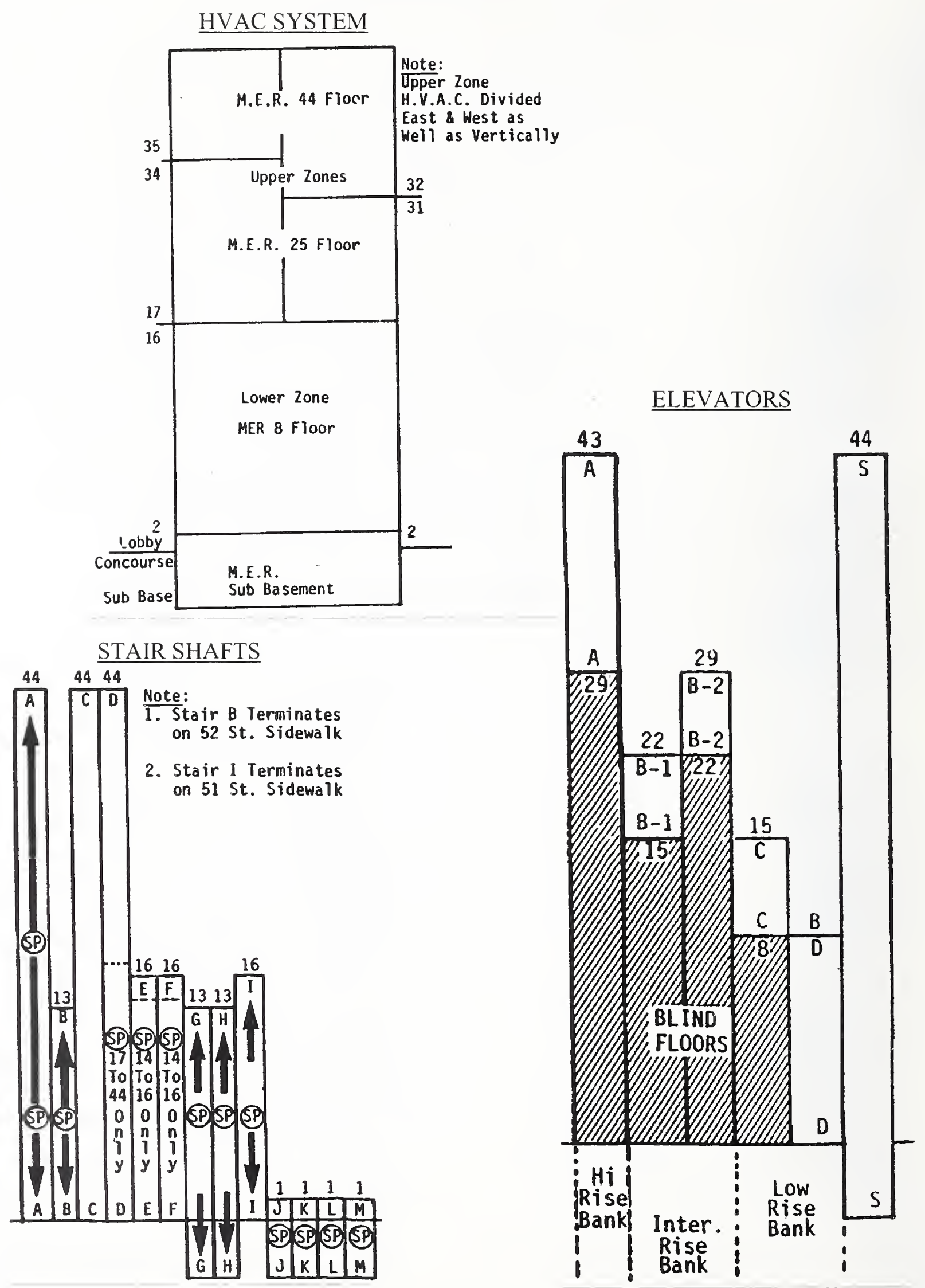




\section{Figure 6-4}

\section{SAMPLE TIPS DATA SHEET}
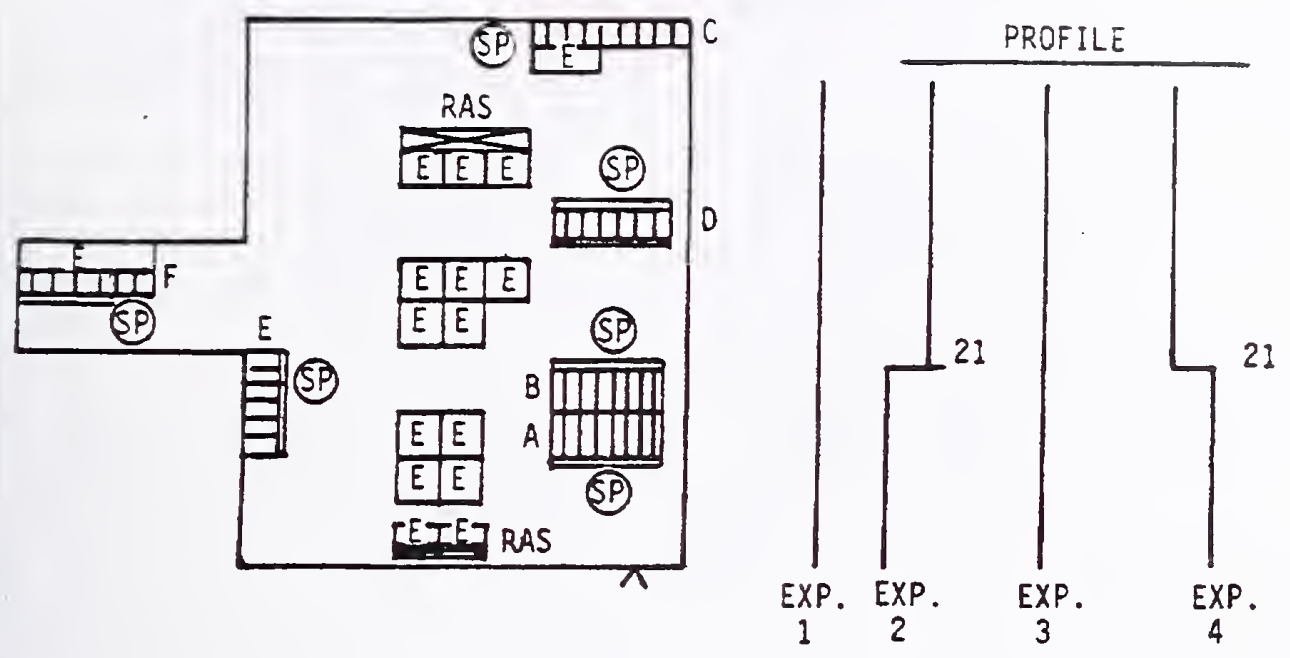

Fig. $6-4$

21

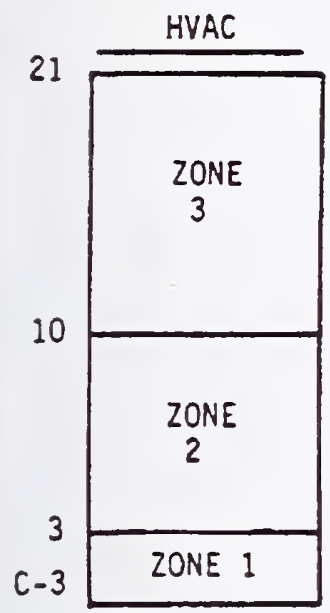

MOTE: NO CENTRAL AIR FROM 22-51

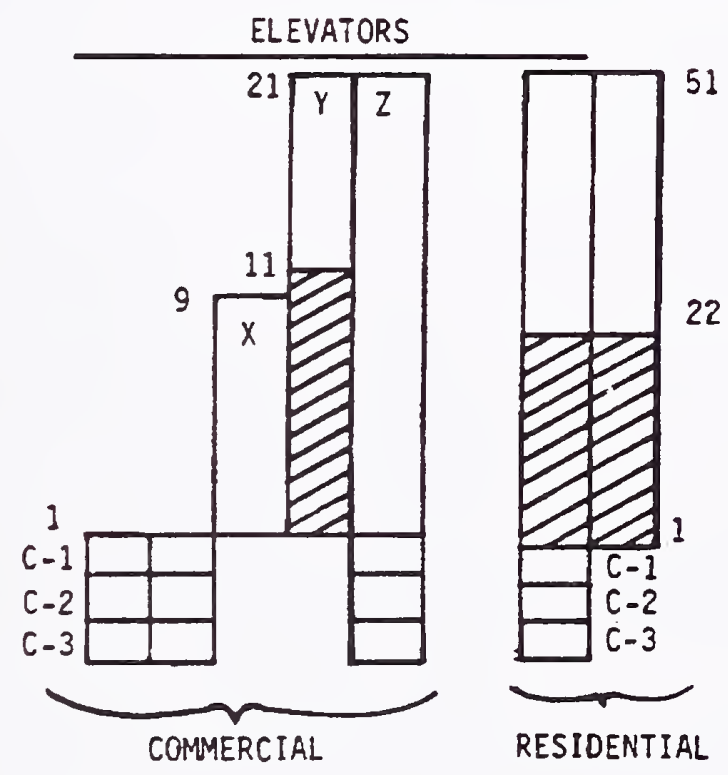

of Siamese

Symbols

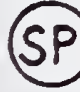

Standpipe

Shaft

Designate Type

(Elevator, Air, Etc.)

Enclosed Stair

Open Stair

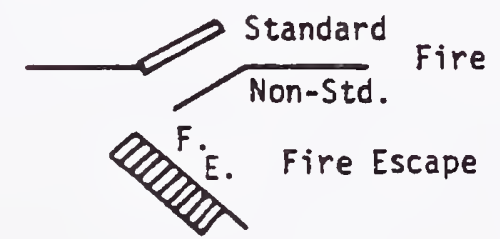

Unprotected

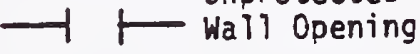

Protected

Wall Opening

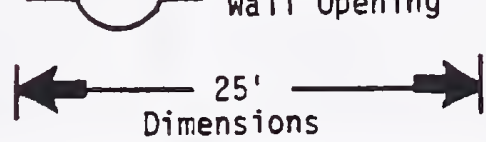

(AS Partial

Sprinkier

(AS) Sutomatic

windows
toth finoors

Windows
STAIRS

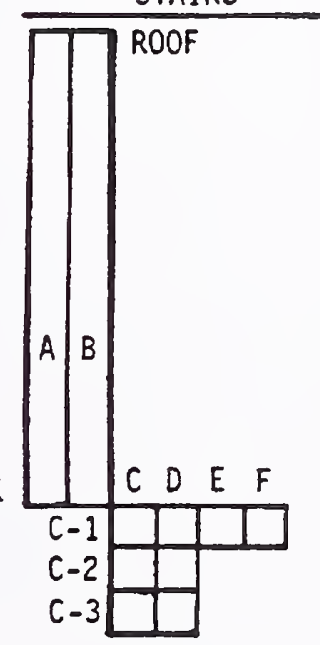

Wire Glass floors 
Figure 6-2

OPERATIONS POST LOG

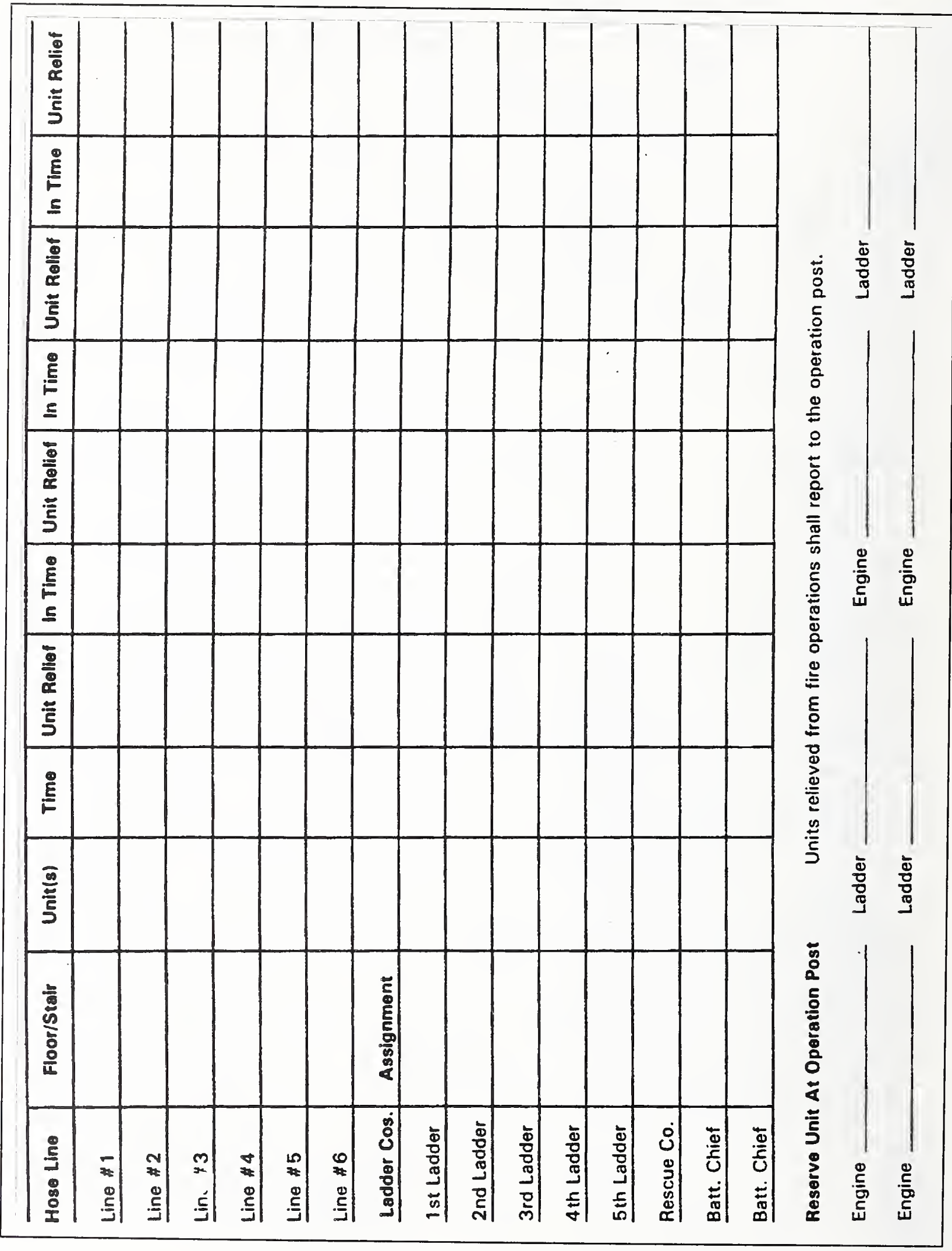


Figure 7-1

\section{COMMUNiCATIONS NETWORK}

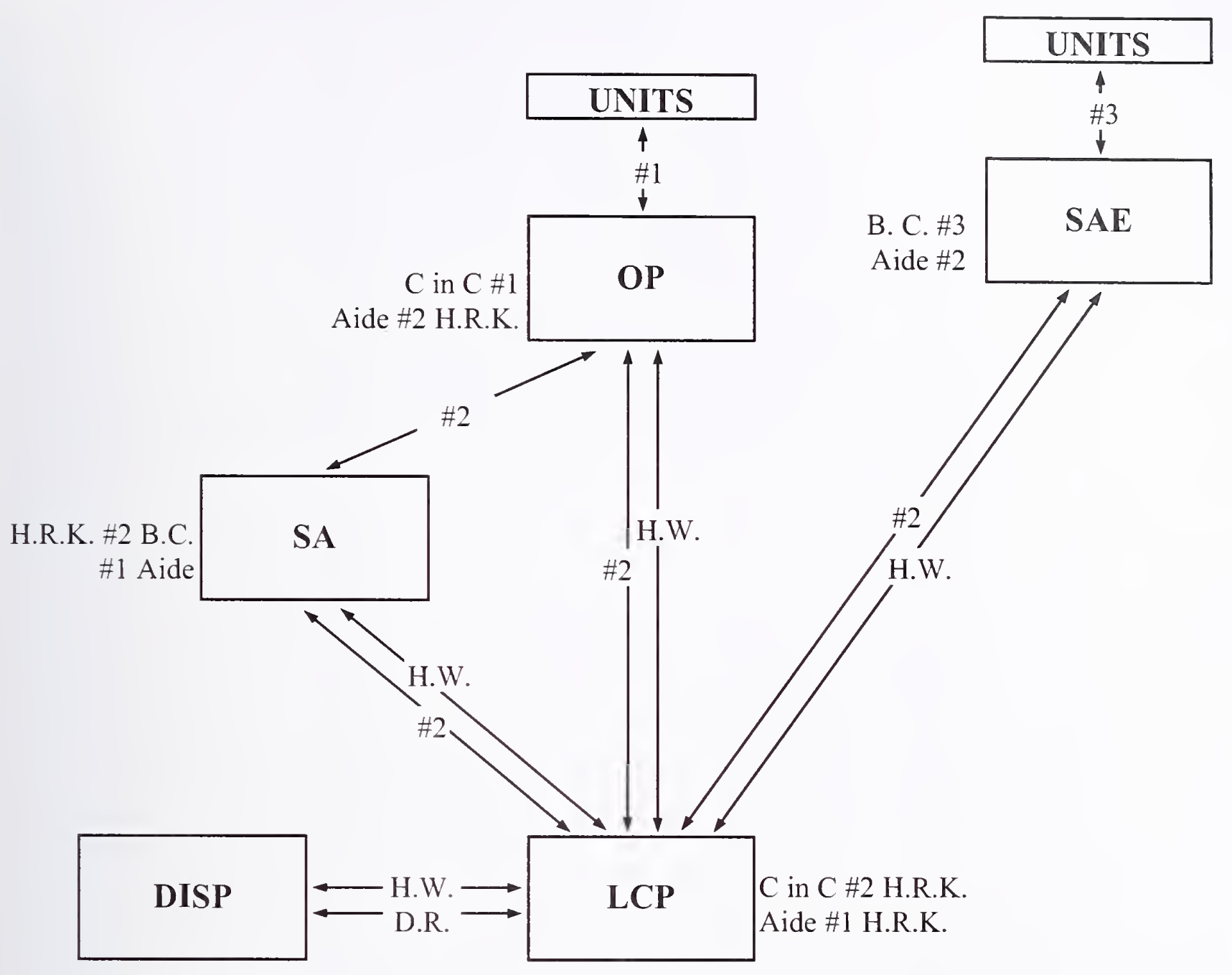

H.W. - Hardwire Components

1. Class E System

2. Standpipe Telephone

3. Outside Telephone

4. In-house Telephone

5. Sound Power Field Telephone

\begin{tabular}{|ll|}
\hline \multicolumn{1}{|c|}{ LEGEND } \\
\hline$\# \mathbf{1}$ & Tactical \\
$\# \mathbf{2}$ & Command \\
\#3 & Second Tactical \\
H.W. & Hard Wire \\
D.R. & Dept. Radio \\
LCP & Lobby Command Post \\
SA & Staging Area \\
OP & Operations \\
SAE & Search \& Evacuation post \\
HRK & High Rise (Communications) Kit \\
\hline
\end{tabular}


Figure 7-2

\section{LOBBY COMMAND LOG}

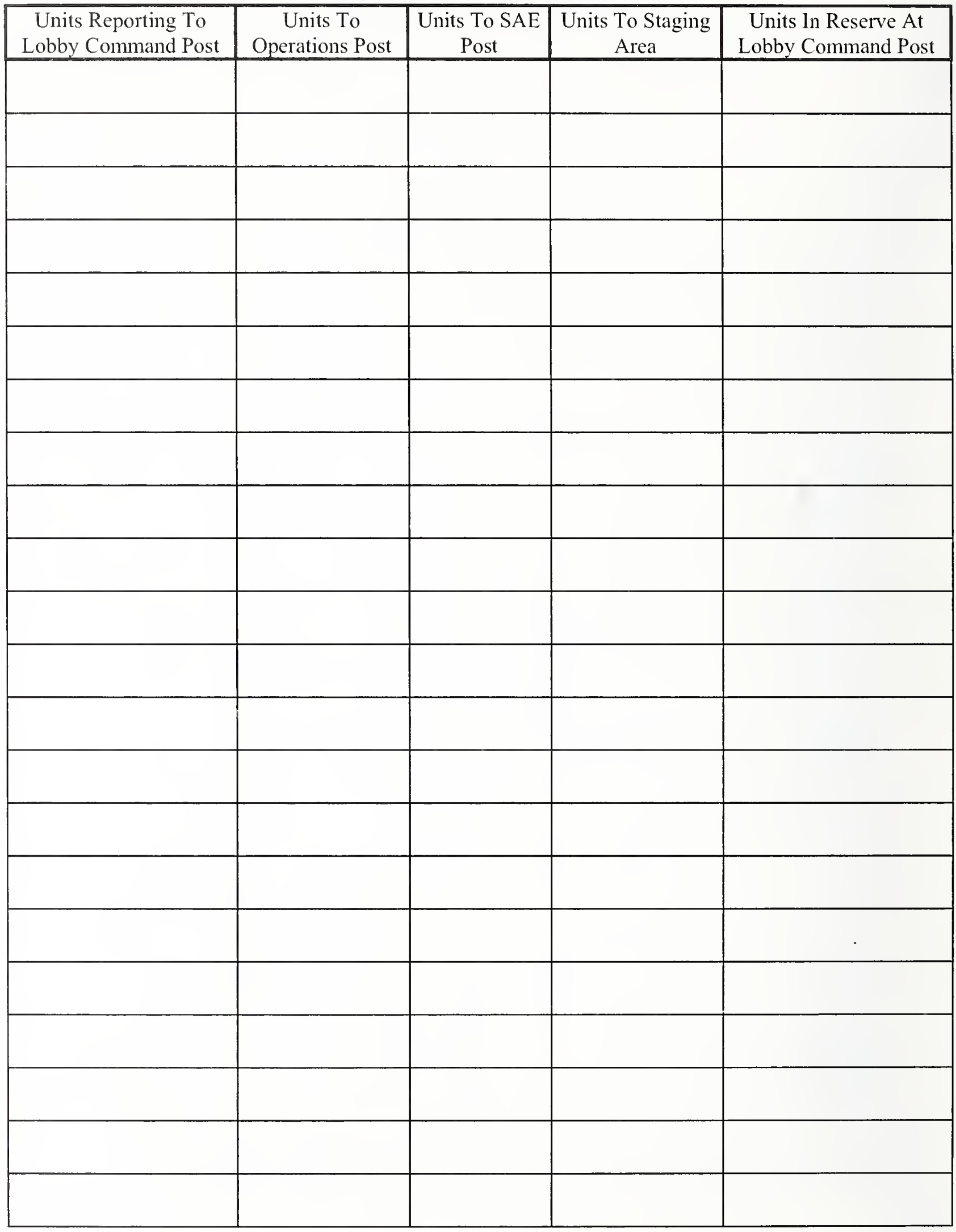


Figure 7-4

STAGING AREA LOG

\begin{tabular}{|c|c|c|c|c|c|c|c|}
\hline \multicolumn{2}{|c|}{ Units Reporting In } & \multicolumn{3}{|c|}{ Units Departing } & \multicolumn{3}{|c|}{ Units Returning } \\
\hline Units & Time & Unit & Assignment & Time & Units & Time & Serviceable \\
\hline & & & & & & & \\
\hline & & & & & & & \\
\hline & & & & & & & \\
\hline & & & & & & & \\
\hline & & & & & & & \\
\hline & & & & & & & \\
\hline & & & & & & & \\
\hline & & & & & & & \\
\hline & & & & & & & \\
\hline & & & & & & & \\
\hline & & & & & & & \\
\hline & & & & & & & \\
\hline & & & & & & & \\
\hline & & & & & & & \\
\hline & & & & & & & \\
\hline & & & & & & & \\
\hline & & & & & & & \\
\hline & & & & & & & \\
\hline
\end{tabular}

RECORD OF INJURIES

\begin{tabular}{|l|l|l|l|l|}
\hline Unit & Name & Time & Injury & Disposition \\
\hline & & & & \\
\hline & & & & \\
\hline & & & & \\
\hline & & & & \\
\hline
\end{tabular}


Figure 7-3

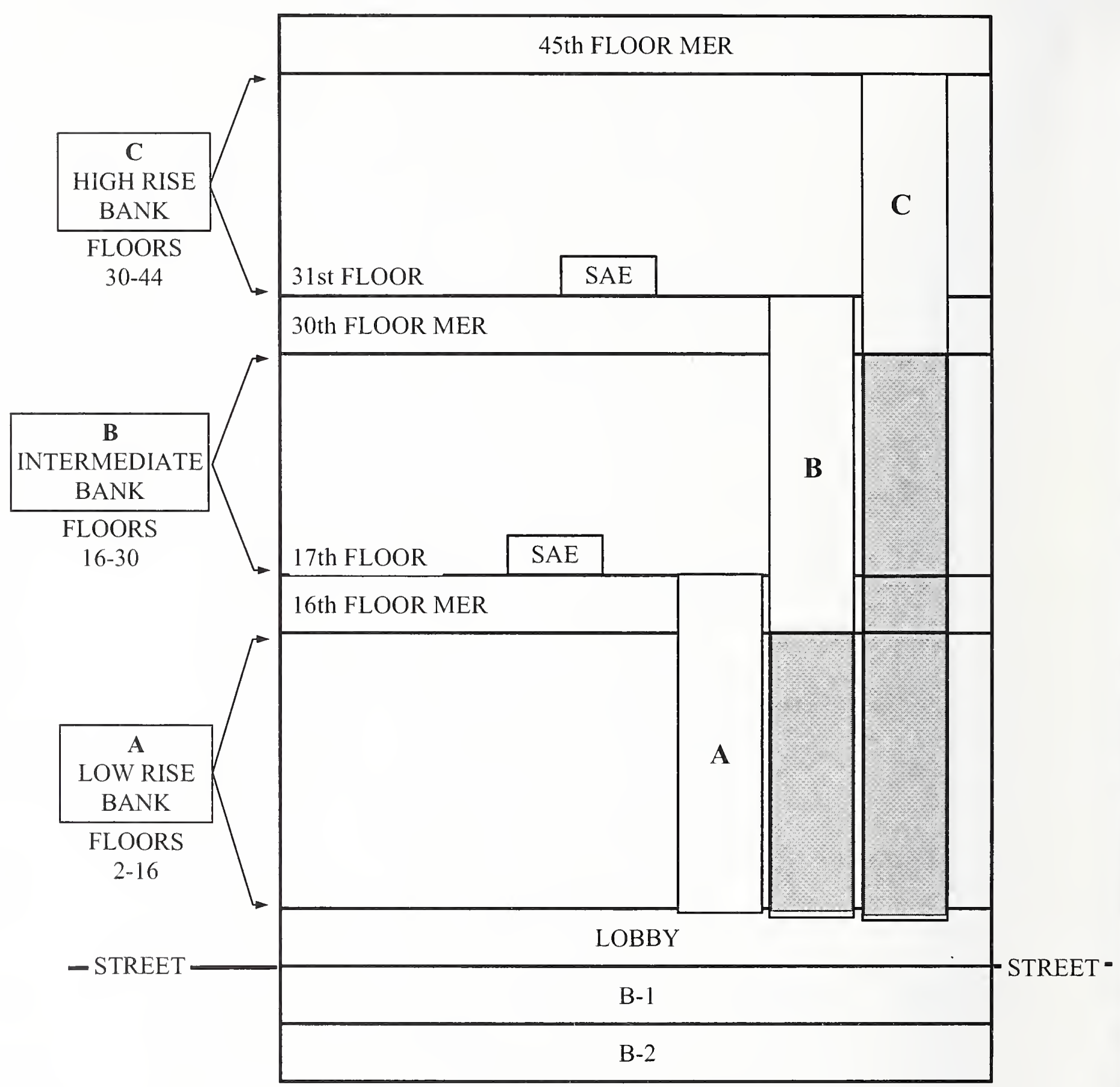

NOTE: Shaded area is a blind shaft 

